\title{
Wirkung schwerer Ionen auf strahlenresistente und strahlensensitive Tumorzellen
}

\author{
Dissertation \\ zur Erlangung des Doktorgrades \\ der Mathematisch-Naturwissenschaftlichen Fakultäten \\ der Georg-August-Universität zu Göttingen
}

\author{
vorgelegt von \\ Hana Hofman-Hüther \\ aus Louny (Tschechische Republik)
}

Göttingen 2002 
D7

Referent: $\quad$ Prof. Dr. R. Hardeland

Korreferent: $\quad$ Prof. Dr. H.-J. Fritz

Tag der mündlichen Prüfung: 31. Oktober 2002 
1. Einleitung 1

2. Fragestellung und Ziel der Untersuchungen 9

3. Material und Methoden 12

$\begin{array}{lll}3.1 & \text { Material } & 12\end{array}$

3.1.1 Zelllinien _ 12

3.1.1.1 WiDr-Zelllinie 12

3.1.1.2 MCF-7-Zellinie 13

3.1.1.3 HNEPC-Zellinie 13

$\begin{array}{lll}3.2 & \text { Methoden } & 13\end{array}$

3.2.1 Zellkultur__ 13

3.2.1.1 Kultivierungsbedingungen 13

3.2.1.2 Subkultivierung der Zellen 14

3.2.1.3 Langzeitlagerung der Zellen 14

3.2.1.4 Mykoplasmentest 15

3.2.1.4.1 DAPI-Test 15

3.2.2 Bestrahlung _ 16

3.2.2.1 Bestrahlungseinrichtungen und Dosimetrie 16

3.2.2.2 Bestimmung der Zellkerngröße 20

3.2.2.3 Bestrahlung der Zellen mit Kohlenstoffionen 20

3.2.2.4 Bestrahlung der Zellen mit $200 \mathrm{kV}$-Röntgenstrahlung 21

3.2.3 Koloniebildungstest 22

3.2.4 Messung der Apoptosenrate __ 25

3.2.5 BrdU-Färbung _ _ 27

3.2.6 Bestimmung der Wachstumskinetik in Abhängigkeit von BrdU __ 28

3.2.7 Chromosomenpräparation und Färbung _ 29

3.2.7.1 Chromosomenpräparation 29

3.2.7.2 Färbung mit Giemsa 30

3.2.7.3 Fluoreszenz-in-situ-Hybridisierung 30

3.2.8 Auswertung und Klassifizierung von Chromosomenaberrationen _ 32

3.2.8.1 Dizentrische Chromosomen und extra azentrische Fragmente 33

3.2.8.2 Reziproke Translokationen 35

3.2.8.3 Komplexe Aberrationen: TVC 36

3.2.8.4 Insertionen 38 
3.2.9 Statistische Auswertung der Aberrationsdaten

3.2.10 Clusterbildung der DNA- $\mathrm{PK}_{\mathrm{cs}^{-}}$, $\mathrm{Ku} 70$ - und Ku86- Reparaturproteine in bestrahlten Zellen. 40

4. Ergebnisse

4.1 Bestimmung der Zellkernflächen

4.2 Berechnung der mittleren Trefferzahl pro Zellkern

4.3 Zellüberleben nach Bestrahlung

4.3.1 Klonogenes Zellüberleben der WiDr-Zellen nach Bestrahlung mit

Kohlenstoffionen 45

4.3.2 Klonogenes Zellüberleben der MCF-7-Zellen nach Bestrahlung mit Kohlenstoffionen 48

4.3.3 Überleben von bestrahlten WiDr-Zellen und MCF-7-Zellen im Vergleich 50

4.3 Strahleninduzierte Apoptose

4.5 Zellproliferation nach Bestrahlung

4.6 Wachstumskinetik in Abhängigkeit von BrdU

4.7 Strahleninduzierte Chromosomenaberrationen

4.7.1 Dosisabhängigkeit von genomischen Häufigkeiten instabiler Chromosomenaberrationen in WiDr- und MCF-7-Zellen 61

4.7.2 Strahleninduzierte dizentrische Chromosomen und extra azentrische Fragmente in Abhängigkeit von Ionenenergie 69

4.7.3 Charakterisierung und Auswertung ausgewählter Chromosomen in WiDrund MCF-7-Zellen: FISH-Analyse

4.7.4 Partielle Häufigkeiten strahleninduzierter reziproker Transloka-tionen in Abhängigkeit von Ionenenergie

4.7.5 Strahleninduzierte komplexe Aberrationen in Abhängigkeit von Ionenenergie 78

4.2.6 Gesamt-Aberrationen: „TA“ 83

4.2.7 Strahleninduzierte Insertionen 88

4.8 Clusterbildung von NHEJ-Reparaturproteinen nach Bestrahlung mit Röntgenstrahlung und Kohlenstoffionen 
$\begin{array}{ll}\text { 5. Diskussion } & 95\end{array}$

$\begin{array}{lll}5.1 & \text { Zellüberleben nach Bestrahlung } & 96\end{array}$

5.2 Genomische Häufigkeiten dizentrischer Chromosomen und extra azentrischer Fragmente in WiDr- und MCF-7-Zellen 99

5.3 Partielle Häufigkeiten reziproker Translokationen in WiDr- und MCF-7-Zellen

5.4 Aberrationsspektrum nach Röntgenbestrahlung und nach

$\begin{array}{lll}5.5 & \text { Gesamt-Aberrationen } & 109\end{array}$

$\begin{array}{lll}5.6 & \text { Clusterbildung von NHEJ-Reparaturproteinen } & 111\end{array}$

$\begin{array}{lll}5.7 & \text { Die relative biologische Wirksamkeit } & 113\end{array}$

$\begin{array}{ll}\text { 6. Zusammenfassung } & 117\end{array}$

$\begin{array}{ll}\text { 7. Literaturverzeichnis } & 119\end{array}$

$\begin{array}{ll}\text { Anhang A } & 133\end{array}$

$\begin{array}{ll}\text { Abkürzungen } & 133\end{array}$

$\begin{array}{ll}\text { Anhang B } & 135\end{array}$

$\begin{array}{lll}\text { B.1 Medien und Zusätze für die Zellkultur } & 135\end{array}$

B.1.1 Medien 135

B.1.2 Zusätze für die Zellkultur _ 136

$\begin{array}{lll}\text { B.2 Chemikalien } & 136\end{array}$

$\begin{array}{lll}\text { B.3 } & \text { Lösungen und Puffer } & 137\end{array}$

$\begin{array}{lll}\text { B.4 Färbelösungen und Färbekits } & 138\end{array}$

$\begin{array}{lll}\text { B.5 Antikörper und Sonden } & 139\end{array}$

B.6 Einwegmaterial und Geräte 139

B.6.1 Einwegmaterial 139

B.6.2 Geräte 140 



\section{1. $\quad$ Einleitung}

Die schädigende Wirkung ionisierender Strahlung auf Zellen, Gewebe und Organismen resultiert vor allem aus den Schädigungen des genetischen Materials, der DNA. Der größte Teil dieser Schäden kann durch verschiedene Reparaturprozesse fehlerfrei behoben werden [Jeggo, 1998; McGregor, 1999; Lindahl et al., 1999; Moustacchi et al., 2000]. Fehlerhaft reparierte DNA-Schäden führen zu Mutationen, Chromosomenaberrationen, zum reproduktivem Zelltod und zu neoplastischen Transformationen.

Sowohl normale Zellen als auch primäre und etablierte Tumorzellen zeigen große Unterschiede in ihrer intrinsischen Strahlenempfindlichkeit. Eine sehr variable Strahlensensitivität wurde bei untransformierten Fibroblasten aus verschiedenen Spendern festgestellt. In Koloniebildungstest wurde nach Bestrahlung mit D = 2 Gy eine Überlebensfraktion $\left(\mathrm{SF}_{2}\right)$ von 0,1 bis 0,6 beobachtet [Peters, 1990 ; Rave-Fränk et al., 2001]. Zellen aus verschiedenen Tumoren zeigen ebenfalls eine große Variabilität, die Überlebensfraktion $\mathrm{SF}_{2}$ liegt zwischen 0,1 und 0,7 [z.B. Lambin et al., 1996]. Sogar Tumorzellen gleicher Art zeigen eine unterschiedliche individuelle Strahlensensitivität in verschiedenen Patienten. Dies wurde z.B. an Melanom-Zellen gezeigt, die $\mathrm{SF}_{2}$ liegt zwischen 0,1 und 0,8 [McKay et al., 1995].

In Bezug auf die Induktion von strukturellen Chromosomenaberrationen wurden ebenfalls große Unterschiede sowohl bei normalen Zellen, als auch bei primären und etablierten Tumorzellen beobachtet. In Zellen von gesunden Spendern wurde bei gleicher Bestrahlungsdosis eine variable Anzahl an dizentrischen und extraazentrischen Fragmenten sowie an Translokationen pro Zelle beobachtet, und das sogar bei unterschiedlichen Zelltypen (Lymphozyten und Fibroblasten) aus demselben Spender [Virsik-Peuckert et al., 1997]. Schwartz [1998] beobachtete in Plattenepithelzellen aus Kopf-Hals-Tumoren verschiedener Patienten nach einer in vitro Röntgenbestrahlung mit 1,5 Gy eine Gesamt-Aberrationsrate zwischen 1,0 und 2,5 Aberrationen pro Zelle. 
Auch auf der Ebene der DNA-Doppelstrangreparatur wurden diese Unterschiede in normalen Zellen und in Tumorzellen beobachtet, und zwar sowohl Unterschiede in der Reparatur-Kinetik als auch in dem Ausmaß des unreparierten Restschadens [Ruiz de Almodóvar et al., 1994; Bunch et al., 1995; Whitaker et al., 1995; Woudstra et al., 1996].

Generell gibt es drei verschiedene Möglichkeiten die intrinsische Strahlensensitivität einzelner Zelltypen zu erklären. Die unterschiedliche Strahlensensitivität der Zellen kann einerseits durch unterschiedliche Anzahl der initialen DNA-Läsionen die bei gleicher Dosis induziert werden, erklärt werden. Nach heutigem Kenntnisstand könnte dafür eine unterschiedliche Struktur des Chromatins verantwortlich sein. Alternativ kann die Strahlensensitivität durch unterschiedliche Effizienz und Fidelität der Reparaturprozesse oder sogar durch das Fehlen eines Reparaturmechanismus verursacht werden [Lees-Miller et al., 1995; Nussenzweig et al., 1997; Guan et al., 2000]. Und schließlich kann die unterschiedliche Strahlensensitivität durch Defekte und Modulation in der Zellzyklusregulation verursacht werden [P. Lambin et al., 1996].

Ein Einfluss der DNA-Reparaturprozesse auf die intrinsische Strahlensensitivität der Zellen wurde vor allem an Zellen gezeigt, die verschiedene Reparaturdefekte und damit auch unterschiedliche Reparaturkapazität aufweisen [George et al., 1987; FrankenbergSchwager et al., 1989; Olive et al., 1994]. Hohe Strahlensensitivität wurde bei normalen primären Zellen von Patienten, die an verschiedenen hereditären Chromosomeninstabilitäts-Syndromen erkrankt waren, beobachtet. $\mathrm{Zu}$ diesen Syndromen gehört u.a. die Ataxia telangiektasia (AT), Nijmegen-Breakage-Syndrom (NBS), Bloom-Syndrom (BS), Werner Syndrom (WS), die Fanconi-Anämie (FA), Down`s Syndrom, Retinoblastom (RB), Cockayne's Syndrom (CS) und das heriditäre Mammakarzinom (BRCA1 und BRCA2 mutiert). Die Zellen dieser Patienten, die eine erhöhte Krebsdisposition haben, haben vor allem Defekte in der DNA-DSB-Reparatur oder in der Zellregulation wie z. B. bei dem hereditären Retinoblastom [Lindahl, 1987]. Sie zeigen spontan oder nach Einwirkung ionisierender Strahlung oder Einwirkung von chemischen Agenzien eine erhöhte Rate an Chromosomenaberrationen.

Eine Ursache der unterschiedlichen Strahlensensitivität der Zellen gegenüber ionisierender Strahlung kann also eine variable Kapazität und Fidelität der DNA- 
Reparatur aufgrund verschiedener Reparaturdefekte sein [Tuteja et al., 2001; Baldeyron et al., 2002; Collis et al., 2002; Cordeiro-Stone et al., 2002; Gaymes et al., 2002]. Dabei spielt vor allem die Reparatur der DNA-Doppelstrangbrüche eine Rolle, da diese DNALäsionen für die Zellen letal, mutagen oder karzinogen sein können. DNADoppelstrangbrüche werden entweder durch die homologe Rekombinations-Reparatur (HR) oder durch die nicht-homologe Endverknüpfung, nonhomolougous end-joining (NHEJ) repariert [Chu et al., 1997].

In Säugetierzellen wird in der $\mathrm{G}_{1}$-Phase und in der frühen S-Phase vor allem die NHEJReparatur eingesetzt [Morrison et al., 2000]. Die HR wird hingegen erst in der späten $\mathrm{S}$-Phase und in $\mathrm{G}_{2}$-Phase des Zellzyklus eingesetzt. Es gibt zumindest zwei Arten der NHEJ-Reparatur: DNA-PK-abhängige und DNA-PK-unabhängige Reparatur [Pfeiffer, 1998; Pfeiffer et al., 2000]. Am besten ist die DNA-PK-abhängige NHEJ-Reparatur untersucht. Bei dieser Reparatur werden die gebrochenen Enden der DNA direkt miteinander ligiert und dieser Vorgang wird in der Regel von einem Verlust kleiner DNA-Sequenzen begleitet ( siehe Abbildung 1.3).

In Gegensatz zu der homologen Rekombination braucht die NHEJ keine oder nur sehr kleine DNA-Homologien (Mikrohomologie) für die Reparatur des Doppelstrangbruchs. Das $\mathrm{Ku}-H e t e r o d i m e r$, das sich aus $\mathrm{Ku}$ 70- und $\mathrm{Ku}$ 86-Protein zusammensetzt, hat eine hohe Affinität zu den freien DNA-Enden und bindet zuerst an die DNA-Enden. Durch diese Bindung wird die exonukleotische Degradation der DNA-Enden verhindert und gleichzeitig wird die katalytische Untereinheit $\left(\mathrm{DNA}-\mathrm{PK}_{\mathrm{CS}}\right)$ der DNA-abhängigen Proteinkinase (DNA-PK) rekrutiert. Nachdem sich das Ku-Heterodimer von den freien DNA-Enden etwa eine Umdrehung nach Innen transloziert hat, bindet die DNA-PK $\mathrm{CS}_{\mathrm{S}}$ direkt an die freien Enden der DNA [Yoo et al., 1999]. Komplexe aus KuHeterodimeren und den DNA-PK $\mathrm{cs}-$ Molekülen bilden an Stellen der Doppelstrangbrüche sog. Cluster, die man mit Hilfe Fluoreszenz-markierter Antikörper visualisieren kann [Boguhn, Dissertation 1999]. Diese Bindung der Ku-Heterodimere und der DNA$\mathrm{PK}_{\mathrm{CS}}$-Moleküle an die freien DNA-Enden erfolgt sehr früh, etwa 5-30 Minuten nach Bestrahlung [Wang et al., 2001]. 


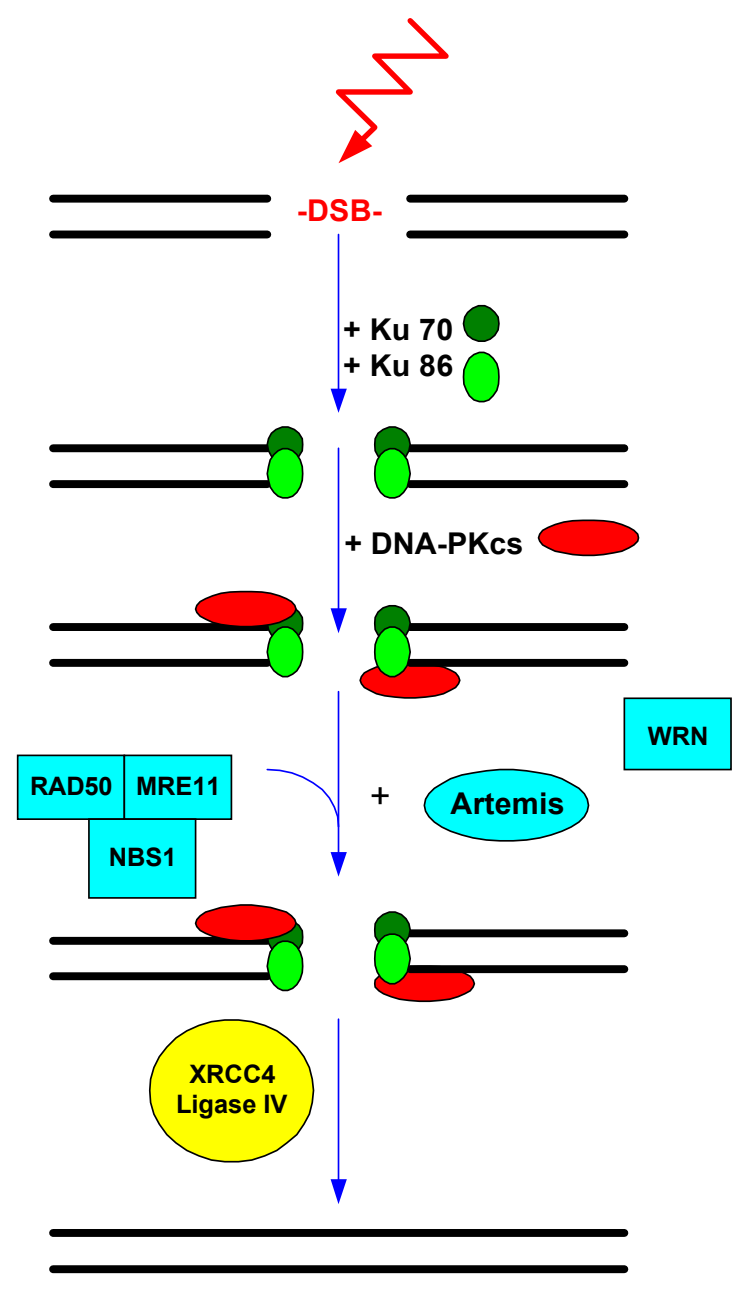

Abbildung 1.1 Mechanismus der DNA-PK-abhängigen NHEJ-Reparatur. Erklärung siehe Text.

Jeweils zwei DNA-PK ${ }_{C S}$ Moleküle bringen die zwei DNA-Enden näher zusammen. Dabei phosphoryliert die DNA-PK ${ }_{C S}$ mehrere Proteine, u.a. auch den RAD50/MRE 11/NBS 1-Komplex, das Artemis-Protein und das WRN-Protein, die alle auch eine 3'5'- bzw. 5'-3'-Exonuklease-Aktivität haben, und die wahrscheinlich bei der Prozessierung der DNA-Enden eine wichtige Rolle spielen [Paull et al., 1999 und 2000; Trujillo et al. 1998; Ma et al., 2002]. Zu einem späterem Zeitpunkt phosphoryliert die DNA-PK ${ }_{C S}$ das XRCC4-Protein und stimuliert damit die Ligations-Aktivität des XRCC4/-Ligase IV-Komplexes [Leber et al., 1998]. Gleichzeitig phosphoryliert die DNA-PK ${ }_{C S}$ die Ku-Proteine und sich selbst und dissoziiert anschließend von der DNA [Chan et al., 1996]. Die Ligation wird von dem XRCC4/Ligase IV-Komplex durchgeführt [Kanaar et al., 1998; Khanna and Jackson, 2001]. 
Durch Fehlreparatur oder durch Nicht-Reparatur von DNA-Doppelstrangbrüchen entstehen strukturelle Chromosomenaberrationen, die ein Maß für die DNASchädigung darstellen [Obe et al., 1985].

Sie können, je nach Zellzyklusphase während der sie induziert werden, in zwei verschiedene Kategorien unterteilt werden: Chromosomen- und Chromatidaberrationen. Wenn die Zellen in $\mathrm{G}_{0^{-}}$bzw. $\mathrm{G}_{1^{-}}$Phase des Zellzyklus bestrahlt werden, werden Chromosomenaberrationen induziert, d.h. Aberrationen die in beiden Schwesterchromatiden vorkommen weil die, während der $\mathrm{G}_{0^{-}}$bzw. $\mathrm{G}_{1^{-}}$Phase entstandenen Aberrationen in der S-Phase mitrepliziert werden. Werden die Zellen in der späten $\mathrm{S}$ - oder in der $\mathrm{G}_{2}$-Phase bestrahlt, werden hingegen nur Chromatidaberrationen die jeweils ein Schwesterchromatid betreffen, induziert [Ottolenghi et al., 1999; Evans et al., 1975].

Chromosomenaberrationen kann man in sog. stabile und instabile Formen unterteilen. Als instabile Aberrationen werden dizentrische (polyzentrische) Chromosomen, azentrische Fragmente und Ringchromosomen bezeichnet [Sachs et al., 2000]. Dizentrische (polyzentrische) Chromosomen führen während der Anaphase zu sog. Anaphase-Brücken, die die Teilung in zwei Tochterzellen verhindern, und damit zum reproduktiven Zelltod führen. Azentrische Fragmente führen zur Bildung von Mikrokernen und damit zum Verlust von DNA.

Stabile Chromosomenaberrationen wie reziproke Translokationen, Deletionen, Inversionen und Insertionen, die auch viele Zellteilungen später noch nachgewiesen werden können, können in letzter Konsequenz zu Mutationen, Krebsentstehung oder zum apoptotischen oder reproduktiven Zelltod führen [Frankenberg-Schwager et al., 1989; Kanaar et al., 1998].

Ionisierende Strahlung erzeugt beim Durchdringen von Materie Anregungen und Ionisationen. Dadurch werden Elektronen aus dem Atom- und Molekülverbänden herausgelöst. $\mathrm{Zu}$ diesen Strahlenarten gehören hochenergetische UV-Strahlen, elektromagnetische Strahlen wie Röntgen- und Gammastrahlung, leichte geladenen Teilchen wie Elektronen und schwere Teilchen wie Ionen [Gerthsen und Vogel et al., 
1993]. Je nach der entsprechenden Ionisationsdichte kann die ionisierende Strahlung als dünn oder dicht ionisierende Strahlung bezeichnet werden.

Der Unterschied zwischen dünn und dicht ionisierender Strahlung liegt in der unterschiedlichen räumlichen Verteilung der Energiedeposition entlang der Teilchenbahnen (siehe Abb. 1.2).
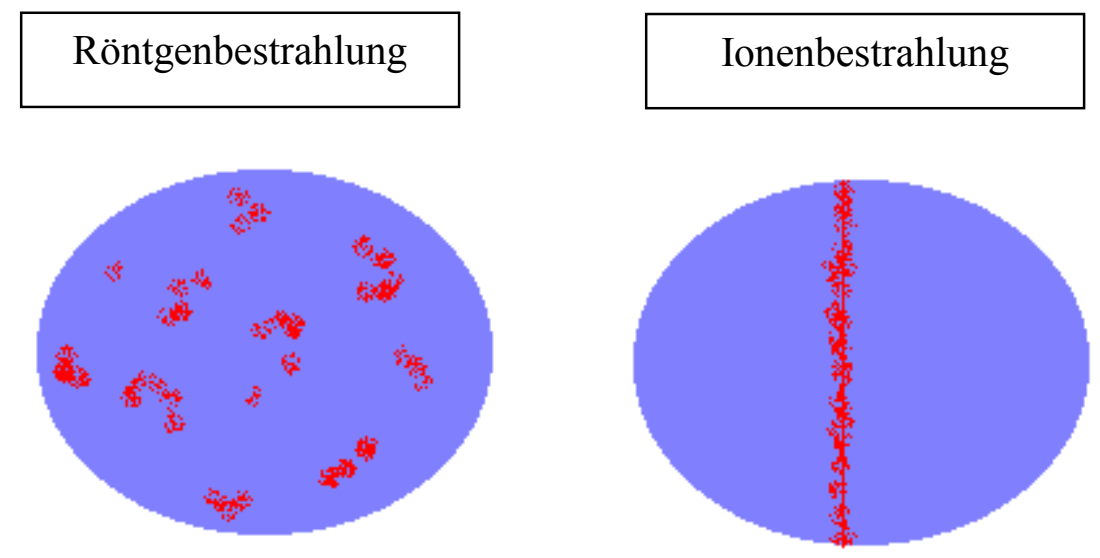
Abbildung 1.2 Schematische Darstellung der unterschiedlichen Ionisations- verteilungen im Zellkern nach bei Röntgenbestrahlung und nach Ionenbestrahlung.

Bei dünn ionisierender Strahlung sind viele Ionisationsereignisse oft weit voneinander entfernt und relativ homogen im Zellkern verteilt. Bei dicht ionisierender Strahlung sind die Ionisationsereignisse dicht nebeneinander lokalisiert und dadurch inhomogen im Zellkern verteilt.

Die geladenen mittelschweren Kohlenstoffionen interagieren mit den Elektronen des Targets (elektronic stopping) und erzeugen längs ihres Weges eine Ionisationsspur. Die lokale Ionisationsdichte der Teilchenspur hängt von der Art und der Energie des primären Teilchens ab. Der Durchmesser der Ionisationsspur hängt von der primären Ionenenergie $\mathrm{ab}$. Innerhalb dieser Spur nimmt die Dosisdeposition radial mit dem Quadrat des Abstandes vom Spurzentrum ab. Im Inneren der Spur erfolgt die Energieabgabe auf einem extrem kleinen Raum. Deshalb sind die Schäden bei 
Teilchenstrahlung nicht gleichmäßig über das bestrahlte Volumen verteilt, wie bei Röntgenstrahlung, sondern konzentrieren sich auf die Flugbahn einzelner Ionen.

Wird die, an das Targetmaterial abgegebene Energie entlang der Wegstrecke gemessen, erhält man die sogenannte „Bragg-Kurve“ (Abb. 1.3). Das Ende der Teilchenbahn wird als Bragg Peak bezeichnet. In diesem Peak erreicht die Energiedeposition ihr Maximum.

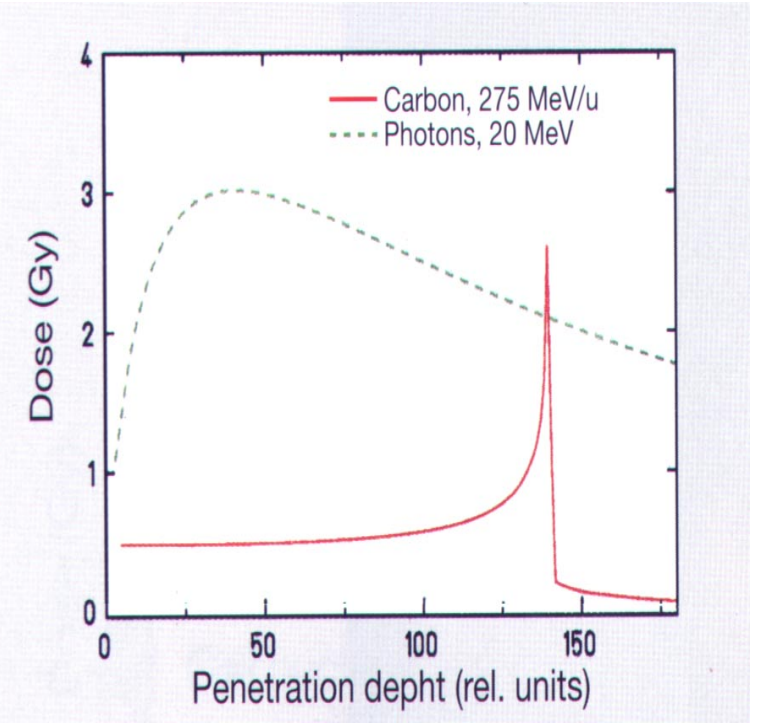

Abbildung 1.3 Tiefendosisprofile eines ${ }^{12} \mathrm{C}$-Ionenstrahls im Vergleich zu PhotonenStrahlung. Die Position des Bragg-Maximums hängt von Energie der Ionen ab und kann daher variiert werden [aus The Wonderful World of Atoms and Nuclei: Heavy Ion Research in Darmstad: Status and Outlook].

Dieses, im Vergleich zur anderen Strahlenarten invertierte Tiefendosisprofil bildet die Grundlage der Strahlentherapie mit Schwerionenstrahlen [Kraft et al., 1997].

Dicht ionisierende Strahlenarten wie z. B. schwere und mittelschwere Ionen, weisen eine erhöhte biologische Wirksamkeit auf. Mechanismen, die dieser erhöhten Wirksamkeit zu Grunde liegen, sind noch nicht vollständig verstanden. Die erhöhte biologische Wirksamkeit resultiert sehr wahrscheinlich aus dem veränderten Schadensspektrum der, durch Ionen induzierten DNA-Schäden. Schon bei kleinen Dosen werden durch dicht ionisierende Strahlenarten mehrfach geschädigte, oft 
unreparable (unreparierbar oder irreparabel) DNA-Läsionen, die sich darüber hinaus auch häufig in mehreren benachbarten Chromosomenterritorien gleichzeitig befinden, induziert [Goodhead et al., 1999; Prise et al., 2001; Sutherland et al., 2001]. Die Wahrscheinlichkeit, dass solche Läsionen entweder gar nicht repariert werden oder dass die Fehlreparatur zur Entstehung komplexer Ausstauschaberrationen führt, ist für Kohlenstoffionen im Vergleich zur Röntgenstrahlung sehr hoch [Yamada et al., 2000]. Es stellt sich die Frage, ob sich die nach Röntgenbestrahlung manifest gewordenen reparaturbedingten Unterschiede in der individuellen Strahlensensitivität, auch nach Ionenbestrahlung manifestieren.

Nach Einwirkung von dicht ionisierender Strahlung entsteht infolge der inhomogenen Ionisationsdichte ein anderes Schadensbild als durch die eher homogene dünn ionisierende Strahlung [Anderson et al., 2000; Ritter et al., 2000; Ritter et al., 2001]. Zur Untersuchung der Strahlenwirkung auf chromosomaler Ebene muss deshalb das gesamte Spektrum der Chromosomenschäden analysiert werden, da je nach Strahlenart unterschiedliche Schadensbilder erwartet werden müssen. 


\section{Fragestellung und Ziel der Untersuchungen}

Ein Verständnis der Mechanismen, die der Entstehung strahleninduzierter Chromosomenaberrationen zu Grunde liegen, ist aufgrund ihrer grundsätzlichen Bedeutung für die Prozesse der Karzinogenese (vor allem Onkogenaktivierung durch Translokationen und Tumorsupressorgenverlust durch Deletionen) und für die Prozesse der Zelltötung sehr wichtig.

Im Rahmen dieser Arbeit sollten verschiedene biologische Endpunkte der Strahlenwirkung wie Zellinaktivierung, Zellzyklusstörung, Apoptose-Induktion, sowie die Induktion von strukturellen Chromosomenaberrationen untersucht werden, die für die Strahlentherapie und für den Strahlenschutz relevant sind. Darüber hinaus sollten auch Proteine, die an der DNA-PK-abhängigen NHEJ-Reparatur beteiligt sind, untersucht werden.

Der Gebrauch von in vitro Zellsystemen hat den Vorteil, dass sie weniger komplex aufgebaut sind als Gewebe, und dass, je nach Fragestellung, die Eigenschaften der Zellen durch die Auswahl eines geeigneten Zellsystems oder durch eine genetische Manipulation variiert werden können. Als Modellsystem für die vorliegende Arbeit wurden zwei etablierte Tumorzelllinien ausgewählt, die eine unterschiedliche intrinsische Strahlensensitivität gegenüber Röntgenstrahlung aufweisen: eine strahlenresistente Kolonkarzinom-Linie, WiDr, und eine strahlenempfindliche Mamma-Karzinom-Linie, MCF-7. Um die Interpretation der Ergebnisse zu erleichtern, wurden für die strahlenbiologischen Untersuchungen nur synchronisierte Zellen verwendet. Die untersuchten Tumorzellen wurden als konfluente Monolayer eingesetzt, etwa $90 \%$ der Zellen befanden sich zum Zeitpunkt der Bestrahlung in der $\mathrm{G}_{0^{-}}$oder $\mathrm{G}_{1^{-}}$ Phase des Zellzyklus.

Zum Vergleich zu konventionellen Röntgenstrahlen, bei denen Energiedepositionen homogen im Zellkern verteilt sind, wurden dicht ionisierende Kohlenstoffionen als Strahlenquelle gewählt, da diese lokalisierte Energiedepositionen und damit verbundene multiple DNA-Schäden (clustered damage) induzieren. Die vergleichende 
Analyse zellulärer Reaktionen auf die unterschiedlichen DNA-Schadensmuster ließ ein tieferes Verständnis der zellulären Schadensprozessierungs- bzw. Reparaturmechanismen erwarten. Für dicht ionisierende Kohlenstoffionen war zudem eine erhöhte biologische Wirksamkeit beschrieben worden, deren Ursachen und genaues Ausmaß noch nicht bekannt sind und weiterer Untersuchungen bedürfen..

Der strahleninduzierte Zelltod wurde als reproduktiver Zelltod (Kolonie-BildungsAssay) und als programmierter Suizid-Zelltod, Apoptose (fluoreszente AnnexinFärbung und ELISA-Assay), untersucht. Als Maß für unreparierte DNADoppelstrangbrüche wurde die Anzahl der extra-azentrischen Fragmente bestimmt (Giemsa-Färbung), und als Maß für die Fehlreparatur von DNA-Doppelstrangbrüchen wurden einfache (dizentrische Chromosomen und reziproke Translokationen) und

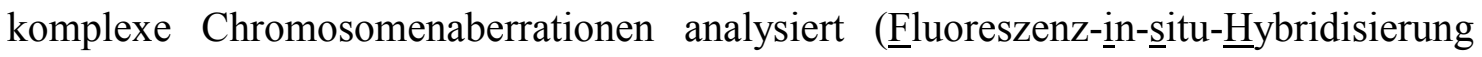
unter Verwendung von Sonden für ganze Chromosomen, FISH-Methode).

$\mathrm{Da}$, in der vorliegenden Arbeit, die Schäden in der $G_{0^{-}}$bzw. $G_{1}$-Phase induziert wurden, in der allem die NHEJ-Reparatur wirksam ist, wurde dieser Reparaturweg näher untersucht. Es wurden drei Proteine als Vertreter der NHEJ-Reparatur gewählt: die katalytische Untereinheit der DNA-abhängigen Proteinkinase DNA-PK $\mathrm{CS}_{\mathrm{C}}$, und das $\mathrm{Ku} 70$ und das $\mathrm{Ku} 86$ Protein. Falls diese Proteine, ähnlich wie in normalen Zellen konstitutionell vorhanden wären, könnten nach einer Bestrahlung Protein-Cluster (Foci) beobachtet werden: die Reparaturproteine bewegen sich $\mathrm{zu}$ den geschädigten DNAStellen hin. Dieser Vorgang und seine Kinetik wurden vergleichsweise in den beiden Zelllinien nach Bestrahlung mit Kohlenstoffionen bzw. mit Röntgenstrahlung untersucht und mit normalen (nasalen) Epithelzellen verglichen. Gleichzeitig wurde auch der DNA-PK ${ }_{C S} / \mathrm{Ku} 70 / \mathrm{Ku} 86-$ Status in den unbestrahlten Zellen mit Hilfe von FITC markierten Antikörpern bestimmt. Eine NHEJ-Defizienz würde eine ausgeprägte Strahlensensitivität der Tumorzelllinie zufolge haben. Dieser Frage wurde im Bezug auf die sehr hohe Strahlensensitivität der MCF-7-Zellen nachgegangen.

Die geplanten Untersuchungen sollten Rückschlüsse auf die Mechanismen die der erhöhten biologischen Wirksamkeit dicht ionisierender Strahlenarten zu Grunde liegen ermöglichen, und gleichzeitig einen Beitrag zur Klärung der Ursachen für die unterschiedliche intrinsische Strahlensensitivität verschiedener Zelltypen leisten. Die Bestimmung von strahleninduzierten Chromosomenaberrationen diente als Indikator 
für die fehlerhafte Doppelstrangbruchreparatur. Da die DNA-PK-abhängige Reparatur maßgeblich an der Reparatur von Doppelstrangbrüchen beteiligt ist, bestehen generell Zusammenhänge zwischen der Induktion und der Reparatur von Doppelstrangbrüchen einerseits, und der Häufigkeit struktureller Chromosomenaberrationen andererseits. Darüber hinaus sind die gewonnenen Erkenntnisse der Aberrationsentstehung auch für das Verständnis der chromosomalen Instabilität, die fast in allen Tumorzellen vorkommt, von Bedeutung. 


\title{
3. Material und Methoden
}

\subsection{Material}

Die verwendeten Materialien sind im Anhang B aufgelistet:
B.1 Medien und Zusätze für die Zellkultur
B.2 Chemikalien
B.3 Lösungen und Puffer
B.4 Färbelösungen und Färbekits
B.5 Antikörper
B.6 Einwegmaterial und Geräte

\begin{abstract}
Alle Lösungen, Medien und Puffer wurden mit zweifach destilliertem Wasser angesetzt. Für die Chromosomenfärbung wurde nur Wasser in Reinstqualität (Ampuwa, Wasser für Injektionszwecke) verwendet. Alle Experimente wurden mit Chemikalien in p.a.-Qualität durchgeführt.
\end{abstract}

\subsubsection{Zelllinien}

\subsubsection{WiDr-Zelllinie}

Die strahlenresistente WiDr-Zelllinie wurde 1971 aus dem primären rectosigmoiden Kolonkarzinom einer 78jährigen Patientin etabliert. Es handelte sich um ein Adenokarzinom des Colons [Noguchi et al., 1979]. Die Zellen haben einen triploiden weiblichen Karyotyp mit einer Modalzahl von 72. Die hier verwendete Zelllinie ist unter der ATCC CCL No.: 218 katalogisiert und wurde von der ATCC (American Type Culture Collection) Zellbank bezogen. 


\subsubsection{MCF-7-Zellinie}

Die strahlensensitive MCF-7-Zelllinie wurde 1973 aus dem malignen Pleuraerguss einer 69jährigen Patientin mit metastasierendem Mammakarzinom etabliert. Es handelte sich um ein Adenokarzinom der Mamma [Brooks et al., 1973]. Die Zellen haben einen triploiden weiblichen Karyotyp mit einer Modalzahl von 71. Die hier verwendete Zelllinie ist unter der TZB No.: 6100030 katalogisiert und wurde aus der Tumorbank des Deutschen Krebsforschungszentrums in Heidelberg bezogen.

\subsubsection{HNEpC-Zelllinie}

Die HNEpC-Zelllinie (Lot-No.: 034H161199) ist eine primäre Kultur aus normalen nasalen Epithelzellen, die aus der Nasenschleimhaut eines gesunden 21jährigen Spenders, gezüchtet wurde. Die hier verwendete Zelllinie ist unter der Bestell-Nr.: C12621 katalogisiert und wurde aus der Zellbank der Firma PromoCell in Heidelberg bezogen.

\subsection{Methoden}

\subsubsection{Zellkultur}

\subsubsection{Kultivierungsbedingungen}

Alle drei Zelllinien wurden bei $37^{\circ} \mathrm{C}$ in einem $\mathrm{CO}_{2}$-Brutschrank mit $5 \% \mathrm{CO}_{2}$ als Monolayer-Kulturen in Zellkulturflaschen oder auf speziellen Objektträgern kultiviert. Jede Zelllinie wurde in einem, für sie optimierten Medium kultiviert.

Die WiDr-Zelllinie wurde im MEM mit EARLE'S Salzen (MEM, Minimal Essential Medium) mit $10 \%$ FKS (FKS, Fötales Kälberserum), $2 \%$ Glutamin und Penicillin/Streptomycin-Lösung (Konzentration: $10.000 \mathrm{U} / 10.000 \mu \mathrm{g} / \mathrm{ml}$ ) kultiviert. 
Die MCF-7-Zelllinie wurde in 50\% DMEM (DMEM, Dulbecco`s Minimal Essential Medium) und 50\% MEM mit 10\% FKS, 2\% Glutamin und Penicillin/StreptomycinLösung kultiviert.

Die HNEpC wurde im Medium der Firma PromoCell kultiviert. Es handelt sich dabei um das „Bronchial Epithelial Cell Growth Medium“.

\subsubsection{Subkultivierung der Zellen}

Zur Subkultivierung (Passagierung) wurden die adhärenten Zellen mit Phosphatpuffer (PBS, phosphate buffered saline) gespült und anschließend durch die Einwirkung von 1 $\mathrm{ml}$ Trypsin-EDTA-Lösung (EDTA, Ethylene-diamine-tetraacetic acid) pro $25 \mathrm{~cm}^{2}$ Kulturoberfläche bei $37^{\circ} \mathrm{C}$ vom Flaschenboden abgelöst. Die abgerundeten Zellen wurden durch Resuspendieren vereinzelt und ins Medium überführt. Dadurch wurde die Wirkung von der Trypsin-EDTA-Lösung gestoppt, da das Serum die Aktivität von Trypsin hemmt. Die Zellen wurden mit Hilfe der Neubauer-Zählkammer gezählt und anschließend wurde eine bestimmte Anzahl an Zellen wieder ausgesät. Das Medium wurde gewechselt, wenn mehr als 3 Tage zwischen zwei Passagen lagen. Für die Experimente wurde eine größere Zellmenge des jeweiligen Zelltyps und der gleichen Passage eingefroren und nur diese Stammkultur des jeweiligen Zelltyps wurde nach dem Auftauen und nach dreimaliger Subkultivierung für die Versuche verwendet.

\subsubsection{Langzeitlagerung der Zellen}

Die Stammkulturen aller Zelllinien wurden in flüssigem Stickstoff $\left(-196^{\circ} \mathrm{C}\right)$ bei einer Konzentration von $1 \times 10^{6}$ Zellen pro Ampulle (1,8 ml Einfriermedium) gelagert. Als Einfriermedium wurde das entsprechende Zellkultur-Medium mit 8,3\% DMSO

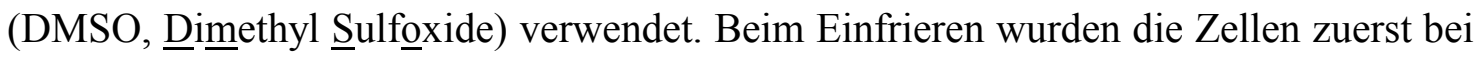
$-20^{\circ} \mathrm{C}$ ca. 2 Stunden langsam heruntergekühlt, um sie dann 24 Stunden in der Gasphase des flüssigen Stickstoffs (ca. $-80^{\circ} \mathrm{C}$ ) zu lagern. Erst nach diesen 24 Stunden können die Zellen in flüssigem Stickstoff $\left(-196^{\circ} \mathrm{C}\right)$ über mehrere Jahre gelagert werden. 
Nach der Entnahme einer Ampulle aus dem flüssigen Stickstoff $\left(-196^{\circ} \mathrm{C}\right)$ wurden die Zellen kurz im $37^{\circ} \mathrm{C}$ warmen Wasserbad angetaut, so dass sich ein beweglicher Pfropfen bildete. Anschließend wurden die Zellen in eine Kulturflasche mit Medium überführt. Nach ca. 2-3 Stunden wurde ein Mediumwechsel durchgeführt. Die Zellen wurden dreimal passagiert, bevor sie für die Experimente verwendet wurden.

\subsubsection{Mykoplasmentest}

Mykoplasmen sind Einzeller, die sich außerhalb von Zellen vermehren können, obwohl sie keine Zellwand besitzen. Viele Mykoplasmen-Arten vermehren sich extrazellulär, d.h. ohne in die Wirtszelle einzudringen. Trotzdem können sie Auswirkung auf das Zellwachstum und die Proliferation einer infizierten Zellkultur haben [Tsai, et al., 1995]. Es ist allgemein bekannt, dass der Durchseuchungsgrad von Zellkulturen mit Mykoplasmen sehr hoch ist. Es handelt sich vor allem um orale Mykoplasmen, die durch den Menschen übertragen werden, aber auch andere Arten, die durch die Medium-Zusätze übertragen werden, kommen sehr häufig vor, wie zum Beispiel: M.bovinis (stammt aus dem fötalem Kälberserum).

Um die Verunreinigung der Zellkulturen durch Mykoplasmen zu verhindern, wurden die Zelllinien in regelmäßigen Abständen mit Hilfe des DAPI-Tests (siehe Kapitel 3.2.1.4.1) überprüft. Die für die Experimente verwendeten Zellkulturen waren während des gesamten Untersuchungszeitraumes mykoplasmenfrei.

\subsection{DAPI-Test}

Die Zellen wurden auf Kunststoff-Objektträgern bis zu einer Dichte von $50-70 \%$ angezüchtet. Das Medium wurde abgenommen und die Kunststoff-Objektträger wurden mit PBS vorsichtig gespült. Anschließend wurden sie mit DAPI-Methanol-Lösung (DAPI, 4,6-iamidino-2-phenylindol) gespült und dann mit dieser 15 Minuten bei $37^{\circ} \mathrm{C}$ gefärbt. Die überschüssige Färbelösung wurde durch mehrmaliges Spülen mit PBS entfernt und die Proben wurden mit einem Deckglas eingedeckelt. Danach wurden sie mit einem Fluoreszenzmikroskop (Fa. Zeiss) mit 100 facher Vergrößerung ausgewertet. 


\subsubsection{Bestrahlung}

\subsubsection{Bestrahlungseinrichtungen und Dosimetrie}

Die Bestrahlung mit hochenergetischen (mittelschweren) ${ }^{12} \mathrm{C}$-Ionen wurde am Schwerionensynchrotron (SIS) der Gesellschaft für Schwerionenforschung $\mathrm{mbH}$ in Darmstadt durchgeführt.

Die Angaben für die Energie des verwendeten Strahls beziehen sich auf diejenige Energie, mit der der Strahl auf das Target trifft. Die Energie der Ionen ist gegenüber der vom Beschleuniger gelieferten Primärenergie geringer, da sie durch die Folien des Austrittsfenster und des Transmissions-Monitors sowie durch die Luftstrecke und durch den Boden der Kulturflasche vermindert wird [Heinrich et al., 1991]. Dies wurde bei der Dosisbestimmung im Target (Zellschicht) berücksichtigt.

Der Teilchenstrahl wurde mit Hilfe eines aktiven magnetischen Scanner-Verfahrens das eine homogene Strahlführung ermöglicht, geführt. Die Inhomogenität im Bestrahlungsfeld war kleiner als 10\% [Haberer et al., 1993; Kraft-Weyrather et al., 1992]. Der Spurdurchmesser der ${ }^{12}$ C-Strahls ist im Vergleich zum Durchmesser des Zellkerns groß, so dass dadurch jeder Zellkern getroffen wird. Die Dosimetrie wurde mit Ionisationskammern von physikalischen Team der GSI durchgeführt [Scholz, 1992].

In den Versuchen wurden Kohlenstoff-Ionen mit Energien $400 \mathrm{MeV} / \mathrm{u}, 200 \mathrm{MeV} / \mathrm{u}$, $100 \mathrm{MeV} / \mathrm{u}$ und Ionen des ausgedehnten (extended) Bragg Peak verwendet. Als ausgedehnter Bragg Peak wird die Überlagerung von vielen Bragg Peaks, die zur verschiedenen Kohlenstoff-Ionen dazugehören, bezeichnet. Die Ionenenergie im Target wurde durch die Länge der davonliegenden Luftstrecke variiert. In Abbildung 3.1 sind die Abstände für die einzelnen Energien dargestellt. 


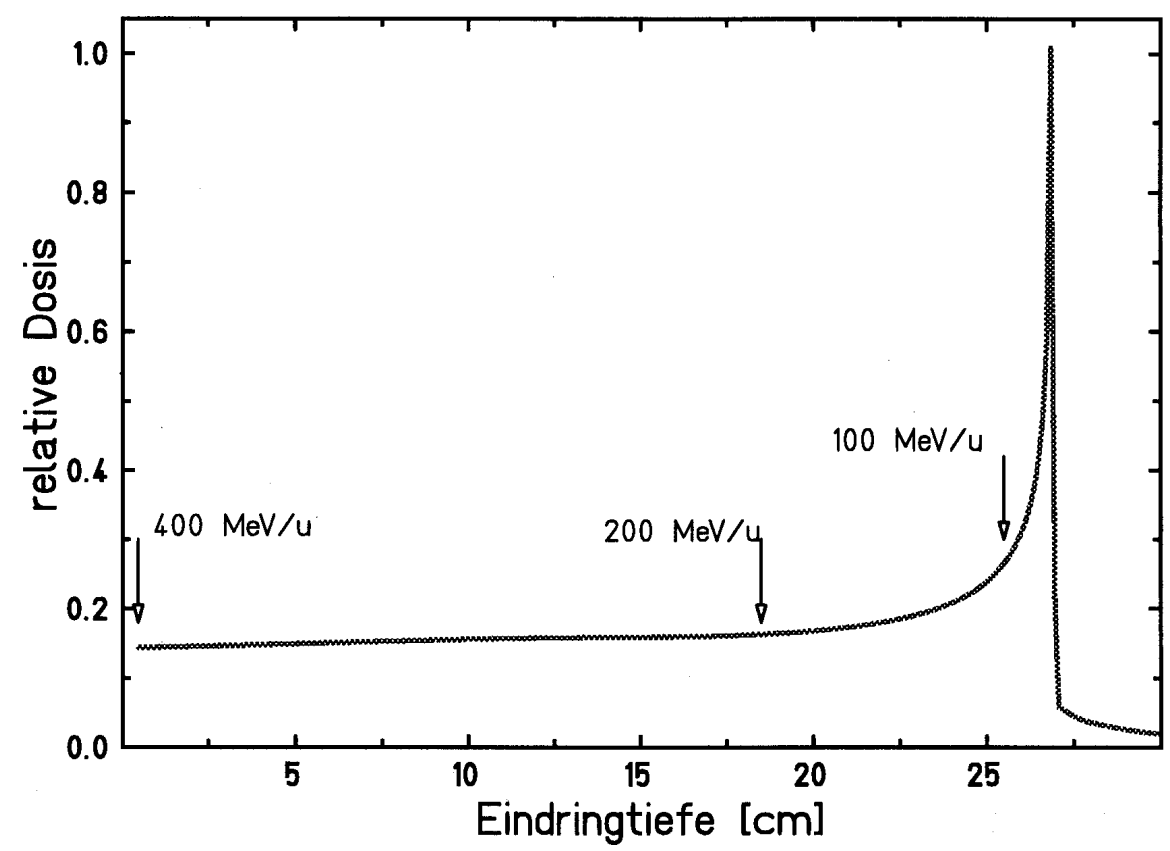

Abbildung 3.1 Die Abstände des Targets für die einzelnen Energien der Kohlenstoffionen (mit freundlicher Genehmigung von M. Scholz)

Das Energiespektrum des verwendeten Bragg Peaks ist in Abbildung 3.2 gezeigt. Eine Übersicht über die verwendete Ionen-Energien und ihre physikalischen Eigenschaften ist in Tabelle 3.1 bzw. in Abbildung 3.2 und 3.3 angegeben.

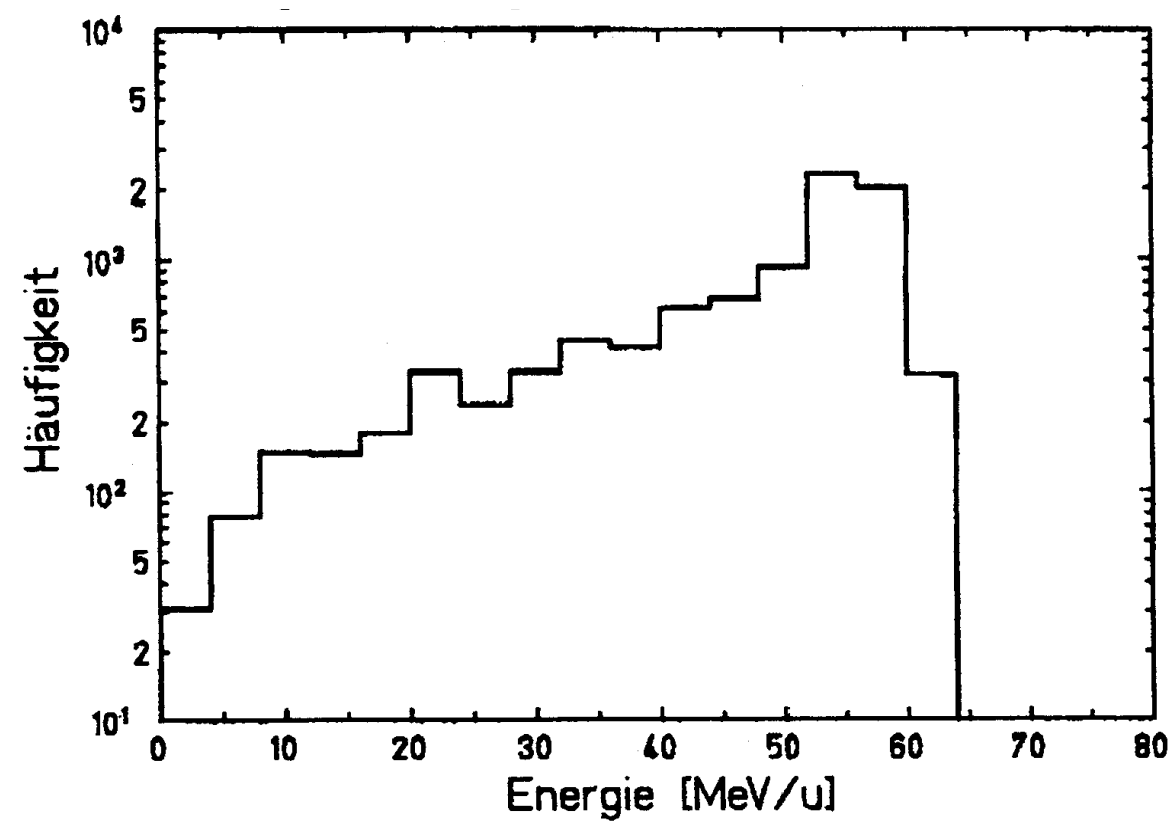

Abbildung 3.2 Energieverteilung im Target nach Bestrahlung mit Kohlenstoffionen im ausgedehnten Bragg Peak (mit freundlicher Genehmigung von M. Scholz) 
Tabelle 3.1 Charakteristische Parameter der verwendeten Ionen

\begin{tabular}{|c|c|c|c|c|c|}
\hline Strahlung & Ion & $\begin{array}{c}\text { Energie } \\
{[\mathrm{MeV} / \mathrm{u}]}\end{array}$ & $\begin{array}{c}\text { LET } \\
{[\mathrm{keV} / \mu \mathrm{m}]}\end{array}$ & $\begin{array}{c}\text { Fluenz je Gy } \\
{\left[\mathrm{T} / \mathrm{cm}^{2}\right]}\end{array}$ & $\begin{array}{c}\text { Dosis } \\
{[\mathrm{Gy}]}\end{array}$ \\
\hline Kohlenstoff & ${ }^{12} \mathrm{C}$ & 100 & 28,0 & $22,4 \times 10^{6}$ & $0-5$ \\
\hline Kohlenstoff & ${ }^{12} \mathrm{C}$ & 200 & 16,5 & $37,8 \times 10^{6}$ & $0-5$ \\
\hline Kohlenstoff & ${ }^{12} \mathrm{C}$ & 400 & 11,0 & $56,7 \times 10^{6}$ & $0-5$ \\
\hline Kohlenstoff & ${ }^{12} \mathrm{C}$ & $\begin{array}{c}\text { Bragg Peak } \\
\text { siehe Abb. 3.2 }\end{array}$ & $\begin{array}{c}\text { Von - bis } \\
\text { siehe Abb. 3.3 }\end{array}$ & n.d. & $0-4$ \\
\hline
\end{tabular}

Die primären Reaktionen zwischen ionisierender Strahlung und den bestrahlten Zellen erfolgen durch direkte Ionisationen oder indirekt durch Wirkung strahleninduzierter freier Radikale. Je höher die Ionisationsdichte einer Strahlenart ist, umso höher ist die biologische Wirksamkeit dieser Strahlung. Für die Charakterisierung der Ionisationsdichte einer Strahlung kann in erster Näherung der LET-Wert (LET, linearer Energie-Transfer) als Maß genommen werden.

Dabei ist LET definiert als der mittlere Energieverlust $(\Delta E)$ entlang des Weges $(\Delta s)$ eines primären, ionisierenden Teilchens im Wasser:

$$
L E T=\frac{\Delta E}{\Delta s}
$$

LET: linearer Energie-Transfer $[\mathrm{keV} / \mu \mathrm{m})$

$\Delta \mathrm{E}$ : Energieverlust eines geladenen Teilchens $[\mathrm{keV}]$ entlang des Bahnabschnitts $\Delta \mathrm{s}$

$\Delta \mathrm{s}: \quad$ Bahnabschnitt eines geladenen Teilchens $[\mu \mathrm{m}]$ 
Die für eine Teilchenstrahlung charakteristische Teilchenflussdichte oder Fluenz F steht mit der Dosis in folgender Beziehung:

$$
F=\rho \times D \times \frac{1}{L E T} \times \frac{1}{1,6 \times 10^{-9}}
$$

D: Dosis [Gy]

LET: Linearer Energie-Transfer $[\mathrm{keV} / \mu \mathrm{m}]$

F: $\quad$ Fluenz [Teilchenzahl $\left./ \mathrm{cm}^{2}\right]$

$\rho: \quad$ Dichte des Wasser $\left[\mathrm{g} / \mathrm{cm}^{3}\right]$

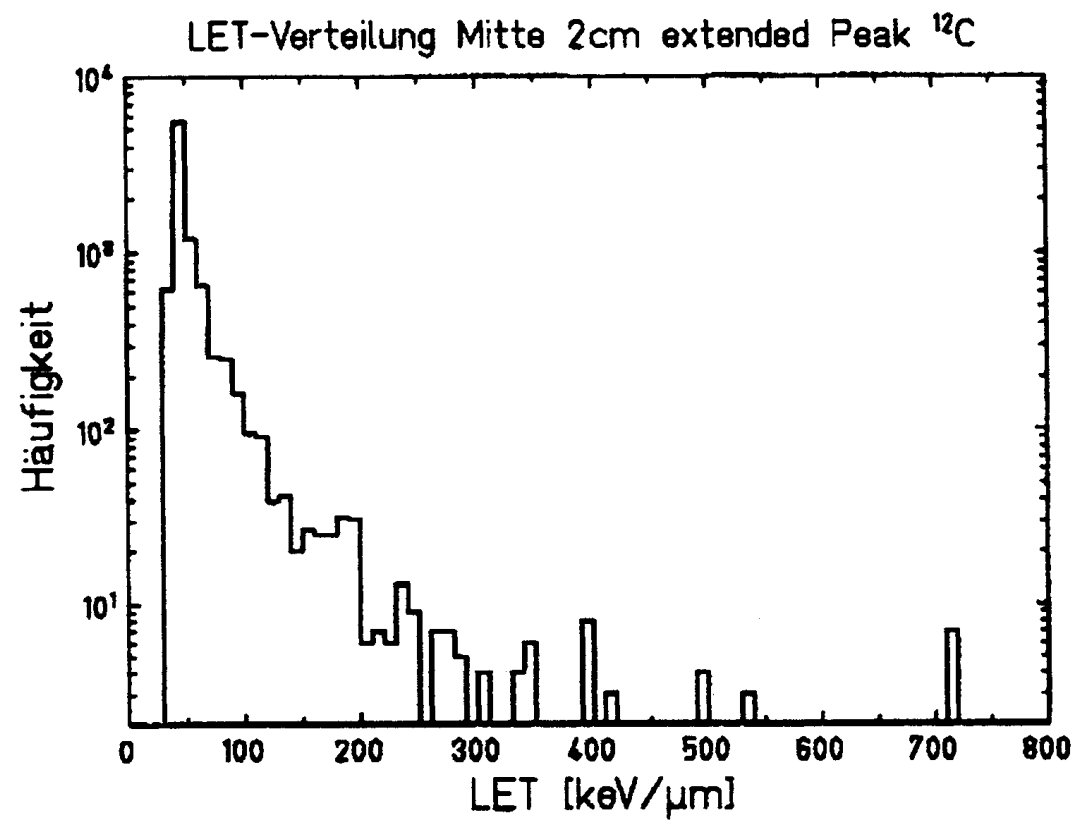

Abbildung 3.3 LET-Verteilung im Target nach Bestrahlung mit Kohlenstoffionen im ausgedehnten Bragg Peak (mit freundlicher Genehmigung von M. Scholz)

Als Referenzstrahlung wurde 200 kV-Röntgenstrahlung verwendet. Die Bestrahlung wurde mit dem Stabilipan 2, einem Röntgengerät der Firma Siemens durchgeführt. Die Röhrenspannung betrug $200 \mathrm{kV}$ und der Kathodenstrom betrug $20 \mathrm{~mA}$. Die Strahlung wurde mit einem 0,5 mm dicken Kupfer-Filter gefiltert. Der Fokusabstand, d.h. die Entfernung zwischen dem Brennpunkt des Strahls und der Probe, betrug 30,2 cm. Die 
Dosisleistung betrug 1,3 Gy/min. Die Dosis und die Dosisleistung wurden durch Physiker der GSI Darmstadt bzw. Klinik für Strahlentherapie und Radioonkologie Göttingen regelmäßig überprüft.

\subsubsection{Bestimmung der Zellkerngröße}

Für die Dosimetrie-Berechnungen wurden die Zellkerngrößen (Targetgrößen) der jeweiligen Zelllinie benötigt. Diese Parameter wurden bei der GSI in Darmstadt bestimmt.

Dazu wurden ca. $3 \times 10^{6}$ Zellen pro Petri-Schale angezüchtet. Die Zellen wurden 1 Tag lang kultiviert und dann fixiert. Zuerst wurden die Zellen zweimal mit PBS-Puffer gewaschen und über Nacht mit Glutaraldehyd-Lösung (1 Teil Glutaraldehyd + 4 Teile PBS) fixiert. Die Fixierlösung wurde mit PBS-Puffer ausgewaschen und ca. $1 \mathrm{ml}$ PBSPuffer wurde als Schutz gegen das Austrocknen auf den Zellen belassen. Die Petrischalen wurden mit Parafilm abgedichtet und zum Transport nach Darmstadt vorbereitet. Die Färbung erfolgte 5 Minuten lang mit 1,55 ml Hoechst 33258 Farbstoff $(16 \mu \mathrm{g} / \mathrm{ml})$ pro Petrischale bei der GSI in Darmstadt. Nach Ablauf der Zeit wurde die Färbelösung dekantiert, es sollte aber ein kleiner Rest dieser Lösung bleiben, so dass sich ein Film ausbilden konnte. Auf diesen Film wurde das Deckglas luftblasenfrei aufgelegt, und die Petrischalen wurden bis zur Auswertung im Dunkeln aufbewahrt.

Am Fluoreszenz-Mikroskop wurden jeweils 50 Kerne ausgewertet. Die Zellkerne leuchten unter dem Fluoreszenz-Mikroskop hell-grün. Die Zellkernumrisse wurden markiert und die Fläche der markierten Kerne berechnet. Hierzu wurde ein an der GSI Darmstadt entwickeltes Computerprogramm [Scholz, 1992] verwendet.

\subsubsection{Bestrahlung der Zellen mit Kohlenstoffionen}

Die Zellen wurden als konfluente Zellpopulationen bestrahlt. Dazu wurden sie 6 Tage vor der Bestrahlung mit $1 \times 10^{5}$ Zellen pro $\mathrm{cm}^{2}$ in Zellkulturflaschen ausgeimpft. Nach 3 Tagen erfolgte ein Mediumwechsel. Nach etwa 4-5 Tagen wurden die Flaschen nach Darmstadt transportiert. 
Der Transport der Zellen erfolgte in geschlossenen Kulturflaschen, die in aufrechter Position in einer wärmeisolierenden Box untergebracht waren. Um dabei die Austrocknung der Zellen zu vermeiden, wurden die Flaschen vollständig mit EBSSPuffer (EBSS, Earle`s buffered salt solution) gefüllt. Nach Ankunft in Darmstadt wurde die Puffer-Lösung entfernt und die Zellen wurden mit frischem Medium gefüttert. Um den einwandfreien Gasaustausch zu gewährleisten, wurden die Verschlüsse der Flaschen durch neue, sterile Verschlüsse ausgetauscht.

Die Bestrahlung von Zellen mit Kohlenstoffionen erfolgte in geschlossenen Kulturflaschen, die in aufrechter Position bestrahlt wurden. Während der Bestrahlung wurde das Kulturmedium durch den EBSS-Puffer ersetzt und die Flaschen wurden vollständig mit diesem Puffer gefüllt, dies sollte die Austrocknung der Zellen während der aufrechten Bestrahlung verhindern. Nach Bestrahlung wurden die Flaschen mit neuem Medium gefüttert.

Bei allen Bestrahlungsversuchen wurden unbestrahlte Zellen als Kontrollen mitgeführt, so dass sie vergleichbare Behandlungs-Bedingungen hatten, wie die bestrahlten Proben. Die Zellen wurden mit Dosen von 1 Gy bis 5 Gy bestrahlt.

\subsubsection{Bestrahlung der Zellen mit $200 \mathrm{kV}$-Röntgenstrahlung}

Die Zellen wurden ebenfalls als konfluente Zellpopulationen bestrahlt. Dazu wurden sie 6 Tage vor der Bestrahlung mit $1 \times 10^{5}$ Zellen pro $\mathrm{cm}^{2}$ in Zellkulturflaschen ausgeimpft. Nach 3 Tagen erfolgte ein Mediumwechsel. Kurz vor der Bestrahlung wurden die Zellen abtrypsiniert und als Zellsuspension bestrahlt.

Bei allen Bestrahlungen wurden unbestrahlte Zellen als Kontrollen mitgeführt, so dass sie vergleichbare Behandlungs-Bedingungen hatten, wie die bestrahlten Proben. Die Zellen wurden mit Dosen von 1 Gy bis 8 Gy bestrahlt. 


\subsubsection{Koloniebildungstest}

Zellen vermehren sich durch Zellteilung und bilden dabei in vitro makroskopisch sichtbare Kolonien. Durch Strahlenschäden nimmt diese Teilungsfähigkeit ab und es kommt zum reproduktiven Zelltod der betroffenen Zellen.

In der vorliegenden Arbeit wurde das klonogene Überleben nach Bestrahlung mit Hilfe des Koloniebildungstests nach Puck und Marcus bestimmt [Puck und Marcus, 1955]. Dabei wird eine Zelle als überlebend definiert, wenn sie in einem Zeitraum von 10-15 Zellzyklen mindestens 50 Tochterzellen bilden konnte. Die Koloniebildungsfähigkeit unbestrahlter Zellen bezeichnet man als „plating efficiency“ (PE).

Die PE berechnet sich nach:

$$
P E=\frac{N_{K}}{N_{0}}
$$

PE: „plating efficiency“, Koloniebildungsfähigkeit unbestrahlter Zellen

$\mathrm{N}_{\mathrm{K}}$ : Anzahl der Kolonien

$\mathrm{N}_{0}$ : Anzahl der eingesäten Zellen

Das relative Zellüberleben der bestrahlten Zellen $\mathrm{S} / \mathrm{S}_{0}$ ergibt sich aus dem Verhältnis der PEs der bestrahlten und der unbestrahlten Zellen, und wird wie folgt berechnet:

$$
\frac{S}{S_{0}}=\frac{P E_{D}}{P E_{K}}
$$

$\mathrm{S} / \mathrm{S}_{0}$ : relatives Überleben der bestrahlten Zellen im Verhältnis zum Überleben der unbestrahlten Zellen

$\mathrm{PE}_{\mathrm{K}}$ : PE der unbestrahlten Zellen (Kontrolle)

$\mathrm{PE}_{\mathrm{D}}$ : $\quad \mathrm{PE}$ der bestrahlten Zellen 
Die graphische Darstellung der Abhängigkeit des Zellüberlebens $\mathrm{S} / \mathrm{S}_{0}$ von der Bestrahlungsdosis wird als Überlebenskurve bezeichnet. Die Überlebenskurven können in einem nicht $\mathrm{zu}$ großen Dosisbereich durch eine linear-quadratische Beziehung hinreichend genau beschrieben werden:

$$
S=S_{0} \times e^{-\left(\alpha D+\beta D^{2}\right)} \quad \text { bzw. } \quad \ln \frac{S}{S_{0}}=-\left(\alpha D+\beta D^{2}\right)
$$

$\mathrm{S}_{0}: \quad$ Überlebensfraktion der unbestrahlten Zellen

S: $\quad$ Überlebensfraktion der bestrahlten Zellen

D: Dosis [Gy]

$\alpha$ : linearer Anteil der halblogarithmisch aufgetragenen Überlebenskurve

$\beta$ : $\quad$ quadratischer Anteil der halblogarithmisch aufgetragenen Überlebenskurve

Generell können Überlebenskurven nach Bestrahlung mit Röntgenstrahlen linearquadratisch angepasst werden, die so angepassten Überlebenskurven werden auch als Schulterkurven bezeichnet. Sehr strahlenempfindliche Zellen weisen keine Schulter auf $\left(\beta=0, \ln \mathrm{S} / \mathrm{S}_{0}=-\alpha \mathrm{D}\right)$ und sind rein exponentielle Überlebenskurven:

$$
\frac{S}{S_{0}}=e^{-\alpha D}
$$

$$
\begin{array}{ll}
\mathrm{S}_{0}: & \text { Überlebensfraktion der unbestrahlten Zellen } \\
\mathrm{S}: & \text { Überlebensfraktion der bestrahlten Zellen } \\
\mathrm{D}: & \text { Dosis }[\mathrm{Gy}] \\
\alpha: & \text { linearer Anteil der halblogarithmisch aufgetragener Überlebenskurve }
\end{array}
$$

Für dicht ionisierende Strahlenarten wie Alpha-Teilchen, Protonen und schwere Ionen werden oft exponentielle Dosis-Effekt-Beziehungen beobachtet. 
Zur Messung des klonogenen Überlebens wurde eine definierte Anzahl von Zellen $\left(\mathrm{N}_{0}\right)$ pro Flasche ausgeimpft. Die Zellzahl wurde entsprechend der zu verabreichenden Dosis variiert. Die Angaben über die verwendeten Zellzahlen sind in Tabelle 3.2 dargestellt.

Tabelle 3.2 Die verwendeten Zellzahlen $\left(\mathrm{N}_{0}\right)$ der untersuchten Zelllinien in Abhängigkeit von der applizierten Dosis nach Röntgenbestrahlung (R.S.) und nach Bestrahlung mit Kohlenstoffionen (S.I.)

\begin{tabular}{|c|c|c|c|c|}
\hline & \multicolumn{2}{|c|}{ WiDr } & \multicolumn{2}{c|}{ MCF-7 } \\
\hline Dosis [Gy] & R.S. & S.I. & R.S. & S.I. \\
\hline \hline $\mathbf{0}$ & 300 & 300 & 300 & 300 \\
\hline $\mathbf{0 , 2 5}$ & - & - & - & 500 \\
\hline $\mathbf{0 , 5}$ & - & - & - & 1.000 \\
\hline $\mathbf{1}$ & - & 500 & 300 & 2.000 \\
\hline $\mathbf{2}$ & 500 & 1.000 & 500 & 3.000 \\
\hline $\mathbf{3}$ & - & 2.000 & 1.000 & 4.000 \\
\hline $\mathbf{4}$ & 1.000 & 3.000 & 2.000 & 5.000 \\
\hline $\mathbf{5}$ & - & 4.000 & - & - \\
\hline $\mathbf{6}$ & 2.000 & - & - & - \\
\hline
\end{tabular}

Die Zellen wurden 10 Tage inkubiert. Während der Inkubationszeit wurde nach 4 Tagen ein Mediumwechsel durchgeführt. Nach Ablauf der Inkubationszeit wurden die Zellen 20 Minuten lang mit 75\% Ethanol fixiert und mindestens 12 Stunden lang bei $50^{\circ} \mathrm{C}$ in einem Wärmeschrank getrocknet. Anschließend wurden die Zellen 20 Minuten lang mit $5 \mathrm{ml}$ Kristallviolett-Färbelösung pro Flasche gefärbt. Die überschüssige Färbelösung wurde durch mehrmaliges Spülen mit Wasser entfernt und die Flaschen wurden noch einmal mindestens 12 Stunden lang bei $50^{\circ} \mathrm{C}$ im Wärmeschrank getrocknet. Kolonien mit 50 oder mehr Zellen wurden als überlebende Zellen (N) gezählt. Die Auswertung erfolgte unter einem Stereomikroskop bei 16- oder 25-facher Vergrößerung.

Jedes Experiment wurde mindestens dreimal wiederholt. Jeder Punkt auf der DosisEffekt-Kurve wurde aus mindestens 12 einzelnen Messpunkten berechnet. Die halblogarithmisch aufgetragenen Überlebenskurven wurden mit einer linearquadratischen Funktion (G1.3.5) oder mit einer linearen Funktion (G1.3.6) mit Hilfe der 
Methode der kleinsten Fehlerquadrate angepasst und die Parameter $\alpha$ und $\beta$ berechnet. Hierfür wurde die Software „KaleidaGraph“ verwendet.

\subsubsection{Messung der Apoptosenrate}

Im Unterschied zum reproduktiven Zelltod, der sich durch den Verlust der Klonogenität manifestiert und häufig erst nach mehreren Zellzyklen sichtbar wird, können Zellen auch durch den apoptotischen und den nekrotischen Tod eliminiert werden.

Bei der Nekrose handelt es sich um eine passive irreversible Zellschädigung, die durch Zellschwellung und Auflösung von Zellorganellen und Zellmembran charakterisiert wird. Im Gegensatz zur Nekrose ist Apoptose (programmierter Zelltod) ein aktiver Prozess. Dieser Prozess läuft in mehreren Phasen ab. Nach einer Zellschädigung bzw. bei seneszenten Zellen werden spezifische Gene exprimiert, die zur einer Aktivierung von Endonukleasen führen. Diese Enzyme bewirken eine DNA-Degradation (Zerschneidung in Oligonukleotide) innerhalb des Zellkerns. Die Zellmembran bleibt während des gesamten Ablaufs intakt. In der letzten Phase wird die Zelle durch Abschnürung der sogenannten „apoptotischen Körpern“, die Zellorganellen und Chromatin enthalten, eliminiert.

Die strahleninduzierte Apoptose und Nekrose wurden mit Hilfe von Annexin V-Assay bestimmt. Die Plasmamembran von Zellen ist asymmetrisch aufgebaut. Der Verlust dieser Asymmetrie ist ein frühes Zeichen der Apoptose. Das Membranphospholipid Phosphatidylserin (PS) befindet sich in nicht-apoptotischen Zellen nur in der intrazellulären Membranschicht. In apoptotischen Zellen wird jedoch dieses Membranphospholipid auch in die äußere Membranschicht transloziert und ist dann mit Hilfe von Annexin V, das sich an Phosphatidylserin binden kann, detektierbar. Durch das Annexin V, das mit einem Fluoreszenzfarbstoff konjugiert ist, können apoptotische Zellen fluoreszenz-mikroskopisch nachgewiesen werden.

Eine Translokation des Phosphatidylserins in die äußere Membranschicht wird zwar auch bei der Nekrose beobachtet, aber im Unterschied zu apoptotischen Zellen ist bei 
nekrotischen Zellen auch die Integrität der Zellmembran zerstört und die Zellkerne lassen sich zusätzlich mit einem gängigen Farbstoff, z.B. Propidiumiodid, anfärben. Fluoreszenz-mikroskopisch lassen sich drei Zelltypen unterscheiden:

1. intakte Zellen: diese Zellen sind sowohl Annexin V und als auch Propidiumiodid negativ.

2. frühe apoptotische Zellen: sind Annexin V-positiv. Sie zeigen eine grünfluoreszierende Membran. Ihre Zellkerne lassen sich jedoch nicht mit Propidiumiodid anfärben.

3. nekrotische und späte apoptotische Zellen: diese Zellen sind Annexin Vund Propidiumiodid positiv. Sie zeigen eine grün-fluoreszierende Membran und ihre Zellkerne sind mit dem rot-fluoreszierenden Farbstoff, Propidiumiodid markiert.

Die Zellen wurden auf Kunststoff-Objektträgern bis zu einer Dichte von 50-70\% angezüchtet. Die Apoptose wurde durch Strahlung (200 kV-Röntgenstrahlung und 100 $\mathrm{MeV} / \mathrm{u}$ Kohlenstoffionen, $\mathrm{D}=4 \mathrm{~Gy}$ ) induziert. Die Kulturzeit betrug 24, 36 und 48 Stunden nach Bestrahlung.

Nach Ablauf der jeweiligen Kulturzeit wurde das Medium verworfen und die Kunststoff-Objektträger wurden mit PBS vorsichtig gespült. Die Kammern der Kunststoff-Objektträger und die Silikondichtungen wurden vorsichtig entfernt und die Objektträger wurden nochmals mit PBS gespült. Die Annexin-V-Markierungslösung wurde immer für die jeweilige Anzahl der Objektträger angesetzt. Die Färbung erfolgte nach den Anweisungen des Herstellers (Boehringer-Mannheim). Die Inkubationsdauer wurde jedoch auf 5-10 Minuten gekürzt. Nach Ablauf der Inkubation wurden die Objektträger sofort mikroskopisch ausgewertet. Die Anzahl der ausgewerteten Zellen pro Objektträger betrug mindestens 500 Zellen. Pro Dosis und Strahlenart wurden zwei voneinander unabhängige Experimente durchgeführt. Die Ergebnisse wurden gemittelt und nach Abzug der Hintergrundwerte aus unbestrahlten Kontrollen wurden strahleninduzierte relative Apoptosenrate berechnet. 


\subsubsection{BrdU-Färbung}

Um die erste und zweite bzw. dritte Mitose nach Bestrahlung voneinander unterscheiden zu können, wurde eine spezielle BrdU/Hoechst-Färbemethode nach Kolin-Gerresheim verwendet [Kolin-Gerresheim, et al., 1981]. Mit dieser Methode kann man die erste Mitose durch die selektive BrdU-Färbung der Chromosomen von der zweiten (und dritten) Mitose eindeutig unterscheiden.

Während der Proliferation wird den Zellen 5-Brom-2-Desoxyuridin (BrdU) in einer Konzentration von $10 \mu \mathrm{g} / \mathrm{ml}$ angeboten, das aufgrund der semikonservativen Replikation während eines Zellzyklus in je einen Einzelstrang der Schwesterchromatiden eingebaut wird. In der ersten Mitose weisen beide Schwesterchromatiden keinen Unterschied in der Färbung auf. Nach einer zweiten Replikationsrunde in Anwesenheit von BrdU enthält ein Schwesterchromatid den Farbstoff in beiden DNA-Einzelsträngen, und wird deshalb nach entsprechender Färbung heller angefärbt. Metaphasechromosomen in der 2. Mitose nach BrdU-Zugabe beinhalten jeweils ein helles und ein dunkles Schwesterchromatid. Sie werden deshalb als Harlekinchromosomen bezeichnet.

Da nicht alle Zellen nach Bestrahlung gleichzeitig in die erste Mitose kommen, musste ein zelllinienspezifisches Zeitfenster, in dem sich die meisten Zellen in der ersten Mitose befinden, bestimmt werden. Deshalb wurde der Anteil der ersten Mitosen nach verschiedenen Kulturzeiten ermittelt. Dies wurde in unbestrahlten sowie in bestrahlten Zellen durchgeführt.

Den Zellkulturen wurde nach Bestrahlung mit 200 kV-Röntgenstrahlung oder 100 $\mathrm{MeV} / \mathrm{u}$ Kohlenstoff-Ionen BrdU $(10 \mu \mathrm{g} / \mathrm{ml})$ zugesetzt und bei $37^{\circ} \mathrm{C}$ entsprechend der gewählten Kulturzeit inkubiert. Da 5-Brom-2-Desoxyuridin sehr lichtempfindlich ist, wurden alle weiteren Schritte im Dunkeln durchgeführt.

Die Präparation der Zellen erfolgte wie unter 3.2.6.1 beschrieben. Die Objektträger wurden daraufhin mindestens 3 Tage staubfrei und lichtgeschützt aufbewahrt und dann 
mit Hoechst-Farbstoff 33258 (Bisbenzimid H 33258) gefärbt. Die Färbelösung wurde immer frisch zubereitet: es wurden $25 \mu \mathrm{g}$ Hoechst-Farbstoff 33258 in $75 \mathrm{ml}$ WeisePuffer aufgelöst und die Objektträger wurden 10 Minuten gefärbt. Die überschüssige Lösung wurde durch das Spülen mit Aqua dest. entfernt. Die Präparate wurden mit Weise-Puffer überschichtet, und um die Verdunstung der Flüssigkeit zu verhindern, wurden die Objektträger mit einem Deckglas versehen, bevor sie 60 Minuten unter einer UV-Lampe belichtet wurden. Anschließend wurden die Objektträger 30 Minuten in $2 \times \operatorname{SSC}(\mathrm{pH} 7,0)$ bei $61^{\circ} \mathrm{C}$ gewaschen, und bevor sie schließlich mit Giemsa gefärbt werden konnten, wurden sie zweimal mit Aqua dest. gespült.

Die Objektträger wurden dann 6-8 Minuten in einer 3\% Giemsa-Lösung gefärbt. Die Färbelösung wurde immer frisch zubereitet. Um eine bessere Qualität der Färbung zu erzielen, wurde die Giemsa-Färbelösung mit Phosphat-Puffer $(\mathrm{pH} \mathrm{6,88)} \mathrm{anstatt} \mathrm{demin.}$ Wasser angesetzt. Die überschüssige Farbe wurde anschließend durch zweimaliges Spülen mit Aqua dest entfernt. Die Objektträger wurden staubfrei getrocknet und bis zur Auswertung lichtgeschützt aufbewahrt. Es wurden 100 bis 800 Mitosen pro Kulturzeit, Dosis und Strahlenart ausgewertet.

\subsubsection{Bestimmung der Wachstumskinetik in Abhängigkeit von BrdU}

Um den Einfluss von BrdU auf das Wachstum der einzelnen Zelllinien zu überprüfen, wurde die Zell-Verdopplungsrate in Anwesenheit und Abwesenheit von BrdU gemessen. Die Konzentration von BrdU betrug $10 \mu \mathrm{g} / \mathrm{ml}$. Die Kulturzeit betrug maximal 72 Stunden. Zum Zeitpunkt 0 wurden 100.000 Zellen pro Well $\left(\mathrm{N}_{0}\right)$ ausgeimpft. Pro Zeitpunkt wurden 2 Wells angesetzt und voneinander unabhängig ausgewertet. Nach 24 Stunden wurden die Zellen mit Trypsin/EDTA-Lösung abtrypsiniert und in einer Neubauer-Zählkammer gezählt $\left(\mathrm{N}_{24}\right)$. Dies wurde alle 12 Stunden bis zum Erreichen der 72 Stunden wiederholt. 
Der Zellwachstumsfaktor wurde wie folgt definiert:

$$
Z W F=\frac{N_{t}}{N_{0}}
$$

ZWF: Zellwachstumsfaktor

$\mathrm{N}_{0}$ : Anzahl der Zellen pro Well zum Zeitpunkt 0

$\mathrm{N}_{\mathrm{t}}$ : Anzahl der Zellen pro Well zum Zeitpunkt $\mathrm{t}$

t: $\quad$ Kulturdauer [h] zum Zeitpunkt der Messung

Die Ergebnisse von zwei voneinander unabhängigen Experimenten wurden gemittelt und graphisch dargestellt.

\subsubsection{Chromosomenpräparation und Färbung}

\subsubsection{Chromosomenpräparation}

Zur mikroskopischen Auswertung der strukturellen strahleninduzierten Chromosomenschäden wurden die Metaphasechromosomen in der ersten Mitose nach Bestrahlung präpariert. Die Dauer des ersten Zellzyklus, die nach der Bestrahlung der Zellen bei den jeweiligen Zelllinien variieren kann, wurde in den Vorversuchen bestimmt. Die Inkubationsdauer nach Bestrahlung betrug je nach Dosis und Strahlenart 24 bis 36 Stunden.

Um die Zellen in der Metaphase zu sammeln, wurde den Kulturen 4 Stunden vor der Chromosomenpräparation eine Colcemid-Lösung in einer Konzentration von $25 \mu \mathrm{l} / \mathrm{ml}$ Medium zugegeben. Colcemid inhibiert die Ausbildung des Mitosespindelapparates und verhindert dadurch die Segregation der Chromosomen auf die Tochterzellen. Die Zellen können die begonnene Mitose nicht beenden sondern bleiben in der, für die Chromosomenpräparation besonders geeignete Metaphase arretiert. 
Die mitotischen Zellen wurden durch kräftiges Abklopfen vom Flaschenboden gelöst und anschließend in einem Zentrifugenröhrchen gesammelt und pelletiert. Nach Verwerfen des Überstandes wurden die Zellen in $37^{\circ} \mathrm{C}$ warmer hypotoner Lösung resuspendiert, 20 Minuten bei $37^{\circ} \mathrm{C}$ inkubiert und anschließend pelletiert. Die hypotone Lösung bestand aus 0,06 M KCl-Lösung plus 6\% Natriumzitrat. Anschließend wurden die Zellen dreimal mit einer Fixierlösung gewaschen. Als Fixierlösung wurde eine Eisessig-Methanol-Mischung (1Teil Essigsäure und 3 Teile Methanol) verwendet. Die Zellsuspension wurde im Kühlschrank bei $4^{\circ} \mathrm{C}$ aufbewahrt.

Für die Hybridisierung und die Giemsa/BrdU-Färbung wurden $25 \mu 1$ der Zellsuspension auf eiskalte, entfettete, feuchte Objektträger mit Hilfe einer EppendorfPipette aufgetropft.

\subsubsection{Färbung mit Giemsa}

Die luftgetrockneten Chromosomenpräparate wurden 10 Minuten mit GiemsaFärbelösung (3\% Giemsa in PBS) gefärbt. Die überschüssige Färbelösung wurde mit demineralisiertem Wasser abgewaschen und die Objektträger wurden staubfrei luftgetrocknet.

Mit dieser einfachen Standard-Methode werden alle Chromosomen unselektiv angefärbt. Es können strukturellen Aberrationen wie dizentrische Chromosomen, extra azentrische Fragmente, zentrische Ringe, Chromatidbrüche und Chromatidaustauschfiguren sowie numerische Aberrationen (Verluste oder Zugewinne an ganzen Chromosomen) detektiert werden.

\subsubsection{Fluoreszenz-in-situ-Hybridisierung}

Selektive Anfärbung einzelner ausgewählter Chromosomen erlaubt es, auch die in Giemsa-gefärbten Präparate nur selten detektierbare Aberrationen zu erkennen und zu analysieren. Dazu gehören reziproke Translokationen, Insertionen und andere komplexe Aberrationen, die meist unter Beteiligung von drei Chromosomen entstehen. 
Hierfür wurde die Methode der „Fluoreszenz- in situ-yybridisierung“ (FISH) eingesetzt.

Für die Analyse wurden die Chromosomen \# 2, \# 4 und \# 5 anhand ihrer genomischen Stabilität (d.h. niedrige Spontanrate an klonalen und nicht-klonalen Aberrationen in unbestrahlten Kontrollen) in unbestrahlten WiDr- und MCF-7-Zellen ausgewählt. Es wurden WCP-Sonden ("Whole Chromosome Probes") der Firma QbiogeneAppligene/Oncor verwendet, die direkt mit einem roten Fluoreszenzfarbstoff (Texas Red) konjugiert waren. Die übrigen Chromosomen wurden mit DAPI blau gegengefärbt.

Die Metaphasenchromosomen wurden wie unter 3.2.6.1 beschrieben präpariert. Nach dem Auftropfen der Zellsuspension wurden die Objektträger 24 Stunden staubfrei luftgetrocknet. Diesen Prozess nennt man das „Altern“, hierdurch werden die Proteine des Chromatingerüsts gehärtet und ein Morphologieverlust bei der folgenden Denaturierung vermieden. Um die Zytoplasmareste $\mathrm{zu}$ entfernen, wurden die Objektträger für 30 Minuten in $2 \times$ SSC mit $0,5 \%$ Igepal-Lösung bei einem pH Wert von 7,0 und einer Temperatur von $37^{\circ} \mathrm{C}$ inkubiert. Die Präparate wurden im Anschluss in einer aufsteigenden Alkoholreihe (70\%, 85\% und 100\% Ethanol) je 2 Minuten bei Raumtemperatur entwässert und danach luftgetrocknet.

Die Hybridisierungs-Sonden (WCP) wurden 5 Minuten bei $37^{\circ} \mathrm{C}$ aufgetaut und anschließend wurden $10 \mu \mathrm{l}$ der Sonde pro Objektträger in $0,5 \mathrm{ml}$ sterile EppendorfHütchen überführt. Die Originalsonde wurde wieder bei $-20^{\circ} \mathrm{C}$ gelagert. Die Proben wurden für 5 Minuten bei $72^{\circ} \mathrm{C}\left( \pm 2^{\circ} \mathrm{C}\right)$ denaturiert. Das Preannealing der Sonden erfolgte für 30 Minuten im Wasserbad bei $37^{\circ} \mathrm{C}$. Da die Sonden sehr lichtempfindlich sind, wurden diese Arbeitschritte in einem abgedunkelten Arbeitsraum durchgeführt.

Zur Vorbereitung der Hybridisierung wurden die Präparate in Hybridisierungslösung für 2 Minuten bei $72^{\circ} \mathrm{C}\left( \pm 2^{\circ} \mathrm{C}\right)$ denaturiert. Die Hybridisierungslösung wurde aus $70 \%$ Formamid/2 x SSC hergestellt und der $\mathrm{pH}$ Wert dieser Lösung wurde auf 7,0 eingestellt. Nach der Denaturierung wurden die Objektträger in einer aufsteigenden 
Alkoholreihe (70\%, 85\% und 100\% Ethanol) je 2 Minuten auf Eis inkubiert und danach luftgetrocknet.

Zur Hybridisierung wurden jeweils $10 \mu \mathrm{l}$ der denaturierten Sonde auf die vorbehandelten Objektträger gegeben und mit einem staubfreien $25 \times 25 \mathrm{~mm}$ Deckglas luftblasenfrei abgedeckt. Nachdem sich die Hybridisierungslösung unter dem Deckglas gleichmäßig verteilt hatte, wurde das Deckglas mit Fixogum (Rubbercement) versiegelt. Die Inkubation erfolgte für 16 Stunden bei $37^{\circ} \mathrm{C}$ in einer feuchten Kammer.

Nach Ablauf der Inkubationsdauer wurde die unspezifisch gebundene und die nicht gebundene DNA-Sonde durch Waschen in $0,5 \times \mathrm{SSC}$ für 5 Minuten bei $72^{\circ} \mathrm{C}\left( \pm 2^{\circ} \mathrm{C}\right)$ entfernt. Anschließend wurden die Objektträger für 2 Minuten in 1 x PBD-Puffer (PBD, phosphate buffered detergent) inkubiert. Die noch feuchten Objektträger wurden mit $10 \mu 1$ DAPI/Antifade gegengefärbt und mit einem staubfreien 25x25 mm Deckglas luftblasenfrei abgedeckt. Das Deckglas wurde mit farblosem Nagellack versiegelt. Bis zur Auswertung wurden die Objektträger bei $-20^{\circ} \mathrm{C}$ lichtgeschützt gelagert.

\subsubsection{Auswertung und Klassifizierung von Chromosomenaberrationen}

Strukturelle Chromosomenaberrationen die nach einer Bestrahlung während der $\mathrm{G}_{0^{-}}$ oder $\mathrm{G}_{1}$-Phase des Zellzyklus entstehen können, lassen sich in zwei Kategorien einordnen: intrachromosomale und interchromosomale Aberrationen. Bei den intrachromosomalen Aberrationen ist nur ein Chromosom an der Entstehung der Aberration beteiligt, bei den interchromosomalen Aberrationen sind zwei oder mehrere Chromosomen an der Entstehung einer Aberration beteiligt [Savage, et al., 1976].

$\mathrm{Zu}$ den intrachromosomalen Aberrationen gehören terminale Deletionen, interstitielle Deletionen, zentrische Ringchromosomen und Inversionen.

Dizentrische Chromosomen und reziproke Translokationen sind die häufigsten interchromosomale Aberrationen. Diese Aberrationskategorien bilden zusammen die Gruppe der sog. „simple exchanges“, d.h. der einfachen Austauschfiguren, die unter Beteiligung zwei Chromosomen entstehen. 
Darüber hinaus können in bestrahlten Zellen auch komplexe Austauschaberrationen induziert werden, die unter Beteiligung von drei oder mehreren Brüchen in zwei oder mehreren Chromosomen gebildet werden. Zu diesem Typ gehören auch Insertionen. In dieser Arbeit wurden alle detektierbaren Aberrationstypen ausgewertet und dokumentiert.

\subsubsection{Dizentrische Chromosomen und extra azentrische Fragmente}

Dizentrische bzw. polyzentrische Chromosomen und extra azentrische Fragmente, die bis zu 90\% aus terminalen und interstitiellen Deletion stammen, wurden in Giemsagefärbten Präparaten ausgewertet.

Ein dizentrisches Chromosom besteht aus zwei fusionierten Chromosomen und wird durch ein fusioniertes azentrisches Fragment begleitet. Dieses Fragment besteht in der Regel aus zwei azentrischen Bruchstücken der beiden an der Aberration beteiligten Chromosomen. Man spricht von einer unvollständigen dizentrischen Aberration, wenn das dizentrische Chromosom von zwei nicht miteinander fusionierten azentrischen Fragmenten begleitet wird [Savage, et al., 1976].

Bei den Deletionen unterscheidet man zwischen terminalen und interstitiellen Deletionen. Die Differenzierung ist jedoch bei der konventionellen Giemsa-Färbung nicht möglich, so dass beide Formen der Deletion unter dem Begriff: „extra azentrische Fragmente" zusammengefasst sind. Extra azentrische Fragmente sind alle Fragmente die nach Abzug derjenigen Fragmente, die mit dizentrischen Chromosomen assoziiert sind, übrigbleiben.

In Abbildung 3.4 sind die hier beschriebenen Aberrationen schematisch dargestellt. 
a)

Bestrahlte Chromosomen

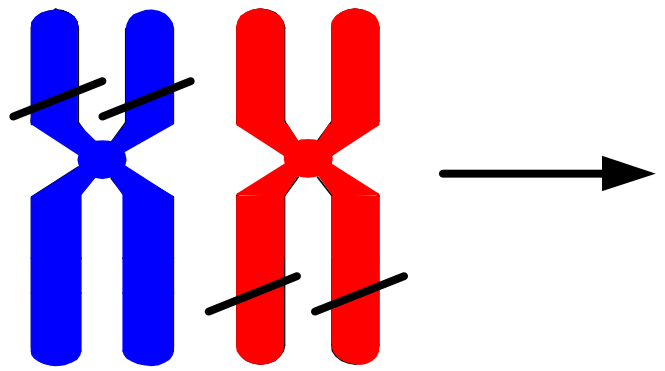

b)
Dizentrisches Chromosom

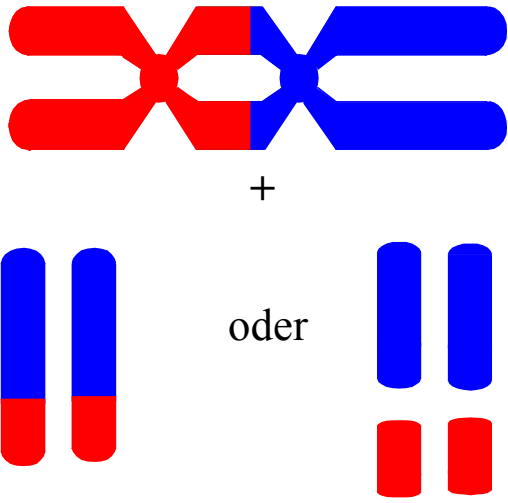

Bestrahltes Chromosom

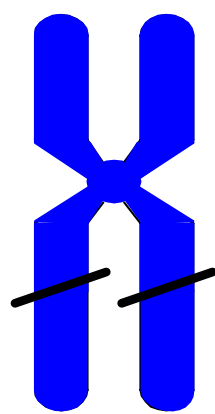

Terminale Deletion
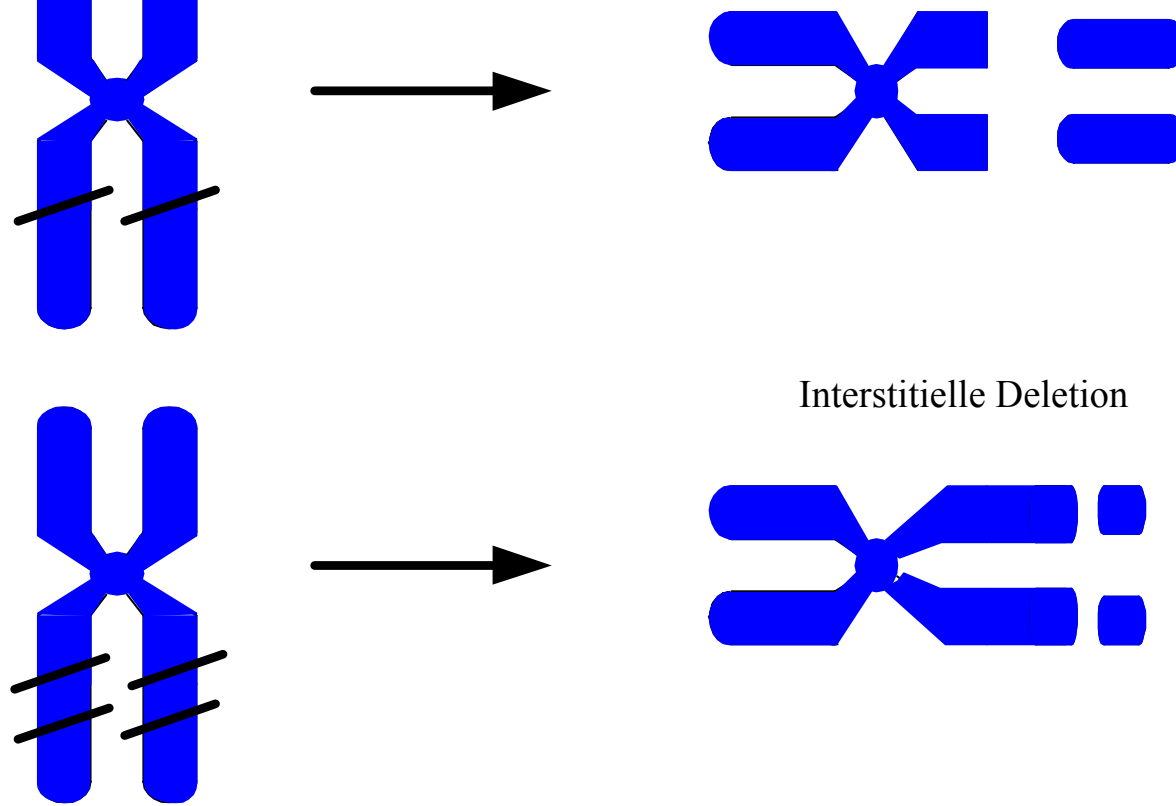

Interstitielle Deletion

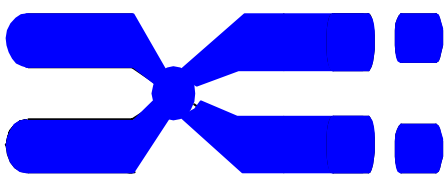

Abbildung 3.4 Schematische Darstellung zur Entstehung eines dizentrischen Chromosoms (a) und terminale bzw. interstitielle Deletion zusammen mit einem extra azentrischen Fragment (b). 
Dizentrische Chromosomen und extra azentrische Fragmente wurden in 100 bis 800 Zellen ausgewertet. Die genomischen Aberrationshäufigkeiten pro Zelle $\mathrm{y}_{\text {dic }}$ bzw. $\mathrm{y}_{\mathrm{ac}}(\mathrm{ex})$ wurden folgendermaßen berechnet:

$$
y_{d i c}=\frac{N_{\text {dic }}}{N} \quad \text { oder } \quad y_{a c}(e x)=\frac{N_{a c}(e x)}{N}
$$

N: $\quad$ Anzahl der ausgewerteten Zellen

$\mathrm{N}_{\text {dic }}$ : Gesamtanzahl dizentrischer Chromosomen in den ausgewerteten Zellen

$\mathrm{N}_{\mathrm{ac}}(\mathrm{ex})$ : Gesamtanzahl extra azentrischer Fragmente in den ausgewerteten Zellen

\subsubsection{Reziproke Translokationen}

Reziproke Translokationen entstehen unter Beteiligung von zwei Chromosomen und können in einer vollständigen und einer unvollständigen Form (siehe Abbildung 3.5) gebildet werden. Eine vollständige reziproke Translokation entsteht durch einen reziproken Austausch von terminalen Chromosomenstücken zwischen zwei Chromosomen. Es entstehen zwei monozentrische Chromosomen, die jeweils Chromatinmaterial beider Chromosomen beinhalten. Bei einer unvollständigen reziproken Translokation entsteht nur ein solches kombiniertes monozentrisches Chromosom, ein deletiertes Chromosom und ein azentrisches Fragment. Verwendet man für die Translokationsdetektion die Einzelfarben-FISH, so weist eine vollständige Translokation zwei zweifarbige monozentrische Chromosomen auf, eine unvollständige Translokation weist ein zweifarbiges monozentrisches Chromosom auf, das von einem verkürzten einfarbigen Chromosom und von einem einfarbigen azentrischen Fragment begleitet wird (siehe Abbildung 3.5). 


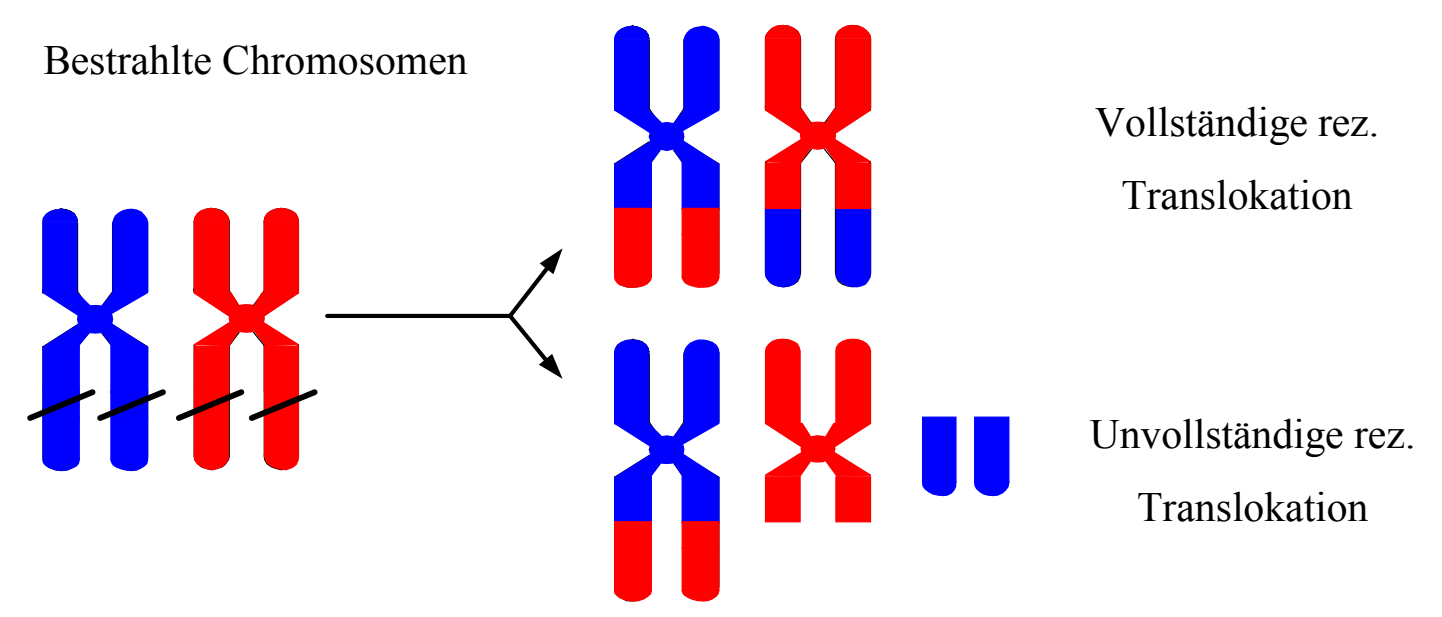

Abbildung 3.5 Schematische Darstellung zur Entstehung einer vollständigen bzw. einer unvollständigen reziproken Translokationen.

Bei den untersuchten Zelllinien waren die unvollständigen Translokationen selten (< 5\%) und deshalb wurden bei der Auswertung mit den vollständigen Translokationen zusammengefasst. Die partiellen Translokationshäufigkeiten pro Zelle $\mathrm{y}_{\text {trans }}($ No.x) wurden folgendermaßen berechnet:

$$
y_{\text {trans }}^{N o . x}=\frac{N_{\text {trans }}(\text { No.x })}{N}
$$

$\mathrm{N}: \quad$ Anzahl der ausgewerteten Zellen

$\mathrm{N}_{\text {trans }}$ (No.x): Gesamtanzahl reziproker Translokationen, die unter Beteiligung des Chromosoms No.x entstanden sind, in den ausgewerteten Zellen

\subsubsection{Komplexe Aberrationen: TVC}

Komplexe Aberrationen, also Austauschfiguren die unter Beteiligung von drei oder mehreren Brüche in zwei oder mehreren Chromosomen entstehen, können in sehr 
vielen verschiedenen Formen vorkommen (Savage et all, 1994). Beispiele von relativ häufig vorkommenden komplexen Aberrationstypen sind in Abbildung 3.6 dargestellt.

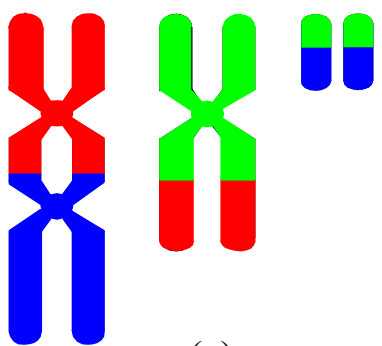

(a)

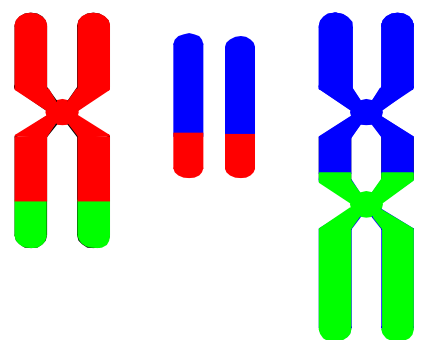

(b)

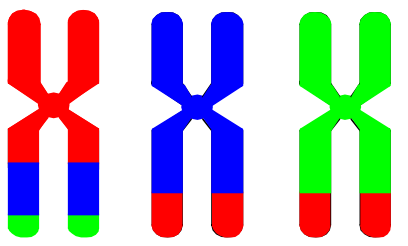

(c)

Abbildung 3.6 Beispiele komplexer Aberrationen, die unter Beteiligung von drei heterologen Chromosomen entstanden sind. Die Formen (a) und (b) bestehen aus einem dizentrischem Chromosom, einer Translokation und einem fusioniertem azentrischem Fragment. Die Form (c) besteht aus zwei einfachen und einer komplexen Translokation.

In den genomisch instabilen Tumorzellen wäre eine Aberrationsdetektion unter Verwendung mehrerer Farben sehr aufwendig. Aus diesem Grund wurde in dieser Arbeit keine Mehrfarben-FISH-Methode verwendet. Bei Verwendung von der Einzelfarbe-FISH-Methode erscheinen die komplexen dreifarbigen Formen (a), (b) und (c) nur als zweifarbige Formen, wie in Abbildung 3.7 dargestellt ist.

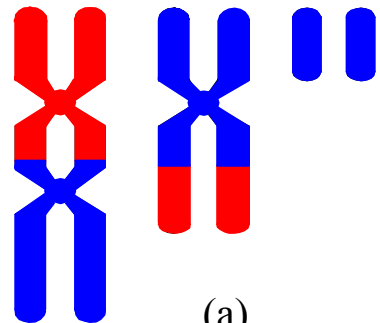

(a)

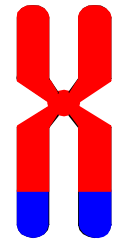

(b)

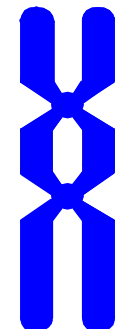

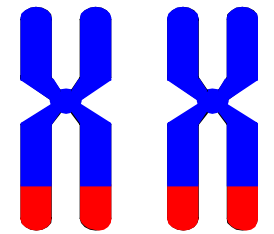

(c)

Abbildung 3.7 Komplexe Aberrationen (vgl. Abb. 3.6) nach Verwendung der Einzelfarbe-FISH-Methode (rote Anfärbung des ausgewählten Chromosoms und blaue Anfärbung aller übrigen Chromosomen). 
Alle sichtbaren komplexen Aberrationen, entsprechen der Klassifizierung von Savage and Simpson wurden als: TVC (total visible complexes) zusammengefasst.

Die partiellen Häufigkeiten $\mathrm{y}_{\mathrm{TVC}}($ No.x) komplexer Aberrationen pro Zelle wurden für die untersuchten Chromosomen 2, 4, und 5 folgendermaßen bestimmt:

$$
y_{T V C}^{N o . x}=\frac{N_{T V C}(\text { No.x })}{N}
$$

$\mathrm{y}_{\mathrm{TVC}}$ (No.x): partielle Häufigkeit komplexer Aberrationen pro Zelle

$\mathrm{N}: \quad$ Anzahl ausgewerteter Zellen

$\mathrm{N}_{\text {TVC}}$ (No.x): Gesamtanzahl komplexer Aberrationen in den ausgewerteten Zellen, die unter Beteiligung des Chromosoms No.x enstanden sind.

Alle sichtbaren Aberrationen (reziproke Translokationen, dizentrische Chromosomen, extra azentrische Fragmente, zentrische Ringe und komplexe Austauschaberrationen) wurden anschließend zusammengefasst und die partielle Häufigkeiten pro Zelle УТА (No.x) für die Chromosomen 2, 4 und 5 bestimmt.

Um die Zelllinien besser untereinander vergleichen zu können, wurden darüber hinaus die partiellen Ausbeuten an allen sichtbaren Aberrationen für die Chromosomen 2, 4 und 5 als Summen berechnet.

\subsubsection{Insertionen}

Eine besondere Klasse der komplexen Aberrationen stellen chromosomale Insertionen dar (siehe Abbildung 3.8). Diese Aberrationsform wird durch dünn ionisierende Strahlung nur sehr selten induziert. Dicht ionisierende Strahlenarten induzieren einfache oder sogar mehrfache Insertionen viel häufiger. An normalen diploiden Zellen konnte gezeigt werden, dass eine hohe Insertionsrate als ein „fingerprint“ für dicht ionisierende Strahlung geeignet ist. 
Bestrahlte Chromosomen

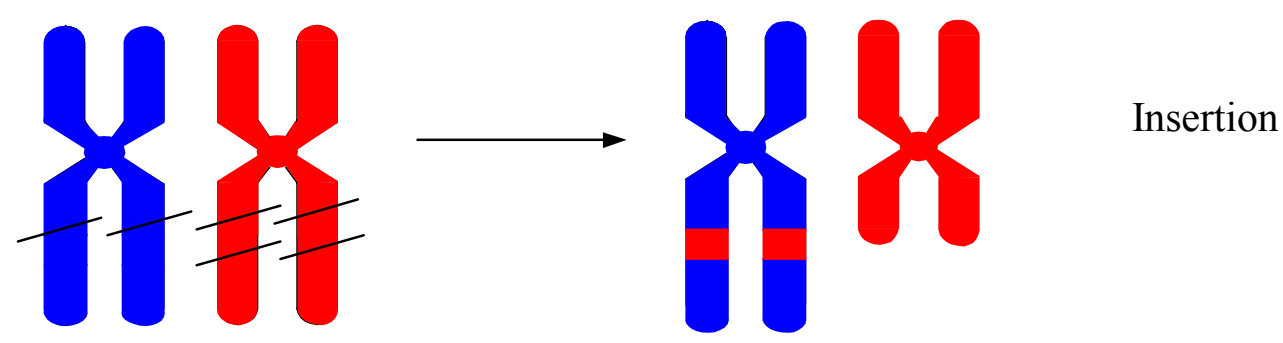

Abbildung 3.8 Schematische Darstellung zur Entstehung einer Insertion

Die vorliegenden Tumordaten wurden deshalb im Bezug auf die Insertionsraten analysiert. Als Maß für die Häufigkeit der Insertionen wurde der Index I bestimmt:

$$
\begin{aligned}
& I=\frac{N_{\text {Trans }}(\text { No.x })}{N_{\text {Insert }}(\text { No.x })} \\
& \mathrm{N}_{\text {Trans }} \text { (No.x): } \quad \text { Anzahl der Translokationen für das Chromosom No.x } \\
& \text { N Insert (No.x): } \quad \text { Anzahl der Insertionen für das Chromosom No.x }
\end{aligned}
$$

\subsubsection{Statistische Auswertung der Aberrationsdaten}

Die Dosisabhängigkeiten der genomischen und partiellen Aberrationshäufigkeiten wurden mit einer linear-quadratischen Funktion $\left(y=\alpha D+\beta D^{2}\right)$ oder mit einer linearen Funktion $(\mathrm{y}=\alpha \mathrm{D})$ mit Hilfe der Methode der kleinsten Fehlerquadrate angepasst und die Parameter $\alpha$ und $\beta$ berechnet. Hierfür wurde die Software „KaleidaGraph“ verwendet. Die Verteilungen der strahleninduzierten Aberrationen folgen der PoissonVerteilung [Edwards et al. 1992]. Als Fehlerbalken für die Aberrationshäufigkeiten pro Zelle wurden deshalb die 95\%-Poisson-Vertrauensbereiche berechnet. 


\subsubsection{Clusterbildung der DNA-PK ${ }_{\mathrm{cs}^{-}}$, Ku70- und Ku86- Reparaturproteine in bestrahlten Zellen.}

Die obigen Reparaturproteine der NHEJ-Reparatur bilden nach Bestrahlung an geschädigten DNA-Stellen, die DNA-Doppelstrangbrüche aufweisen, Cluster (siehe Einleitung). In dieser Arbeit wurden die Reparaturproteine mit Hilfe eines entsprechenden primären antihumanen Antikörpers der Maus markiert. Der primäre Maus-Antikörper wurde mit einem sekundären, mit einem Fluorochrom konjugierten Anti-Maus-Antikörper visualisiert. Die Cluster wurden dann unter einem ZeissFluoreszenz-Mikroskop detektiert, mit einer CCD-Kamera aufgenommen und mit Hilfe einer Spezialsoftware [Boguhn, Dissertation 1999] quantitativ ausgewertet.

Die untersuchten Zellen wurden in speziellen Objektträgerflaschen, „Flasketten“ der Firma Nunc angezüchtet. Diese haben eine spezielle Oberflächenbehandlung für die optimale Zelladhäsion und Proliferation der Zellen. Jeder Objektträger ist in vier Kammern unterteilt. Pro Objektträger wurden insgesamt 150.000 Zellen ausgeimpft. Die Zellen wurden 48 Stunden bei $37^{\circ} \mathrm{C}$ inkubiert, nach 24 Stunden erfolgte ein Mediumwechsel. Die Zellen wurden mit $100 \mathrm{MeV} / \mathrm{u}$ Kohlenstoffionen oder $200 \mathrm{kV}$ Röntgenstrahlung bestrahlt und entweder sofort oder nach Ablauf einer bestimmten Reparaturzeit (bis zu 4 Stunden) fixiert.

Dafür wurden die Zellen zuerst in PBS-Puffer gewaschen und dann bei $-20^{\circ} \mathrm{C} 5$ Minuten in $100 \%$ Ethanol und dann 5 Minuten in Aceton fixiert. Die Objektträger wurden luftgetrocknet, bevor sie 3 Minuten in einer $\mathrm{NaOH}$-Lösung $(0,07 \mathrm{~N} \mathrm{NaOH}$ in $70 \%$ Ethanol) inkubiert wurden. Die Präparate wurden anschließend in einer aufsteigenden Alkoholreihe $(70 \%, 85 \%$ und $100 \%$ Ethanol) je 1 Minute bei Raumtemperatur dehydriert, danach luftgetrocknet und bis zur eigentlichen Färbung staubfrei aufbewahrt.

Unmittelbar vor der Färbung wurden die so fixierten Zellen 5 Sekunden mit Proteinase $\mathrm{K}(10 \mu \mathrm{g} / \mathrm{ml})$ bei $37^{\circ} \mathrm{C}$ behandelt und anschließend 5 Minuten in PBS/Tween-Puffer bei Raumtemperatur gewaschen. Danach wurden sie 20 Minuten mit einer RNAse-Lösung ( $1 \mu \mathrm{g}$ RNAse pro $1 \mathrm{ml}$ PBS-Puffer) bei $37^{\circ} \mathrm{C}$ behandelt. Die überschüssige RNAseLösung wurde durch 5 minütiges Waschen in PBS/Tween-Puffer entfernt. Pro Kammer 
des jeweiligen Objektträgers wurde $20 \mu \mathrm{l}$ Suspension mit dem jeweiligen anti-DNA$\mathrm{PK}_{\mathrm{cs}^{-}}$, anti-Ku 70- und anti-Ku 86-Antikörper zugegeben.

Die Antikörpersuspensionen bestanden aus den jeweils verwendeten primären Antikörpern der Maus (Fa. KAMIYA Biomedical, USA), die 1:20 in PBS verdünnt wurden.

Nach der Zugabe des jeweiligen primären Antikörpers wurden die Zellen 70 Minuten in einer feuchten Kammer bei $37^{\circ} \mathrm{C}$ inkubiert. Die nicht gebundenen Antikörper wurden durch viermaliges Waschen in PBS/Tween-Puffer entfernt. Der primäre MausAntikörper wurde mit einem sekundären Anti-Maus-Antikörper (Fa. KAMIYA Biomedical, USA) markiert. Dieser sekundäre Anti-Maus-Antikörper war mit FITC (FITC, Fluorescein-issothiocyanate) konjugiert. Die Antikörper wurden mit den Zellen wiederum 70 Minuten in einer feuchten Kammer bei $37^{\circ} \mathrm{C}$ inkubiert. Die nicht gebundenen Antikörper wurden durch viermaliges Waschen in PBS/Tween-Puffer entfernt. Die noch feuchten Objektträger wurden mit $40 \mu \mathrm{l}$ DAPI/Antifade (Fa. Oncor) gegengefärbt und mit einem staubfreien 25 x 25 mm Deckglas luftblasenfrei abgedeckt. Das Deckglas wurde mit farblosem Nagellack versiegelt.

Bis zur Auswertung wurden die Objektträger bei $-20^{\circ} \mathrm{C}$ lichtgeschützt gelagert.

Die in den Zellkernen gebildeten Reparaturprotein-Cluster wurden mit FluoreszenzMikroskop, mit einer digitalen CCD-Kamera und mit Hilfe der BildverarbeitungsSoftware „Metamorph“ aufgenommen und auf einem PC gespeichert.

Für die Auswertung der Cluster wurde eine spezielle Software [Boguhn; Dissertation, 1999] verwendet, die für die Tumorzellen modifiziert wurde. Als Grundlage für die Erkennung eines Clusters diente die Ermittlung des mittleren und des maximalen Fluoreszenzgrauwertes der einzelnen Pixel. Bei diesem Verfahren wird jeder Zellkern markiert und eine Verteilung der Fluoreszenzgrauwerte pro Pixel erstellt. Die Grauwerte folgen in unbestrahlten Zellen einer Gaußverteilung, da die Reparaturproteine gleichmäßig in der Zelle verteilt sind. Durch Bestrahlung werden DNA-Doppelstrangbrüche induziert und es kommt zu örtlichen Anhäufungen (ClusterBildung) der Reparaturproteine und damit zur Erhöhung der Fluoreszenzintensität an 
den geschädigten Stellen. Die Grauwertverteilung ist dann eine Verteilung mit einer asymmetrischen Flanke in Richtung der höheren Grauwerte.

Pro Kammer wurden 20 verschiedene Bilder aufgenommen. Pro Bild wurden etwa 5 Zellkerne markiert und zur Berechnung der Cluster ausgewählt. Anschließend wurde die mittlere Anzahl der Cluster berechnet.

Die Clusterbildung der NHEJ-Reparaturproteine nach Bestrahlung mit $100 \mathrm{MeV} / \mathrm{u}$ Kohlenstoffionen bzw. mit $200 \mathrm{kV}$-Röntgenstrahlung wurde in strahlenresistenten WiDr-Zellen und in strahlensensitiven MCF-7-Zellen untersucht. Zum Vergleich wurde die Clusterbildung der NHEJ-Reparaturproteine nach Bestrahlung auch in normalen menschlichen Epithelzellen gemessen. Hierfür wurden die HNEpC-Zellen verwendet. Es handelte sich dabei um eine primäre Kultur der Nasenschleimhautzellen eines gesunden Spenders. 


\title{
4. Ergebnisse
}

\subsection{Bestimmung der Zellkernflächen}

Bei der Bestrahlung mit hochenergetischen Kohlenstoffionen, die einen mittleren LET aufweisen, ist der Spurdurchmesser groß im Vergleich zum Durchmesser des Zellkerns. Dadurch wird jeder Zellkern getroffen. Für die Berechnung der Energiedosen bzw. der Teilchenfluenzen bei den Kohlenstoffionen werden die Zellkernflächen benötigt.

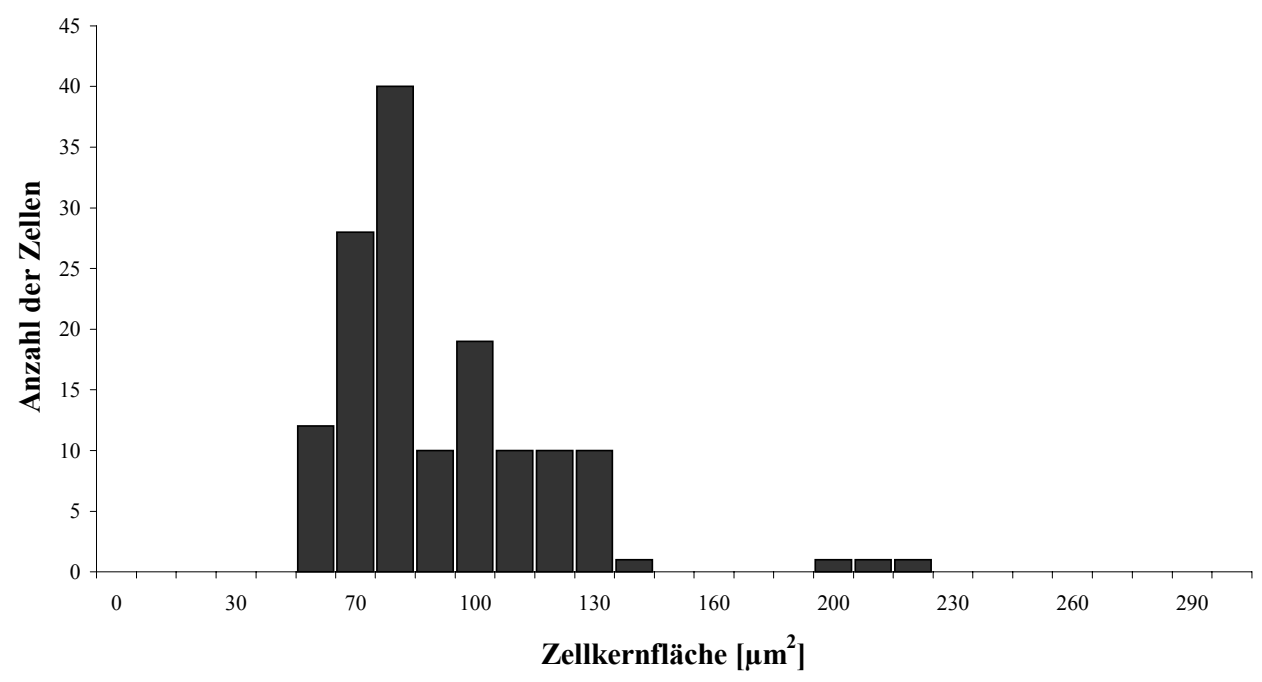

\begin{abstract}
Abbildung 4.1 Verteilung der Zellkernflächen in konfluenten WiDr-Zellen zum Zeitpunkt der Bestrahlung.
\end{abstract}

Die Messung der Kernfläche in konfluenten WiDr-Zellen ergab eine mittlere Kernfläche von $(90 \pm 7) \mu \mathrm{m}^{2}$, für die MCF-7-Zellen wurde eine mittlere Kernfläche von $(130 \pm 4) \mu \mathrm{m}^{2}$ ermittelt. Die Verteilung der Kerngrößen innerhalb der gesamten Zellpopulation ist in Abbildung 4.1 für die WiDr-Zellen und in Abbildung 4.2 für MCF-7-Zellen dargestellt. 


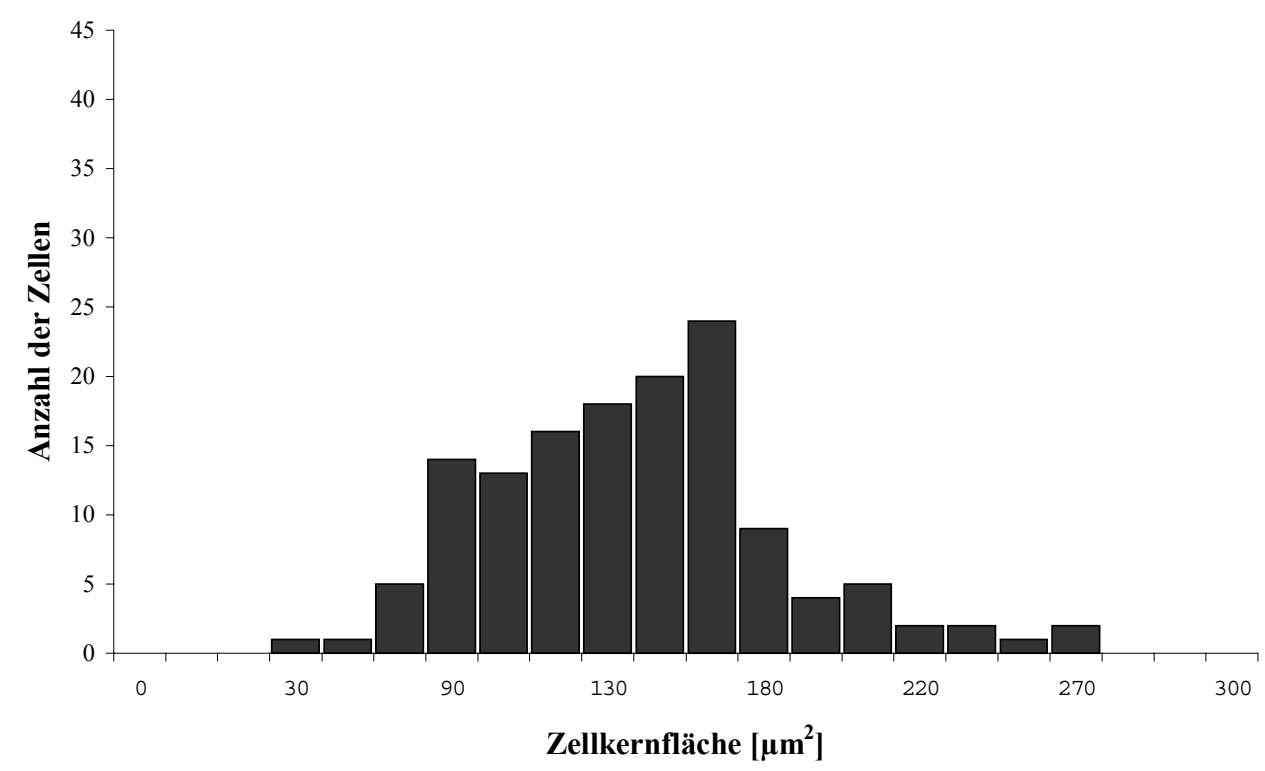

Abbildung 4.2 Verteilung der Zellkernflächen in konfluenten MCF-7-Zellen zum Zeitpunkt der Bestrahlung.

\subsection{Berechnung der mittleren Trefferzahl pro Zellkern}

Zur Bestimmung der mittleren Trefferzahl pro Zellkern werden die Fluenz der verwendeten Strahlung und die Fläche des Zellkerns benötigt. Die mittleren Trefferzahlen je Dosis wurden entsprechend der Gleichung (2.2) berechnet. Die Trefferzahlen pro Zellkern für die verschiedenen Ionen-Energien sind zusammen mit den Fluenzen für die beiden Zelllinien in Tabelle 4.1 angegeben.

Tabelle 4.1 Vergleich der mittleren Trefferzahlen pro Kern je Gy in WiDr- und MCF7-Zellen, zusammen mit den charakteristischen Parametern der Ionenstrahlung.

\begin{tabular}{|c|c|c|c|c|}
\hline Energie & LET & Fluenz & WiDr-Zellen & MCF-7-Zellen \\
\hline$[\mathrm{MeV} / \mathrm{u}]$ & {$[\mathrm{keV} / \mu \mathrm{m}]$} & je Gy & Treffer/Kern je Gy & Treffer/Kern je Gy \\
\hline \hline 400 & 11,0 & $5,67 \times 10^{7}$ & $50 \pm 4$ & $75 \pm 2$ \\
\hline 200 & 16,5 & $3,78 \times 10^{7}$ & $34 \pm 3$ & $50 \pm 1$ \\
\hline 100 & 28,0 & $2,24 \times 10^{7}$ & $20 \pm 2$ & $30 \pm 1$ \\
\hline
\end{tabular}


Vergleicht man die Trefferzahlen in beiden Zelllinien, so kann man sehen, dass je Gray die Trefferzahl in MCF-7-Zellen 1,5 mal höher ist als in WiDr-Zellen.

\subsection{Zellüberleben nach Bestrahlung}

Die Tumorzellen bilden eine heterogene Zellpopulation mit unterschiedlichen Chromosomenploidien und unterschiedlichen klonalen und spontanen strukturellen Aberrationen in verschiedenen Chromosomen. Für alle Versuche wurde wie in Kapitel 3.2.1.2 beschrieben, die gleiche Zellpopulation der jeweiligen Zelllinie verwendet.

\subsubsection{Klonogenes Zellüberleben der WiDr-Zellen nach Bestrahlung mit Kohlenstoffionen}

Die Ergebnisse der Überlebensexperimente nach Bestrahlung mit Kohlenstoffionen mit verschiedenen Energien und im ausgedehntem Bragg Peak im Vergleich mit 200 kVRöntgenstrahlung sind in Abbildung 4.3 dargestellt. Jeder Punkt auf der Dosis-EffektKurve wurde aus mindestens 12 einzelnen Messpunkten berechnet. Die experimentell ermittelten relativen Überlebensfraktionen $\mathrm{S} / \mathrm{S}_{0}$ sind in der Tabelle 4.2 aufgelistet.

Tabelle 4.2 Relative Überlebensfraktionen $\mathrm{S} / \mathrm{S}_{0}$ der WiDr-Zellen nach Bestrahlung mit Kohlenstoffionen verschiedener Energien und im ausgedehntem Bragg Peak im Vergleich mit 200 kV-Röntgenstrahlung. Die Bestrahlung erfolgte mit Dosen bis zu 8 Gy. $( \pm$ s.d. $=$ Standardabweichung des Mittelwertes $)$

\begin{tabular}{|c|c|c|c|c|c|}
\hline \multirow{2}{*}{$\begin{array}{l}\text { Dosis } \\
\text { Gy }\end{array}$} & \multicolumn{4}{|c|}{ Kohlenstoff-Ionen } & Röntgenstrahlung \\
\hline & $400 \mathrm{MeV} / \mathrm{u}$ & $200 \mathrm{MeV} / \mathrm{u}$ & $100 \mathrm{MeV} / \mathrm{u}$ & Bragg Peak & $200 \mathrm{kV}$ \\
\hline & $\mathrm{S} / \mathrm{S}_{0} \pm$ s.d. & $\mathrm{S} / \mathrm{S}_{0} \pm$ s.d. & $\mathrm{S} / \mathrm{S}_{0} \pm$ s.d. & $\mathrm{S} / \mathrm{S}_{0} \pm$ s.d. & $\mathrm{S} / \mathrm{S}_{0} \pm$ s.d. \\
\hline 0 & 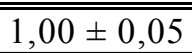 & 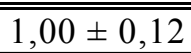 & $1,00 \pm 0,18$ & $1,00 \pm 0,12$ & $1,00 \pm 0,17$ \\
\hline 1 & $0,92 \pm 0,08$ & $0,51 \pm 0,07$ & $0,47 \pm 0,13$ & $0,48 \pm 0,08$ & -- \\
\hline 2 & $0,43 \pm 0,08$ & $0,31 \pm 0,10$ & $0,16 \pm 0,04$ & $0,23 \pm 0,02$ & $0,74 \pm 0,24$ \\
\hline 3 & $0,30 \pm 0,05$ & $0,22 \pm 0,03$ & $0,09 \pm 0,02$ & $0,04 \pm 0,01$ & -- \\
\hline 4 & $0,17 \pm 0,02$ & $0,12 \pm 0,01$ & $0,03 \pm 0,003$ & $0,01 \pm 0,001$ & $0,45 \pm 0,27$ \\
\hline 5 & $0,09 \pm 0,01$ & $0,06 \pm 0,01$ & $0,01 \pm 0,001$ & $0,002 \pm 0,001$ & -- \\
\hline 6 & -- & -- & -- & -- & $0,11 \pm 0,04$ \\
\hline 8 & -- & $\overline{--}$ & -- & $\overline{--}$ & $0,03 \pm 0,02$ \\
\hline
\end{tabular}




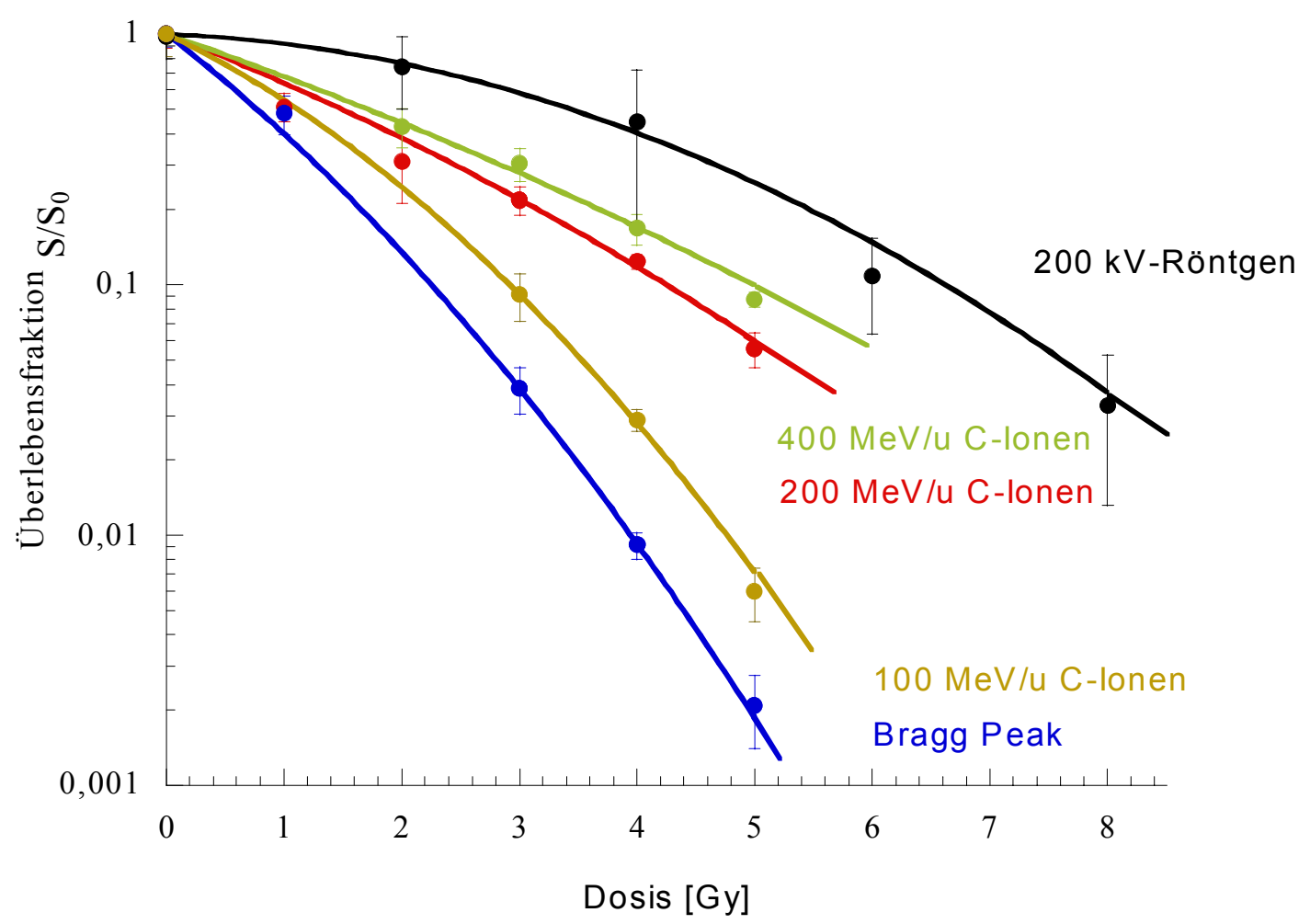

Abbildung 4.3 Relatives Zellüberleben $\mathrm{S} / \mathrm{S}_{0}$ nach Bestrahlung mit Kohlenstoffionen verschiedener Energien und im ausgedehntem Bragg Peak im Vergleich mit 200 $\mathrm{kV}$-Röntgenstrahlung. Die relative Überlebensrate $\mathrm{S} / \mathrm{S}_{0}$ ist in Abhängigkeit von Dosis aufgetragen. Die Fehlerbalken repräsentieren die Standardabweichungen der Mittelwerte. (Die Größenverhältnisse der Fehlerbalken sind durch die halblogarithmische Auftragung verzerrt, vgl. Tabelle 4.2).

Die Überlebenskurven wurden mit einer linear-quadratischen Funktion, $\ln \mathrm{S} / \mathrm{S}_{0}=$ $\left(\alpha \mathrm{D}+\beta \mathrm{D}^{2}\right)$ angepasst. Die entsprechenden Koeffizienten $\alpha$ und $\beta$ sind in der Tabelle 4.3 zusammengefasst.

Nach Bestrahlung mit Kohlenstoffionen wurden bei WiDr-Zellen ausschließlich Überlebenskurven des Schultertyps beobachtet (linear-quadratische Anpassung). Wie die Tabelle 4.3 zeigt, steigt der $\alpha$ Koeffizient mit zunehmendem LET an. Der $\beta$ Koeffizient steigt zuerst mit zunehmendem LET an, erreicht dann aber bei $100 \mathrm{MeV} / \mathrm{u}$ eine Sättigung. 
Tabelle 4.3 Berechnete Werte für die Parameter $\alpha$ und $\beta$ und die $\mathrm{RBW}_{10 \%}$ bzw. $\mathrm{RBW}_{40 \%}$ für das Überleben der WiDr-Zellen nach Bestrahlung mit Kohlenstoffionen verschiedener Energien und mit 200 kV-Röntgenstrahlung als Referenzstrahlung.

\begin{tabular}{|c|c|c|c|c|c|}
\hline Strahlung & LET & $\boldsymbol{\alpha}$ & $\boldsymbol{\beta}$ & $\mathbf{R B W}_{\mathbf{1 0} \%}$ & $\mathbf{R B W}_{\mathbf{4 0} \%}$ \\
\hline & {$[\mathrm{keV} / \mu \mathrm{m}]$} & {$\left[\mathrm{Gy}^{-1}\right]$} & {$\left[\mathrm{Gy}^{-2}\right]$} & & \\
\hline \hline $200 \mathrm{kV}$ Röntgen & & $0,04 \pm 0,04$ & $0,046 \pm 0,011$ & 1 & 1 \\
\hline $400 \mathrm{MeV} / \mathrm{u}$ C-Ionen & 11,0 & $0,37 \pm 0,04$ & $0,018 \pm 0,012$ & 1,3 & 1,7 \\
\hline $200 \mathrm{MeV} / \mathrm{u}$ C-Ionen & 16,5 & $0,42 \pm 0,04$ & $0,029 \pm 0,012$ & 1,5 & 2,1 \\
\hline $100 \mathrm{MeV} / \mathrm{u}$ C-Ionen & 28,0 & $0,51 \pm 0,03$ & $0,096 \pm 0,008$ & 2,2 & 2,9 \\
\hline Bragg Peak & s. Abb. 2.3 & $0,83 \pm 0,02$ & $0,085 \pm 0,005$ & 2,9 & 4 \\
\hline
\end{tabular}

Die relative biologische Wirksamkeit der Kohlenstoffionen (RBW) wurde auf einem Überlebensniveau von 10\% bzw. 40\% anhand der angepassten Überlebenskurven bestimmt. Die relative biologische Wirksamkeit RBW, ist wie folgt definiert:

$$
\mathrm{RBW}=\frac{\boldsymbol{D} \quad \text { (Röntgen })}{D \quad(\text { Ionen })}
$$

Dabei wird jeweils der gleich große biologische Effekt, z.B. das gleiche Überleben, der Berechnung zugrunde gelegt, und das Verhältnis zwischen den entsprechenden Strahlendosen, die den gleich großen Effekt induzieren, berechnet.

Die berechneten RBW-Werte steigen für beide Überlebensniveaus mit steigendem LET an. 


\subsubsection{Klonogenes Zellüberleben der MCF-7-Zellen nach Bestrahlung mit Kohlenstoffionen}

Die Ergebnisse der Überlebensexperimente nach Bestrahlung mit Kohlenstoffionen mit verschiedenen Energien und im ausgedehntem Bragg Peak im Vergleich mit 200 kVRöntgenstrahlung sind in Abbildung 4.4 dargestellt. Jeder Punkt auf der Dosis-EffektKurve wurde aus mindestens 12 einzelnen Messpunkten berechnet. Die experimentellen Daten sind in der Tabelle 4.4 aufgelistet.

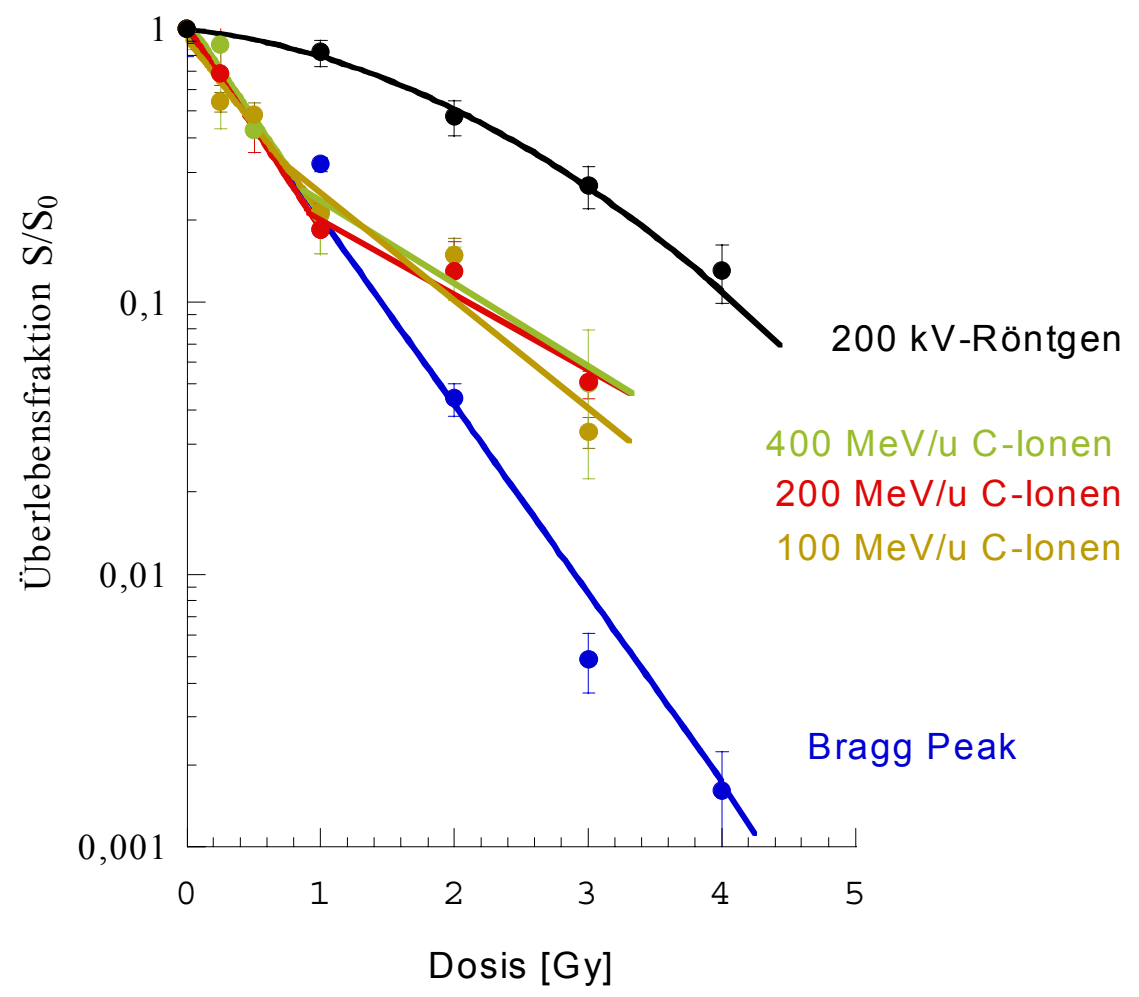

Abbildung 4.4 Zellüberleben nach Bestrahlung mit Kohlenstoffionen verschiedener Energien und im ausgedehntem Bragg Peak im Vergleich mit $200 \mathrm{kV}$ Röntgenstrahlung. Die relative Überlebensrate $\mathrm{S} / \mathrm{S}_{0}$ ist in Abhängigkeit von Dosis aufgetragen. Die Fehlerbalken repräsentieren die Standardabweichungen der Mittelwerte. (Die Größenverhältnisse der Fehlerbalken sind durch die halblogarithmische Auftragung verzerrt, vgl Tabelle 4.4). 
Tabelle 4.4 Die experimentellen Daten der Überlebensfraktionen und der zugehörigen Standardabweichungen der MCF-7-Zellen nach Bestrahlung mit Kohlenstoffionen verschiedener Energien und im ausgedehntem Bragg Peak im Vergleich mit 200 kV-Röntgenstrahlung. $( \pm$ s.d. = Standardabweichung des Mittelwertes)

\begin{tabular}{|c|c|c|c|c|c|}
\hline \multirow{2}{*}{$\frac{\text { Dosis }}{[\text { Gy }]}$} & \multicolumn{4}{|c|}{ Kohlenstoff-Ionen } & Röntgenstrahlung \\
\hline & $400 \mathrm{MeV} / \mathrm{u}$ & $200 \mathrm{MeV} / \mathrm{u}$ & $100 \mathrm{MeV} / \mathrm{u}$ & Bragg Peak & $200 \mathrm{kV}$ \\
\hline & $\mathrm{S} / \mathrm{S}_{0} \pm$ s.d. & $\mathrm{S} / \mathrm{S}_{0} \pm$ s.d. & $\mathrm{S} / \mathrm{S}_{0} \pm$ s.d. & $\mathrm{S} / \mathrm{S}_{0} \pm$ s.d. & $\mathrm{S} / \mathrm{S}_{0} \pm$ s.d. \\
\hline 0 & $1,00 \pm 0,12$ & $1,00 \pm 0,16$ & $1,00 \pm 0,14$ & $1,00 \pm 0,12$ & $1,00 \pm 0,12$ \\
\hline 0,25 & $0,87 \pm 0,25$ & $0,69 \pm 0,26$ & $0,54 \pm 0,04$ & -- & -- \\
\hline 0,5 & $0,42 \pm 0,07$ & $0,24 \pm 0,04$ & $0,49 \pm 0,05$ & -- & -- \\
\hline 1 & $0,21 \pm 0,02$ & $0,18 \pm 0,03$ & $0,22 \pm 0,02$ & $0,32 \pm 0,02$ & $0,82 \pm 0,09$ \\
\hline 2 & $0,15 \pm 0,02$ & $0,13 \pm 0,03$ & $0,15 \pm 0,02$ & $0,04 \pm 0,01$ & $0,48 \pm 0,07$ \\
\hline 3 & $0,05 \pm 0,01$ & $0,05 \pm 0,03$ & $0,003 \pm 0,004$ & $0,005 \pm 0,001$ & $0,27 \pm 0,05$ \\
\hline 4 & -- & -- & -- & $0,001 \pm 0,001$ & $0,13 \pm 0,03$ \\
\hline
\end{tabular}

Die Überlebenskurve für die $200 \mathrm{kV}$-Röntgenstrahlung wurde mit einer linearquadratischen Funktion $\ln \mathrm{S} / \mathrm{S}_{0}=-\left(\alpha \mathrm{D}+\beta \mathrm{D}^{2}\right)$ angepasst. Nach Bestrahlung mit Kohlenstoffionen weisen die Überlebenskurven der MCF-7-Zellen einen biphasischen Verlauf ohne Schulter auf. Dies könnte ein Zeichen für das Vorhandensein von zwei unterschiedlich strahlensensitiven Subpopulationen in der MCF-7-Zelllinie sein. Die biphasischen Kurven wurden mit zwei linearen Funktionen, $\ln \mathrm{S} / \mathrm{S}_{0}=-\alpha \mathrm{D}$ angepasst. Der zweite Anteil der biphasischen Überlebenskurve repräsentiert das Überleben der resistenten Subpopulation (weniger steiler Verlauf). Der zugehörige Koeffizient $\alpha$ der angepassten Linearen Funktion wird als $\alpha_{\text {res }}$ bezeichnet. Die entsprechenden Koeffizienten $\alpha$ und $\alpha$ res sind in der Tabelle 4.5 zusammengefasst.

Nach Bestrahlung mit Kohlenstoffionen verschiedener Energien wurde kein signifikanter Unterschied zwischen den einzelnen Überlebenskurven beobachtet. Der strahlenresistentere Zellanteil ist durch niedrigere $\alpha_{\text {res }}$-Werte charakterisiert, die jedoch für die unterschiedlichen Ionenenergien nicht signifikant voneinander unterschiedlich sind (t-Test: $\mathrm{p}<0,05)$. Nach Bestrahlung im ausgedehntem Bragg Peak ist kein biphasischer Verlauf der Überlebenskurve vorhanden. Der $\alpha$-Koeffizient steigt stark an und die Effizienz der Ionen im Bragg Peak ist offensichtlich so groß, dass die 
resistenteren Zellen im Unterschied zur Strahlung mit niedrigem LET schon bei kleineren Dosen getötet werden.

Anhand der Überlebenskurven wurden die RBW-Werte für die Kohlenstoffionen auf einem Überlebensniveau von 10\% bzw. 40\% im Vergleich zu der Referenzstrahlung bestimmt.

Tabelle 4.5 Berechnete Werte für die Parameter $\alpha$ und $\beta$ und die $\operatorname{RBW}_{10}$ bzw. $\mathrm{RBW}_{40 \%}$ aus den Überlebenskurven der MCF-7-Zellen nach Bestrahlung mit Kohlenstoffionen verschiedener Energien und nach 200 kV-Röntgenstrahlung.

\begin{tabular}{|c|c|c|c|c|c|c|}
\hline Strahlung & LET & $\boldsymbol{\alpha}$ & $\boldsymbol{\alpha}_{\text {resistent }}$ & $\boldsymbol{\beta}$ & $\mathbf{R B W}_{\mathbf{1 0} \%}$ & $\mathbf{R B W}_{\mathbf{4 0} \%}$ \\
\hline & {$[\mathrm{keV} / \mu \mathrm{m}]$} & {$\left[\mathrm{Gy}^{-1}\right]$} & {$\left[\mathrm{Gy}^{-1}\right]$} & {$\left[\mathrm{Gy}^{-2}\right]$} & & \\
\hline \hline $200 \mathrm{kV}$ Röntgen & & $0,12 \pm 0,04$ & - & $0,107 \pm 0,019$ & 1 & 1 \\
\hline $400 \mathrm{MeV} / \mathrm{u}$ C-Ionen & 11,0 & $1,69 \pm 0,19$ & $0,72 \pm 0,11$ & -- & 1,8 & 4 \\
\hline $200 \mathrm{MeV} / \mathrm{u}$ C-Ionen & 16,5 & $1,71 \pm 0,12$ & $0,64 \pm 0,08$ & -- & 1,9 & 4 \\
\hline $100 \mathrm{MeV} / \mathrm{u}$ C-Ionen & 28,0 & $1,45 \pm 0,09$ & $0,93 \pm 0,13$ & -- & 2 & 4 \\
\hline Bragg Peak & S. Abb. 2.3 & $1,59 \pm 0,03$ & - & -- & 2,9 & 4 \\
\hline
\end{tabular}

Die RBW-Werte für $10 \%$ Überlebensniveau steigen mit zunehmendem LET ähnlich wie bei WiDr-Zellen an. Die RBW-Werte für $40 \%$ Überlebensniveau bleiben in den MCF-7-Zellen hingegen konstant.

\subsection{3 Überleben von bestrahlten WiDr-Zellen und MCF-7-Zellen im Vergleich}

Die unterschiedliche intrinsische Strahlensensitivität der einzelnen Zelllinien nach Röntgenbestrahlung findet sich auch nach Bestrahlung mit Ionen verschiedener Energien und im ausgedehntem Bragg Peak wieder. Ähnlich wie bei Röntgenstrahlung, die WiDr-Zellen sind gegenüber Bestrahlung mit Kohlenstoffionen viel resistenter als die MCF-7-Zellen. Sogar nach Bestrahlung im Bragg Peak weist die Überlebenskurve 
der WiDr-Zellen eine Schulter auf. Die entsprechende Überlebenskurve der strahlensensitiven MCF-7-Zellen hat allerdings keine Schulter mehr. Normale Zellen, die mit mittelschweren oder schweren Ionen bestrahlt wurden, zeigen in ihren halblogarithmisch aufgetragenen Überlebenskurven auch einen rein linearen Verlauf.

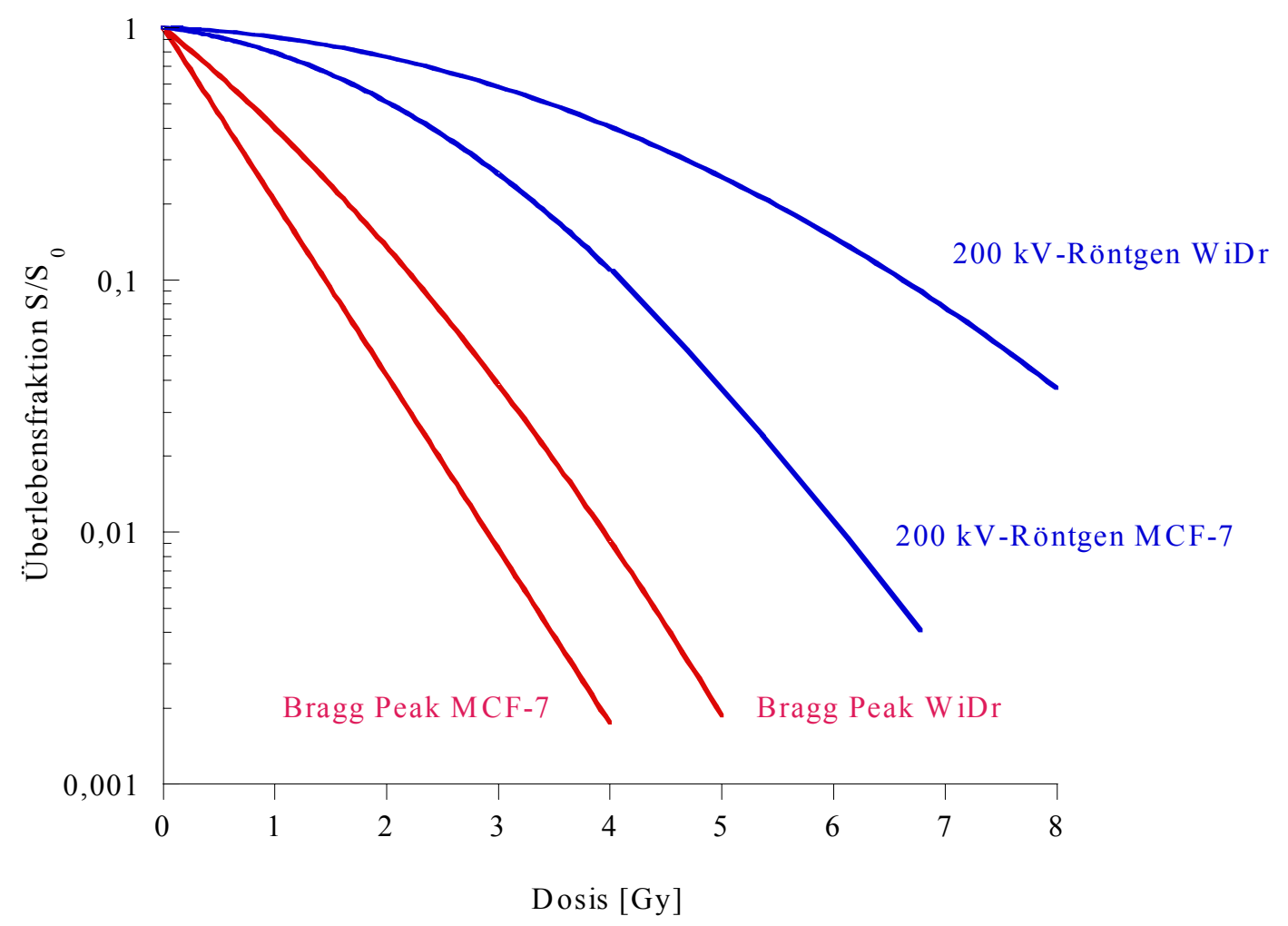

Abbildung 4.5. Vergleich des Zellüberlebens der WiDr- und MCF-7 Zellen nach Bestrahlung mit Kohlenstoffionen im ausgedehntem Bragg Peak und mit 200 kVRöntgenstrahlung. Die relative Überlebensrate $\mathrm{S} / \mathrm{S}_{0}$ ist in Abhängigkeit von Dosis aufgetragen.

Die RBW-Werte beider Zelllinien nach Bestrahlung im ausgedehnten Bragg Peak erreichen gleiche Werte von 2,9 bzw. 4,0 für das $10 \%$ - bzw. für das 40\%Überlebensniveau. 


\subsection{Strahleninduzierte Apoptose}

Die Induktion von Apoptose wurde in Zellen, die mit $100 \mathrm{MeV} / \mathrm{u}$ Kohlenstoffionen oder mit 200 kV-Röntgenstrahlung und D = 4 Gy bestrahlt wurden, gemessen.. Die Anteile apoptotischer Zellen wurden 24, 36 und 48 Stunden nach Bestrahlung unter der Verwendung von Annexin-V-Färbung bestimmt. Pro Dosis und Strahlenart wurden zwei voneinander unabhängige Experimente durchgeführt. Die Ergebnisse wurden gemittelt und nach Abzug der entsprechenden, in unbestrahlten Zellen ermittelten Kontrollwerte wurden die relativen Anteile der apoptotischen Zellen berechnet. Die Ergebnisse sind in Abbildung 4.6 für die strahlenresistente WiDr-Zelllinie und in Abbildung 4.7 für die strahlensensitive MCF-7-Zelllinie dargestellt.

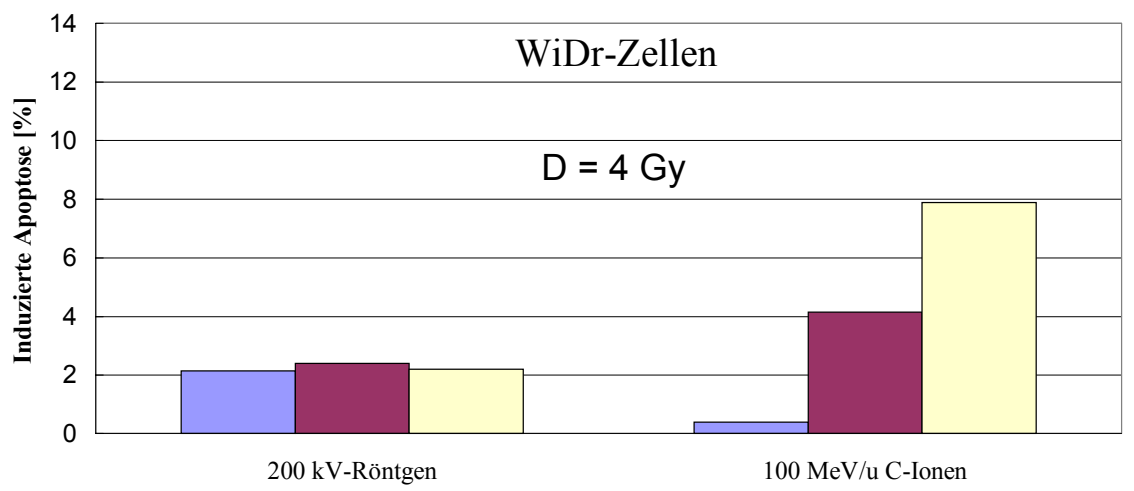

Abbildung 4.6 Strahleninduzierte Apoptose in WiDr-Zellen nach Bestrahlung mit $100 \mathrm{MeV} / \mathrm{U}$ Kohlenstoffionen oder mit 200 kV-Röntgenbestrahlung mit Dosis $\mathrm{D}=4$ Gy. Die Inkubationsdauer der Zellen nach Bestrahlung betrug 24h ( $\square$ ), 36h ( $\square$ ) und 48h ( $\square$ ). Die Kontrollwerte (Spontanrate in unbestrahlten Zellen) wurden subtrahiert. 


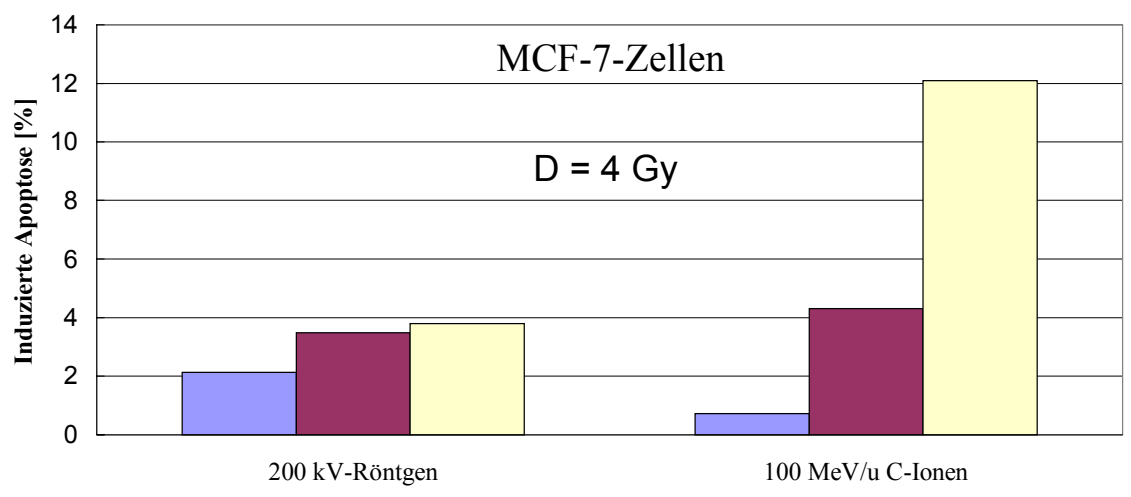

Abbildung 4.7 Strahleninduzierte Apoptose in MCF-7-Zellen nach Bestrahlung mit $100 \mathrm{MeV} / \mathrm{U}$ Kohlenstoffionen oder mit 200 kV-Röntgenbestrahlung mit Dosis D = 4 Gy. Die Inkubationsdauer der Zellen nach Bestrahlung betrug 24h ( $\square$ ), 36h ( $\square$ ) und 48h ( $\square$ ). Die Kontrollwerte (Spontanrate in unbestrahlten Zellen) wurden subtrahiert.

Der relative Anteil apoptotischer Zellen beträgt 48 Stunden nach Bestrahlung mit 100 $\mathrm{MeV} / \mathrm{u}$ Kohlenstoffionen und $\mathrm{D}=4$ Gy maximal ca. $8 \%$ bzw. 12\% in WiDr- bzw. MCF-7-Zellen. Diese Ergebnisse bedeuten, dass die Kohlenstoffionen in den untersuchten Zellen nur in relativ wenigen Zellen den apoptotischen Zelltod induzieren und der strahleninduzierte Zelltod überwiegend durch den Verlust der Klonogenität (reproduktiver Zelltod) verursacht wird. Die niedrige Apoptosenrate erlaubt darüber hinaus eine Untersuchung der chromosomalen Aberrationen in einer repräsentativen Zellpopulation.

\subsection{Zellproliferation nach Bestrahlung}

Durch Bestrahlung werden in allen Zellen verschiedene Typen von strukturellen Chromosomenaberrationen induziert. Diese Aberrationen kann man in zwei Kategorien unterteilen: 
1. sog. „instabile“ Aberrationen: dizentrische (polyzentrische) Chromosomen, azentrische Fragmente, komplexe Austauschaberrationen (die dizentrische Chromosomen enthalten)

2. sog. „stabile“ Aberrationen: reziproke Translokationen, Inversionen, Deletionen, zentrische Ringe, Duplikationen, Insertionen und komplexe Austauschaberrationen

Die instabilen Chromosomenkonfigurationen haben entweder zwei oder mehrere Centromere in einem zusammengesetzten Chromosom, oder gar keine Centromere. Während der Zellteilung führen dizentrische Chromosomen zur Bildung von Anaphasenbrücken. Dies ist ein Vorgang bei dem das dizentrische Chromosom über seine zwei Centromere gleichzeitig zu beiden entgegensetzten Spindelapparat-Polen gezogen wird. Diese Anordnung entsteht mit einer Wahrscheinlichtkeit von ca. 50 \%. Die Zelle wird dadurch in ihrer Anaphase arretiert und verliert ihre Teilungsfähigkeit (reproduktiver Zelltod).

Azentrische Fragmente, also Chromosomenteile ohne Centromere, werden aufgrund der fehlenden Assoziationsmöglichkeiten mit dem Spindelapparat aus dem Zellkern in Form von Mikrokernen eliminiert.

Um alle strahleninduzierten Aberrationen zu erfassen, ist es daher notwendig, die Aberrationen in Zellen, die sich in ihrer ersten Mitose (Metaphase) nach Bestrahlung befinden, auszuwerten. Da sich sogar sehr gut synchronisierte Zellen nicht alle auf einmal in ihrer ersten Mitose nach Bestrahlung befinden, musste für die beiden untersuchten Zelllinien ein Zeitfenster bestimmt werden, in dem sich die meisten Zellen in der ersten Mitose befanden. Dies wurde mit Hilfe von BrdU-Einbau in die DNA in unbestrahlten sowie in bestrahlten Zellen durchgeführt. In Abbildungen 4.8 und 4.9 sind die relativen Mitosenanteile in Abhängigkeit von der Kulturzeit dargestellt.

Aus den zeitlichen Verläufen der relativen Anteile an ersten Mitosen wurden die optimalen Kulturzeiten für die Auswertung der chromosomalen Aberrationen gewählt. Darüber hinaus wurden der Zellzyklusverlauf und die Zellzyklusverzögerung durch Bestrahlung geschätzt. 
a)

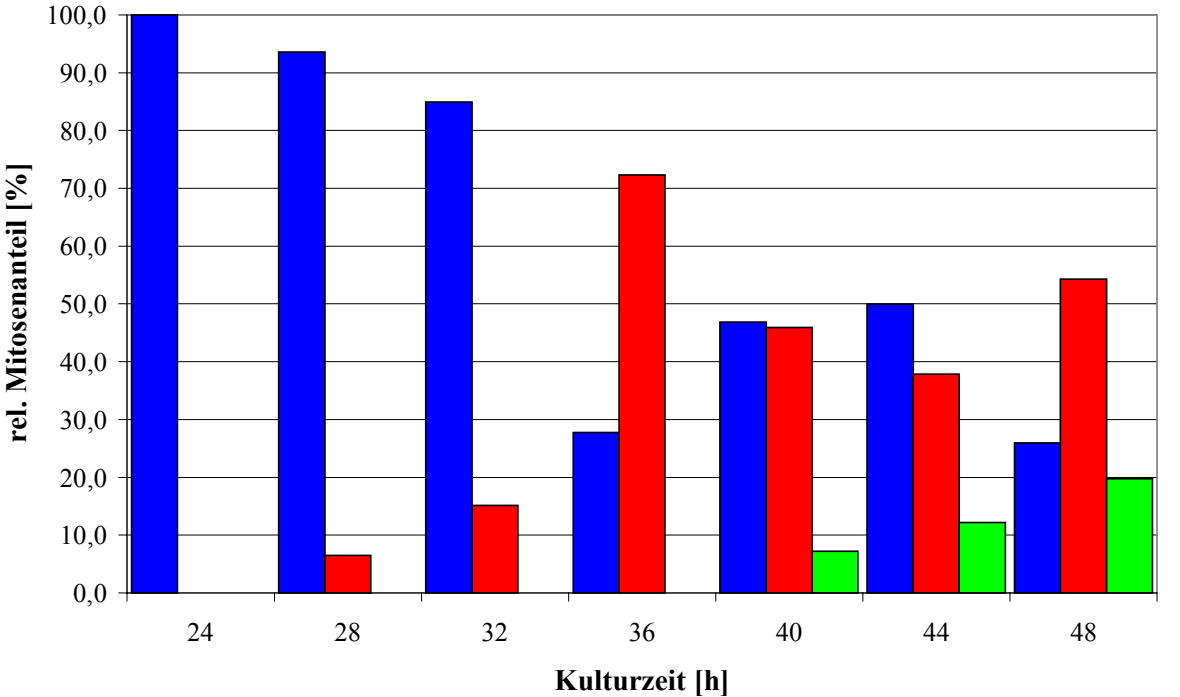

b)

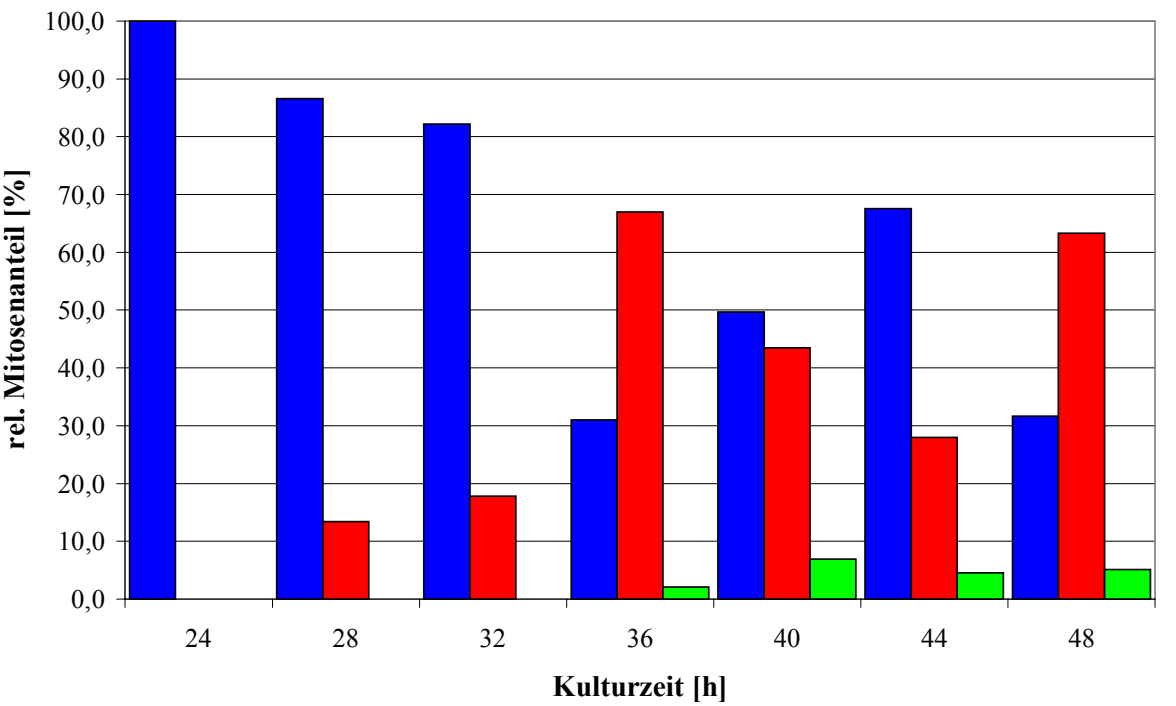

c)

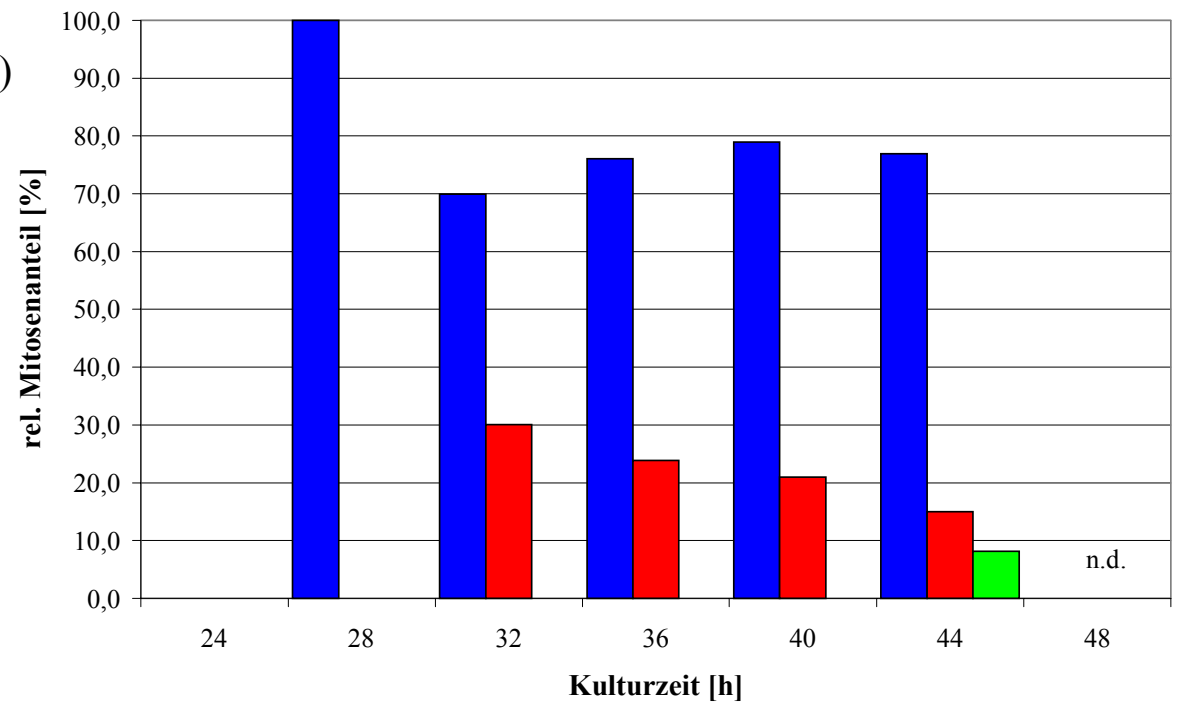

Abbildung 4.8 Relative Anteile an unbestrahlten (a) und an bestrahlten (b, c) WiDrZellen in ihrer 1.Mitose $\square$, 2.Mitose $\square$ und 3. Mitose $\square$ in Abhängigkeit von der Kulturzeit. Die Zellen wurden mit 200 kV-Röntgenstrahlung (b) und mit $100 \mathrm{MeV} / \mathrm{u}$ Kohlenstoff-Ionen (c) mit D = 1 Gy bestrahlt. (n.d. = Wert wurde nicht bestimmt). 

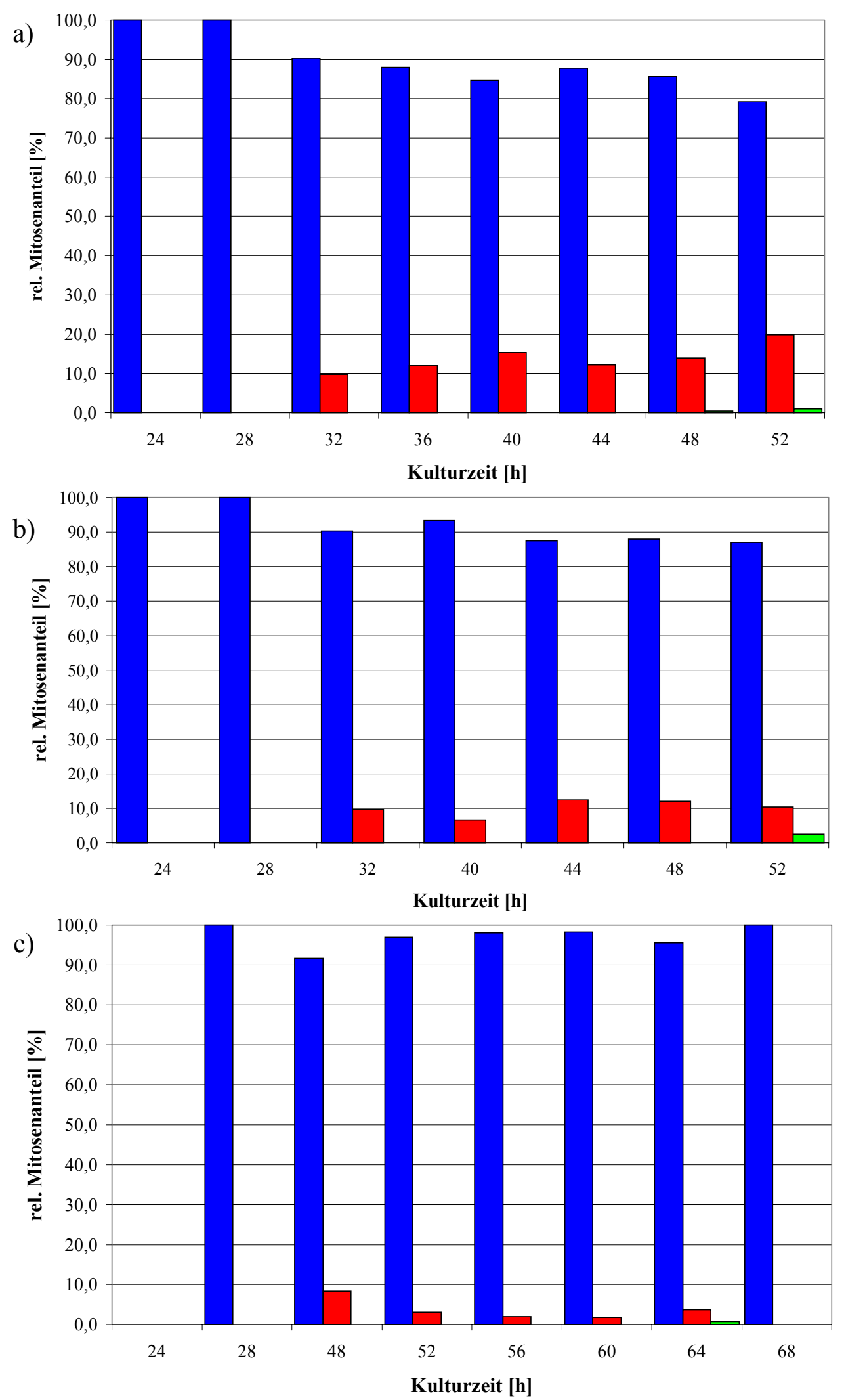

Abbildung 4.9 Relative Anteile an unbestrahlten (a) und an bestrahlten (b, c) MCF7-Zellen in ihrer 1.Mitose $\square$, 2.Mitose $\square$ und 3. Mitose $\square$ in Abhängigkeit von der Kulturzeit. Die Zellen wurden mit 200 kV-Röntgenstrahlung (b) und mit $100 \mathrm{MeV} / \mathrm{u}$ Kohlenstoff-Ionen (c) mit D = 1 Gy bestrahlt. (n.d. = Wert wurde nicht bestimmt). 
Anhand der experimentellen Ergebnisse wurden für beide untersuchten Zelllinien als optimal die Kulturzeiten zwischen 24-32 Stunden nach Bestrahlung gewählt.

Bei der strahlenresistenten WiDr-Zelllinie ist nach $200 \mathrm{kV}$-Röntgenbestrahlung mit D = 1 Gy noch keine Verzögerung der ersten Mitose im Vergleich zur Kontrolle sichtbar.

Der relative Mitosenanteil zeigt jedoch in seinem Verlauf, dass zwei WiDrSubpopulationen vorhanden sind. Die erste Subpopulation zeigt in unbestrahlten und mit 200 kV-Röntgenstrahlung bestrahlten Zellen einen normalen Verlauf der einzelnen mitotischen Wellen, entsprechend einem 24 Stunden langen Zellzyklus. Ab diesem Zeitpunkt nimmt der Anteil der ersten Mitose kontinuierlich ab, 36 Stunden nach Bestrahlung liegt dieser Anteil unter 40\% und der relative Anteil an zweiten Mitosen ist etwa 70\%. Die zweite Subpopulation der WiDr-Zellen zeigt einen langsameren Verlauf entsprechend einem Zellzyklus mit einer Dauer von etwa 40 Stunden.

Nach Bestrahlung mit $100 \mathrm{MeV} / \mathrm{u}$ Kohlenstoffionen mit D = 1 Gy zeigt sich im Gegensatz zur Röntgenstrahlung eine Verzögerung der ersten Mitose von etwa 4 Stunden. Die Dauer der ersten Mitose ist jedoch stark verlängert. Durch die Verzögerung der schnelleren Subpopulation kommt es zur Verschiebung des Verlaufs und man findet 44 Stunden nach Bestrahlung noch über 70\% der Zellen in der ersten Mitose. Ob die langsamere Population auch eine strahleninduzierte Verzögerung zeigt, ist anhand der experimentellen Daten nicht feststellbar.

Auch bei der strahlensensitiven MCF-7-Zelllinie ist nach $200 \mathrm{kV}$-Röntgenbestrahlung mit $\mathrm{D}=1$ Gy keine Verzögerung der ersten Mitose im Vergleich zur Kontrolle sichtbar. Die Zellen zeigen einen normalen Zellzyklus von 28 Stunden Dauer. Zwar waren nach 24 Stunden vereinzelt erste Mitosen vorhanden, aber in Übereinstimmung mit den Wachstumskurven (s. Abb. 4.9) wurden signifikante Anteile erster Mitosen erst nach 28 Stunden beobachtet.

Sowohl die biphasischen Überlebenskurven als auch der Proliferationsverlauf deuten auf das Vorhandensein von zwei MCF-7-Subpopulationen hin. Die erste Subpopulation zeigt in unbestrahlten und mit $200 \mathrm{kV}$-Röntgenstrahlung bestrahlten Zellen einen normalen Verlauf der einzelnen mitotischen Wellen, entsprechend einem 28 Stunden 
langen Zellzyklus. Die zweite Population ist jedoch langsamer. Diese hat eine Zellzyklusdauer von etwa 44 Stunden. Die relativen Anteile der beiden Subpopulation lassen sich aus den experimentellen Daten nicht direkt ermitteln.

Nach Bestrahlung mit $100 \mathrm{MeV} / \mathrm{u}$ Kohlenstoffionen mit D = 1 Gy zeigt sich eine wenig ausgeprägte Verzögerung der ersten Mitose von etwa 4 Stunden. Der relative Anteil der ersten Mitosen in unbestrahlten und in bestrahlten Zellen nimmt jedoch nicht ab. Er bleibt bei einem Wert von ca. $80 \%$ bis zu einer Kulturdauer von 52 Stunden, und das sowohl bei unbestrahlten als auch bei bestrahlten Zellen (200 kV-Röntgenbestrahlung) konstant. Nach Bestrahlung mit Kohlenstoffionen zeigt sich dieser konstante relative Mitosenanteil bis zu einer Kulturdauer von 68 Stunden. Diese Ergebnisse deuten daraufhin, dass die Proliferation der MCF-7-Zellen durch die BrdU-Zugabe beeinflusst wird.

\subsection{Wachstumskinetik in Abhängigkeit von BrdU}

Um den Einfluss von BrdU auf das Wachstum der untersuchten Zelllinien zu überprüfen, wurde die Zell-Verdopplungsrate in Anwesenheit und Abwesenheit von BrdU gemessen. Die Konzentration von BrdU betrug $10 \mu \mathrm{g} / \mathrm{ml}$. Die ermittelten Daten aus zwei Experimenten sind in Abbildung 4.10 und 4.11 graphisch dargestellt. 


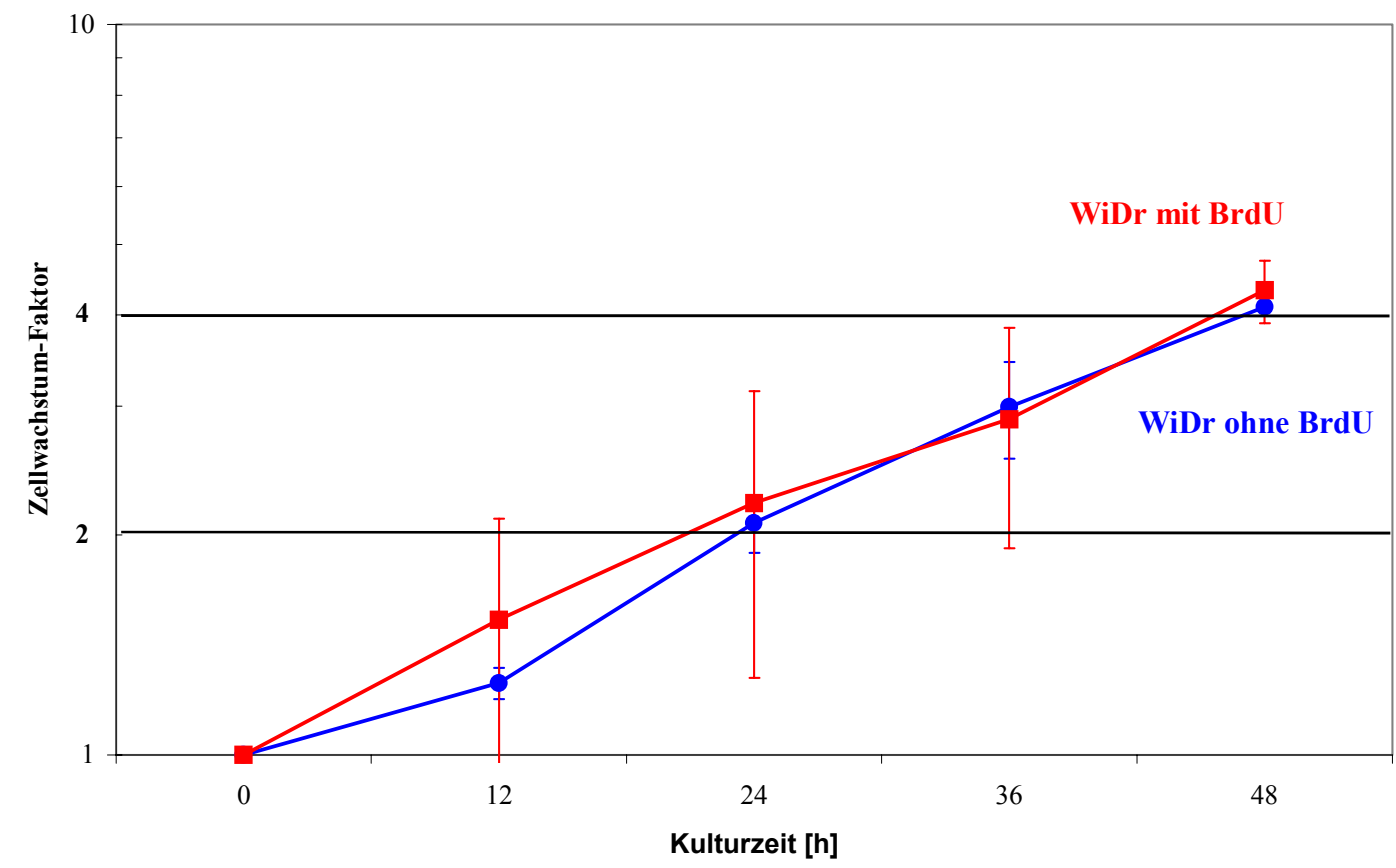

Abbildung 4.10 Wachstumskurve unbestrahlter WiDr-Zellen ohne ( $-\boldsymbol{c}$ ) und mit Zugabe von $10 \mu \mathrm{g} / \mathrm{ml} \mathrm{BrdU} \mathrm{zum} \mathrm{Kulturmedium} \mathrm{(-)} \mathrm{in} \mathrm{Abhängigkeit} \mathrm{von} \mathrm{der}$ Kulturzeit. Die Fehlerbalken repräsentieren Standardabweichungen der Mittelwerte.

Bei den WiDr-Zellen ist kein Einfluss von BrdU auf die Verdopplungszeit feststellbar. Die Verdopplungszeit beträgt mit und ohne BrdU ca. 24 Stunden.

Bei den MCF-7 Zellen ist der Einfluss von BrdU auf die Zellproliferation offensichtlich. Die ermittelte Verdopplungszeit beträgt in Kulturen ohne BrdU ca. 24 Stunden, nach Zugabe von BrdU verlängert sich die Verdopplungszeit auf ca. 36 Stunden. In Anwesenheit von BrdU kann man eine lag-Phase, die etwa 24 Stunden lang ist, beobachten. Erst danach setzt das exponentielle Wachstum mit gleicher Geschwindigkeit wie ohne BrdU ein. 


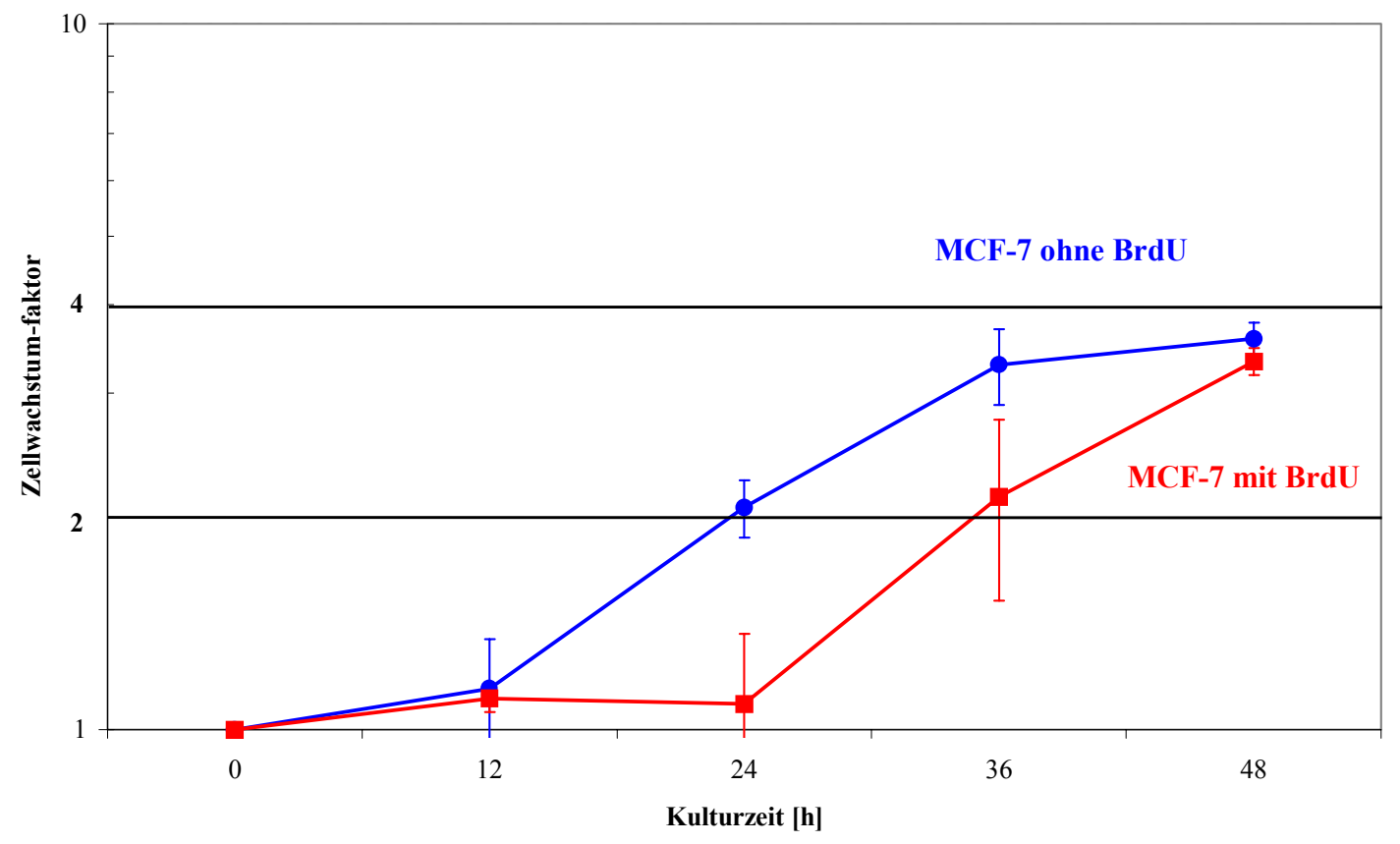

Abbildung 4.11 Wachstumskurve unbestrahlter WiDr-Zellen ohne (- - ) und mit Zugabe von $10 \mu \mathrm{g} / \mathrm{ml}$ BrdU zum Kulturmedium (-) in Abhängigkeit von der Kulturzeit. Die Fehlerbalken repräsentieren Standardabweichungen der Mittelwerte.

\subsection{Strahleninduzierte Chromosomenaberrationen}

Die Analyse der strahleninduzierten Chromosomenaberrationen liefert ein breites Spektrum an Daten. Zur Untersuchung dieser Schäden wurden WiDr- und MCF-7Zellen in der Plateauphase bestrahlt und unmittelbar nach Bestrahlung aus der Kontanktinhibition durch Umsetzen ins frische Medium gelöst. Zur mikroskopischen Auswertung der strukturellen Chromosomenaberrationen nach Bestrahlung wurden die Metaphasenchromosomen präpariert. Die Dauer des ersten Zellzyklus, die nach der Bestrahlung der Zellen bei den jeweiligen Zelllinien variieren kann, wurde in Vorversuchen bestimmt. Die Inkubationsdauer nach Bestrahlung betrug 24 bis 36 Stunden. 


\subsubsection{Dosisabhängigkeit von genomischen Häufigkeiten instabiler Chromo- somenaberrationen in WiDr- und MCF-7-Zellen}

Metaphasenchromosomen wurden mit 2\% Giemsa-Lösung gefärbt und ausgewertet. Es wurden dizentrische (polyzentrische) Chromosomen, zentrische Ringe und azentrische Fragmente analysiert. Die Auswertungskriterien sind in Kapitel 3.2.8. beschrieben. Eine aberrante Metaphase ist in Abbildung 4.12 dargestellt.

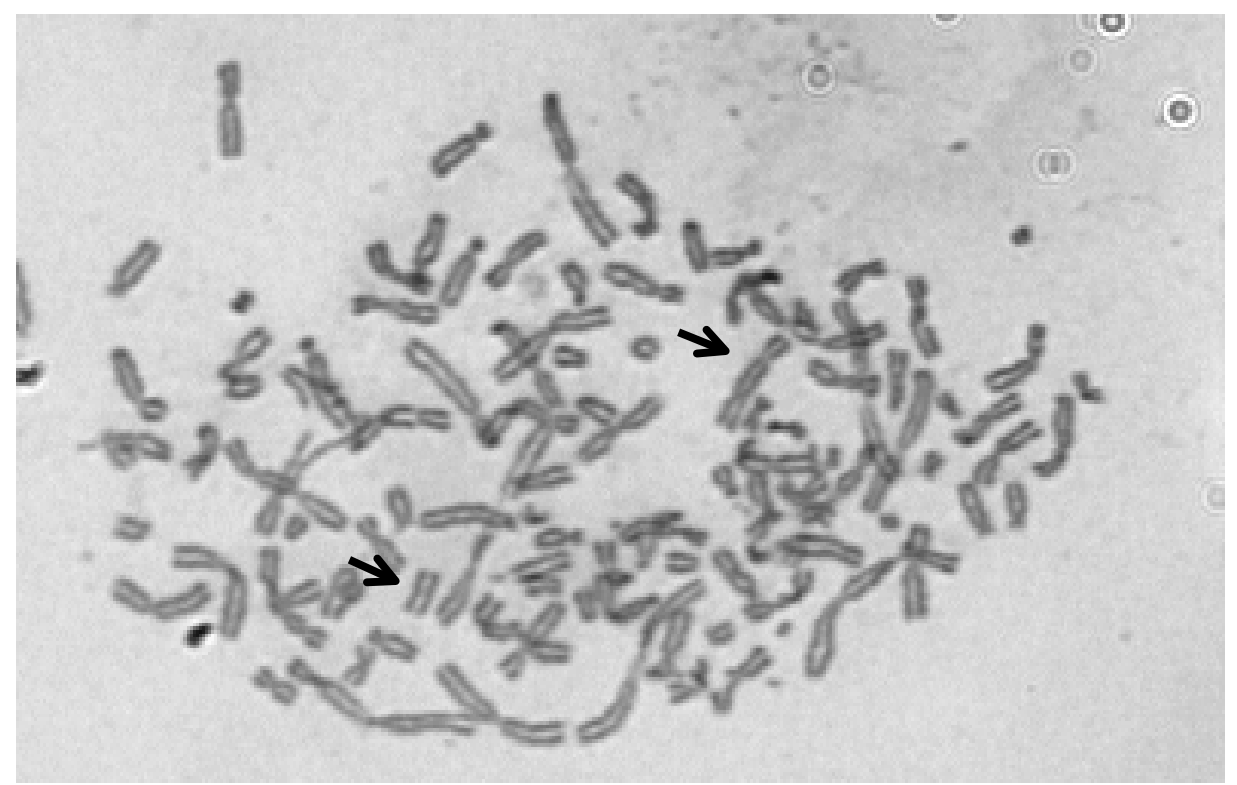

Abbildung 4.12 Originalaufnahme einer aberranten Metaphase der WiDr-Zelllinie nach Bestrahlung mit Kohlenstoffionen (100 MeV/u und D = 1 Gy). Die Chromosomen wurden mit Giemsa gefärbt und unter 1000 facher Vergrößerung aufgenommen. Die Pfeile kennzeichnen ein dizentrisches Chromosom mit einem dazugehörigen azentrischen Fragment. 


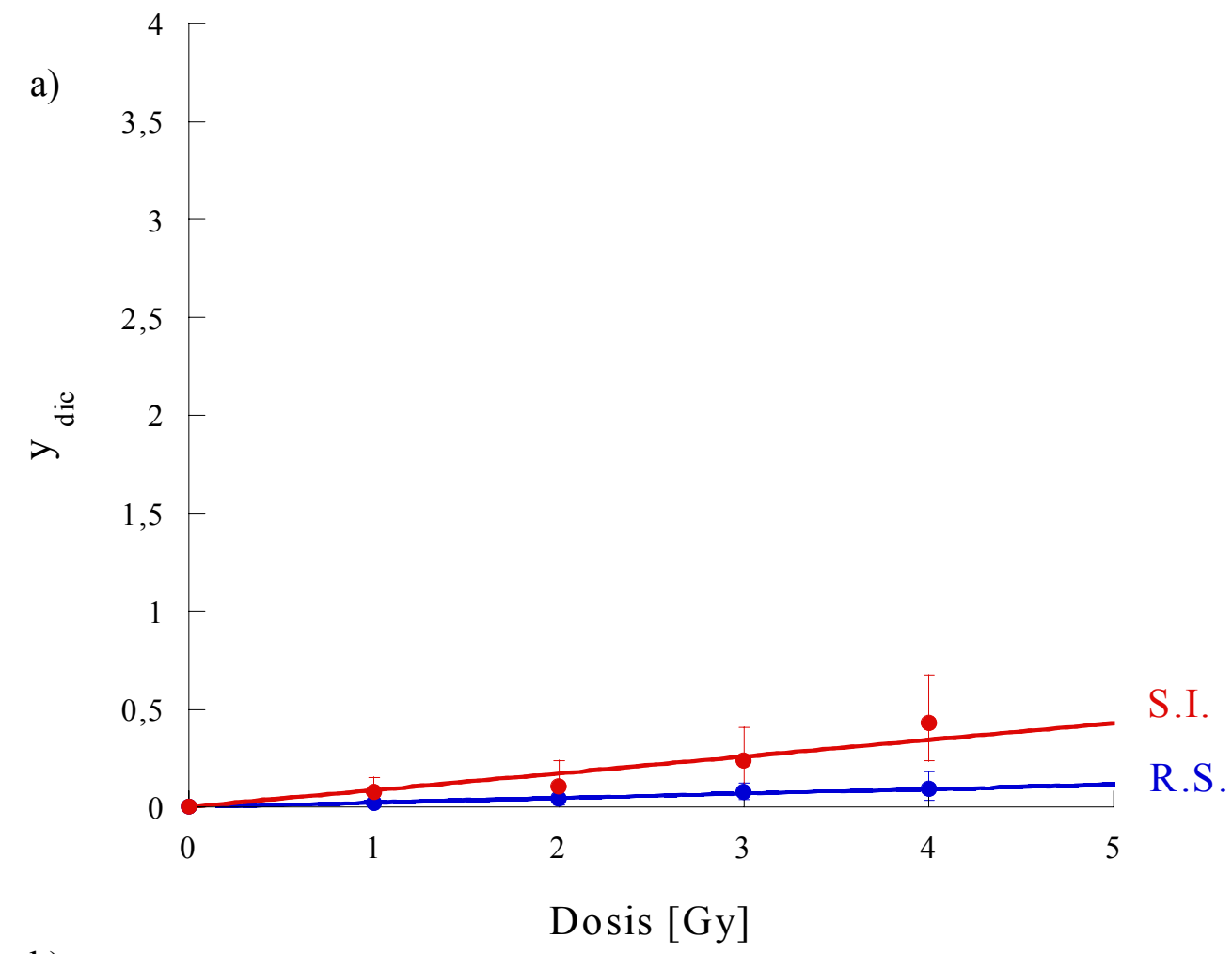

b)

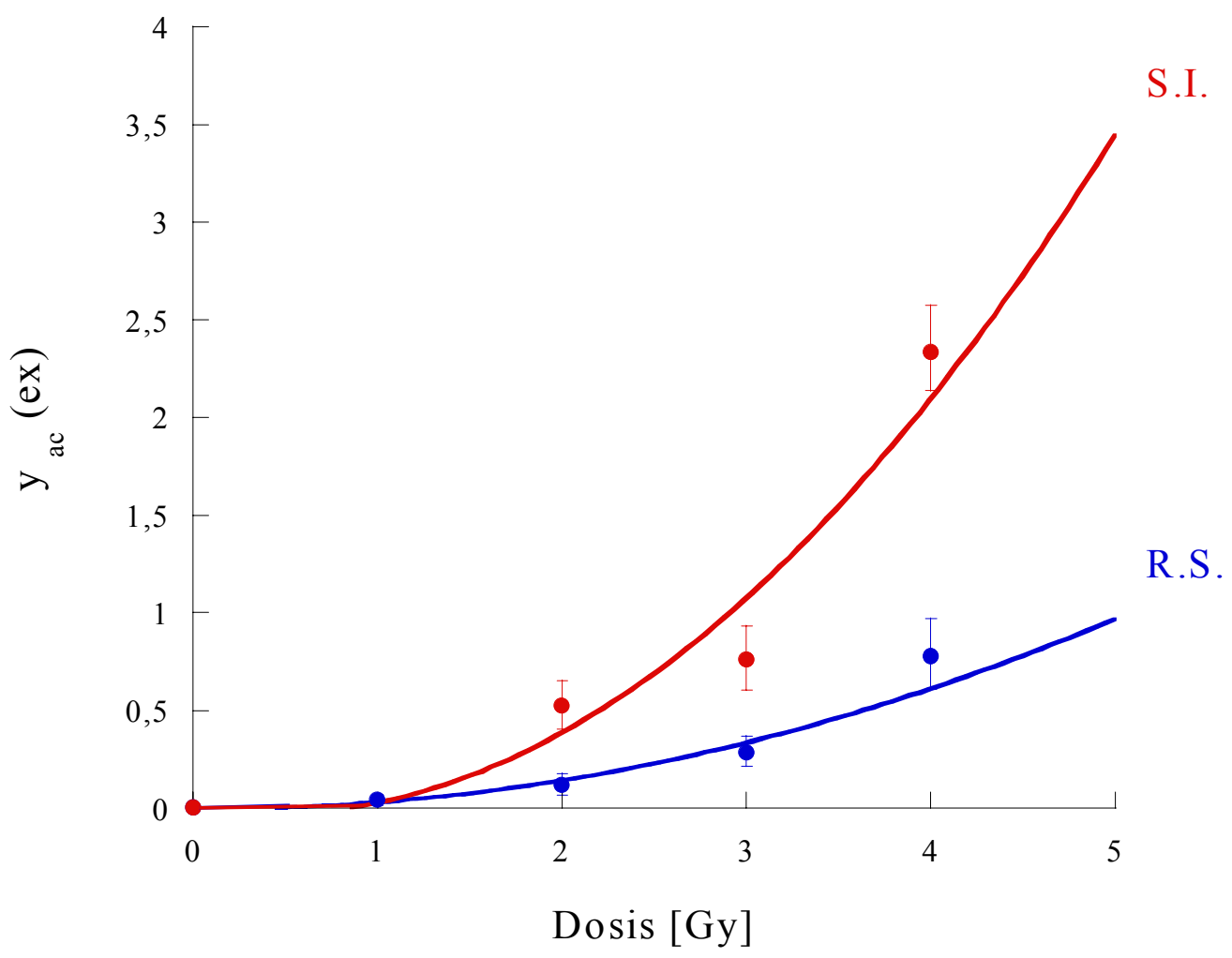

Abbildung 4.13 Dosisabhängigkeit dizentrischer Chromosomen (a) und extra azentrischer Fragmenten (b) pro Zelle in WiDr-Zelllinie nach Bestrahlung mit $100 \mathrm{MeV} / \mathrm{u}$ Kohlenstoffionen (S.I.) und $200 \mathrm{kV}$-Röntgenstrahlung (R.S.). Die Fehlerbalken repräsentieren 95 \% -Poisson-Vertrauensbereiche. 
In Abbildung 4.13 sind die genomischen Häufigkeiten dizentrischer Chromosomen und extra azentrischer Fragmente in WiDr-Zellen dargestellt. Die Dosis-Effekt-Kurven wurden mit einer linearen $(\mathrm{y}=\alpha \mathrm{D})$ oder mit einer linear-quadratischen $\left(\mathrm{y}=\alpha \mathrm{D}+\beta \mathrm{D}^{2}\right)$ Funktion angepasst. Die genomische Instabilität der Tumorzellen manifestiert sich u.a. dadurch, dass man auch in unbestrahlten Zellen klonale und nicht-klonale Chromosomaberrationen findet. Die Aberrationshäufigkeiten in bestrahlten Zellen wurden durch das Subtrahieren der entsprechenden Kontrollwerte $\mathrm{y}_{\mathrm{dic}}=0,05 \pm 0,02$ bzw. $y_{\text {ac }}(\mathrm{ex})=0,09 \pm 0,02$ (Aberrationsrate in unbestrahlten Zellen) korrigiert. Die entsprechenden Koeffizienten $\alpha$ und $\beta$ sind in der Tabelle 4.6 enthalten.

Zum besseren Vergleich sind die angepassten Dosis-Effekt-Kurven für beide Aberrationstypen zusammen in Abbildung 4.14 dargestellt.

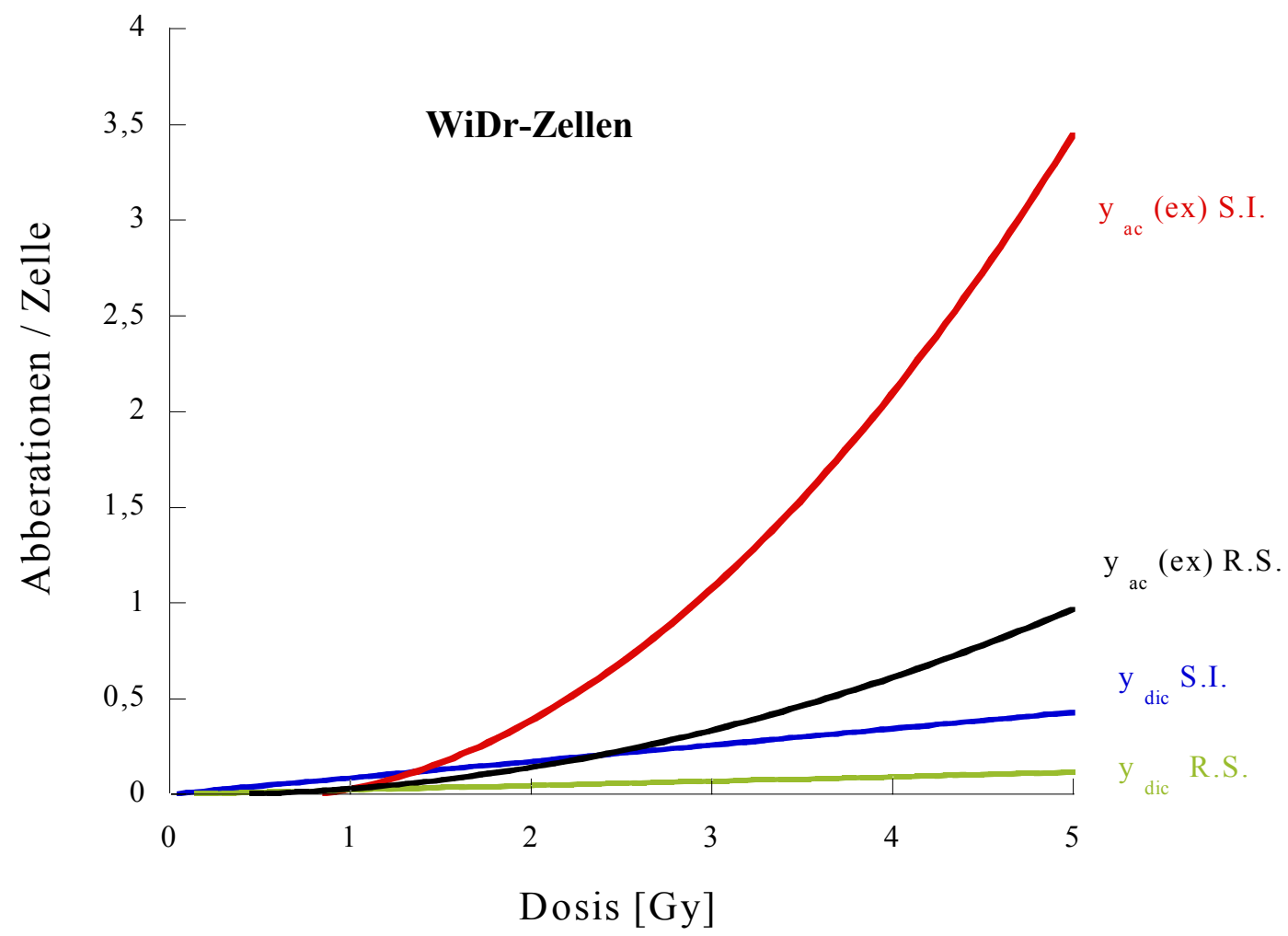

Abbildung 4.14 Die angepassten Dosis-Effekt-Kurven für dizentrische Chromosomen $\left(\mathrm{y}_{\mathrm{dic}}\right)$ und extra azentrische Fragmente $\left(\mathrm{y}_{\mathrm{ac}}(\mathrm{ex})\right)$ nach $200 \mathrm{kV}$ Röntgenbestrahlung (R.S.) und nach Bestrahlung mit $100 \mathrm{MeV} / \mathrm{u}$ Kohlenstoffionen (S.I.). 
Tabelle 4.6 Die Parameter $\alpha$ und $\beta$ der angepassten Dosis-Effekt-Kurven für WiDrZellen nach Bestrahlung mit $100 \mathrm{MeV} / \mathrm{u}$ Kohlenstoffionen und mit $200 \mathrm{kV}$ Röntgenstrahlung, sowie RBW-Werte für extra azentrische Fragmente.

\begin{tabular}{|c|c|c|c|c|c|}
\hline Strahlung & Aberrationsart & $\boldsymbol{\alpha}$ & $\boldsymbol{\beta}$ & $\mathbf{R B W}_{\mathbf{0 , 5}}$ & $\mathbf{R B W}_{\mathbf{1}}$ \\
\hline & & {$\left[\mathrm{Gy}^{-1}\right]$} & {$\left[\mathrm{Gy}^{-2}\right]$} & & \\
\hline \hline $200 \mathrm{kV}$-Röntgen & Dizentrische Chr. & $0,02 \pm 0,01$ & -- & 1 & 1 \\
\hline $100 \mathrm{MeV} / \mathrm{u}$ C-Ionen & Dizentrische Chr. & $0,09 \pm 0,02$ & -- & 4,5 & 4,5 \\
\hline $200 \mathrm{kV}$-Röntgen & Ex. azentr. Frag. & -- & $0,04 \pm 0,02$ & 1 & 1 \\
\hline $100 \mathrm{MeV} / \mathrm{u}$ C-Ionen & Ex. azentr. Frag. & -- & $0,17 \pm 0,04$ & 1,6 & 1,8 \\
\hline
\end{tabular}

In der resistenten WiDr-Zelllinie wurde nach $200 \mathrm{kV}$-Röntgenbestrahlung eine sehr niedrige Ausbeute an dizentrischen Chromosomen pro Zelle induziert. Nach einer Bestrahlung mit $\mathrm{D}=4$ Gy betrug $\mathrm{y}_{\text {dic }}=0,14 \pm 0,08$, d.h. ein Dreifaches der Spontanrate. Die strahleninduzierte Ausbeute an extra azentrischen Fragmenten pro Zelle war hingegen viel höher als die Spontanrate. Sie betrug $\mathrm{y}_{\mathrm{ac}}(\mathrm{ex})=0,87 \pm 0,19$. Nach Bestrahlung mit $100 \mathrm{MeV} / \mathrm{u}$ Kohlenstoffionen wurden erwartungsgemäß viel höhere Aberrationsraten pro Zelle beobachtet. Die Dosisabhängigkeit der Induktion von dizentrischen Chromosomen ist in dem untersuchten Dosisbereich, sowohl für 200 kV-Röntgenstrahlung als auch für die Bestrahlung mit Kohlenstoffionen, linear. Für die extra azentrischen Fragmente wurde eine überwiegend quadratische Abhängigkeit beobachtet ( $\alpha$ nicht signifikant).

Anhand der angepassten Dosis-Effekt-Beziehungen wurden für die Induktion von dizentrischen Chromosomen und von extra azentrischen Fragmenten die entsprechenden RBW-Werte berechnet, und zwar für ein Effektniveau von 0,5 bzw. 1,0 Aberrationen pro Zelle. Die Induktion von dizentrischen Chromosomen wurde aufgrund der sehr niedrigen Ausbeuten rechnerisch bestimmt. Die RBW-Werte sind in der Tabelle 4.6 angegeben. 

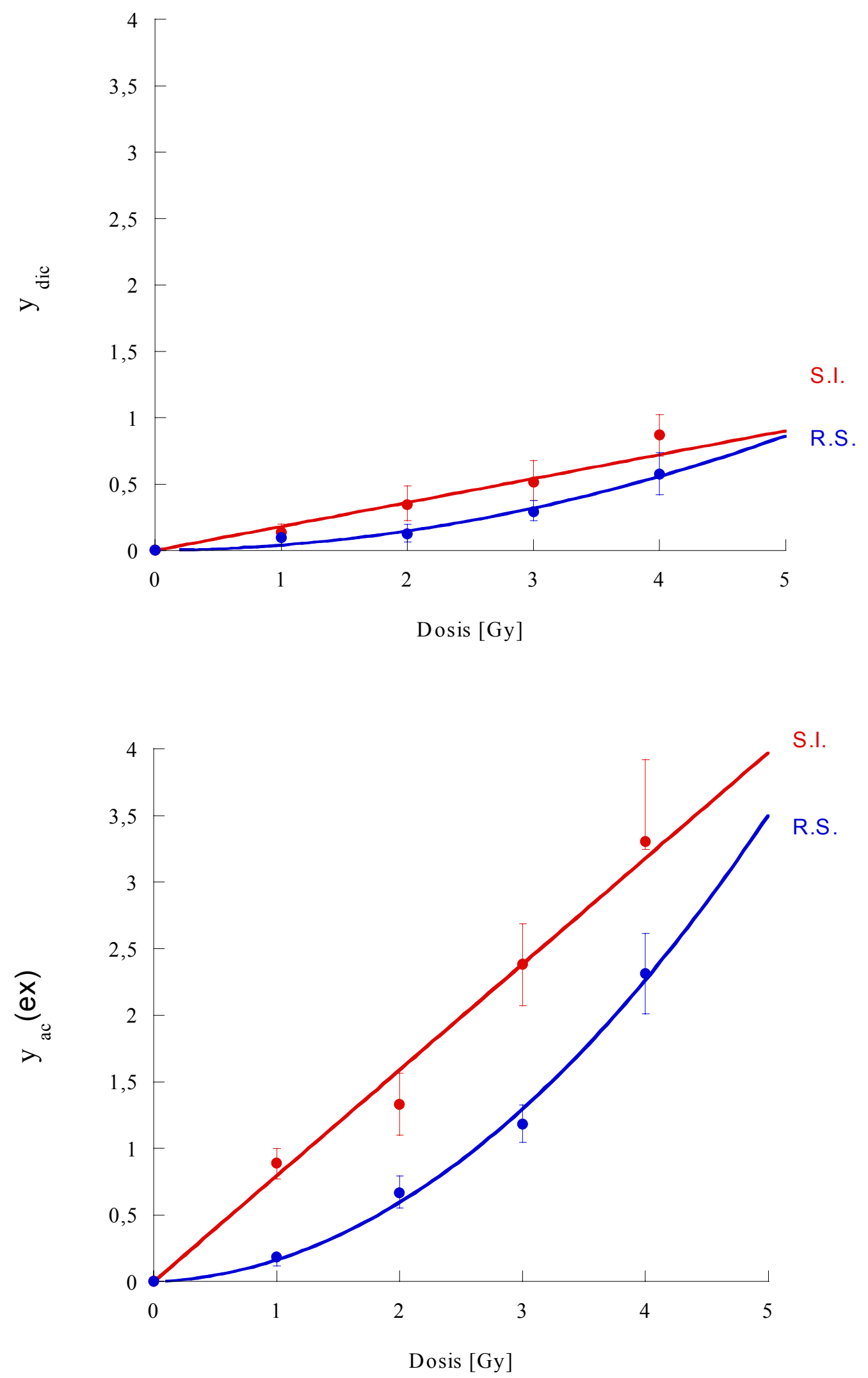

Abbildung 4.15 Dosisabhängigkeit dizentrischer Chromosomen (a) und extra azentrischer Fragmenten (b) pro Zelle in MCF-7-Zelllinie nach Bestrahlung mit $100 \mathrm{MeV} / \mathrm{u}$ Kohlenstoffionen (S.I.) und $200 \mathrm{kV}$-Röntgenstrahlung (R.S.). Die Fehlerbalken repräsentieren 95 \% -Poisson-Vertrauensbereiche. 
Die genomischen Häufigkeiten dizentrischer Chromosomen und extra azentrischer Fragmente in der strahlensensitiven MCF-7-Zelllinie in Abhängigkeit von der Strahlendosis sind in Abbildung 4.15 dargestellt. Die Dosis-Effekt-Kurven wurden mit einer linearen $(\mathrm{y}=\alpha \mathrm{D})$ oder mit einer linear-quadratischen $\left(\mathrm{y}=\alpha \mathrm{D}+\beta \mathrm{D}^{2}\right)$ Funktion angepasst. Die Aberrationshäufigkeiten in bestrahlten Zellen wurden durch das Subtrahieren der entsprechenden Kontrollwerte korrigiert. Die spontane (genomische) Häufigkeit dizentrischer Chromosomen in unbestrahlten Zellen betrug $\mathrm{y}_{\mathrm{dic}}=0,07 \pm$ 0,02, die Häufigkeit azentrischer Fragmente betrug $y_{\text {ac }}(\mathrm{ex})=0,07 \pm 0,02$. Zum besseren Vergleich sind alle angepassten Dosis-Effekt-Kurven zusammen in Abbildung 4.16 dargestellt. Die entsprechenden Koeffizienten $\alpha$ und $\beta$ sind in der Tabelle 4.7 aufgelistet.

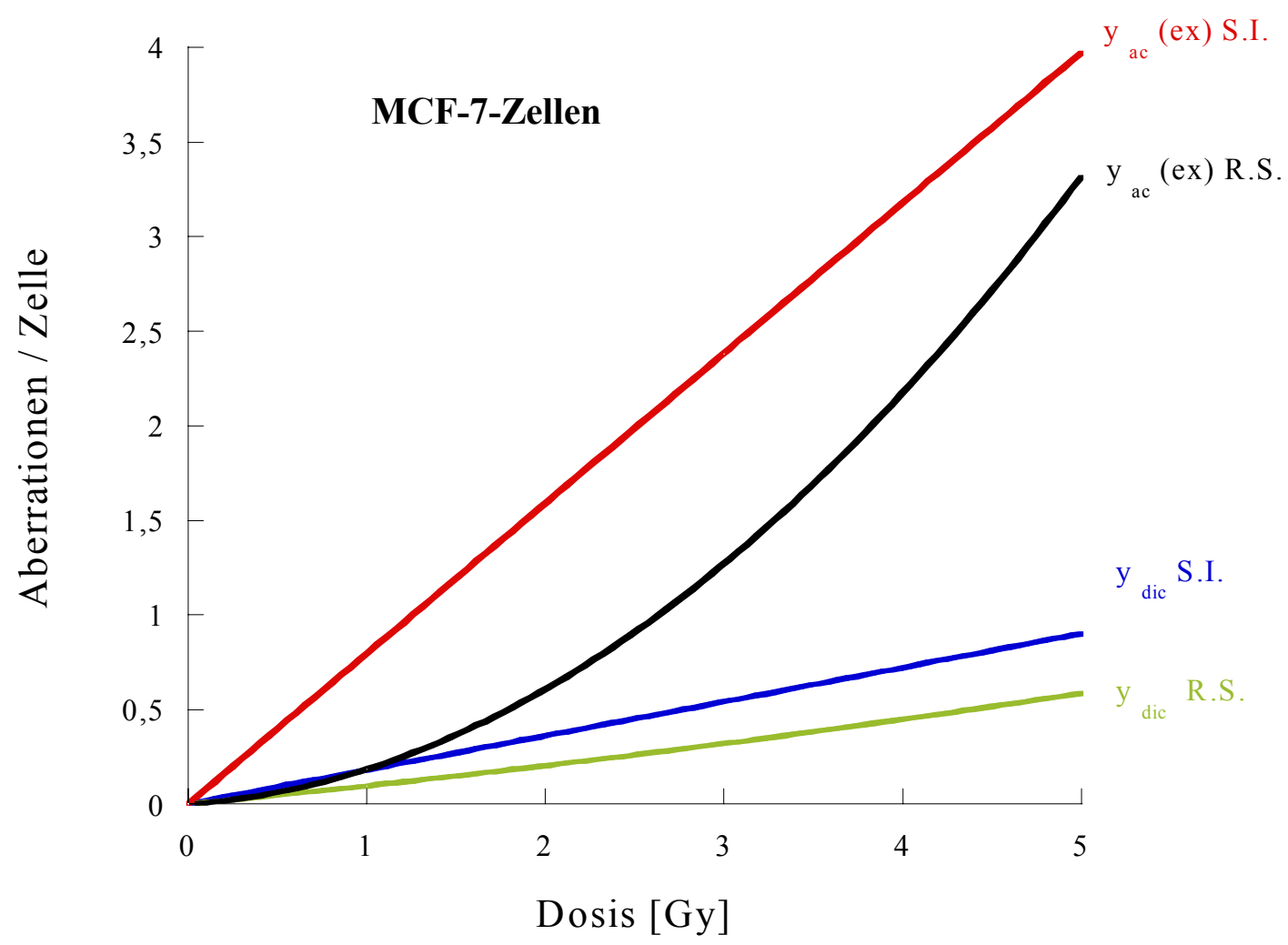

Abbildung 4.16 Die angepassten Dosis-Effekt-Kurven für dizentrische Chromosomen $\left(\mathrm{y}_{\mathrm{dic}}\right)$ und extra azentrische Fragmente ( $\left.\mathrm{y}_{\mathrm{ac}}(\mathrm{ex})\right)$ nach $200 \mathrm{kV}$ Röntgenbestrahlung (R.S.) und nach Bestrahlung mit $100 \mathrm{MeV} / \mathrm{u}$ Kohlenstoffionen (S.I.). 
In der strahlensensitiven MCF-7-Zelllinie wurden wiederum viel höhere Aberrationsraten pro Zelle nach Bestrahlung mit $100 \mathrm{MeV} / \mathrm{u}$ Kohlenstoffionen im Vergleich mit Röntgenstrahlung beobachtet. Die Dosisabhängigkeit der Induktion von dizentrischen Chromosomen ist in dem untersuchten Dosisbereich, sowohl für $200 \mathrm{kV}$ Röntgenstrahlung als auch für die Bestrahlung mit Kohlenstoffionen, linear. Für die extra azentrischen Fragmente wurde für $200 \mathrm{kV}$-Röntgenstrahlung eine quadratische Abhängigkeit beobachtet ( $\alpha$ nicht signifikant). Nach Bestrahlung mit Kohlenstoffionen wurde jedoch eine lineare Abhängigkeit beobachtet.

Tabelle 4.7. Parameter $\alpha$ und $\beta$ der angepassten Dosis-Effekt-Beziehungen für MCF7-Zellen nach Bestrahlung mit $100 \mathrm{MeV} / \mathrm{u}$ Kohlenstoffionen und nach $200 \mathrm{kV}$ Röntgenstrahlung, sowie RBW-Werte für dizentrische Chromosomen und für extra azentrische Fragmente.

\begin{tabular}{|c|c|c|c|c|c|}
\hline Strahlung & Aberrationsart & $\boldsymbol{\alpha}$ & $\boldsymbol{\beta}$ & $\mathbf{R B W}_{\mathbf{0 , 5}}$ & $\mathbf{R B W}_{\mathbf{1}}$ \\
\hline & & {$\left[\mathrm{Gy}^{-1}\right]$} & {$\left[\mathrm{Gy}^{-2}\right]$} & & \\
\hline \hline $200 \mathrm{kV}-$ Röntgen & Dizentrische Chr. & $0,10 \pm 0,02$ & $0,03 \pm 0,01$ & 1 & 1 \\
\hline $100 \mathrm{MeV} / \mathrm{u}$ C-Ionen & Dizentrische Chr. & $0,18 \pm 0,02$ & -- & 1,4 & 0,9 \\
\hline $200 \mathrm{kV}-$ Röntgen & Ex. azentr. Frag. & -- & $0,13 \pm 0,02$ & 1 & 1 \\
\hline $100 \mathrm{MeV} / \mathrm{u}$ C-Ionen & Ex. azentr. Frag. & $0,79 \pm 0,06$ & -- & 2,1 & 2,1 \\
\hline
\end{tabular}

Die RBW-Werte für 0,5 bzw.1,0 sind für die Ausbeute an dizentrischen Chromosomen 1,4 bzw. 0,9. Für die Ausbeuten an extra azentrischen Fragmenten steigen diese Werte für beide RBW-Werte auf 2.1 .

In Abbildung 4.17 sind die Vergleiche der angepassten Dosis-Effekt-Kurven für dizentrische Chromosomen (a) und extra azentrische Fragmente (b) nach Bestrahlung dargestellt. 
a)

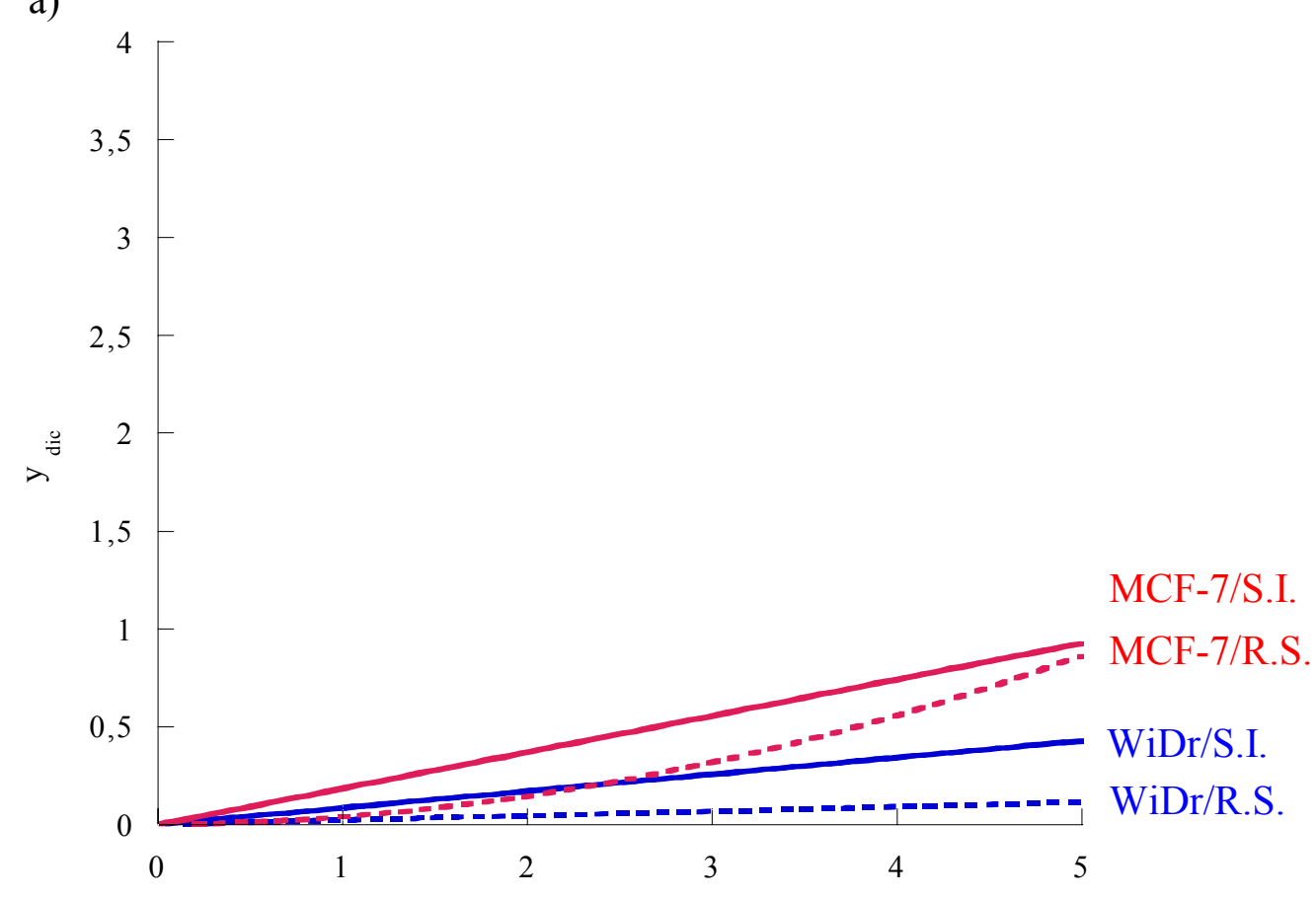

b)

Dosis $[\mathrm{Gy}]$

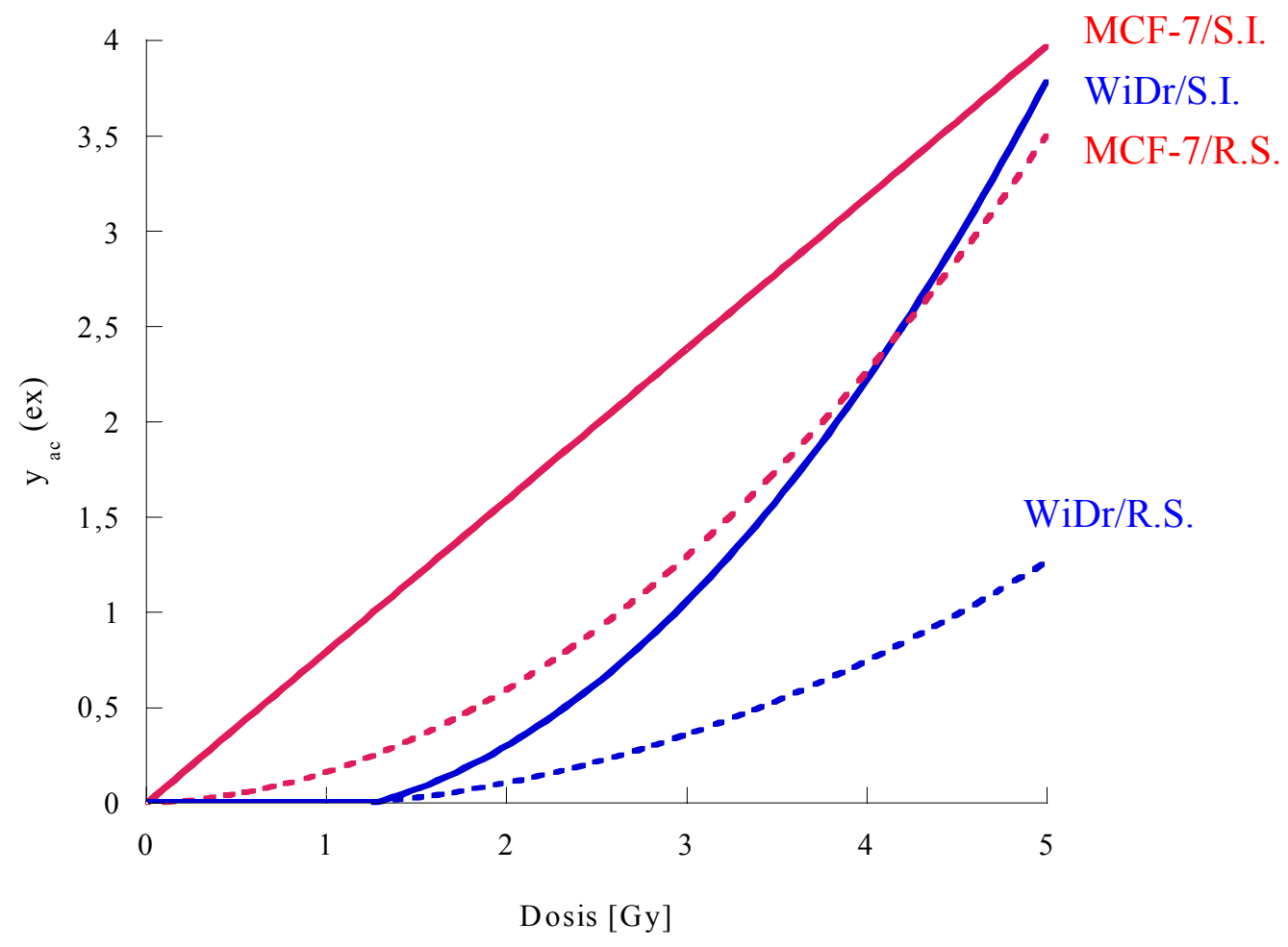

Abbildung 4.17 Vergleiche der angepassten Dosis-Effekt-Kurven für dizentrische Chromosomen (a) und extra azentrische Fragmente (b) nach 200 kVRöntgenbestrahlung (R.S.) und nach Bestrahlung mit $100 \mathrm{MeV} / \mathrm{u}$ Kohlenstoffionen (S.I.) in den beiden untersuchten Zelllinien. 
Der Vergleich beider Zelllinien zeigt, dass die unterschiedliche intrinsische Strahlensensitivität der untersuchten Zellen auch bezüglich der Aberrationsinduktion nach Bestrahlung mit Kohlenstoffionen nachzuweisen ist.

\subsubsection{Strahleninduzierte dizentrische Chromosomen und extra azentrische Fragmente in Abhängigkeit von Ionenenergie}

Die Ausbeuten an dizentrischen Chromosomen und an extra azentrischen Fragmenten in WiDr-Zellen nach Bestrahlung mit D = 4 Gy mit Kohlenstoffionen unterschiedlicher Energien im Vergleich zur Referenzstrahlung (200 kV-Röntgenstrahlung) sind in Abbildung 4.18 dargestellt. Die Zellen wurden in der ersten Mitose nach Bestrahlung ausgewertet. Als Kontrolle dienten die Spontanraten unbestrahlter Zellen der jeweiligen Zelllinie.

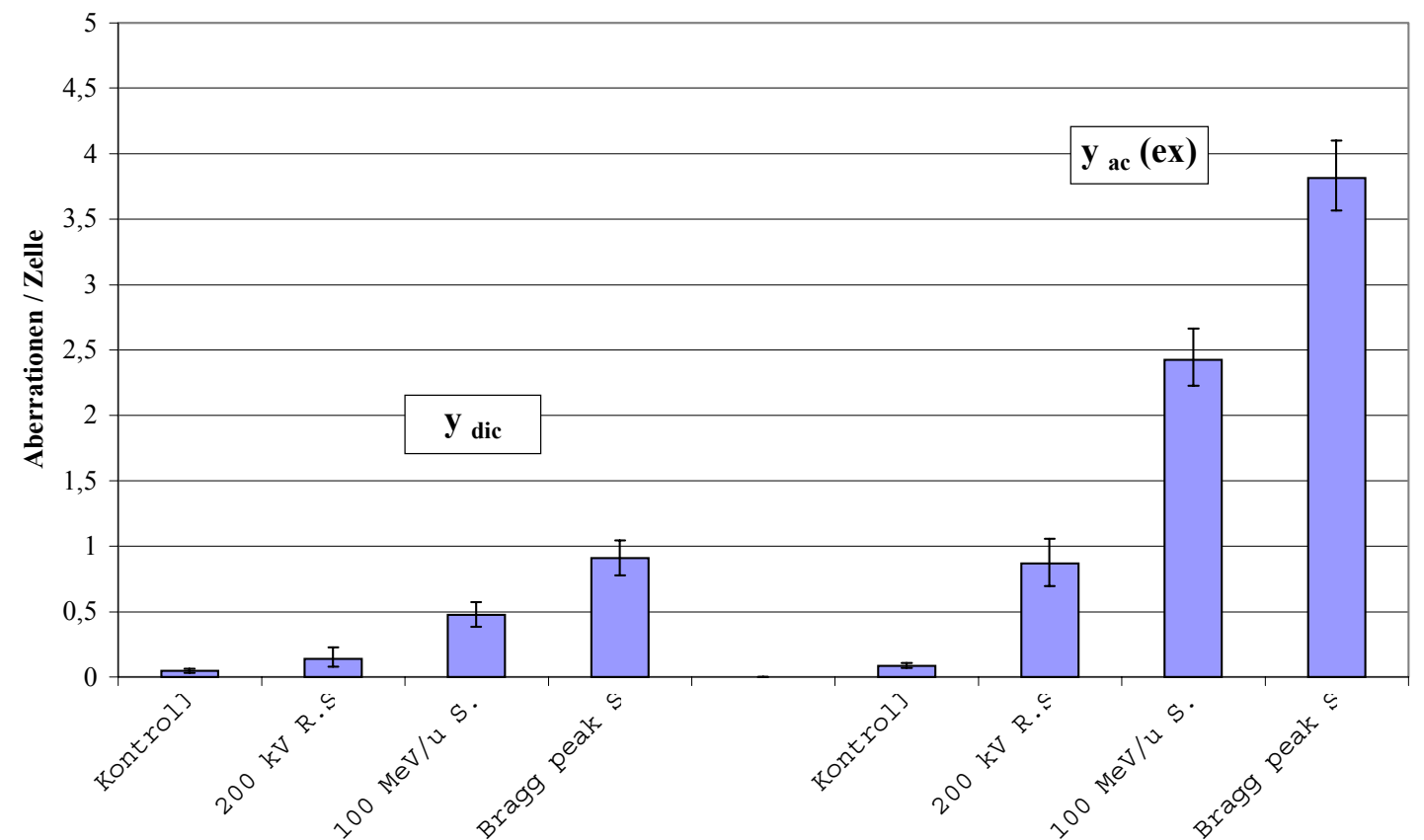

Abbildung 4.18 Genomische Häufigkeiten dizentrischer Chromosomen und extra azentrischer Fragmente in WiDr-Zellen. Tumorzellen wurden mit D = 4 Gy mit 200 kV-Röntgenstrahlung (R.S.) oder mit Kohlenstoffionen (S.I.) verschiedener Energien (100 MeV/u und im ausgedehntem Bragg Peak) bestrahlt und in der 1. Mitose nach Bestrahlung ausgewertet. Als Kontrolle dienten die Spontanraten unbestrahlter Zellen. Die Fehlerbalken repräsentieren 95 \%-Poisson-Vertrauensbereiche. 
In den resistenten WiDr-Zellen waren die Ausbeuten an dizentrischen Chromosomen und an extra azentrischen Fragmenten nach Bestrahlung mit D = 1 Gy sehr niedrig und es wurde kaum ein Einfluss der Ionenenergie beobachtet. Ein nennenswerter Anstieg der Aberrationsausbeute wurde erst nach Bestrahlung im Bragg Peak beobachtet. Die jeweiligen Aberrationsausbeuten betrugen $\mathrm{y}_{\mathrm{dic}}=0,3 \pm 0,1$ bzw. $\mathrm{y}_{\mathrm{ac}}(\mathrm{ex})=1,1 \pm 0,1$.

Nach Bestrahlung mit $\mathrm{D}=4$ Gy stieg die Aberrationsrate für dizentrische Chromosomen und für die extra azentrischen Fragmente mit der steigenden Ionenenergie bzw. mit dem steigendem LET der Strahlung an. Sie erreichte ein Maximum von $\mathrm{y}_{\mathrm{dic}}=0,9 \pm$ 0,1 bzw. $\mathrm{y}_{\mathrm{ac}}(\mathrm{ex})=3,8 \pm 0,3$ im Bragg Peak. Der Einfluss der einzelnen Ionenenergien war deutlicher ausgeprägt. Die Ausbeuten an dizentrischen Chromosomen und an extra azentrischen Fragmenten in MCF-7-Zellen nach Bestrahlung mit Dosen von 1 Gy bzw. 4 Gy mit Kohlenstoffionen unterschiedlicher Energien im Vergleich zur Referenzstrahlung (200kV-Röntgenstrahlung) sind in Abbildung 4.19 bzw. 4.20 dargestellt.

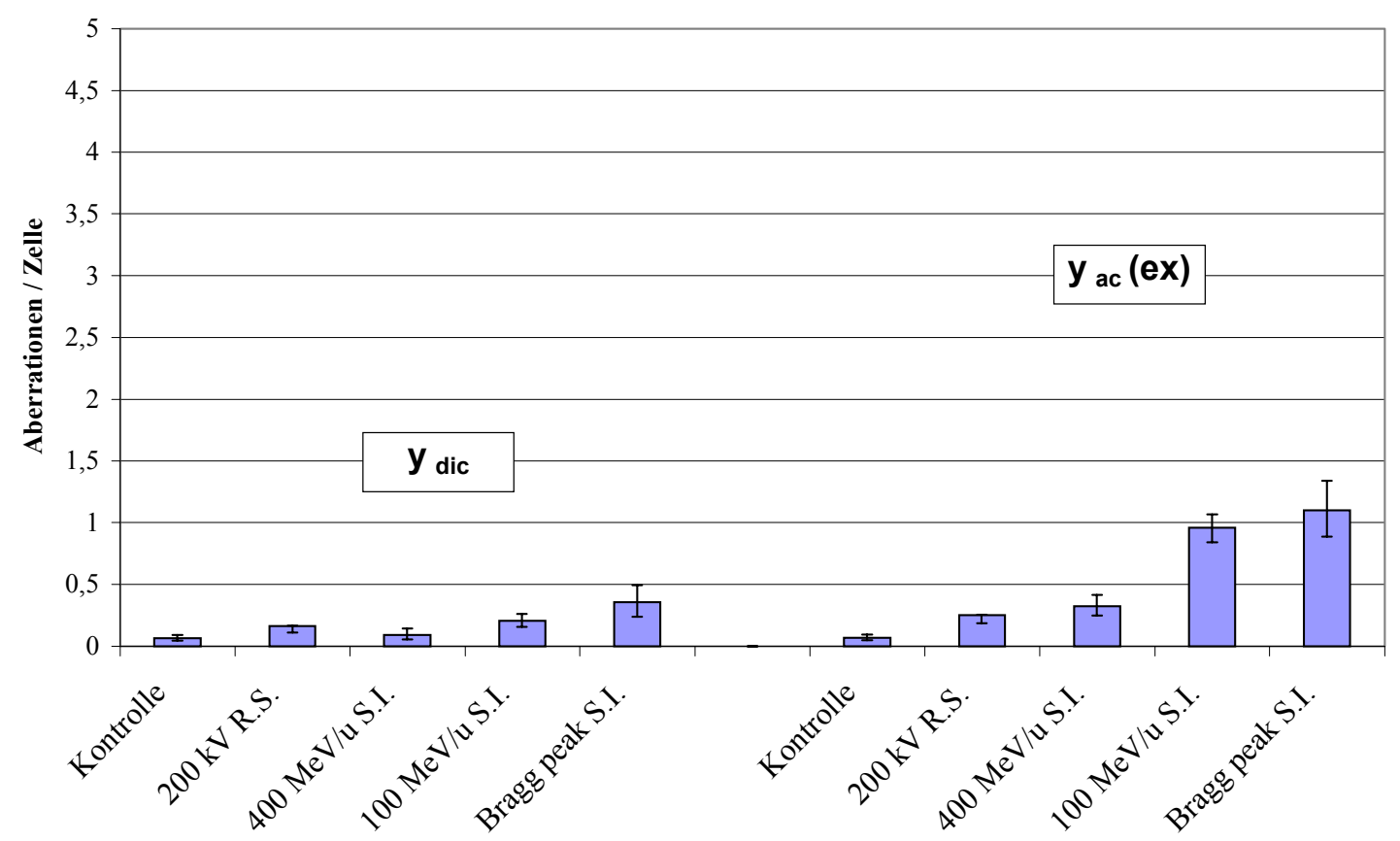

Abbildung 4.19 Genomische Häufigkeiten dizentrischer Chromosomen und extra azentrischer Fragmente in MCF-Zellen. Tumorzellen wurden mit D = 1 Gy mit 200 kV-Röntgenstrahlung (R.S.) oder mit Kohlenstoffionen (S.I.) verschiedener Energien (400 MeV/u, $100 \mathrm{MeV} / \mathrm{u}$ und im ausgedehntem Bragg Peak) bestrahlt und in der 1. Mitose nach Bestrahlung ausgewertet. Als Kontrolle dienten die 
Spontanraten unbestrahlter Zellen. Die Fehlerbalken repräsentieren $95 \%$ Poisson-Vertrauensbereiche.

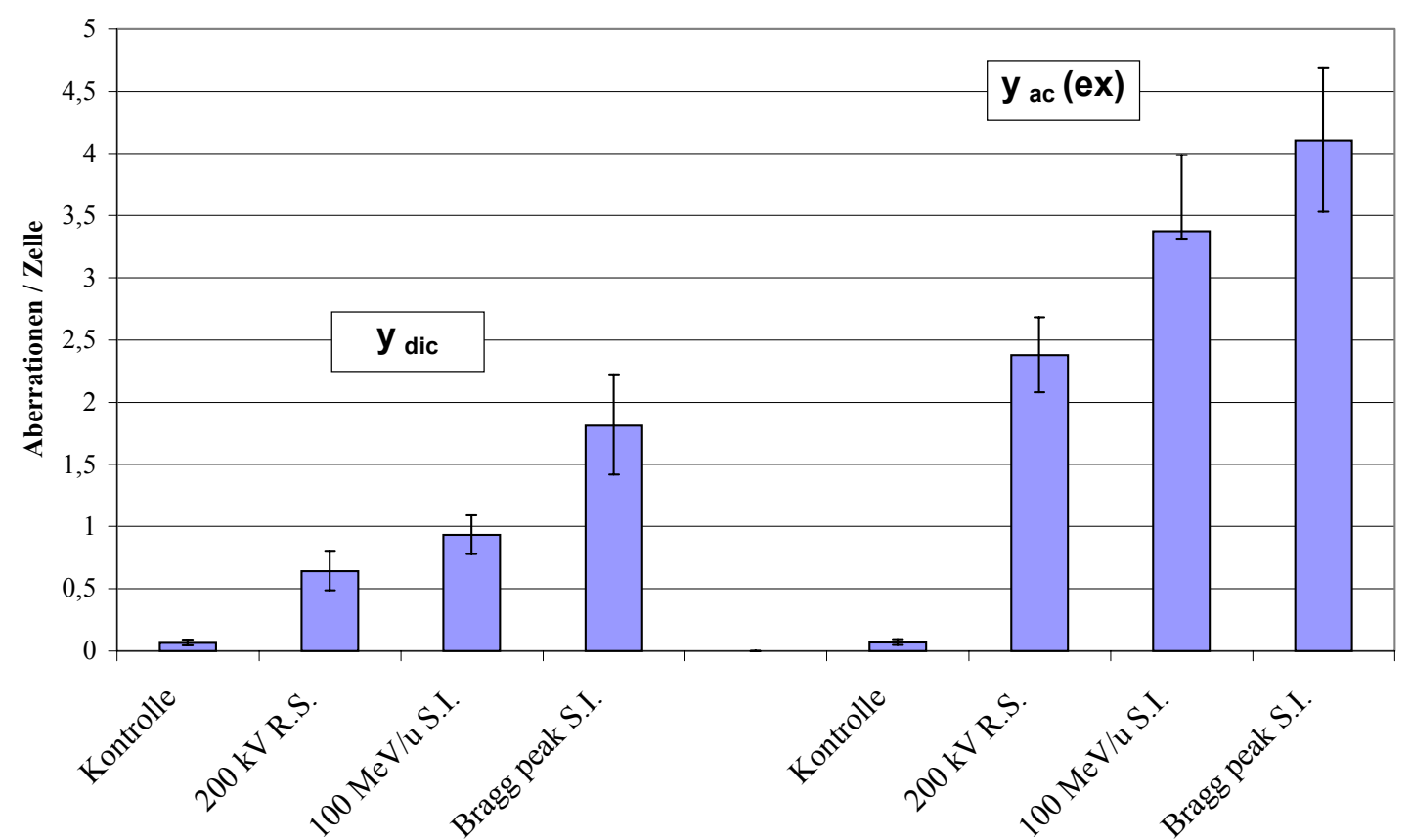

Abbildung 4.20 Genomische Häufigkeiten dizentrischer Chromosomen und extra azentrischer Fragmente in MCF-7-Zellen. Tumorzellen wurden mit D = 4 Gy mit 200 kV-Röntgenstrahlung (R.S.) oder mit Kohlenstoffionen (S.I.) verschiedener Energien (400 MeV/u, $100 \mathrm{MeV} / \mathrm{u}$ und im ausgedehntem Bragg Peak) bestrahlt und in der 1. Mitose nach Bestrahlung ausgewertet. Als Kontrolle dienten die Spontanraten unbestrahlter Zellen. Die Fehlerbalken repräsentieren $95 \%$-Poisson-Vertrauensbereiche.

Bei der strahlensensitiven MCF-7 Zelllinie waren die Ausbeuten an dizentrischen Chromosomen und an extra azentrischen Fragmenten nach Bestrahlung mit D $=1$ Gy sehr niedrig und es wurde kaum Einfluss der Ionenenergie beobachtet. Es wurden nur $\mathrm{y}_{\mathrm{dic}}=0,4 \pm 0,1$ bzw. $\mathrm{y}_{\mathrm{ac}}(\mathrm{ex})=1,1 \pm 0,2$ pro Zelle ermittelt. Erst nach Bestrahlung mit der Dosis D = 4 Gy erhöhte sich die Ausbeute an beiden Aberrationstypen signifikant, und erreichte ein Maximum von 1,8 $\pm 0,4$ an dizentrischen Chromosomen pro Zelle bzw. 4,1 $\pm 0,6$ an extra azentrischen Fragmenten pro Zelle nach Bestrahlung im 
ausgedehnten Bragg Peak. Wie schon bei den WiDr-Zellen, steigt auch bei den MCF-7Zellen die Aberrationsausbeute mit steigendem LET der Strahlung an.

\subsubsection{Charakterisierung und Auswertung ausgewählter Chromosomen in WiDr- und MCF-7-Zellen: FISH-Analyse}

Bei den genomisch instabilen Tumorzellen handelt es sich generell um heterogene Zellpopulationen. Dies wird durch die variable, nicht diploide Chromosomenanzahl pro Zelle (Aneuploidie) dokumentiert. Darüber hinaus sind die Tumorzellchromosomen auch strukturell instabil und können sehr viele spontane (klonale und nicht-klonale) Aberrationen aufweisen.

Um einfache und komplexe strahleninduzierte Aberrationen in einzelnen Fluoreszenzmarkierten Chromosomen erkennen und auswerten $\mathrm{zu}$ können, müssten einzelne Chromosomen gefunden werden, die eine relativ niedrige spontane Aberrationsrate aufweisen. Falls auch eine klonale Aberration auf einem der Chromosomen auftritt, muss diese eindeutig identifizierbar sein.

Im Rahmen dieser Arbeit wurden in den beiden Tumorzelllinien 10 größere Chromosomen (Chromosomen 1, 2, 3, 4, 5, 6, 7, 8, 9, 12) in unbestrahlten Zellen untersucht. Es wurden dann drei, für beide Zelllinien geeignete, relativ stabile Chromosomen, die über mehrere intakte Chromosomenkopien verfügten, ausgewählt. Die übrigen Kopien dieser Chromosomen hatten Aberrationen die klonalen Ursprungs waren und in der Mehrheit aller Zellen dieser Zellpopulation vorhanden waren. Darüber hinaus waren die relativen Anteile dieser Zellsubpopulation umfangreich und machten mindestens $80 \%$ der Gesamtpopulation aus. 


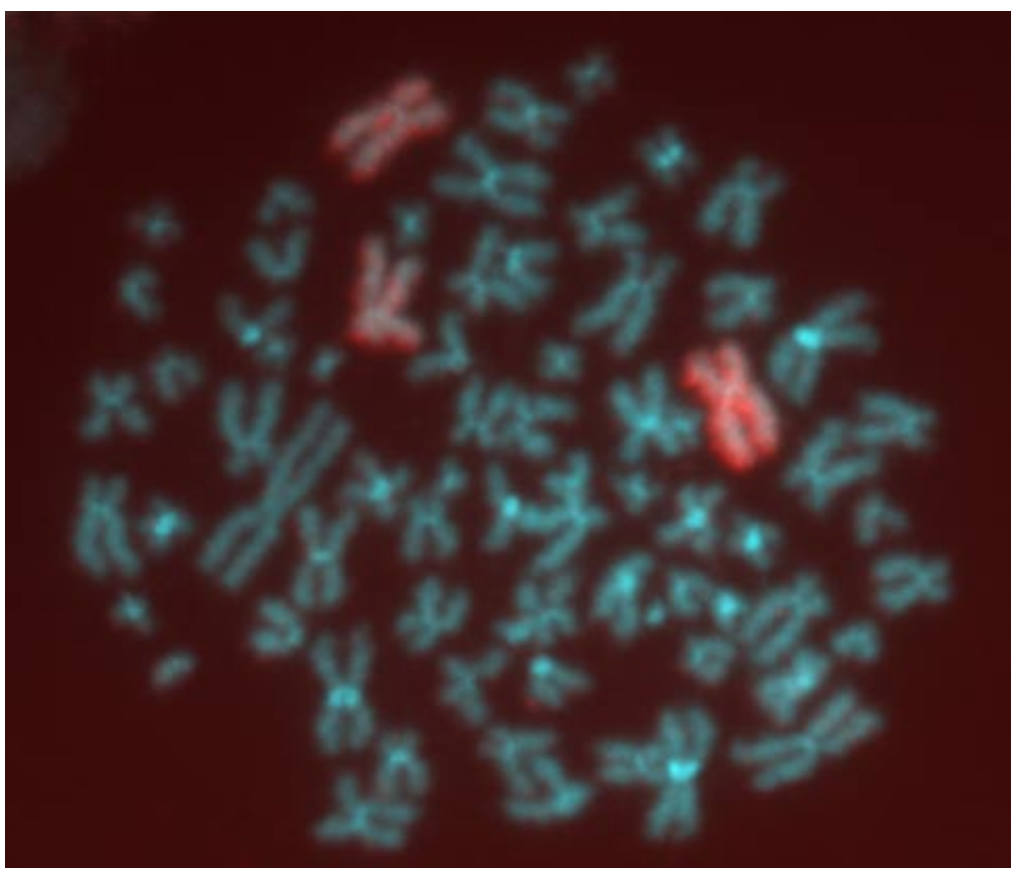

Abbildung 4.21 Originalaufnahme einer unbestrahlten WiDr-Zelle nach Anfärbung des Chromosoms \# 2. Es handelt sich um den partiellen Karyotyp: 3 intakte Chromosomen. Dieser Karyotyp kommt in 98 \% aller Zellen vor.

Nach diesen Kriterien wurden Chromosomen \# 2, \# 4 und \# 5 ausgewählt. Tabelle 4.8 zeigt die cytogenetische Charakterisierung dieser Chromosomen, ihre Ploidie, d.h. die Anzahl der Chromosomenkopien, und die relativen Anteile der Zellen.

Tabelle 4.8 Cytogenetische Charakterisierung der ausgewählten Chromosomen, ihre Ploidie und die relativen Anteile der ausgewerteten Zellpopulationen. $\left(\mathrm{N}_{\text {rel }}=\right.$ rel. Anteil der Zellen mit entsprechendem partiellen Karyotyp an der Gesamtpopulation)

\begin{tabular}{|c|c|c|l|c|c|}
\hline Zelllinie & Chr.-Nr. & $\begin{array}{c}\text { Chr.- } \\
\text { Ploidie }\end{array}$ & \multicolumn{1}{|c|}{ Partielle Karyotyp } & $\begin{array}{c}\text { Gesamt- } \\
\text { DNA-Gehalt }\end{array}$ & $\begin{array}{c}\mathbf{N}_{\text {rel }} \\
\text { [\%] }\end{array}$ \\
\hline \hline WiDr & $\# 2$ & $3 \times$ & 3 intakte Chromosomen & $395 \mathrm{Mb}$ & 98 \\
\hline WiDr & $\# 4$ & $4 \times$ & $\begin{array}{l}3 \text { intakte Chromosomen plus 1 Chromosom mit } \\
\text { einer Deletion (del 4q, del 4p) }\end{array}$ & $355 \mathrm{Mb}$ & 80 \\
\hline WiDr & $\# 5$ & $4 \times$ & $\begin{array}{l}\text { 2 intakte Chromosomen plus 1 Chromosom mit } \\
\text { einer Deletion (del 5q, del 5p) und 1 Chromosom } \\
\text { mit einer terminalen Translokation t }(5 ; ?)\end{array}$ & $354 \mathrm{Mb}$ & 97 \\
\hline MCF-7 & $\# 2$ & $3 \times$ & 3 intakte Chromosomen & $395 \mathrm{Mb}$ & 85 \\
\hline MCF-7 & $\# 4$ & $3 \times$ & $\begin{array}{l}\text { 2 intakte Chromosomen plus 1 Chromosom mit } \\
\text { einer Deletion (del 4q, del 4p) }\end{array}$ & $255 \mathrm{Mb}$ & 88 \\
\hline MCF-7 & $\# 5$ & $4 \times$ & $\begin{array}{l}\text { 2 intakte Chromosomen plus 1 Chromosom mit } \\
\text { einer Deletion (del 5q, del 5p) und 1 verkürztes } \\
\text { Chromosom als Folge einer unvollständigen } \\
\text { terminalen Translokation t(?;5) }\end{array}$ & $354 \mathrm{Mb}$ & 87 \\
\hline
\end{tabular}


Die Chromosomen \# 4 und \# 5 sind in beiden Zelllinien in gleicher Weise verändert. Das Chromosom \# 4 erscheint als ein „Minichromosom“: beide Arme des Chromosoms sind stark deletiert (del 4p; del 4q). Die strahlenresistente Zelllinie enthält vier Kopien des Chromosoms \# 4, die MCF-7 Zelllinie nur drei Kopien.

Das Chromosom \# 5 ist ebenfalls in gleicher Weise in beiden Zelllinien verändert. Beide Zelllinien enthalten zwei intakte Kopien des Chromosoms \# 5, ein Minichromosom (del 5p; del 5q) und jeweils eine Kopie, die eine klonale terminale Translokation trägt.

Der Gesamt-DNA-Gehalt der einzelnen Chromosomen ist etwa gleich groß bei beiden Zelllinien. Eine Ausnahme stellt nur das Chromosom \# 4 in der MCF-7-Zelllinie dar.

Das Chromosom verfügt nur über drei Kopien und der Gesamt-DNA-Gehalt beträgt etwa $255 \mathrm{Mb}$.

\subsubsection{Partielle Häufigkeiten strahleninduzierter reziproker Transloka- tionen in Abhängigkeit von Ionenenergie}

In allen Versuchen wurden strahleninduzierte Aberrationen nur in den hier beschriebenen Zellsubpopulationen anhand Fluoreszenz-markierter Chromosomen \# 2, \# 4 und \# 5 (Einzelfarbe-FISH) ausgewertet.

Tabelle 4.9 Spontane partielle Ausbeuten an reziproken Translokationen pro Zelle für das jeweilige Chromosom und Zelllinie in unbestrahlten Zellen.

\begin{tabular}{|c|c|c|c|}
\hline Zelllinie & Chromosom \# 2 & Chromosom \# 4 & Chromosom \# 5 \\
\hline & Transl. / Zelle & Transl. / Zelle & Transl. / Zelle \\
\hline \hline WiDr & $0,005 \pm 0,009$ & $0,004 \pm 0,005$ & 0 \\
\hline MCF-7 & 0 & 0 & $0,020 \pm 0,021$ \\
\hline
\end{tabular}

Die partiellen Ausbeuten an reziproken Translokationen nach Bestrahlung mit Kohlenstoffionen unterschiedlicher Energien im Vergleich mit $200 \mathrm{kV}$ - 
Röntgenstrahlung als Referenzstrahlung, sind in Abbildung 4.22 für D $=1$ Gy und in Abbildung 4.23 ( $\mathrm{a}$ und $\mathrm{b}$ ) für $\mathrm{D}=4$ Gy dargestellt.

Die Spontanraten der nicht-klonalen Translokationen sind in Tabelle 4.9 angegeben.

a)

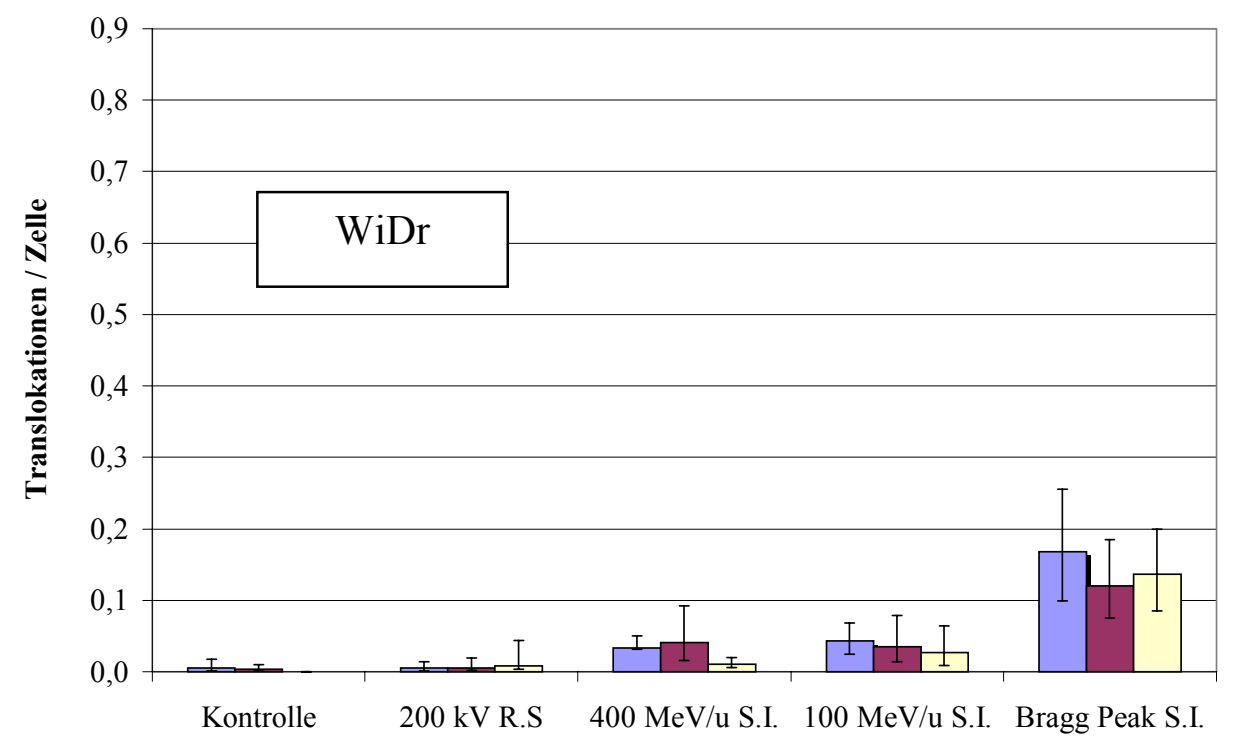

b)

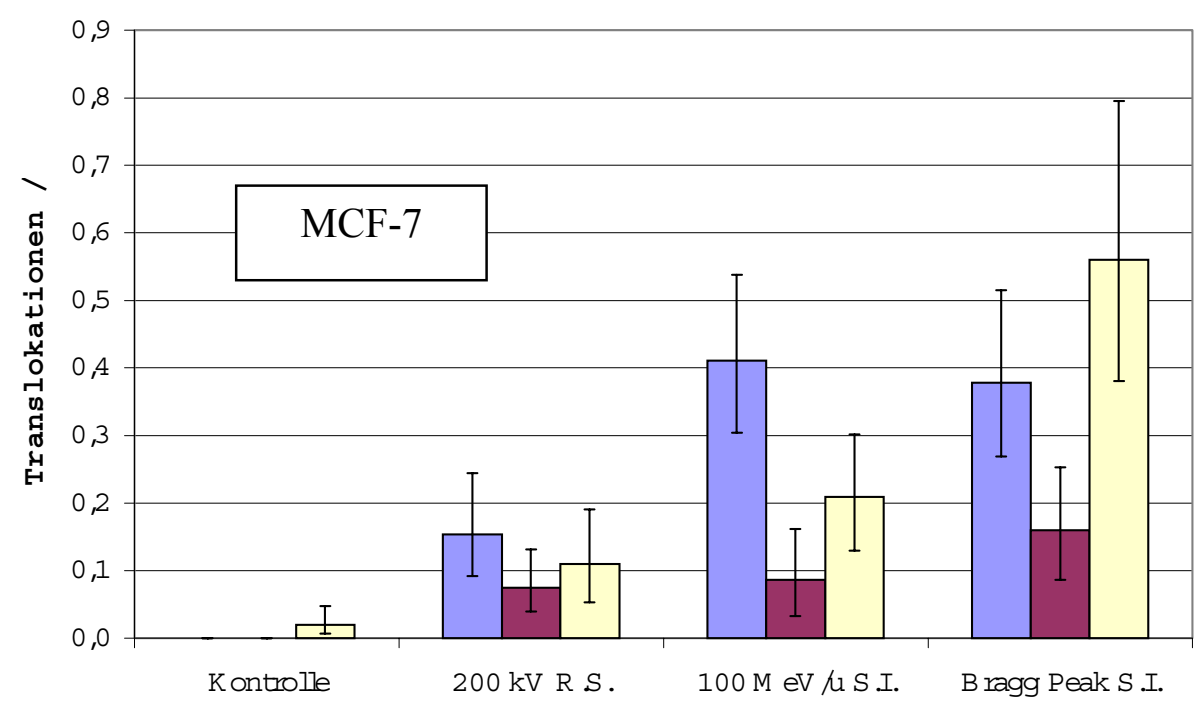

Abbildung 4.22 Partielle Aberrationsausbeuten reziproker Translokationen pro Zelle. Die Aberrationsraten wurden für Chromosom \# $2 \square$, \# $4 \square$ und \# $5 \square$ in WiDrZellen (a) und MCF-7-Zellen (b) bestimmt. Tumorzellen wurden mit einer Dosis D = 1 Gy mit 200 kV-Röntgenstrahlung (R.S.) oder mit Kohlenstoffionen (S.I.) verschiedener Energien (100 MeV/u und Bragg Peak) bestrahlt. Die Fehlerbalken repräsentieren die 95\% - Poisson-Vertrauensbereiche. 
Nach Bestrahlung mit 200 kV-Röntgenstrahlung und D = 1 Gy zeigten die resistenten WiDr-Zellen sehr niedrige Aberrationsausbeuten an reziproken Translokationen. Nach Bestrahlung mit Kohlenstoffionen wurden zwar mehr Aberrationen induziert, eine substantielle Erhöhung der Aberrationsrate wurde erst nach Bestrahlung im Bragg Peak beobachtet.

Die MCF-7-Zellen reagierten empfindlicher als WiDr-Zellen auch bezüglich der strahleninduzierten Translokationsrate. Schon nach Bestrahlung mit Röntgenstrahlung und $\mathrm{D}=1$ Gy wurden relativ hohe Ausbeuten ermittelt. Nach Bestrahlung mit Kohlenstoffionen stiegen die Ausbeuten stark an. Die Bestrahlung im Bragg Peak führte im Vergleich mit $100 \mathrm{MeV} / \mathrm{u}$ zu einem weiteren Anstieg der Translokationsrate nur bei den Chromosomen \# 4 und \# 5 .

a)

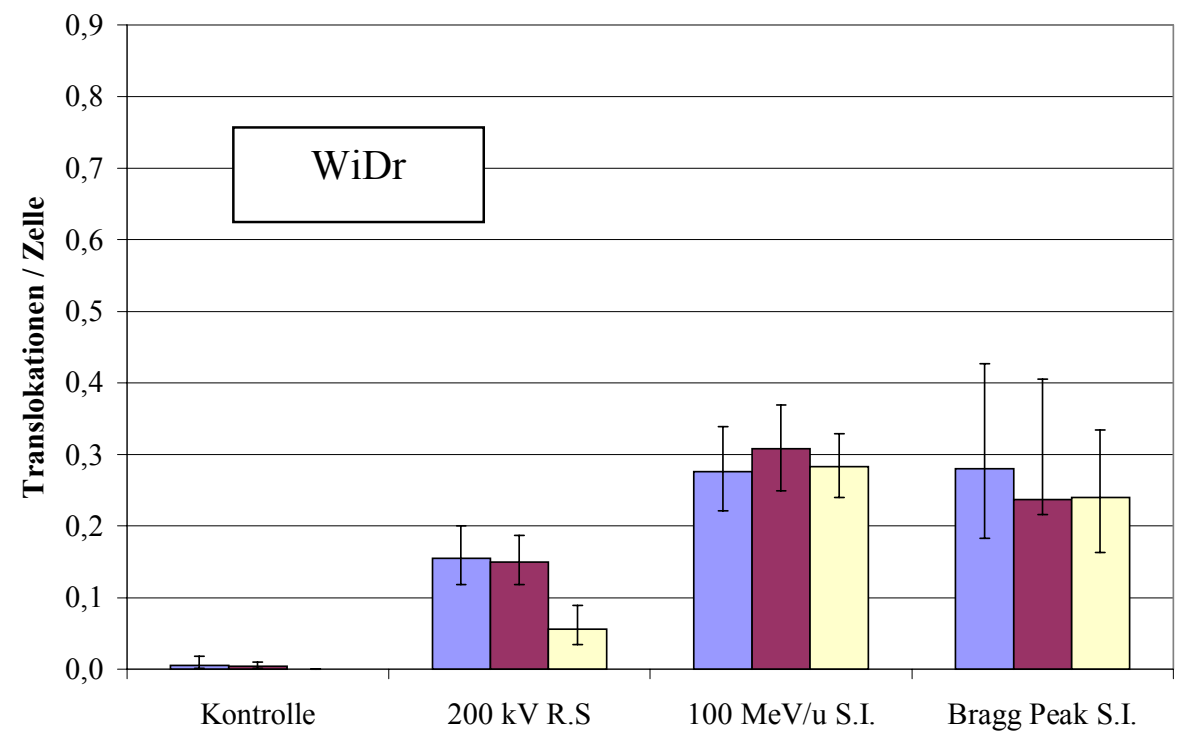

Abbildung 4.23 a Partielle Aberrationsausbeuten reziproker Translokationen pro Zelle. Die Aberrationsraten wurden für Chromosom \# $2 \square$ \# $4 \square$ und \# $5 \square$ in WiDr-Zellen (a) und MCF-7-Zellen (b) bestimmt. Tumorzellen wurden mit einer Dosis D = 4 Gy mit 200 kV-Röntgenstrahlung (R.S.) oder mit Kohlenstoffionen (S.I.) verschiedener Energien (100 MeV/u und Bragg Peak) bestrahlt. Die Fehlerbalken repräsentieren die 95\% - Poisson-Vertrauensbereiche. 


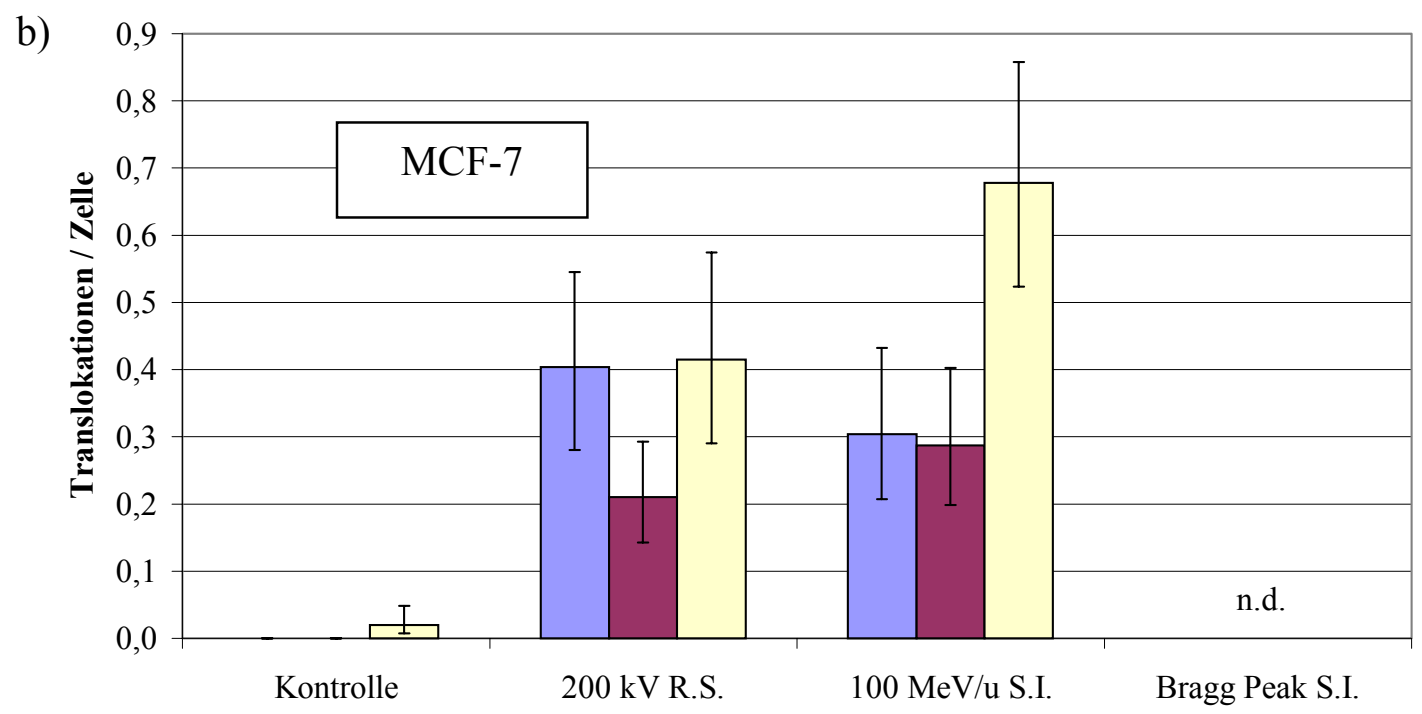

Abbildung 4.23 b Partielle Aberrationsausbeuten reziproker Translokationen pro Zelle. Die Aberrationsraten wurden für Chromosom \# $2 \square$ \# $4 \square$ und \# $5 \square$ in WiDr-Zellen (a) und MCF-7-Zellen (b) bestimmt. Tumorzellen wurden mit einer Dosis D $=4$ Gy mit 200 kV-Röntgenstrahlung (R.S.) oder mit Kohlenstoffionen (S.I.) verschiedener Energien (100 MeV/u und Bragg Peak) bestrahlt. Die Fehlerbalken repräsentieren die 95 \% - Poisson-Vertrauensbereiche.

Nach Bestrahlung mit Kohlenstoffionen und D $=4$ Gy wurden wieder mehr Translokationen als mit $200 \mathrm{kV}$-Röntgenstrahlung in den WiDr-Zellen induziert, es wurde jedoch kein Unterschied mehr zwischen $100 \mathrm{MeV} / \mathrm{u}$ und Bragg Peak beobachtet. Dieser Effekt ist darauf zurückzuführen, dass vermehrt komplexe Aberrationen induziert werden, die eine weitere Zunahme der Translokationsrate verhindern, da sie mit diesen Aberrationen um die Primärläsionen konkurrieren.

In MCF-7-Zellen konnte aufgrund ihrer hohen Strahlensensitivität die Translokationsrate nach Bestrahlung im Bragg Peak nicht ausgewertet werden. Nach Bestrahlung mit $100 \mathrm{MeV} / \mathrm{u}$ Kohlenstoffionen wurden insgesamt mehr Translokationen als bei $200 \mathrm{kV}$-Röntgenstrahlung beobachtet, der Anstieg war jedoch relativ klein, da wiederum vermehrt komplexe Aberrationen induziert wurden, die mit den Translokationen um die DNA-Läsionen konkurrieren. 
Vergleicht man die beiden Zelllinien, so kann man sehen, dass die WiDr-Zelllinie im Bezug auf die reziproken Translokationen strahlenresistenter als die MCF-7 Zelllinie ist. In beiden Zelllinien sind die Translokationsausbeuten annähernd proportional den jeweiligen Gesamt-DNA-Gehalten der jeweiligen Chromosomen.

\subsubsection{Strahleninduzierte komplexe Aberrationen in Abhängigkeit von Ionenenergie}

Komplexe Aberrationen sind Austauschereignisse an denen $\geq 3$ Brüche in $\geq 2$ Chromosomen beteiligt sind. Die komplexen Aberrationen wurden in einer gemeinsamen Klasse als TVC (total visible complexes) zusammengefasst. Abbildung 4.24 zeigt ein Beispiel.

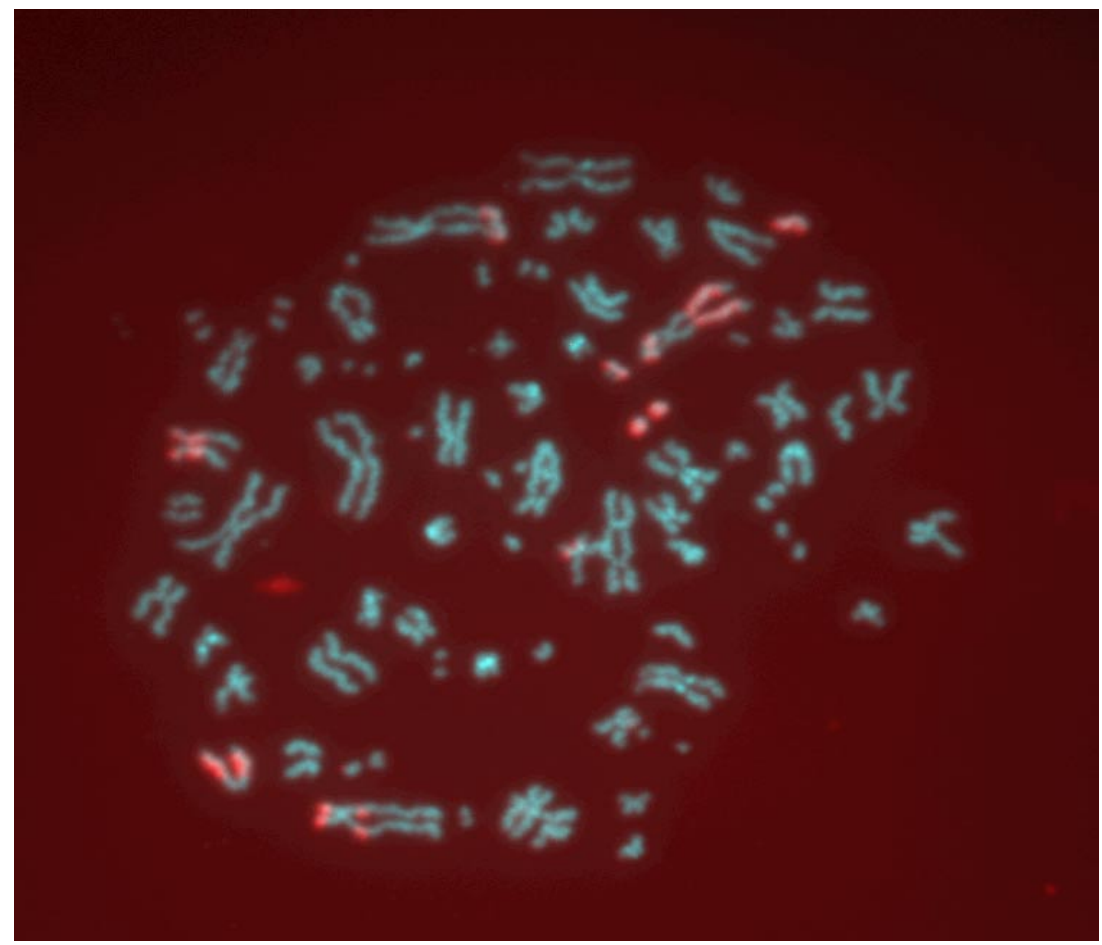

Abbildung 4.24 Originalaufnahme einer WiDr-Metaphase nach Bestrahlung im Bragg Peak mit $\mathrm{D}=1 \mathrm{~Gy}$. Die vier Chromosomen \# 5 sind rot gefärbt. Drei Chromosomen \# 5 sind an komplexen Austauschaberrationen beteiligt. Die restlichen Chromosomen (blau) sind mit DAPI gegengefärbt. 


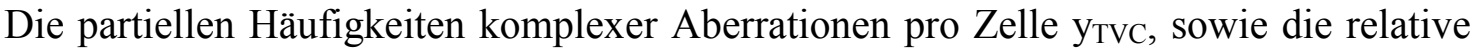
Anzahl von Zellen mit einer oder mit mehreren komplexen Aberrationen $\mathrm{N}$ (TVC $\geq 1$ )/N wurden für die Chromosomen \# 2, \# 4, und \# 5 bestimmt (Kapitel 3.2.8.3). $\mathrm{N}$ bezeichnet die Anzahl der ausgewerteten Zellen.
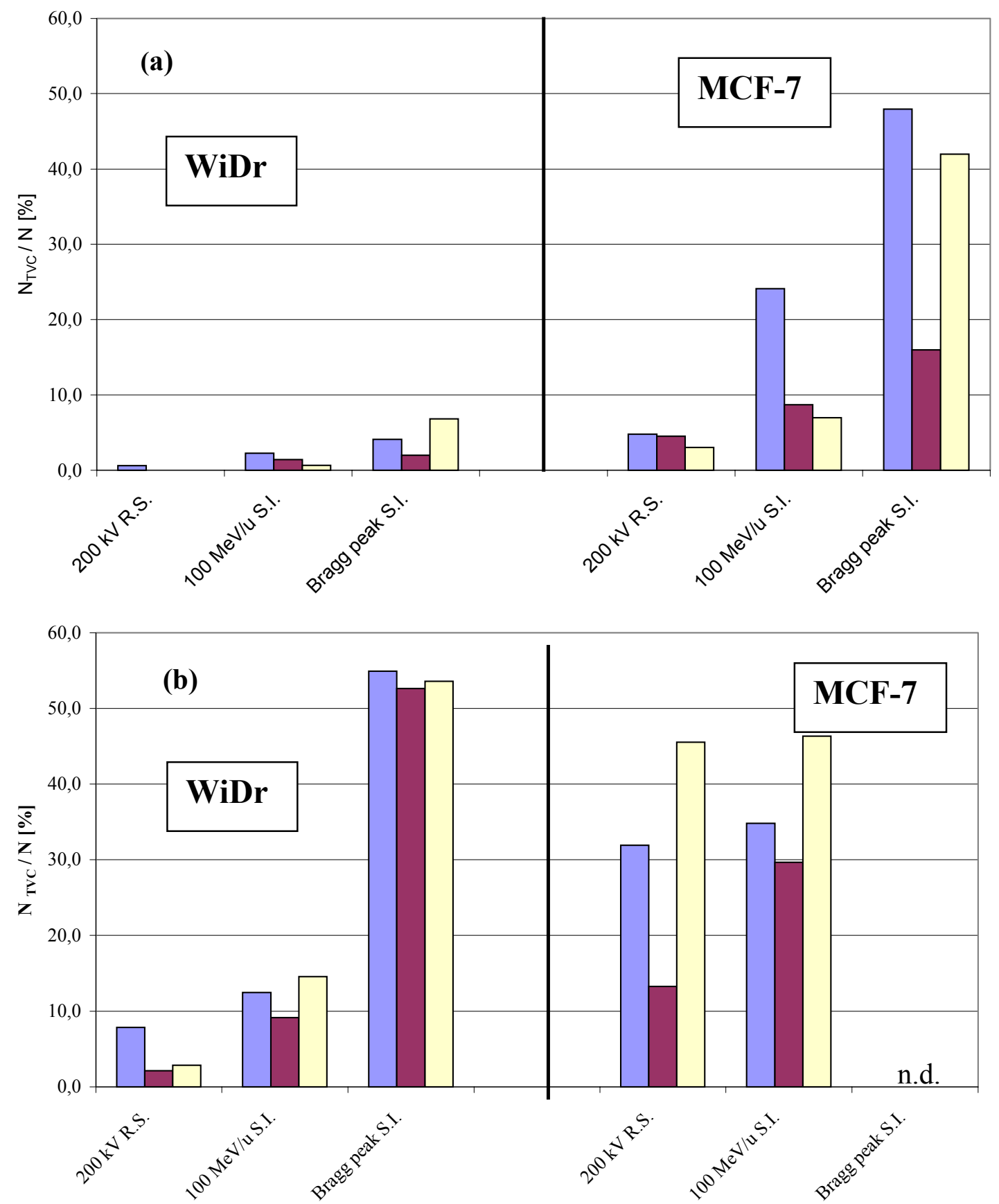

Abbildung 4.25 Die relativen Anteile an Zellen mit komplexen Aberrationen wurden für Chromosom \# $2 \square$, \# $4 \square$ und \# $5 \square$ in WiDr- und in MCF-7-Zellen bestimmt. Tumorzellen wurden mit Dosen von 1 Gy (a) und 4 Gy (b) mit 200 
kV-Röntgenstrahlung (R.S.) oder mit schweren Kohlenstoffionen (S.I.) verschiedener Energien (100 MeV/u und Bragg Peak) bestrahlt.

Die relativen Anteile der Zellen mit komplexen Aberrationen $N(T V C \geq 1) / N$ für die Chromosomen \# 2, \# 4 und \# 5 sind in Abbildung 4.24 für WiDr-Zellen und MCF-7Zellen dargestellt.

Bei der strahlenresistenten WiDr-Zelllinie ist die Anzahl der Zellen mit TVC nach Bestrahlung mit der $\mathrm{D}=1$ Gy sehr gering. Die Häufigkeit liegt unter 6\%. Erst nach Bestrahlung mit 4 Gy im Bragg Peak steigt die Häufigkeit sehr stark an, auf über 50\%. Die einzelnen untersuchten Chromosomen waren an komplexen Austauschaberrationen nach Bestrahlung mit Kohlenstoffionen etwa gleich häufig beteiligt.

Die große Strahlensensitivität der MCF-7-Zelllinie ist auch bezüglich der Induktion von komplexen Aberrationen schon nach Bestrahlung mit $\mathrm{D}=1$ Gy offensichtlich. Nach Bestrahlung im Bragg Peak weisen über 40\% der Zellen komplexe Aberrationen auf, ein Anteil der bei WiDr-Zellen erst bei einer Dosis D = 4 Gy beobachtet wurde.

Nach Bestrahlung mit $\mathrm{D}=4$ Gy ist ein Anstieg im Vergleich mit D $=1$ Gy zu beobachten, aber kaum ein Unterschied zwischen Kohlenstoffionen und 200 kVRöntgenstrahlung.

Die genaue Anzahl komplexer Aberration pro Zelle wurde hier nicht berücksichtigt. Wie Abbildung 4.23 zeigt, können mehrere komplexe Aberrationen pro Zelle entstehen. Die partiellen Häufigkeiten komplexer Aberrationen pro Zelle (УтVC) für die Chromosomen \# 2, \# 4 und \# 5 sind in Abbildung 4.25 für WiDr-Zellen und in für MCF-7-Zellen dargestellt.

Die Originaldaten sind in Tabelle 4.7 für WiDr-Zellen und MCF-7-Zellen aufgelistet. 
Tabelle 4.7 Zusammenstellung partiellen Häufigkeiten komplexer Aberrationen pro Zelle ( $\left.\mathrm{y}_{\mathrm{TVC}}\right)$ und der Anzahlen der Zellen mit komplexen Aberrationen (N (TVC $\left.\geq 1\right)$ ) für WiDr- und MCF-7-Zellen nach Bestrahlung mit $200 \mathrm{kV}$-Röntgenstrahlung oder nach Bestrahlung mit schweren Kohlenstoffionen verschiedener Energien. Die Tumorzellen wurden mit den Dosen $\mathrm{D}=1$ Gy und $\mathrm{D}=4$ Gy bestrahlt.

\begin{tabular}{|c|c|c|c|c|c|c|c|c|c|}
\hline \multicolumn{10}{|c|}{ Chromosom \# 4} \\
\hline $1 \mathrm{~Gy}$ & $\mathbf{N}$ & TVC & $y(T V C)$ & $\mathbf{N}$ & TVC & $y(T V C)$ & $\mathbf{N}$ & TVC & $y(T V C)$ \\
\hline 200 kV R.S. & 624 & 4 & 0,01 & 738 & 0 & 0,00 & 120 & 0 & 0,00 \\
\hline $400 \mathrm{MeV} / \mathrm{u}$ S.I. & 634 & 0 & 0,00 & 121 & 0 & 0,00 & 964 & 2 & 0,00 \\
\hline $100 \mathrm{MeV} / \mathrm{u}$ S.I. & 441 & 10 & 0,02 & 142 & 2 & 0,01 & 150 & 1 & 0,01 \\
\hline Bragg peak S.I. & 171 & 9 & 0,05 & 150 & 4 & 0,03 & 161 & 19 & 0,12 \\
\hline \multicolumn{10}{|l|}{$4 \mathrm{~Gy}$} \\
\hline 200 kV R.S. & 406 & 40 & 0,10 & 467 & 18 & 0,04 & 284 & 12 & 0,04 \\
\hline $100 \mathrm{MeV} / \mathrm{u}$ S.I. & 330 & 53 & 0,16 & 328 & 44 & 0,13 & 544 & 95 & 0,17 \\
\hline Bragg peak S.I. & 82 & 75 & 0,91 & 38 & 30 & 0,79 & 125 & 134 & 1,07 \\
\hline
\end{tabular}

\begin{tabular}{|c|c|c|c|c|c|c|c|c|c|}
\hline & \multicolumn{3}{|c|}{ Chromosom \# 2} & \multicolumn{3}{|c|}{ Chromosom \# 4} & \multicolumn{3}{|c|}{ Chromosom \# 5} \\
\hline $1 \mathrm{~Gy}$ & $\mathbf{N}$ & N (TVC) & $\%$ & $\mathbf{N}$ & N (TVC) & $\%$ & $\mathbf{N}$ & N (TVC) & $\%$ \\
\hline 200 kV R.S. & 624 & 4 & 0,6 & 738 & 0 & 0,0 & 120 & 0 & 0,0 \\
\hline $400 \mathrm{MeV} / \mathrm{u}$ S.I. & 634 & 0 & 0,0 & 121 & 0 & 0,0 & 964 & 2 & 0,2 \\
\hline $100 \mathrm{MeV} / \mathrm{u}$ S.I. & 441 & 10 & 2,3 & 142 & 2 & 1,4 & 150 & 1 & 0,7 \\
\hline Bragg peak S.I. & 171 & 7 & 4,1 & 150 & 3 & 2,0 & 161 & 11 & 6,8 \\
\hline $4 \mathrm{~Gy}$ & & & & & & & & & \\
\hline 200 kV R.S. & 406 & 32 & 7,9 & 467 & 10 & 2,1 & 284 & 8 & 2,8 \\
\hline $100 \mathrm{MeV} / \mathrm{u}$ S.I. & 330 & 41 & 12,4 & 328 & 30 & 9,1 & 544 & 79 & 14,5 \\
\hline Bragg peak S.I. & 82 & 45 & 54,9 & 38 & 20 & 52,6 & 125 & 67 & 53,6 \\
\hline
\end{tabular}

MCF-7

\begin{tabular}{|c|c|c|c|c|c|c|c|c|c|}
\hline & \multicolumn{3}{|c|}{ Chromosom \# 2} & \multicolumn{3}{|c|}{ Chromosom \# 4} & \multicolumn{3}{|c|}{ Chromosom \# 5} \\
\hline $1 \mathrm{~Gy}$ & $\mathbf{N}$ & TVC & $y(T V C)$ & $\mathbf{N}$ & TVC & $y(T V C)$ & $\mathbf{N}$ & TVC & $y$ (TVC) \\
\hline 200 kV R.S. & 104 & 7 & 0,07 & 133 & 6 & 0,05 & 100 & 3 & 0,03 \\
\hline $100 \mathrm{MeV} / \mathrm{u}$ S.I. & 112 & 36 & 0,32 & 92 & 10 & 0,11 & 115 & 38 & 0,33 \\
\hline Bragg peak S.I. & 98 & 58 & 0,59 & 94 & 21 & 0,22 & 50 & 31 & 0,62 \\
\hline $4 \mathrm{~Gy}$ & & & & & & & & & \\
\hline 200 kV R.S. & 94 & 54 & 0,57 & 143 & 19 & 0,13 & 90 & 54 & 0,60 \\
\hline $100 \mathrm{MeV} / \mathrm{u}$ S.I. & 92 & 44 & 0,48 & 108 & 42 & 0,39 & 82 & 76 & 0,93 \\
\hline
\end{tabular}

\begin{tabular}{|c|c|c|c|c|c|c|c|c|c|}
\hline & \multicolumn{3}{|c|}{ Chromosom \# 2} & \multicolumn{3}{|c|}{ Chromosom \# 4} & \multicolumn{3}{|c|}{ Chromosom \# 5} \\
\hline $1 \mathrm{~Gy}$ & $\mathbf{N}$ & N (TVC) & $\%$ & $\mathbf{N}$ & \begin{tabular}{l|}
$\mathbf{N}$ (TVC) \\
\end{tabular} & $\%$ & $\mathbf{N}$ & $\begin{array}{l}\mathbf{N} \text { (TVC) } \\
\end{array}$ & $\%$ \\
\hline 200 kV R.S. & 104 & 5 & 4,8 & 133 & 6 & 4,5 & 100 & 3 & 3,0 \\
\hline $100 \mathrm{MeV} / \mathrm{u}$ S.I. & 112 & 27 & 24,1 & 92 & 8 & 8,7 & 115 & 8 & 7,0 \\
\hline Bragg peak S.I. & 98 & 47 & 48,0 & 94 & 15 & 16,0 & 50 & 21 & 42,0 \\
\hline \begin{tabular}{|l|}
$4 \mathbf{G y}$ \\
\end{tabular} & & & & & & & & & \\
\hline 200 kV R.S. & 94 & 30 & 31,9 & 143 & 19 & 13,3 & 90 & 41 & 45,6 \\
\hline $100 \mathrm{MeV} / \mathrm{u}$ S.I. & 92 & 32 & 34,8 & 108 & 32 & 29,6 & 82 & 38 & 46,3 \\
\hline
\end{tabular}

TVC $=\quad$ (total visible complexes), Gesamtanzahl der komplexen Aberrationen $\mathrm{N} \quad=\quad$ Anzahl der ausgewerteten Zellen

$\mathrm{N}(\mathrm{TVC} \geq 1)=\quad$ Anzahl der Zellen mit einer oder mehreren komplexen Aberrationen.

$\mathrm{y}_{\mathrm{TVC}} \quad=\quad$ Anzahl der komplexen Aberrationen pro Zelle 

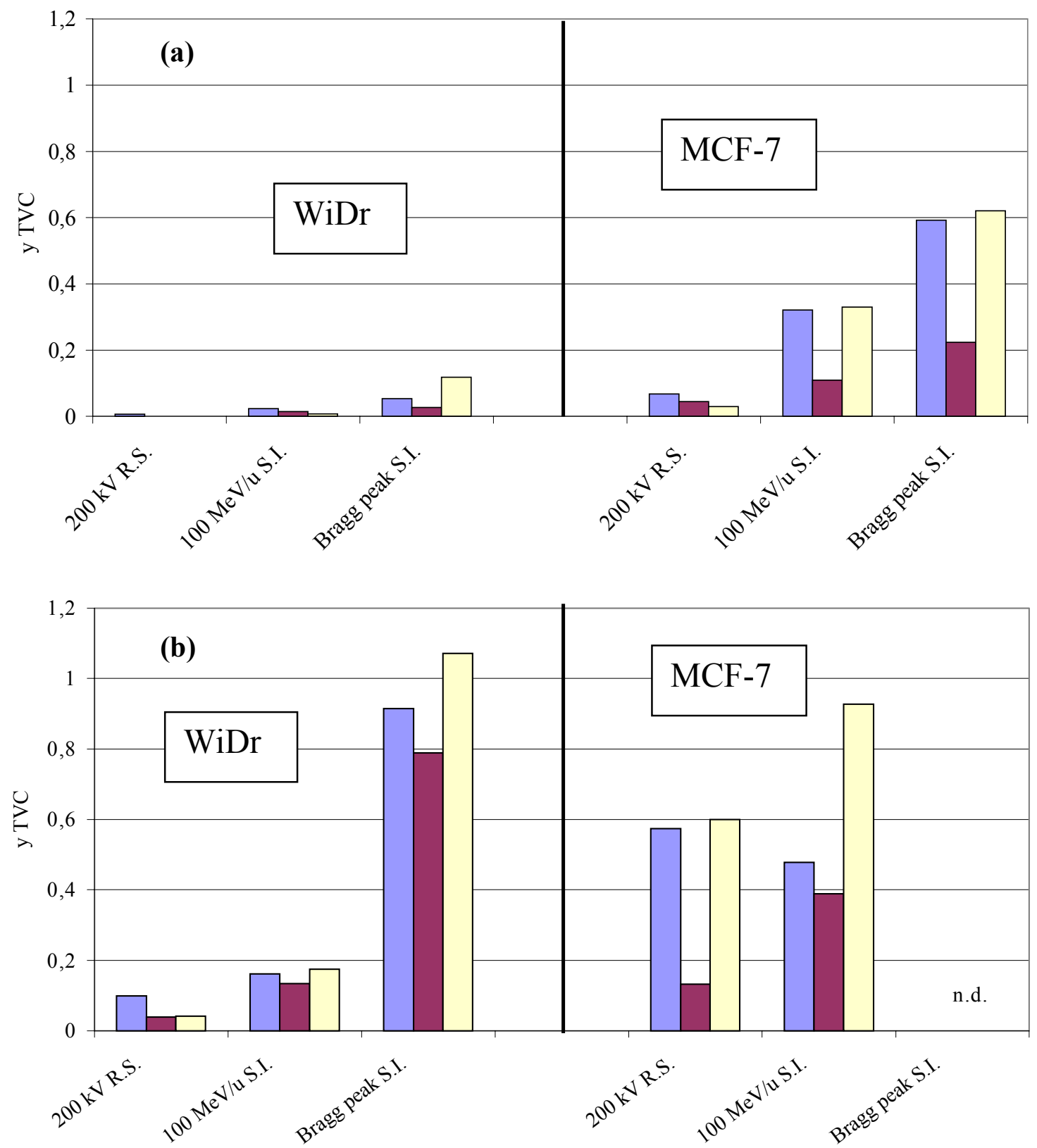

Abbildung 4.26 Die partiellen Häufigkeiten komplexer Aberrationen pro Zelle y TVC wurden für Chromosom \# 2 $\square$, \# $4 \square$ und \# $5 \square$ in WiDr-Zellen und in MCF-7Zellen bestimmt. Tumorzellen wurden mit $\mathrm{D}=1$ Gy (a) und $\mathrm{D}=4$ Gy (b) mit 200 kV-Röntgenstrahlung (R.S.) oder mit schweren Kohlenstoffionen (S.I.) verschiedener Energien (100 MeV/u und Bragg Peak) bestrahlt. 
Wird die Anzahl komplexer Aberrationen pro Zelle betrachtet, so zeigt sich ein ähnlicher Verlauf wie bei der Anzahl von Zellen mit komplexen Aberrationen.

In den strahlenresistenten WiDr-Zellen wurden nach Bestrahlung mit D = 1 Gy sowohl mit 200 kV-Röntgenstrahlung als auch mit schweren Kohlenstoffionen nur sehr wenige komplexe Aberrationen beobachtet. Erst nach einer Erhöhung der Dosis auf D = 4 Gy werden Komplexe häufiger induziert. Die Aberrationsausbeute steigt mit steigendem LET und ist praktisch gleich hoch für alle drei untersuchten Chromosomen. Nach Bestrahlung mit schweren Kohlenstoffionen und D = 4 Gy im Bragg Peak wird eine sehr hohe Häufigkeit an Komplexen, fast 1 Komplex pro Zelle, beobachtet.

In den MCF-7-Zellen wurden nach Bestrahlung mit D = 1 Gy bzw. 4 Gy wesentlich mehr komplexe Aberrationen als in WiDr-Zellen induziert. Der Unterschied zwischen $\mathrm{D}=1 \mathrm{~Gy}$ und $\mathrm{D}=4$ Gy ist aber nicht so ausgeprägt wie bei den WiDr-Zellen.

\subsubsection{Gesamt-Aberrationen: „TA“6}

Alle mit Einzelfarbe-FISH detektierbaren Aberrationen, d.h. Translokationen, dizentrische Chromosomen, extra azentrische Fragmente, Deletionen, zentrische Ringe und komplexe Austauschaberrationen, wurden schließlich als Gesamt-Aberrationen TA (total aberrations) für die einzelnen Chromosomen \# 2, \# 4 und \# 5 zusammengefasst.

Die partiellen Häufigkeiten der TA, die jeweils unter Beteiligung der Chromosomen 2, 4 und 5 entstanden sind, sind in Abbildung 4.27 für WiDr-Zellen und für MCF-7Zellen nach Bestrahlung mit D = 1 Gy (a) und mit D = 4 Gy (b) dargestellt. 

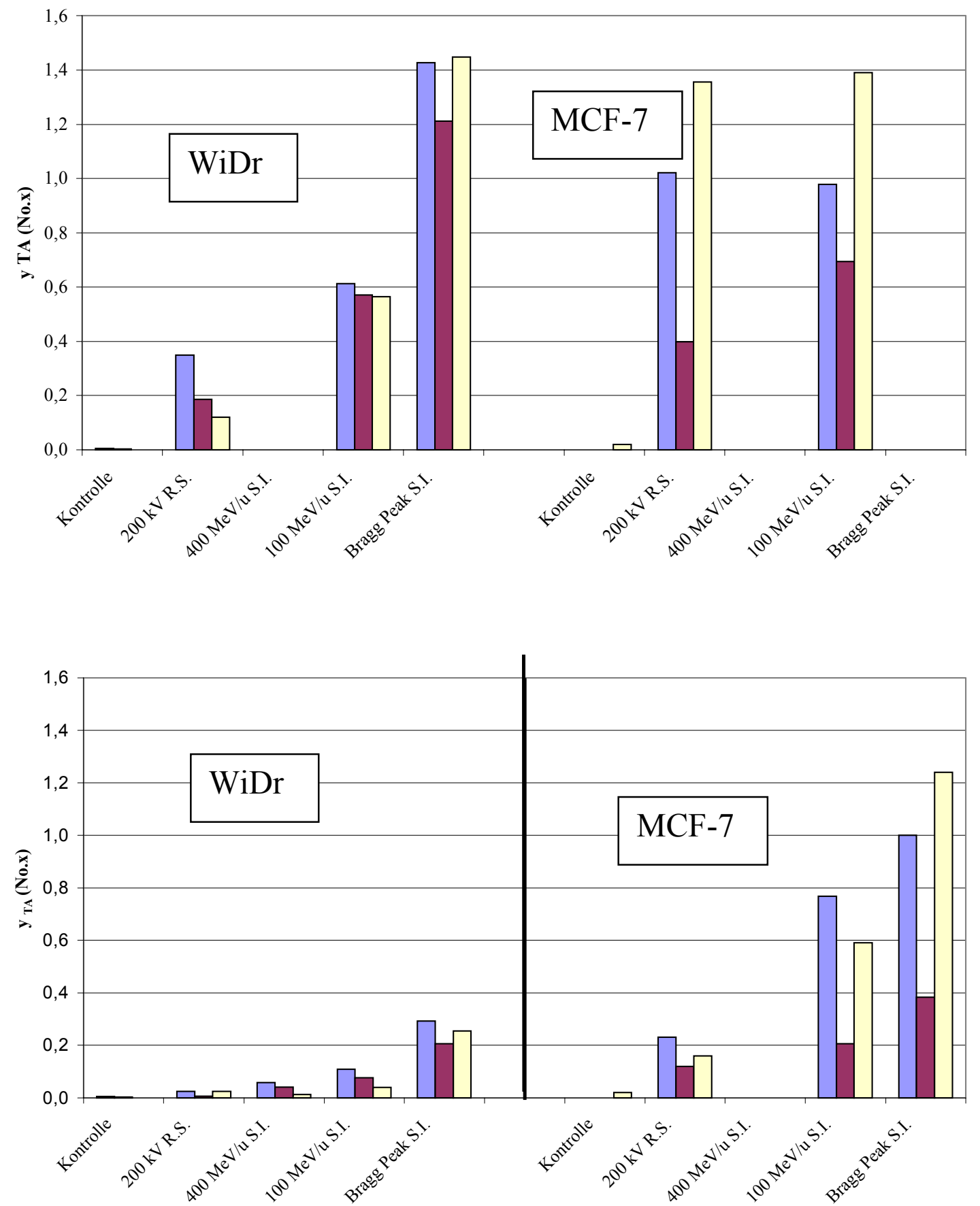

Abbildung 4.27 Die partiellen Häufigkeiten an Gesamt-Aberrationen pro Zelle, УTA wurden für Chromosom \# 2 , \# 4 und \# 5 in WiDr-Zellen und in MCF-7Zellen bestimmt. Tumorzellen wurden mit Dosen von D $=1$ Gy (a) und D $=4$ Gy (b) mit $200 \mathrm{kV}$-Röntgenstrahlung (R.S.) oder mit Kohlenstoffionen (S.I.) verschiedener Energien (400 MeV/u, $100 \mathrm{MeV} / \mathrm{u}$ und Bragg Peak) bestrahlt. (n.d. = nicht bestimmt) 
In der WiDr-Zelllinie wurden nach Bestrahlung mit $\mathrm{D}=1$ Gy niedrige Aberrationsraten beobachtet, die erst nach Bestrahlung im Bragg Peak einen größeren Anstieg zeigte.

Nach Bestrahlung mit 200 kV-Röntgenstrahlung ( $\mathrm{D}=1$ Gy) wurden in der MCF-7Zellen im Vergleich mit WiDr-Zellen viel höhere Aberrationsraten induziert. Die partiellen Häufigkeiten $\mathrm{y}_{\mathrm{TA}}$, nehmen bei dieser Dosis mit steigendem LET zu. Nach Bestrahlung mit $\mathrm{D}=4$ Gy ist zwar eine höhere Aberrationsrate als bei $\mathrm{D}=1 \mathrm{~Gy} z \mathrm{zu}$ beobachten, es ist jedoch kaum ein Unterschied zwischen $200 \mathrm{kV}$-Röntgenstrahlung und $100 \mathrm{MeV} / \mathrm{u}$ Kohlenstoffionen feststellbar.

Nimmt man das stabile Chromosom \# 2 als Maßstab, so können unter der sehr vereinfachten Annahme, dass die Aberrationsausbeuten proportional dem DNA-Gehalt des jeweiligen Chromosoms sind, die zu erwartenden Ausbeuten für das Chromosom \# 5 und \# 4 berechnet werden. Die berechneten und beobachteten Ausbeuten sind in Abbildung 4.28 für WiDr-Zellen (a) und für MCF-7-Zellen (b) graphisch dargestellt.

a)

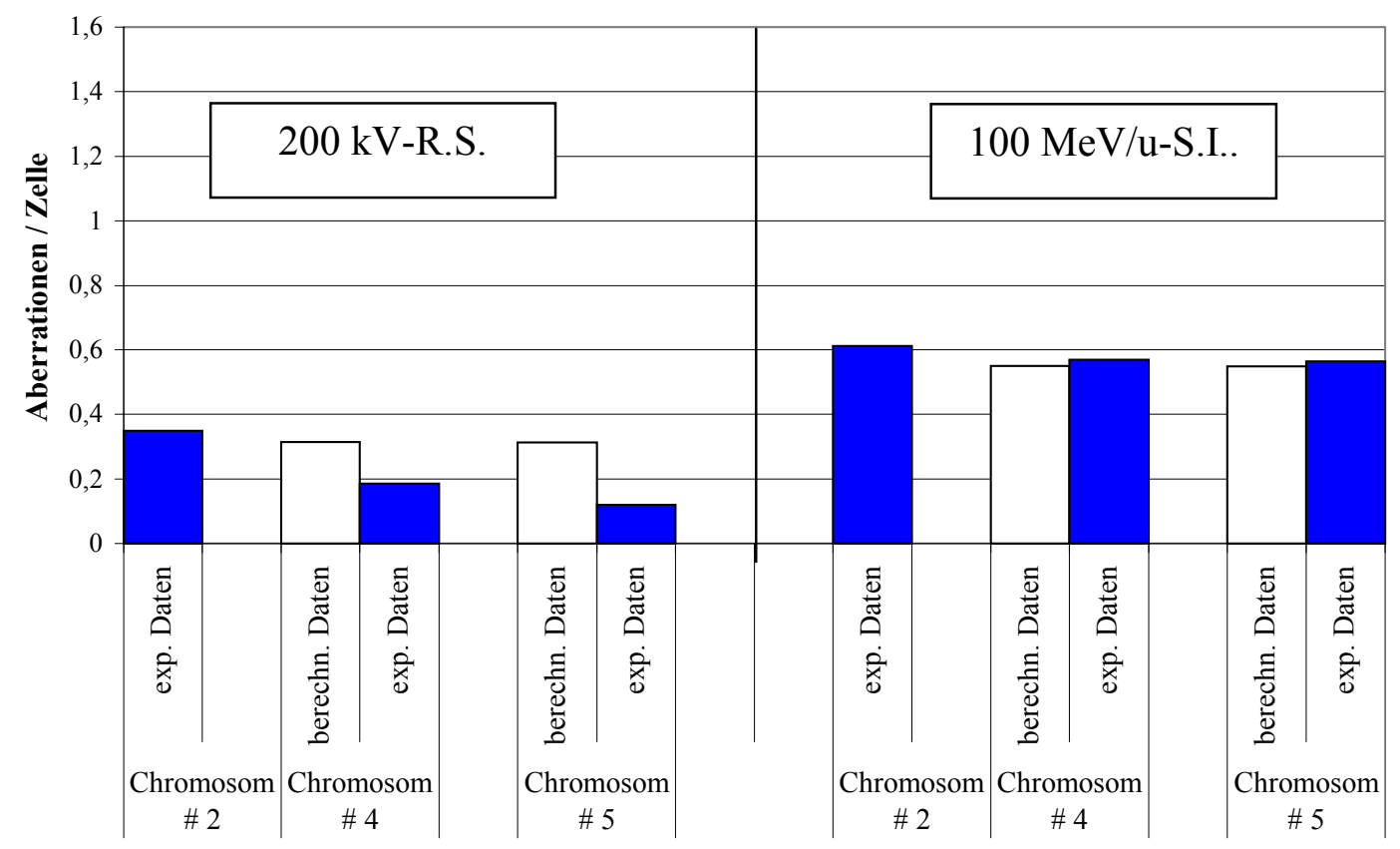


b)

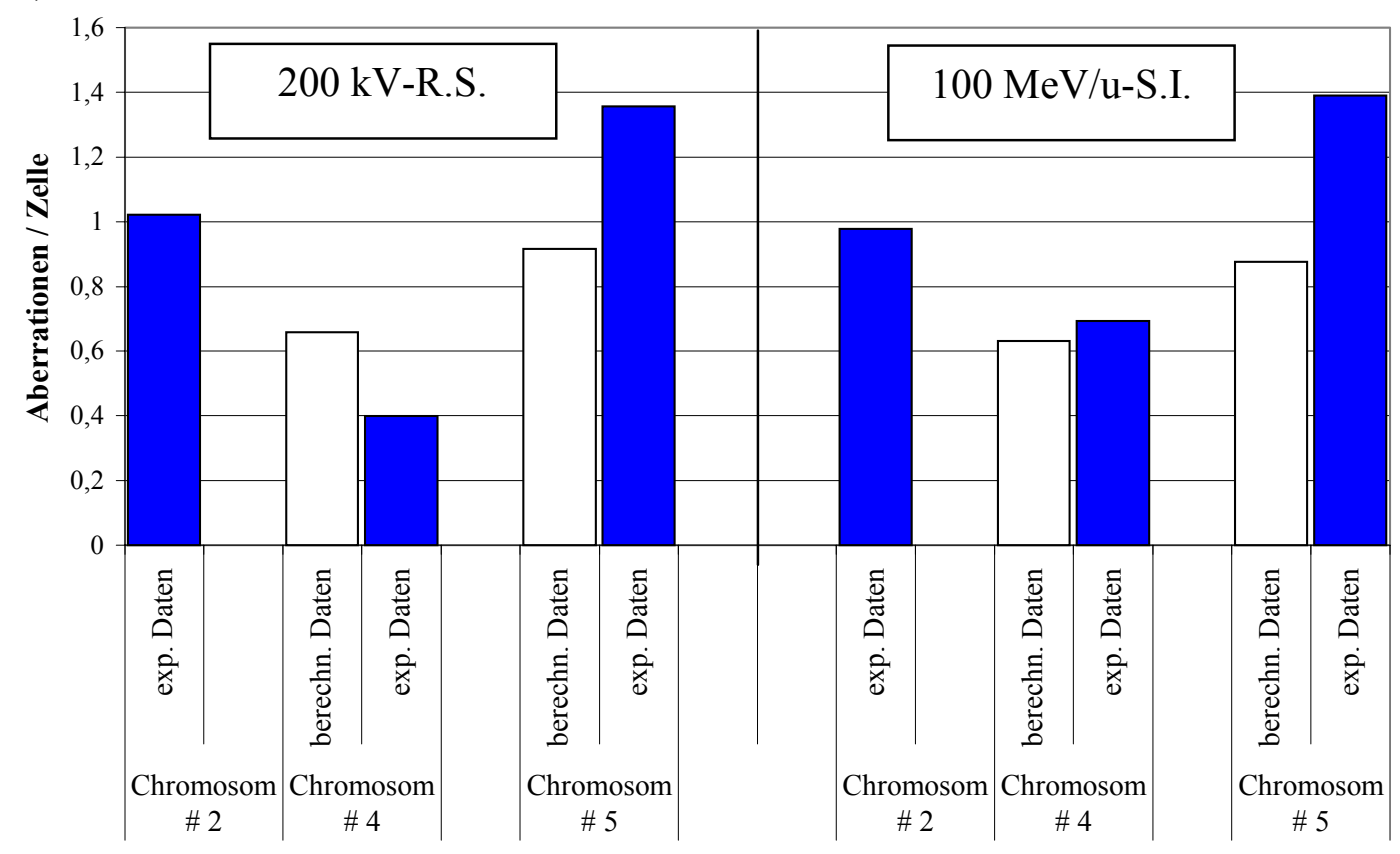

Abbildung 4.28 Vergleich der erwarteten (berechneten) Aberrationsausbeuten für die untersuchten Chromosomen (\# 4 und \# 5) mit den experimentell ermittelten Aberrationsausbeuten für WiDr-Zellen (a) und MCF-7-Zellen (b) nach Bestrahlung mit $200 \mathrm{kV}$-Röntgenstrahlung (R.S.) oder nach Bestrahlung mit $100 \mathrm{MeV} / \mathrm{u}$ Kohlenstoffionen (S.I.) mit der Dosis D = 4 Gy. Als Maß für die Berechnung wurde das in beiden Zelllinien stabile Chromosom \# 2 verwendet.

Nach Bestrahlung mit 200 kV-Röntgenstrahlung wurden in den Chromosomen 4 und 5 in WiDr-Zellen weniger Aberrationen induziert als man bei einer Proportionalität zu den Gesamt-DNA-Gehalten erwartet hätte. Beide Chromosomen sind unterrepräsentiert. Nach Bestrahlung mit Kohlenstoffionen entsprechen die berechneten Ausbeuten im Rahmen der experimentellen Genauigkeit den ermittelten Werten.

Auch die Aberrationsausbeuten in den strahlensensitiven MCF-7-Zellen sind nach Bestrahlung mit 200 kV-Röntgenstrahlung dem DNA-Gehalt der jeweiligen Chromosomen nicht proportional. Das Chromosom \# 4 ist im Vergleich zu den berechneten Daten unterrepräsentiert, das Chromosom \# 5 ist überrepräsentiert. Nach Bestrahlung mit Kohlenstoffionen entspricht die berechneten Ausbeute für das Chromosom \# 4 im Rahmen der experimentellen Genauigkeit dem ermittelten Wert. 
Die Ausbeute für das Chromosom \# 5 bleibt auch nach Bestrahlung mit Kohlenstoffionen überrepräsentiert.

Um die beiden Zelllinien besser vergleichen $\mathrm{zu}$ können, wurden die partiellen Ausbeuten der einzelnen Chromosomen summiert und in Abbildung 4.29 graphisch dargestellt.

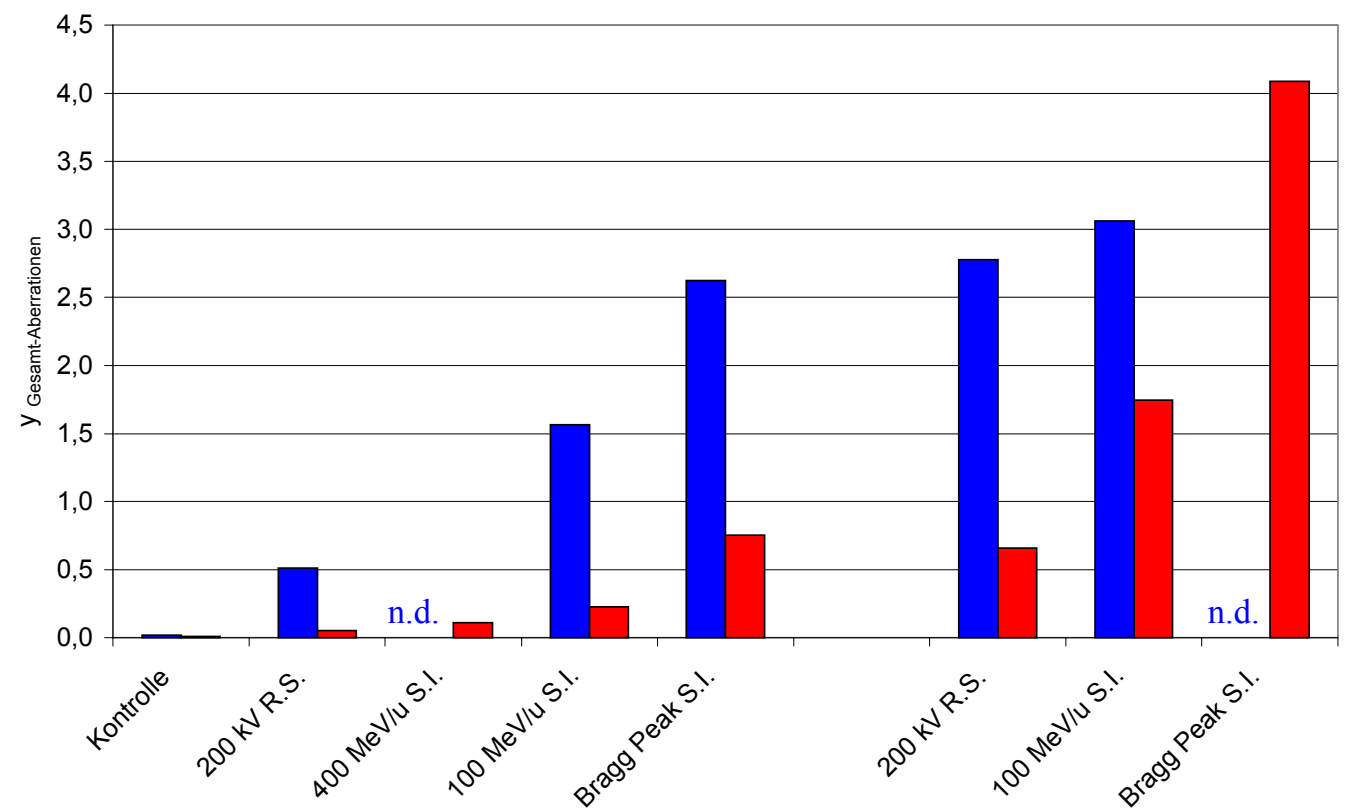

Abbildung 4.29 Vergleich der Ausbeuten an Gesamt-Aberrationen УТА $(2,4,5)$ in WiDr $\square$ und MCF-7 Zellen nach Bestrahlung mit 200 kV-Röntgenstrahlung (R.S.) oder nach Bestrahlung mit Kohlenstoffionen (S.I.) verschiedener Energien (400 MeV/u, $100 \mathrm{MeV} / \mathrm{u}$ und Bragg Peak) mit Dosen D = 1 Gy und D $=4$ Gy. Für diesen Vergleich wurden die partiellen Gesamtaberrationsausbeuten für Chromosom \# 2, \# 4 und \# 5 summiert. (n.d. = nicht bestimmt)

Die Induktion von allen Aberrationstypen ist in WiDr-Zellen bei $\mathrm{D}=1$ Gy niedrig. Erst nach Bestrahlung mit $\mathrm{D}=4$ Gy nimmt sie stark zu und es werden, erwartungsgemäß, mehr Aberrationen mit schweren Kohlenstoffionen als mit Röntgenstrahlung induziert. Ein starker Anstieg aller Aberrationstypen mit steigendem LET ist ebenfalls zu beobachten. 
In MCF-7-Zellen sind die Aberrationsausbeuten höher als in WiDr-Zellen, die УТА (2, 4,5 ) nimmt nach Bestrahlung mit $\mathrm{D}=1 \mathrm{~Gy}$ mit steigendem LET zu. Bei $\mathrm{D}=4 \mathrm{~Gy}$ ist wiederum kaum ein Anstieg mit steigendem LET erkennbar.

\subsubsection{Strahleninduzierte Insertionen}

Nach Bestrahlung mit Röntgenstrahlung werden Insertionen nur selten beobachtet. Strahlenarten mit hohem LET induzieren diese Aberrationsart in normalen Zellen viel häufiger [Boei et al., 2001]. Die Induktion von Insertionen, charakterisiert durch den Index I wurde deshalb in den untersuchten Tumorzellen gesondert ausgewertet. Der Index I, d.h. das Verhältnis der reziproken Translokationen zu den Insertionen, wurde berechnet und anschließend gemittelt. Die einzelnen Insertionsdaten sind in Tabelle 4.8 aufgelistet.

Tabelle 4.8 Der mittlere Index I für WiDr und MCF-7-Zellen nach Bestrahlung mit 200 kV-Röntgenstrahlung (R.S.) oder mit schweren Kohlenstoffionen (S.I.) verschiedener Energien (100 MeV/u und Bragg Peak) mit Dosen D = 1 Gy und $\mathrm{D}=4$ Gy. Die Indexwerte für die einzelnen Chromosomen $(2,4,5)$ wurden gemittelt.

\begin{tabular}{|c|c|c|c|c|c|c|}
\hline & $\mathbf{2 0 0}$ kV R.S. & $\mathbf{1 0 0}$ MeV/u S.I. & Bragg Peak S.I. & 200 kV R.S. & $\mathbf{1 0 0}$ MeV/u S.I. & Bragg Peak S.I. \\
\hline I (Transl./Insert.) & $1 \mathrm{~Gy}$ & $1 \mathrm{~Gy}$ & $1 \mathrm{~Gy}$ & $4 \mathrm{~Gy}$ & $4 \mathrm{~Gy}$ & $4 \mathrm{~Gy}$ \\
\hline \hline $\mathrm{I}(\mathrm{WiDr})$ & 0 & 0 & 0 & $12,5 \pm 4,2$ & $9,2 \pm 4,0$ & $2,5 \pm 1,8$ \\
\hline $\mathrm{I}$ (MCF-7) & $12,3 \pm 3,2$ & $3,0 \pm 2,4$ & $3,0 \pm 0,8$ & $7,0 \pm 2,7$ & $2,5 \pm 0,5$ & n.d. \\
\hline
\end{tabular}

In WiDr-Zellen wurden nach Bestrahlung mit D = 1 Gy keine Insertionen beobachtet. In der strahlensensitiven MCF-7-Zelllinie hingegen wurde schon nach Bestrahlung mit $\mathrm{D}=1$ Gy dieser Aberrationstyp beobachtet, und es wurde eine starke Zunahme der Aberrationen nach Bestrahlung mit Kohlenstoffionen im Vergleich zur Röntgenstrahlung beobachtet.

In der strahlenresistenten WiDr-Zelllinie wurden erst nach Bestrahlung mit D $=4$ Gy Insertionen induziert. 
Der mittlere Index I nimmt mit steigendem LET in beiden Zelllinien ab, d.h., mit steigendem LET nimmt die Induktion von Insertionen zu.

\subsection{Clusterbildung von NHEJ-Reparaturproteinen nach Bestrah- lung mit Röntgenstrahlung und Kohlenstoffionen}

Die strahleninduzierten DNA-Doppelstrangbrüche werden in Säugertierzellen in $\mathrm{G}_{0^{-}}$ bzw. $G_{1}-$ Phase vor allem mit Hilfe des NHEJ repariert. Die DNA-PK-abhängige NHEJ-Reparatur ist bisher am besten untersucht. Die, an dem NHEJ-Prozess beteiligten Proteine bilden in bestrahlten Zellen an Stellen der DNADoppelstrangbrüche Cluster. Zu den, an diesem Prozess beteiligten Proteinen gehören auch die DNA-PK $\mathrm{CS}^{-}$, die $\mathrm{Ku}$ 70- und Ku 86-Proteine. Die unterschiedliche intrinsische Strahlensensitivität der normalen sowie der Tumorzellen, wie sie speziell auch für Chromosomenaberrationen beobachtet wurde, könnte u.a. durch unterschiedlich effiziente NHEJ-Reparatur verursacht sein.

Die Clusterbildung der Proteine der NHEJ-Reparatur nach Bestrahlung wurde deshalb in normalen NEC-Zellen sowie in WiDr- und MCF-7-Zellen untersucht. Die Cluster wurden immunozytochemisch gefärbt und analysiert. Als ein Cluster wurde eine Häufung von Pixel im Zellkern bezeichnet, die folgende Kriterien erfüllte. Es wurden nur Pixel oberhalb einer bestimmten Helligkeitsschwelle (Helligkeit $>80 \%$ ) berücksichtigt und es wurde ein Clusterradius vorgegeben, und zwar 3 Pixel groß. Innerhalb des 3-Pixel- Radius mussten sich mindestens 10 Nachbarn befinden, die auch diese Bedingungen erfüllten.

Abbildung 4.30 zeigt als Beispiel einzelne Kernaufnahmen von unbestrahlten und bestrahlten Zellen nach Anfärbung des $\mathrm{Ku}$ 70-Proteins zu verschiedenen Zeitpunkten nach Bestrahlung mit D = 5 Gy mit $100 \mathrm{MeV} / \mathrm{u}$ Kohlenstoffionen oder mit $200 \mathrm{kV}$ Röntgenstrahlung. Die digitalisierten Aufnahmen wurden in Graustufen aufgenommen und anschließend mit Pseudofarben koloriert. 


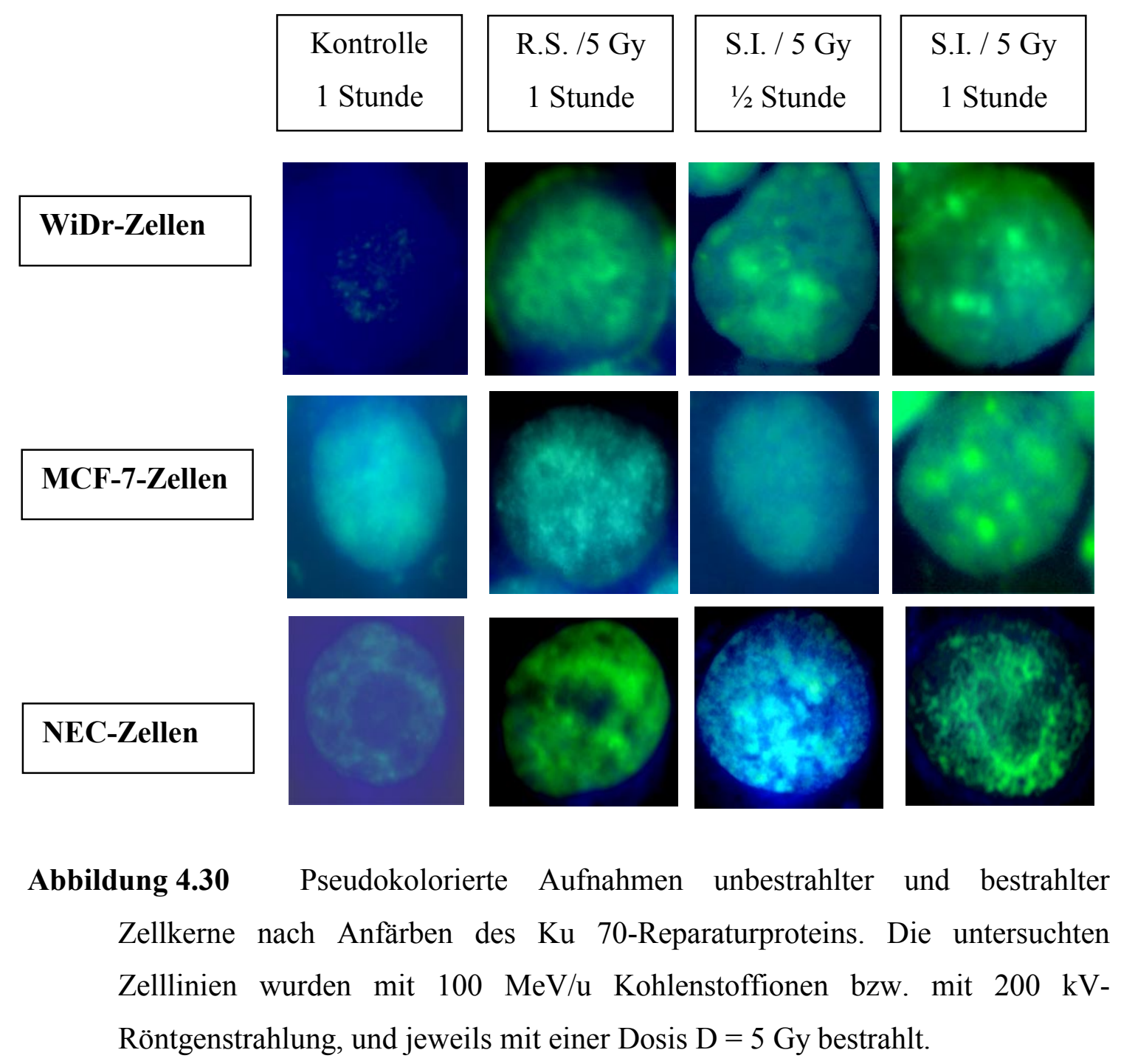

Die vorhandene Clusterbildung in WiDr- und in MCF-7-Zellen zeigt zuerst, dass beide Zelllinien über die DNA-PK $\mathrm{CS}^{-}, \mathrm{Ku}$ 70- und $\mathrm{Ku}$ 86-Proteine der NHEJ-Reparatur verfügen. Die ermittelte Anzahl der Cluster des jeweiligen Reparaturproteins (DNA$\mathrm{PK}_{\mathrm{CS}^{-}}, \mathrm{Ku}$ 70- und $\mathrm{Ku}$ 86-Protein) wurde im Verhältnis $\mathrm{zu}$ den entsprechenden Kontrollwerten gesetzt und ein Induktionsfaktor $\left(\mathrm{F}_{1}, \mathrm{~F}_{2}\right.$ und $\left.\mathrm{F}_{3}\right)$ wurde berechnet. In der Tabelle 4.9 sind diese Faktoren für die jeweilige Zelllinie aufgelistet. In Abbildung 4.31 sind die gemittelten Maximalwerte $F_{1}, F_{2}$ und $F_{3}$ in Abhängigkeit von der Zeit aufgetragen.

Vergleicht man den zeitlichen Verlauf der Clusterinduktion der einzelnen Reparaturproteine, so kann man feststellen, dass alle Reparaturproteine der NHEJReparatur schon 30 Minuten nach Bestrahlung Cluster gebildet haben. Dies gilt für beide untersuchten Strahlenarten. 


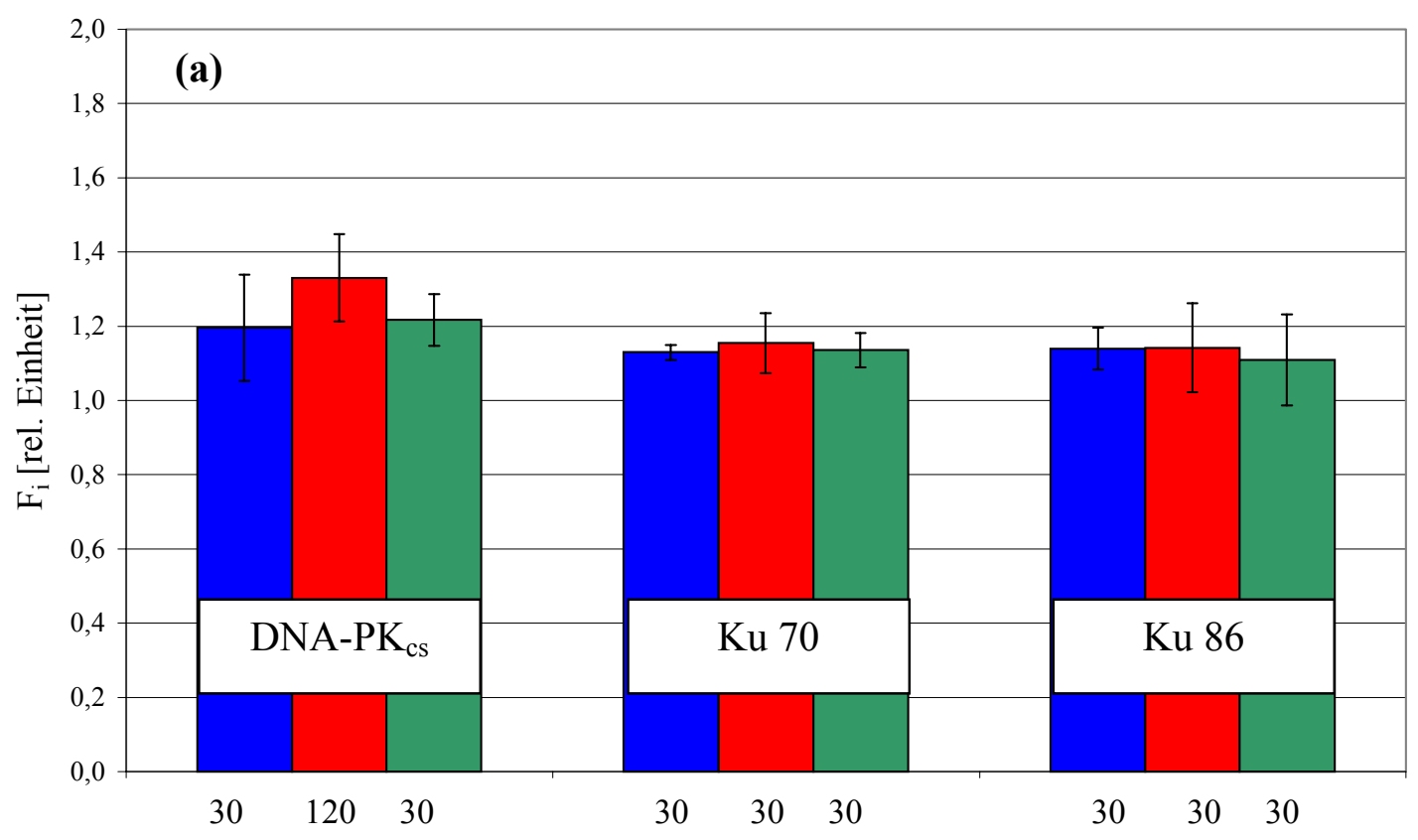

Zeit [Minuten]

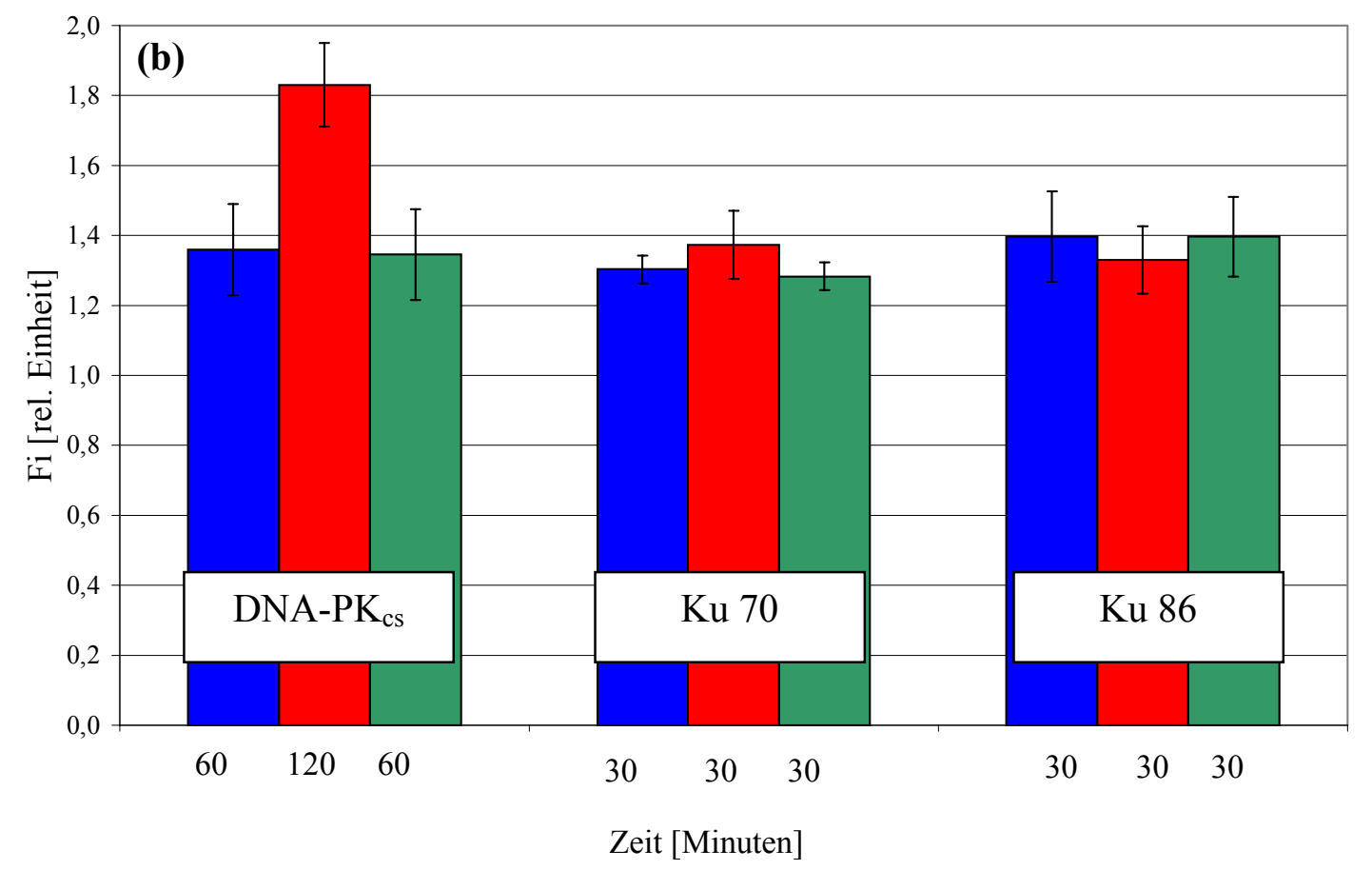

Abbildung 4.31 Induktion der Clusterbildung von Reparaturproteinen in NECMCF-7- $\square$ und WiDr-Zellen $\square$ in Abhängigkeit von Zeit nach Bestrahlung mit 200 kV-Röntgenstrahlung (a) oder nach Bestrahlung mit $100 \mathrm{MeV} / \mathrm{u}$ Kohlenstoffionen (b) mit $\mathrm{D}=5 \mathrm{~Gy}$. Die Clusterbildung ist durch die maximalen Werte der Induktionsfaktoren $F_{i}$ charakterisiert. Die Fehlerbalken repräsentieren die Standardabweichung. 
$\mathrm{Ku}$ 70-Cluster waren in allen drei Zelllinien schon 30 Minuten nach Bestrahlung sowohl mit Röntgenstrahlung als auch mit Kohlenstoffionen gebildet.

$\mathrm{Ku}$ 86-Cluster sind 30 Minuten ebenfalls sowohl nach Bestrahlung mit Röntgenstrahlung als auch nach Bestrahlung mit Kohlenstoffionen, ähnlich wie $\mathrm{Ku}$ 70, in allen drei Zelllinien gebildet.

Eine Clusterbildung des Reparaturproteins DNA-PK $\mathrm{cs}_{\mathrm{cs}}$ wurde in allen drei Zelllinien induziert. Für 200 kV-Röntgenstrahlung war eine maximale Clusterbildung 30 Minuten nach Bestrahlung in NEC- und WiDr-Zellen zu beobachten, in MCF-7-Zellen erst nach 120 Minuten. Die Induktionsfaktoren waren im Rahmen der experimentellen Genauigkeit in den drei Zelllinien etwa gleich. Für $100 \mathrm{MeV} / \mathrm{u}$ Kohlenstoffionen wurde eine maximale Clusterbildung 60 Minuten nach Bestrahlung in NEC- und WiDr-Zellen beobachtet, in MCF-7-Zellen erst 120 Minuten nach Bestrahlung beobachtet.

Die Proteine $\mathrm{Ku} 70$ und $\mathrm{Ku} 86$ bilden im Verlauf der Reparatur Heterodimere, deshalb sollte die Kinetik der Clusterbildung sowie das Verhältnis der beiden strahleninduzierten Clusterfaktoren $\left(\mathrm{F}_{2}: \mathrm{F}_{3}\right)$ gleich $(1: 1)$ sein. Im Rahmen der experimentellen Genauigkeit konnten diese Annahmen für beide Strahlenarten für alle drei Zelllinien bestätigt werden. DNA-PK $\mathrm{CS}_{\mathrm{CS}}$ bildet dann ein Komplex mit diesen Heterodimeren, das Verhältnis der Cluster $\left(\mathrm{F}_{1}: \mathrm{F}_{2}\right.$ bzw. $\left.\mathrm{F}_{1}: \mathrm{F}_{3}\right)$ sollte deshalb ebenfalls 1:1 sein. Dieses Verhältnis wurde im Rahmen der experimentellen Genauigkeit ebenfalls bestätigt. Die Kinetik der Clusterbildung ist nach KohlenstoffionenBestrahlung in NEC- und WiDr-Zellen langsamer als nach Röntgenbestrahlung. In MCF-7-Zellen ist die DNA-PK ${ }_{\mathrm{CS}}-$ Clusterbildung schon nach Röntgenbestrahlung langsamer als die $\mathrm{Ku}$ 70/Ku 86-Clusterbildung und dieser „delay“ bleibt auch nach Bestrahlung mit Kohlenstoffionen gleich. 
Tabelle 4.9 Strahleninduzierte Clusterbildung der jeweiligen Reparaturproteine in den untersuchten Zelllinien nach Bestrahlung mit $100 \mathrm{MeV} / \mathrm{u}$ Kohlenstoffionen oder nach $200 \mathrm{kV}$-Röntgenbestrahlung mit Dosis $\mathrm{D}=5 \mathrm{~Gy}$, charakterisiert durch die Induktionsfaktoren $\mathrm{F}_{1}, \mathrm{~F}_{2}$ und $\mathrm{F}_{3}$.(* Objektträger durchgebrochen)

NE C - R öntgen

\begin{tabular}{|c|c|c|c|c|c|c|}
\hline Zeit & D N A-P k & $\pm S A$ & $\mathrm{Ku} 70$ & $\pm S A$ & $\mathrm{Ku} 86$ & $\pm S A$ \\
\hline Minuten & $F_{1}$ & & $F_{2}$ & & $F_{3}$ & \\
\hline 30 & 1,11 & 0,11 & 1,09 & 0,10 & 1,11 & 0,14 \\
\hline 60 & 1,18 & 0,14 & 1,03 & 0,06 & 1,15 & 0,09 \\
\hline 120 & 1,30 & 0,18 & 1,30 & 0,18 & 1,17 & 0,04 \\
\hline 240 & 0,95 & 0,06 & 1,10 & 0,13 & 1,13 & 0,01 \\
\hline
\end{tabular}

NEC-Kohlenstoffionen

\begin{tabular}{|c|c|c|c|c|c|c|}
\hline Zeit & D N A -P & \pm S A & $\mathbf{K u ~} \mathbf{7 0}$ & \pm S A & $\mathbf{K ~ u ~ 8 ~ 6 ~}$ & \pm S A \\
\hline M inuten & $\mathbf{F}_{\mathbf{1}}$ & & $\mathbf{F}_{\mathbf{2}}$ & & $\mathbf{F}_{\mathbf{3}}$ & \\
\hline 30 & $\mathbf{1 , 1 5}$ & 0,15 & $\mathbf{1 , 2 3}$ & 0,10 & $\mathbf{1 , 4 1}$ & 0,23 \\
\hline 60 & $\mathbf{1 , 4 2}$ & 0,12 & $\mathbf{1 , 3 1}$ & 0,14 & $\mathbf{1 , 3 8}$ & 0,14 \\
\hline 120 & $\mathbf{1 , 3 0}$ & 0,14 & $\mathbf{1 , 3 7}$ & 0,12 & $\mathbf{1 , 4 0}$ & 0,02 \\
\hline 240 & $\mathbf{1 , 1 6}$ & 0,18 & $\mathbf{1 , 1 6}$ & 0,07 & $\mathbf{0 , 9} \mathbf{9}$ & 0,05 \\
\hline
\end{tabular}

M C F - 7-Röntgen

\begin{tabular}{|c|c|c|c|c|c|c|}
\hline Zeit & D N A -P k & \pm S A & $\mathbf{K ~ u ~ 7 0}$ & \pm SA & $\mathbf{K ~ u ~ 8 ~ 6 ~}$ & \pm S A \\
\hline M inuten & $\mathbf{F}_{\mathbf{1}}$ & & $\mathbf{F}_{\mathbf{2}}$ & & $\mathbf{F}_{\mathbf{3}}$ & \\
\hline 30 & $\mathbf{0 , 9 9}$ & 0,05 & $\mathbf{1 , 1 5}$ & 0,15 & $\mathbf{1 , 1 1}$ & 0,04 \\
\hline 60 & $\mathbf{1 , 1 0}$ & 0,05 & $\mathbf{1 , 1 5}$ & 0,04 & $\mathbf{1 , 1 0}$ & 0,02 \\
\hline 120 & $\mathbf{1 , 3 3}$ & 0,02 & $\mathbf{1 , 1 7}$ & 0,07 & $\mathbf{1 , 1 2}$ & 0,02 \\
\hline 240 & $\mathbf{1 , 2 0}$ & 0,03 & $\mathbf{1 , 1 5}$ & 0,07 & $\mathbf{1 , 2 4}$ & 0,10 \\
\hline
\end{tabular}

M C F-7-Kohlenstoffionen

\begin{tabular}{|c|c|c|c|c|c|c|}
\hline Zeit & D N A -P k & \pm S A & K u 7 0 & \pm S A & $\mathbf{K ~ u ~ 8 ~ 6 ~}_{|c|}$ & \pm S A \\
\hline M inuten & $\mathbf{F}_{\mathbf{1}}$ & & $\mathbf{F}_{\mathbf{2}}$ & & $\mathbf{F}_{\mathbf{3}}$ & \\
\hline 30 & $\mathbf{1 , 2 0}$ & 0,12 & $\mathbf{1 , 2 3}$ & 0,15 & $\mathbf{1 , 0 8}$ & 0,05 \\
\hline 60 & $\mathbf{1 , 5 2}$ & 0,09 & $\mathbf{1 , 4 7}$ & 0,11 & $\mathbf{1 , 3 3}$ & 0,06 \\
\hline 120 & $\mathbf{1 , 8 3}$ & 0,04 & $\mathbf{1 , 4 2}$ & 0,10 & $\mathbf{1 , 3 3}$ & 0,03 \\
\hline 240 & $\mathbf{1 , 0 2}$ & 0,11 & $\mathbf{1 , 1 9}$ & 0,02 & ${ }^{*}$ & 0,05 \\
\hline
\end{tabular}

W iD r-Röntgen

\begin{tabular}{|c|c|c|c|c|c|c|}
\hline Zeit & D N A -P k & \pm SA & $\mathbf{K ~ u ~ 7 0}$ & \pm SA & $\mathbf{K ~ u ~ 8 ~ 6 ~}$ & \pm S A \\
\hline M inuten & $\mathbf{F}_{\mathbf{1}}$ & & $\mathbf{F}_{\mathbf{2}}$ & & $\mathbf{F}_{\mathbf{3}}$ & \\
\hline 30 & $\mathbf{1 , 2 5}$ & 0,01 & $\mathbf{1 , 1 2}$ & 0,08 & $\mathbf{1 , 1 2}$ & 0,11 \\
\hline 60 & $\mathbf{1 , 1 6}$ & 0,07 & $\mathbf{1 , 1 0}$ & 0,06 & $\mathbf{1 , 0 6}$ & 0,11 \\
\hline 120 & $\mathbf{1 , 2 4}$ & 0,09 & $\mathbf{1 , 2 5}$ & 0,23 & $\mathbf{1 , 2 1}$ & 0,16 \\
\hline 240 & $\mathbf{1 , 0 8}$ & 0,07 & $\mathbf{1 , 0 7}$ & 0,11 & $\mathbf{1 , 0 5}$ & 0,11 \\
\hline
\end{tabular}

W iD r-Kohlenstoffionen

\begin{tabular}{|c|c|c|c|c|c|c|}
\hline Zeit & D N A -P k & \pm S A & K u 7 0 & \pm S A & $\mathbf{K ~ u ~ 8 ~ 6 ~}$ & \pm S A \\
\hline M inuten & $\mathbf{F}_{\mathbf{1}}$ & & $\mathbf{F}_{\mathbf{2}}$ & & $\mathbf{F}_{\mathbf{3}}$ & \\
\hline 30 & $\mathbf{1 , 2 2}$ & 0,05 & $\mathbf{1 , 3 2}$ & 0,12 & $\mathbf{1 , 5 0}$ & 0,15 \\
\hline 60 & $\mathbf{1 , 2 8}$ & 0,14 & $\mathbf{1 , 2 6}$ & 0,01 & $\mathbf{1 , 1 2}$ & 0,01 \\
\hline 120 & $\mathbf{1 , 4 1}$ & 0,12 & $\mathbf{1 , 2 7}$ & 0,16 & $\mathbf{1 , 5 7}$ & 0,18 \\
\hline 240 & $\mathbf{1 , 1 3}$ & 0,06 & $\mathbf{1 , 0 3}$ & 0,03 & $\mathbf{0 , 9} \mathbf{8}$ & 0,08 \\
\hline
\end{tabular}


Die normalen diploiden humanen NEC-Zellen haben keine Reparatur-Defizite, so dass man hier am besten die Wirkung der Röntgenstrahlung mit den Kohlenstoffionen vergleichen kann. Die experimentellen Daten zeigen, dass nach Bestrahlung mit Kohlenstoffionen mehr Cluster als nach Röntgenbestrahlung gebildet werden. Diese Befunde korrelieren mit den RBW-Werten, die für Induktion der Doppelstrangbrüche veröffentlicht wurden. Durch die Kohlenstoffionen werden 1,2-1,5 mal mehr Doppelstrangbrüche als mit Röntgenstrahlung induziert [E. Höglund et al., 1999].

Bei den Tumorzellen werden ebenfalls mehr Cluster nach Bestrahlung mit Kohlenstoffionen induziert als nach Röntgenbestrahlung.

Zusammenfassend lässt sich feststellen, dass die WiDr-Zellen bezüglich der DNA$\mathrm{PK}_{\mathrm{CS}^{-}}, \mathrm{Ku}$ 70- und $\mathrm{Ku}$ 86-Clusterbildung mit den normalen NEC-Zellen vergleichbar sind. In den strahlensensitiven MCF-7-Zellen werden nach Bestrahlung mit Kohlenstoffionen anscheinend mehr DNA-PK-Cluster beobachtet als die entsprechenden $\mathrm{Ku} 70$ - und $\mathrm{Ku}$ 86-Cluster. Die Kinetik der Clusterbildung nach Bestrahlung sowohl mit Röntgenstrahlung als auch mit Kohlenstoffionen ist in MCF-7Zellen langsamer als in NEC- und WiDr-Zellen. Möglicherweise ist hierfür eine aberrante Chromatinstruktur der MCF-7-Zellen verantwortlich. 


\section{Diskussion}

Im Rahmen der vorliegenden Arbeit wurden Untersuchungen zur Klärung der Mechanismen, die der hohen biologischen Wirksamkeit dicht ionisierender Strahlung zugrunde liegen, durchgeführt. Diese Untersuchungen sollten Rückschlüsse auf die Ursachen der erhöhten biologischen Wirksamkeit mittelschwerer Kohlenstoffionen bei strahlenresistenten sowie bei strahlensensitiven Tumorzellen ermöglichen, und darüber hinaus zu Klärung der Ursachen für die unterschiedliche intrinsische Strahlensensitivität verschiedener Zelltypen beitragen.

Die biologische Wirksamkeit von Kohlenstoffionen verschiedener Energien wurde mit der Wirksamkeit konventioneller 200 kV-Röntgenstrahlung verglichen. Als Zellmodellsystem wurden zwei etablierte humane Tumorzelllinien ausgewählt, die unterschiedliche Strahlensensitivität nach Bestrahlung mit 200 kV-Röntgenstrahlung aufweisen. Strahlenresistente WiDr-Zellen und strahlensensitive MCF-7-Zellen wurden im Bezug auf mehrere biologische Endpunkte untersucht.

Generell zeigte sich, dass die Zellantwort auf die Bestrahlung mit unterschiedlichen Strahlenarten für viele biologische Endpunkte qualitativ ähnlich ist, es wurde jedoch ein unterschiedliches Spektrum der chromosomalen Schäden für dicht ionisierende Alpha-Teilchen und Neutronenbeobachtet [Griffin et al., 1995; Grigorowa et al., 1998; Anderson et al., 2000]. Hierfür sind u.a. die für die schweren Ionen typischen multiplen lokalen DNA-Schäden verantwortlich. Das für die schweren Ionen charakteristische Spektrum der chromosomalen Schäden wurde erstmalig in dieser Arbeit in Tumorzellen untersucht.

In den folgenden Kapiteln werden die einzelnen Ergebnisse im Vergleich mit der relevanten Literatur diskutiert und abschließend zusammengefasst. 


\subsection{Zellüberleben nach Bestrahlung}

Der strahleninduzierte reproduktive Zelltod wurde mit Hilfe des Koloniebildungstests untersucht. Die Koloniebildungsfähigkeit der untersuchten WiDr- und MCF-7Zelllinien wurde nach Bestrahlung mit Kohlenstoffionen unterschiedlicher Energien mit 200 kV-Röntgenstrahlung verglichen.

Die nach Röntgenbestrahlung erhaltenen Dosis-Effekt-Kurven und daraus bestimmte Parameter sind mit den in der Literatur bereits beschriebenen Werten für beide Zelllinien vergleichbar [Olive et al.,1994; Virsik-Peuckert et al., 1996; Björk-Eriksson et al., 1998]. In Tabelle 5.1 sind die ermittelten Überlebensfraktionen nach Bestrahlung mit $\mathrm{D}=2$ Gy mit publizierten Daten verglichen.

Tabelle 5.1 Überlebensfraktion $\mathrm{SF}_{2}$ bei WiDr- und MCF-7-Zellen.

\begin{tabular}{|l|l|l|l|}
\hline \multicolumn{1}{|c|}{ Zelllinie } & \multicolumn{1}{|c|}{ Strahlenart } & \multicolumn{1}{c|}{ SF $_{\mathbf{2}} \pm$ S.D. } & \multicolumn{1}{c|}{ Referenz } \\
\hline \hline WiDr & $200 \mathrm{kV}-$ Röntgen & $0,74 \pm 0,24$ & vorl. Doktorarbeit \\
\hline WiDr & Cobalt-60 & 0,62 & T. Björk-Eriksson et.al.,1998 \\
\hline WiDr & $250 \mathrm{kV}-$ Röntgen & $0,76 \pm 0,08$ & P.L. Olive et.al.,1994 \\
\hline WiDr & $200 \mathrm{kV}-$ Röntgen & $0,85 \pm 0,09$ & P. Virsik-Peuckert et.al., 1994 \\
\hline MCF-7 & $200 \mathrm{kV-Röntgen}$ & $0,48 \pm 0,07$ & vorl. Doktorarbeit \\
\hline MCF-7 & Cobalt-60 & 0,55 & T. Björk-Eriksson et.al.,1998 \\
\hline MCF-7 & $200 \mathrm{kV-Röntgen}$ & $0,34 \pm 0,03$ & P. Virsik-Peuckert et.al., 1994 \\
\hline
\end{tabular}

In Abbildung 5.1 wurden die in dieser Arbeit untersuchten Tumorzellen mit untransformierten aber immortalisierten humanen Epithelzellen (HaCaT) verglichen. 


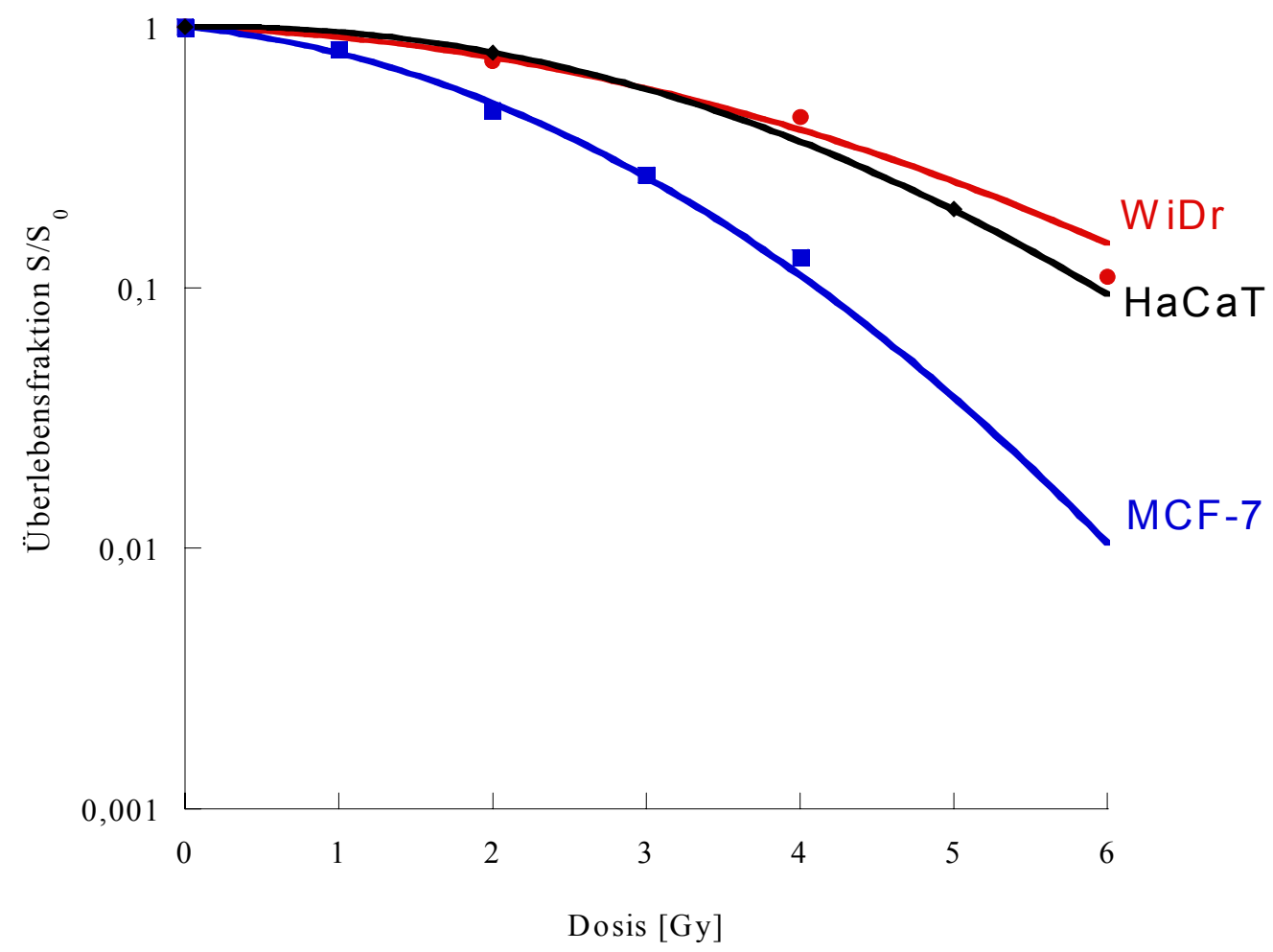

Abbildung 5.1 Vergleich der Überlebenskurven von WiDr-, MCF-7- und HaCaTZellen nach Bestrahlung mit Röntgenstrahlung bzw. Cobalt-60 (HaCaT) [Seymour et al., 1997].

Aus dieser Abbildung wird ersichtlich, dass die WiDr-Zellen mit untransformierten Epithelzellen im Bezug auf ihre Strahlenresistenz vergleichbar sind, die MCF-7-Zellen hingegen besonders strahlensensitiv sind.

Die hohe Strahlensensitivität der MCF-7-Zellen manifestiert sich auch in der Überlebenskurven-Form: die generell beobachtete Schulterform ist nach Bestrahlung mit Kohlenstoffionen nicht mehr vorhanden, das Überleben hat einen rein exponentiellen Verlauf. Dagegen zeigen die WiDr-Zellen auch nach Bestrahlung mit Kohlenstoffionen ausschließlich Überlebenskurven des Schultertyps (linearquadratische Anpassung). Unter der Annahme, dass für die Schulter die DNAReparaturprozesse verantwortlich sind, wäre dies ein Hinweis auf eine verminderte Reparatur in den MCF-7-Zellen.

Im Unterschied zu Röntgenbestrahlung weisen die Überlebenskurven der MCF-7Zellen nach Bestrahlung mit Kohlenstoffionen ( $400 \mathrm{MeV} / \mathrm{u}$ bis $100 \mathrm{MeV} / \mathrm{u}$ ) einen 
biphasischen Verlauf auf, falls halblogarithmisch aufgetragene Überlebensdaten angepasst worden sind. Dies könnte als ein Zeichen für das Vorhandensein von zwei unterschiedlich strahlensensitiven Subpopulationen in der MCF-7-Zelllinie gedeutet werden, kann aber im Rahmen der Unsicherheit dieser Anpassung (wenige Überlebenspunkte) nicht statistisch abgesichert werden. In Rahmen dieser Anpassung wird bei den MCF-7-Zellen nach Bestrahlung im Bragg Peak ein einfacher Verlauf beobachtet. Andererseits würden keine Unterschiede zwischen den einzelnen Ionenenergien und kein biphasischer Verlauf beobachtet werden, falls die Überlebensdaten linear und nicht halblogarithmisch aufgetragen und angepasst wären.

In der folgenden Tabelle 5.2 sind die wenigen, mit Kohlenstoffionen ermittelten Daten anderer Autoren auf der Basis der relativen biologischen Wirksamkeit (RBW) mit den experimentellen Daten aus dieser Arbeit verglichen worden. Es wurden nur Überlebensdaten die mit Ionen vergleichbarer LET-Werte ermittelt worden sind, berücksichtigt.

Tabelle 5.2 Vergleiche von RBW-Werte für das 10\% ige Überlebensniveau der Tumorzellen und der normalen humanen Zellen nach Bestrahlung mit Kohlenstoffionen.

\begin{tabular}{|c|c|c|c|l|}
\hline Zelllinie & Strahlenart & LET & RBW $_{\mathbf{1 0} \%}$ & \multicolumn{1}{|c|}{ Referenz } \\
\hline & & {$[\mathbf{k e V / \mu \mathbf { m } ]}$} & & \\
\hline \hline WiDr & C-Ionen & 11 & 1,3 & vorl. Doktorarbeit \\
\hline WiDr & C-Ionen & 16,5 & 1,5 & vorl. Doktorarbeit \\
\hline MCF-7 & C-Ionen & 11 & 1,8 & vorl. Doktorarbeit \\
\hline MCF-7 & C-Ionen & 16,5 & 1,9 & vorl. Doktorarbeit \\
\hline NB1RGB & C-Ionen & 13 & 1,2 & Suzuki et al., 1998 \\
\hline NB1RGB & C-Ionen & 20 & 1,2 & Tsuboi et al.,1998 \\
\hline HFL-III & C-Ionen & 13 & 1,2 & Suzuki et al., 1998 \\
\hline AG & C-Ionen & 16 & 1,2 & Berger, Diss.2001 \\
\hline
\end{tabular}

Für die WiDr-Zellen wurden, wie schon beim Vergleich mit HaCaT-Zellen, ähnliche RBW-Werte wie für die normalen Zellen (Fibroblasten-Zelllinien: NB1RGB, HFL III, AG-Zellen) ermittelt. Für die MCF-7-Zellen wurden höhere RBW-Werte ermittelt, wodurch ihre erhöhte Strahlensensitivität auch gegenüber Ionen manifestiert wird. 


\subsection{Genomische Häufigkeiten dizentrischer Chromosomen und extra azentrischer Fragmente in WiDr- und MCF-7-Zellen}

Die strukturellen Chromosomenaberrationen entstehen aus unreparierten oder falsch reparierten DNA-Doppelstrangbrüchen [z.B. Obe et al., 1992; Bauchinger et al.,1998].

Allgemein induzierten Kohlenstoffionen mehr Aberrationen als Röntgenstrahlung. In der resistenten WiDr-Zelllinie wurde durch $200 \mathrm{kV}$-Röntgenbestrahlung eine sehr niedrige Ausbeute an dizentrischen Chromosomen induziert. Die Ausbeute an extra azentrischen Fragmenten war hingegen deutlich höher. Die MCF-7-Zellen verhielten sich diesbezüglich ähnlich wie die WiDr-Zellen, die entsprechenden Aberrationsausbeuten waren aber viel höher als in den WiDr-Zellen.

Generell nahmen die Aberrationsausbeuten mit steigendem LET der Strahlung zu. Die vorliegenden Ergebnisse bestätigten die erwartete erhöhte Ionenwirksamkeit infolge multipler, oft irreparabler DNA-Schäden (azentrische Fragmente) [Ritter at al. 1997; Goodwin et al., 1989; Heilmann et al., 1996; Limoli et al., 2000]. Durch Ionenbestrahlung werden häufiger eng benachbarte Läsionen induziert als durch Röntgenbestrahlung [Ritter at al. 1997; Testard et al. 1997].

Der lineare Term der Dosis-Effekt-Abhängigkeit (die generell linear-quadratisch ist) repräsentiert die Ausstauschaberrationen, die durch eine einzelne Teilchenbahn induziert werden. Der quadratische Term repräsentiert die Ausstauschaberrationen, die durch zwei voneinander unabhängige Teilchenbahnen induziert werden [z.B. Simpson and Savage, 1996]. Da in den WiDr-Zellen für dizentrische Chromosomen sowohl nach Röntgenbestrahlung als auch nach Ionenbestrahlung eine lineare Dosis-Effekt-Abhängigkeit beobachtet wurde, wurden die dizentrischen Chromosomen in dem untersuchten Dosisbereich nur durch einzelne Teilchendurchgänge induziert. Dies bedeutet, dass in diesen strahlenresistenten Zellen jeweils nur zwei solche Chromosomen, die sich in unmittelbarer Nachbarschaft, möglicherweise in der gleichen Chromosomen-Domäne befanden, ein dizentrisches Chromosom bilden könnten. Die Chromatinstruktur und die Größe und Struktur der einzelnen Chromosomen-Domänen spielen bei der Aberrations- 
-entstehung vermutlich eine wichtige Rolle [Wu et al., 2000]. Falls in den WiDr-Zellen die einzelnen Chromosomen-Domänen größere Abstände hätten, wären nach einer relativ homogenen Röntgenbestrahlung die Interaktionen zwischen Läsionen, die durch zwei unabhängige Teilchendurchgänge induziert werden eher unwahrscheinlich, und folglich wären dizentrische Chromosomen vor allem aus jeweils zwei Chromosomen derselben Domäne gebildet.

In den MCF-7-Zellen wurde dahingegen eine linear-quadratische Dosis-EffektAbhängigkeit beobachtet. Dies bedeutet, dass sowohl einzelne Teilchendurchgänge als auch zwei unabhängige Teilchendurchgänge dizentrische Chromosomen induzieren können, dizentrische Chromosomen könnten also aus jeweils zwei Chromosomen, die sich in einer oder in zwei unterschiedlichen Domänen befanden, gebildet werden. Die Abstände zwischen den einzelnen Domänen müssten in den MCF-7-Zellen aufgrund dieser Ergebnisse kleiner als in den WiDr-Zellen sein. Die Vermutung liegt nahe, dass im Gegensatz zu den WiDr-Zellen, die MCF-7-Zellen räumlich ausgedehntere Chromosomen-Domänen besitzen.

Als Maß für unreparierte DNA-Doppelstrangbrüche wurde in dieser Arbeit die Anzahl extra azentrischer Fragmente untersucht. Generell zeigt die Dosis-Effekt-Abhängigkeit einen linear-quadratischen Verlauf, der die Induktion von interstitiellen und terminalen Deletionen widerspiegelt. In beiden Zelllinien wurden nach Bestrahlung mit Kohlenstoffionen viel mehr interstitielle als terminale Deletionen im Vergleich zur Röntgenstrahlung induziert. Zur Induktion von interstitiellen Deletion werden zwei Doppelstrangbrüche die sich in unmittelbarer Nachbarschaft auf gleichem Chromosom befinden, benötigt. Für die Induktion von terminalen Deletion wird nur ein Doppelstrangbruch benötigt. Die Dosisabhängigkeit extra azentrischer Fragmente zeigt in beiden Zelllinien nach Röntgenbestrahlung einen quadratischen Verlauf. Nach Bestrahlung mit Kohlenstoffionen zeigen die MCF-7-Zellen jedoch einen linearen Verlauf, die WiDr-Zellen zeigen überraschenderweise weiterhin einen quadratischen Verlauf. Die interstitiellen Deletionen, die generell zwei Doppelstrangbrüche für ihre Entstehung benötigen, werden in MCF-7-Zellen nach einer Ionenbestrahlung erwartungsgemäß durch einzelne Teilchendurchgänge induziert. In WiDr-Zellen hingegen werden weiterhin zwei Teilchendurchgänge in demselben Chromosom benötigt. Dieser Befund könnte durch eine sehr unterschiedliche Chromatinverteilung 
innerhalb der einzelnen Chromosomen-Domänen in den untersuchten Zelllinien erklärt werden.

Johnston et al. [1997] analysierten in verschiedenen Zellinien, u.a. in den WiDr- und MCF-7-Zellen, den DNA-Gehalt einzelner Domänen die zwei oder mehrere Doppelstrangbrüche aufwiesen, und zur Entstehung von azentrischen Fragmenten führten. Sie fanden keine signifikanten Unterschiede zwischen den einzelnen Zelllinien, also auch keine Korrelation mit der jeweiligen intrinsischen Strahlensensitivität der untersuchten Zelllinien. Die Wahrscheinlichkeit mit der mehrere Doppelstrangbrüche in einer etwa gleich großen Domäne (ca. 1,64 Mbp) induziert werden, ist folglich in den untersuchten Zelllinien WiDr und MCF-7, gleich groß. Die in MCF-7-Zellen im Vergleich mit WiDr-Zellen beobachtete höhere Rate an extra azentrischen Fragmenten ist folglich nicht auf eine erhöhte Rate an mehrfach geschädigten DNA-Stellen in den strahlenempfindlicheren Zellen zurückzuführen.

Die RBW-Werte für die Induktion von dizentrischen Chromosomen sind in beiden Zelllinien unterschiedlich. Für die resistenten WiDr-Zellen wurde eine $\mathrm{RBW}_{1}$ von ca. 4 und für die MCF-7-Zellen eine $\mathrm{RBW}_{1}$ von ca. 1 beobachtet.

Die RBW-Werte für die Induktion von extra azentrischen Fragmenten sind im Rahmen der Genauigkeit etwa gleich $\left(\mathrm{RBW}_{1}\right.$ ist 1,8 für die WiDr- und 2,1 für die MCF-7Zellen), damit zeigen beide Zelllinien etwa eine Verdopplung des unreparierten Schadens nach Bestrahlung mit Kohlenstoffionen. Sie wird nach Ionenbestrahlung im Vergleich mit Röntgenstrahlung vor allem durch die, für Kohlenstoffionen typischen multiplen lokalen und oft irreparablen DNA-Schäden hervorgerufen.

Um die Tumorzellen quantitativ mit normalen Zellen vergleichen zu können, muss berücksichtigt werden, dass die hier untersuchten Tumorzellen 71 Chromosomen enthalten und damit ca. 1,5 mal mehr DNA-Gehalt (Target) als normale diploide Zellen haben. Deshalb wurden die hier ermittelten Daten auf diploide Zellen umgerechnet. In Tabelle 5.3 sind die berechneten Tumordaten mit normalen Hautfibroblasten und mit fötalen Vorhautfibroblasten (AG-Zellen) verglichen. 
Tabelle 5.3 Vergleiche der genomischen Häufigkeiten dizentrischer Chromosomen und extra azentrischer Fragmente der umgerechneten Daten (diploid) der Tumorzellen mit normalen humanen Hautfibroblasten und Vorhautfibroblasten (diploid) nach Röntgenbestrahlung.

\begin{tabular}{|c|c|c|c|c|c|c|c|c|}
\hline Dosis & \multicolumn{2}{|c|}{ AG-Zellen } & \multicolumn{2}{c|}{ Fibroblasten } & \multicolumn{2}{c|}{ WiDr } & \multicolumn{2}{c|}{ MCF-7 } \\
\hline$[\mathbf{G y}]$ & $\mathbf{y}_{\text {dic }}$ & $\mathbf{y}_{\text {ac }}(\mathbf{e x})$ & $\mathbf{y}_{\text {dic }}$ & $\mathbf{y}_{\text {ac }}(\mathbf{e x})$ & $\mathbf{y}_{\text {dic }}$ & $\mathbf{y}_{\text {ac }}(\mathbf{e x})$ & $\mathbf{y}_{\text {dic }}$ & $\mathbf{y}_{\text {ac }}(\mathbf{e x})$ \\
\hline \hline 0 & 0,028 & 0,048 & -- & -- & 0,031 & 0,059 & 0,043 & 0,046 \\
\hline 2 & -- & -- & 0,086 & 0,164 & 0,060 & 0,138 & 0,126 & 0,490 \\
\hline 3 & 0,558 & 0,390 & -- & -- & 0,081 & 0,251 & 0,239 & 0,833 \\
\hline 4 & -- & -- & 0,300 & 0,450 & 0,090 & 0,580 & 0,427 & 1,587 \\
\hline Referenz & Berger et.al., Diss. 2001 & \multicolumn{6}{|c|}{ Rave-Fränk et.al.,2001 } & \multicolumn{3}{|c|}{ vorl. Arbeit } & \multicolumn{2}{c|}{ vorl. Arbeit } \\
\hline
\end{tabular}

Die Induktion von dizentrischen Chromosomen ist in WiDr-Zellen mit normalen Fibroblasten vergleichbar. Die MCF-7-Zellen zeigen eine deutlich erhöhte Strahlensensitivität. Auch die Häufigkeiten extra azentrischer Fragmente, also des unreparierten Schadens, sind in WiDr-Zellen mit den Fibroblasten-Daten vergleichbar. Die MCF-7Zellen zeigen auch hier eine deutlich höhere Sensitivität.

In der Literatur gibt es nur sehr wenige vergleichbare Untersuchungen von Zellen, die mit Kohlenstoffionen bestrahlt wurden, und meist wurden Hamsterzellen untersucht. Es wurden Untersuchungen mit anderen Ionen, wie z.B. Argon-, Gold- oder Helium-Ionen durchgeführt, die leider nicht mit Kohlenstoffionen vergleichbar sind, da die LETWerte dieser Ionenstrahlungen viel höher sind.

Die RBW-Werte für Kohlenstoffionen verschiedener Energien in Bezug auf die Induktion von DNA-Doppelstrangbrüchen liegen bei 1,2 bis 1,5 [Heilman et al., 1993; Höglund et al., 2000]. Für die Induktion von Chromosomenaberrationen wurden in dieser Arbeit höhere RBW-Werte ermittelt. Zu der höheren biologischen Wirksamkeit schwerer Ionen könnte die Induktion von multiplen lokalen DNA-Schäden beitragen, die häufig zu irreparablen DNA-Doppelstrangbrüchen führen [Savage et al., 1996; Sutherland et al., 2001; Prise et al., 2001; Goodhead, 1999]. Nach Bestrahlung mit dicht ionisierender Strahlung findet man deshalb sowohl einen höheren Anteil an unreparierten DNA-Doppelstrangbrüchen als auch einen höheren Anteil an Fehlreparatur als nach Bestrahlung mit dünn ionisierender Strahlung. 


\subsection{Partielle Häufigkeiten reziproker Translokationen in WiDr- und MCF-7-Zellen}

Die WiDr-Zellen zeigen nach Bestrahlung mit Röntgenstrahlung relativ niedrige Ausbeuten an reziproken Translokationen in allen drei untersuchten Chromosomen (2, 4 und 5). Diese Ausbeuten sind mit Ausbeuten die in normalen diploiden Fibroblasten ermittelt worden sind, vergleichbar [Virsik-Peuckert et al., 1996]. Vor allem die Untersuchungen der Chromosomen 2, 4 und 5 in den normalen Fibroblasten nach Bestrahlung mit 250 kV-Röntgenstrahlung (2 Gy und 5 Gy) stimmen mit den vorliegenden Daten überein [Simpson et al., 1996]. Die MCF-7-Zellen zeigen eine deutliche Strahlensensitivität der drei untersuchten Chromosomen im Vergleich mit den WiDr-Zellen und den normalen Fibroblasten.

Nach Bestrahlung mit Kohlenstoffionen wurden in WiDr-Zellen mehr Aberrationen induziert, aber eine substantielle Erhöhung der Aberrationsrate konnte erst nach Bestrahlung im Bragg Peak festgestellt werden. Die MCF-7-Zellen reagierten wiederum viel empfindlicher als die WiDr-Zellen.

Eine variable intrinsische Strahlensensitivität der einzelnen Chromosomen konnte nicht festgestellt werden. Die Gesamt-DNA-Gehalte der jeweiligen Chromosomen in WiDrZellen sind sehr ähnlich, so dass eine erhöhte Aberrationsinduktion in einem Chromosom ein Hinweis für eine erhöhte Strahlensensitivität des Chromosoms wäre. Die Translokationsausbeuten sind den entsprechenden Gesamt-DNA-Gehalten etwa proportional. In MCF-7-Zellen sind die Gesamt-DNA-Gehalte für Chromosomen 2 und 5 ähnlich, das Chromosom 4 ist etwas kleiner. Bei Berücksichtigung der unterschiedlichen DNA-Gehalte der einzelnen Chromosomen sind auch hier, wie schon bei den WiDr-Zellen die Translokationsausbeuten der Gesamt-DNA-Gehalten etwa proportional. Vergleicht man die Translokationsausbeuten der beiden Tumorzellen untereinander, sieht man, dass in den MCF-7-Zellen mehr Translokationen in allen drei Chromosomen induziert wurden als in den WiDr-Zellen. 
Die Frage, ob dizentrische Chromosomen und reziproke Translokationen als Ergebnisse der selben Reparatur- oder Fehlreparaturprozesse entstehen, ist bis heute ein Thema wissenschaftlicher Diskussionen. Theoretisch wurde nach den klassischen Vorstellungen erwartet, dass die Häufigkeit reziproker Translokationen und dizentrischer Chromosomen in der ersten Mitose nach Bestrahlung gleich sein müsste [Lea et al., 1946; Sax et al., 1938; Evans et al., 1979]. Es wurden jedoch mehr Translokationen als dizentrische Chromosomen in Lymphozyten, sowie in Tumorzellen beobachtet [Deng et al., 2000]. Dies könnte ein Hinweis dafür sein, dass diese zwei Aberrationstypen durch unterschiedliche Prozesse entstehen könnten oder alternativ aus unterschiedlichen Arten der DNA-Doppelstrangbrüche, die mit ungleichen Häufigkeiten induziert werden. Deshalb wurden die numerischen Verhältnisse berechnet:

$$
k=\frac{\sum_{i} y_{\text {trans }}(i=2,4,5)}{\sum_{i} y_{d i z}(i=2,4,5)}
$$

Die Verhältnisse von Translokationen und dizentrischen Chromosomen für die untersuchten Chromosomen 2, 4 und 5 sind in Tabelle 5.4 dargestellt.

Tabelle 5.4 Berechnete Verhältnisse $\mathrm{k}$ für alle untersuchten Chromosomen nach Bestrahlung mit 200 kV-Röntgenstrahlung und mit $100 \mathrm{MeV} / \mathrm{u}$ Kohlenstoffionen und Dosis D = 4 Gy.

\begin{tabular}{|c|c|c|}
\hline & $\mathbf{k}$ & $\mathbf{k}$ \\
\hline & $200 \mathrm{kV}$-Röntgen & $100 \mathrm{MeV} / \mathbf{u}$ C-Ionen \\
\hline \hline WiDr & 8,2 & 8,5 \\
\hline MCF-7 & 29,4 & 23,4 \\
\hline
\end{tabular}

Die Verhältnisse der Translokationen zu den dizentrischen Chromosomen sind nach Bestrahlung mit Röntgenstrahlung und mit Kohlenstoffionen gleich, und das in beiden untersuchten Zelllinien, die sehr unterschiedlich strahlensensitiv sind. Die Kohlenstoffionen produzieren einen höheren Anteil an komplexen Schaden als die Röntgenstrahlung [Testard et al., 1997; Boei et al., 2001]. Wenn die verschiedenen einfachen Aberrationstypen durch unterschiedliche Arten der DNA-Doppel- 
strangbrüche induziert wären, müssten sich die Verhältnisse k für Ionenbestrahlung erhöhen. Eine Erhöhung des k-Wertes wurde allerdings nicht beobachtet. Dieser Befund weist daraufhin, dass die zwei einfachen Ausstauschaberrationstypen wahrscheinlich durch unterschiedliche Reparaturprozesse entstehen.

\subsection{Aberrationsspektrum nach Röntgenbestrahlung und nach Ionenbestrahlung}

Die vorliegenden Daten zeigen deutlich, dass die verwendeten Strahlenarten, Kohlenstoffionen und Röntgenstrahlung ein unterschiedliches Spektrum an Aberrationen induzieren.

Nach Röntgenbestrahlung mit der Dosis $\mathrm{D}=1$ Gy lag der prozentuelle Anteil komplexer Aberrationen in beiden Zelllinien für die untersuchten Chromosomen (2, 4 und 5) unter 5\%. Diese Werte zeigen gute Übereinstimmung mit den publizierten Daten in humanen Fibroblasten für die gleichen Chromosomen. Simpson und Savage [Simpson et al., 1996] haben nach Röntgenbestrahlung in humanen Fibroblasten ein relativ seltenes Vorkommen komplexer Aberrationen gegenüber der einfachen Aberrationen beobachtet. Der prozentuelle Anteil komplexer Aberrationen lag auch hier unter 5\%. Nach Röntgenbestrahlung mit der Dosis D = 4 Gy konnte ein Anstieg an komplexen Aberrationen beobachtet werden, dieser war in MCF-7-Zellen jedoch deutlicher. In WiDr-Zellen lag der prozentuelle Anteil komplexer Aberrationen unter 10\%, diese Daten sind mit den publizierten Daten von Simpson sehr gut vergleichbar, da auch hier dieser Anteil unter 10\% lag. Die MCF-7-Zellen zeigten jedoch eine deutlich erhöhte Strahlensensitivität im Bezug auf die komplexen Aberrationen, da der prozentuelle Anteil komplexer Aberrationen etwa 40\% betrug.

Nach Bestrahlung mit Kohlenstoffionen im Bragg Peak ( $\mathrm{D}=4$ Gy) konnte in WiDrZellen ein deutlicher Anstieg komplexer Aberrationen, bis auf $50 \%$ beobachtet werden. Die MCF-7-Zellen wiesen schon nach Bestrahlung im Bragg Peak mit einer viel kleineren Dosis ( $\mathrm{D}=1 \mathrm{~Gy}$ ) einen solchen hohen Anteil komplexer Aberrationen auf. In Abbildung 5.2 sind partielle Häufigkeiten komplexer Aberrationen pro Zelle für 
die untersuchten Chromosomen 2, 4 und 5 in WiDr- und MCF-7-Zellen nach Bestrahlung dargestellt.

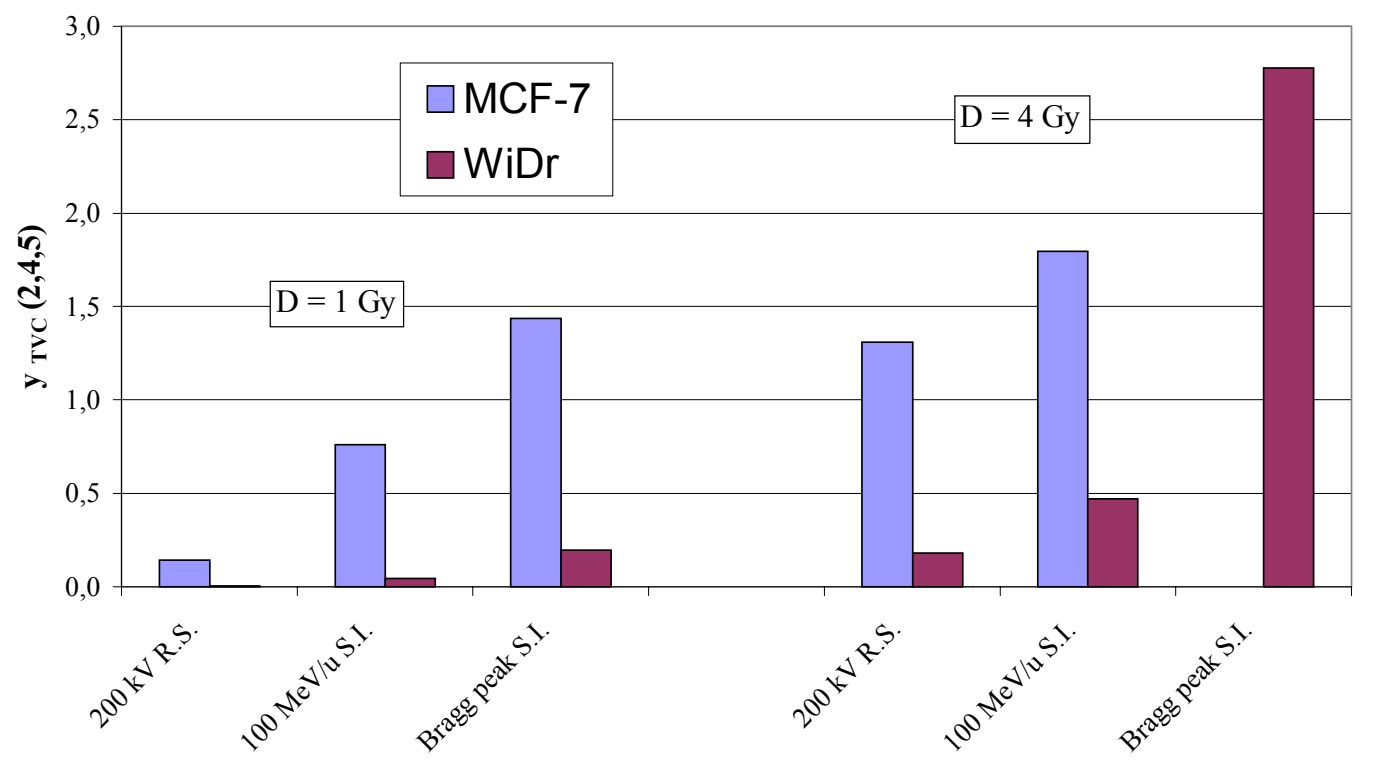

Abbildung 5.2 Partielle Häufigkeiten komplexer Aberrationen pro Zelle y тVC (2, 4, 5) wurden für Chromosom 2, 4 und 5 in Wider- und MCF-7-Zellen bestimmt. Zellen wurden mit Dosen von 1 Gy und 4 Gy mit 200 kV-Röntgenstrahlung (R.S.) oder mit Kohlenstoffionen (S.I.) mit unterschiedlichen Energien (100 $\mathrm{MeV} / \mathrm{u}$ und Bragg Peak) bestrahlt.

Die Induktion komplexer Aberrationen nahm in beiden Zelllinien mit steigendem LET und steigender Dosis zu. Die Steigung der einzelnen Häufigkeiten der beiden Zelllinien war jedoch unterschiedlich.

Eine besondere Klasse der komplexen Aberrationen stellen die Insertionen dar. Dieser Aberrationstyp tritt nach Röntgenstrahlung praktisch nicht auf, Insertionen scheinen eine für dicht-ionisierende Strahlung typische Aberrationsform zu sein [z. B. Griffin et al., 1995; Deng et al., 2000]. In beiden Tumorzelllinien nahm auch die InsertionenAnzahl mit steigendem LET zu. Im Gegensatz zu den MCF-7-Zellen, in denen schon bei niedrigen Dosen Insertionen beobachtet wurden, konnten sie in WiDr-Zellen erst nach Bestrahlung mit einer Dosis D $=4$ Gy beobachtet werden. Da Insertionen aus $\geq 3$ Brüchen in zwei Chromosomen entstehen, ist dieses Ergebnis wiederum im Einklang 
mit der Annahme, dass die Chromatinverteilung in den untersuchten Zellen unterschiedlich ist.

Nach Bestrahlung mit Kohlenstoffionen im Vergleich zur Röntgenstrahlung sieht man einen stark erhöhten Anteil an komplexen Aberrationen. Auch die Insertionen werden nach Ionenbestrahlung viel häufiger induziert, der Index I nimmt stark ab, ähnlich wie bei $\alpha$-Teilchen [Griffin et al., 1995; Anderson et al., 2000].

Ein Teil der induzierten Schäden wird repariert oder fehlrepariert. Aus den fehlreparierten Schäden entstehen Aberrationen. Ein Teil der Schäden kann aufgrund der Schwere des Schadens nicht repariert werden und diese unreparierten Schäden sind auf der Aberrationsebene als extra azentrische Fragmente erkennbar. Kohlenstoffionen induzieren aufgrund ihrer inhomogenen Energieverteilung im Zellkern und aufgrund ihrer hohen LET-Werte einen anderen Schadenstyp als die Röntgenstrahlung. Der Anteil an komplexen Schäden, d.h. mehrfach geschädigten DNA-Stellen, ist erhöht und damit auch der Anteil an unreparierten Schäden.

Vergleicht man die Anteile der einfachen Aberrationen also der dizentrischen Chromosomen und der reziproken Translokationen nach Röntgenbestrahlung, würde man ein 1:1 Verhältnis der beiden Aberrationstypen erwarten - falls sie durch dieselbe Fehlreparatur entstehen.

Ein (1:1) Verhältnis zwischen reziproken Translokationen und dizentrischen Chromosomen wurde nach Röntgenbestrahlung bei den untersuchten Tumorzellen nicht beobachtet. Auch bei anderen Zelltypen, wie aus der Tabelle 5.8 ersichtlich wird, wurde kein 1:1 Verhältnis beobachtet.

Tabelle 5.5 Verhältnisse $\mathrm{y}_{\text {trans }} / \mathrm{y}_{\text {dic }}$ in unterschiedlichen Zellen nach Bestrahlung mit Röntgenstrahlung und $\mathrm{D}=1 \mathrm{~Gy}$. Bei den normalen Zellen handelt es sich um Hautfibroblasten und Endothelzellen aus der Nabelschnur.

\begin{tabular}{|c|c|l|}
\hline Zelllinie & $\mathbf{y}_{\text {trans }} / \mathbf{y}_{\text {dic }}$ & \multicolumn{1}{|c|}{ Referenz } \\
\hline WiDr & 8 & vorl. Arbeit \\
\hline MCF-7 & 29 & vorl. Arbeit \\
\hline Fibroblasten & 5 & Virsik-Peuckert et al., 1997 \\
\hline Endothelzellen & 2,5 & pers. Mitteilung v. Virsik-Köpp \\
\hline
\end{tabular}


Die unterschiedlichen Verhältnisse der beiden Aberrationstypen weisen darauf hin, dass die beiden Aberrationstypen nicht durch denselben Reparaturmechanismus, sondern durch unterschiedliche Reparaturmechanismen gebildet werden. Nach Bestrahlung mit Kohlenstoffionen bleiben die Verhältnisse $\mathrm{y}_{\text {trans }} / \mathrm{y}_{\text {dic }}$ in beiden untersuchten Zelllinien gleich. Dies bedeutet, dass diese Reparaturmechanismen je nach Zelltyp unterschiedlich an der Reparatur beteiligt sind, diese aber unabhängig vom LET sind.

Da Ionen einen inhomogenen und komplexeren Schaden als die Röntgenstrahlung induzieren, könnte einer der beteiligten Reparaturmechanismen begünstigt bzw. benachteiligt werden. Das Verhältnis der beiden Aberrationstypen würde sich dadurch verändern. Da aber für Ionen unveränderte Verhältnisse beobachtet wurden, muss angenommen werden, dass die verschiedenen Reparaturprozesse unabhängig von Art und Verteilung des Schadens an der Gesamtreparatur beteiligt sind, die als Fehlreparatur zu einfachen Austauschaberrationen führt.

Vergleicht man den Anteil an fehlrepariertem Schaden, also die Summe der dizentrischen Chromosomen und Translokationen mit dem Anteil an unrepariertem Schaden, also dem Anteil an extra azentrischen Fragmenten nach Bestrahlung mit Röntgenstrahlung mit D = 4 Gy ( niedriger Anteil komplexer Austauschaberrationen) in unterschiedlichen Zellen, so sind auch hier unterschiedliche Verhältnisse von fehlrepariertem zum unrepariertem Schaden offensichtlich (siehe Tabelle 5.6).

Tabelle 5.6 Unterschiedliche Verhältnisse von unrepariertem zum fehlreparierten Schaden in normalen Zellen und in untersuchten Tumorzellinien nach Röntgenbestrahlung mit D = 4 Gy.

\begin{tabular}{|c|c|l|}
\hline Zelllinien & $\boldsymbol{\Sigma}$ (diz+trans)/yac $\mathbf{~}(\mathbf{e x})$ & \multicolumn{1}{|c|}{ Referenz } \\
\hline MCF-7 & 0,71 & vorl. Arbeit \\
\hline WiDr & 1,25 & vorl. Arbeit \\
\hline Endothelzellen & 1,25 & pers. Mitteilung von Virsik-Köpp \\
\hline Fibroblasten & 2,50 & Virsik-Peuckert et al., 1997 \\
\hline Lympohzyten & 2,50 & pers. Mitteilung von Virsik-Köpp \\
\hline
\end{tabular}


Vergleicht man den Anteil an unrepariertem Schaden mit der intrinsischen Strahlensensitivität der einzelnen Zelllinien, so ergibt sich folgendes Bild: die sensitiven MCF-7-Zellen können weniger effizient reparieren als die resistenteren WiDr-Zellen und die Endothelzellen, in normalen Fibroblasten und Lymphozyten ist der Anteil an unrepariertem Schaden am kleinsten. Die MCF-7-Zellen sind offensichtlich im Bezug auf die DNA-DSB-Reparatur defizient.

Zusammenfassend lässt sich sagen, dass mehrere Reparatur- bzw. Fehlreparaturprozesse zur Bildung unterschiedlicher Aberrationstypen führen können, und diese Prozesse können in den Zellen unterschiedlich ausgeprägt sein. Der unreparierte Restschaden allein kann aber die intrinsische Strahlensensitivität der Zellen nicht erklären.

\subsection{Gesamt-Aberrationen}

Alle, in den untersuchten Chromosomen 2, 4 und 5 mit Einzelfarbe-FISH detektierbaren Aberrationen wurden als Gesamt-Aberrationen zusammengefasst.

Nach Bestrahlung mit Dosis D = 1 Gy sind die partiellen Häufigkeiten an GesamtAberrationen pro Zelle in beiden Zelllinien dem LET proportional. Nach Bestrahlung mit $\mathrm{D}=4$ Gy ist in den MCF-7-Zellen kein Unterschied zwischen der Röntgenstrahlung und den Kohlenstoffionen (100 MeV/u) feststellbar. Die Aberrationsausbeuten in den einzelnen Chromosomen entsprechen dem DNA-Gehalt der jeweiligen Chromosomen.

Um die experimentellen Daten mit normalen Zellen vergleichen zu können, müssen die DNA-Gehalte der einzelnen Chromosomen der Tumorzellen mit normalen diploiden Zellen verglichen werden. Die in der Tabelle 5.5 angegebenen diploiden Werte sind die veröffentlichen Daten des „Human Genom Sequencing Consortium“(2001). 
Tabelle 5.7 DNA-Gehalt-Faktoren der untersuchten Tumorzellen

\begin{tabular}{|c|c|c|c|}
\hline Chromosom & dipl.Zelle & \multicolumn{2}{|c|}{ DNA-Faktor } \\
\hline & {$[\mathbf{M b}]$} & WiDr & MCF-7 \\
\hline 2 & 255 & 1,5 & 1,5 \\
\hline 4 & 197 & 1,8 & 1,3 \\
\hline 5 & 198 & 1,8 & 1,8 \\
\hline
\end{tabular}

In der Tabelle 5.8 sind die korrigierten Ausbeuten an Gesamt-Aberrationen pro Zelle УтА $^{*}$ im Vergleich mit normalen diploiden Fibroblasten nach Röntgenbestrahlung mit der Dosis D = 4 Gy aufgelistet.

Tabelle 5.8 Die korrigierten Ausbeuten an Gesamt-Aberrationen pro Zelle $\mathrm{y}_{\mathrm{TA}}{ }^{*}$ sind im Vergleich mit normalen diploiden Fibroblasten nach Röntgenbestrahlung mit der Dosis D = 4 Gy aufgelistet.

\begin{tabular}{|c|c|c|c|}
\hline Chromosom & Fibroblasten & WiDr & MCF-7 \\
\hline & $\mathbf{y}_{\text {TA }}$ & $\mathbf{y}_{\text {TA }}{ }^{*}$ & $\mathbf{y}_{\text {TA }}{ }^{*}$ \\
\hline 2 & 0,312 & 0,233 & 0,681 \\
\hline 4 & 0,204 & 0,103 & 0,307 \\
\hline 5 & 0,195 & 0,067 & 0,753 \\
\hline
\end{tabular}

Vergleicht man die Aberrationsausbeuten der beiden Tumorzellen nach Röntgenbestrahlung ( $\mathrm{D}=4$ Gy) mit normalen Fibroblasten-Daten [Simpson et al., 1996], so sind die Aberrationsausbeuten der WiDr-Zellen im Rahmen der experimentellen Genauigkeit niedriger im Vergleich mit den Aberrationsausbeuten der normalen humanen Fibroblasten. Die Ausbeuten in den strahlensensitiven MCF-7Zellen sind auch in diesem Fall deutlich erhöht. Es gibt leider keine vergleichbaren Daten nach Bestrahlung mit Kohlenstoffionen. 


\subsection{Clusterbildung von NHEJ-Reparaturproteinen}

Wie schon erwähnt wurde, werden die strahleninduzierten DNA-Doppelstrangbrüche in Säugertierzellen in $\mathrm{G}_{0^{-}}$bzw. $\mathrm{G}_{1}$-Phase vor allem mit Hilfe des NHEJ repariert [Pfeiffer, 1998; Muller et al., 1999; Feldmann et al., 2001; Pfeiffer et al., 2001; Fergusson et al., 2001; van Gent et al.,2001; Rothkamm et al., 2001; Dámours et al. , 2002; DeFazio et al., 2002; Hsu et al., 2002]. Ein Defekt in der NHEJ-Reparatur in SCID (severe combined immunodeficiency) Zellen hat $\mathrm{zu}$ Folge, dass diese Zellen u.a. eine Hypersensitivität gegenüber der ionisierenden Strahlung zeigen [Pluth et al., 2001]. Das

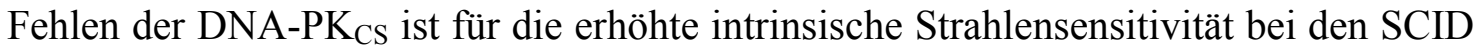
Mäusezellen verantwortlich.

Aus zwei verschiedenen Gewebeteilen eines Glioblastoms wurden zwei isogene Zelllinien, die sich in der DNA-PK $\mathrm{CS}_{\mathrm{CS}}$-Expression unterscheiden, etabliert [AllalunisTurner et al., 1993]. M059K mit normaler DNA-PK $\mathrm{CS}$-Expression und Aktivität, und

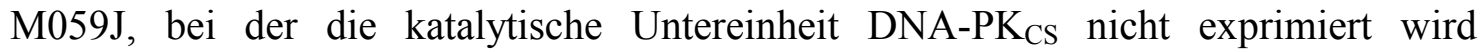
[Galloway et al., 2000; Hope et al., 2000]. Die NHEJ-Defekte Zelllinie ist sehr strahlenempfindlich im Bezug auf das reproduktive Überleben und zeigt eine stark erhöhte Rate an strahleninduzierten Chromosomenaberrationen [Virsik-Köpp et al., 2002]. Die M059K zeigt dagegen eine Resistenz gegenüber der Strahlung. Diese zwei Zelllinien zeigen, dass ein Zusammenhang zwischen der fehlenden DNA-PK-Aktivität, also zwischen einem NHEJ-Defekt und der intrinsischen Strahlensensitivität, die auf der Aberrationsebene manifestiert ist, besteht.

In dieser Arbeit wurde eine mögliche NHEJ-Defizienz als Ursache der hohen Strahlenempfindlichkeit der MCF-7-Zellen untersucht. Die experimentellen Ergebnisse haben gezeigt, dass beide Tumorzelllinien über die drei wichtigen Reparaturproteine (DNA-PK $_{\mathrm{CS}}, \mathrm{Ku} 70$ und $\mathrm{Ku}$ 86) verfügen, und dass diese Proteine in bestrahlten Zellen Cluster bilden.

Allgemein induzierten Kohlenstoffionen in beiden Tumorzelltypen und in der Kontrollzelllinie NEC (normale diploiden Epithelzellen) mehr Cluster als die 
Röntgenstrahlung. Dieser Befund stimmt mit der beobachteten erhöhten Induktion von DNA-Doppelstrangbrüchen nach Bestrahlung mit dicht ionisierender Strahlung überein [Höglund et al., 2000]. Wie diese Autoren gezeigt haben, induzieren Ionen etwa 1,2-1,5 mal mehr DNA-Doppelstrangbrüche als Röntgenstrahlung. Um diesen Faktor wurden auch die entsprechenden Clusteranzahlen in Zellkernen, die mit Ionen bestrahlt wurden gegenüber der Röntgenstrahlung erhöht. Dieses Ergebnis weist daraufhin, dass ein (DNA-PK)-Komplex auch viele, durch Ionen induzierte DNA-Doppelstrangbrüche erkennt und repariert. Die unterschiedliche intrinsische Strahlensensitivität der untersuchten Tumorzelllinien ist nicht auf eine fehlende Clusterbildung der obengenannten NHEJ-Reparaturproteine zurückzuführen.

Die Clusterbildung per se ist aber für eine effektive NHEJ-Reparatur nicht ausreichend. Wie Untersuchungen an verschiedenen Tumorzelllinien gezeigt haben [Vaganay-Juery et al., 2000], kann die enzymatische DNA-PK-Aktivität stark variieren. In verschiedenen Tumorzelllinien wurde zwar fast immer eine Korrelation zwischen der DNA-PK-Aktivität und der intrinsischen Strahlensensitivität, gemessen in Kolonieassay beobachtet [Polischouk et al. 1999; Sirzen et al., 1999; Vaganay-Juery et al., 2000; Martin, Diplomarbeit 2001]. Allalunis-Turner et al. (1995) fanden hingegen keine solche Korrelation bei Glioblastom-Zelllinien.

Für die Zelllinien, die in der vorliegenden Arbeit untersucht wurden, wurde die enzymatische DNA-PK-Aktivität bis dato nur in den strahlensensitiven MCF-7-Zellen untersucht [Martin, Diplomarbeit 2001]. Diese zeigten eine etwas niedrigere Aktivität im Vergleich zu den strahlenresistenten MO59K-Zellen, die ihrerseits eine mit den WiDr-Zellen vergleichbare Strahlenresistenz aufweisen.

Die Unterschiede in der Induktion der DNA-Schäden oder in der, für die DNAReparatur benötigten Zeit, könnten auch einen Einfluss auf die intrinsische Strahlensensitivität der Zellen haben. Es konnte aber keine Korrelation zwischen der Induktion von DNA-Doppelstrangbrüchen und der Strahlensensitivität verschiedener Melanom-Tumorzellen festgestellt werden [McKay et al., 1995]. Für die, in dieser Arbeit untersuchten Tumorzelllinien wurde eine etwa gleiche Reparaturzeit (bestimmt in einem DNA-Doppelstrang-rejoining-assay) beobachtet. Die Reparaturkinetik setzte sich bei beiden Zelllinien aus einer schnellen und einer langsamen Komponente zusammen. Der Restschaden war jedoch unterschiedlich. Die MCF-7-Zellen zeigten 
nach 4 Stunden Reparatur einen Restschaden von etwa 20\%, dagegen zeigten die WiDr-Zellen einen Restschaden von etwa 10\% [Bunch et al. , 1995; Olive et al., 1995]. Die Clusterbildung-Ergebnisse in WiDr- und MCF-7-Zellen stimmen mit diesen Befunden überein: In MCF-7-Zellen ist die DNA-PK ${ }_{\mathrm{CS}}-C_{\text {Clusterbildung sowohl nach }}$ Röntgenbestrahlung als auch nach Bestrahlung mit Kohlenstoffionen langsamer als in den WiDr-Zellen.

\subsection{Die relative biologische Wirksamkeit}

Die relative biologische Wirksamkeit (RBW) dient als Maß der Effektivität einer getesteten Strahlung im Vergleich mit der Referenzstrahlung (200 kV-Röntgenstrahlung). Generell steigt die RBW zunächst mit steigendem LET, erreicht ein Maximum und fällt anschließend auf Werte unter 1 [Barendsen et al., 1963; Skarsgard et al., 1967]. Der Maximalwert zeigt mit steigender Ordnungszahl des Ions eine Verschiebung zu höheren LET-Werten und liegt für Protonen bei etwa $25 \mathrm{keV} / \mu \mathrm{m}$ und für Kohlenstoffionen zwischen 150 und $200 \mathrm{keV} / \mu \mathrm{m}$ [Kraft 1999; Weyrather et al. 1999]. Bei allen, in dieser Arbeit untersuchten biologischen Endpunkten zeigte sich ein Anstieg von RBW-Werten mit steigendem LET der Kohlenstoffionen. Je nach Endpunkt wurden RBW-Werte bis ca. 4 ermittelt.

Für die resistenten WiDr-Zellen wurden generell höhere RBW-Werte als für die sensitiven MCF-7-Zellen ermittelt. Nach Bestrahlung im Bragg Peak wurden in Bezug auf das Überleben für beide Zelllinien gleich große RBW-Werte $(\mathrm{RBW}=4)$ ermittelt. Bei diesen hohen LET-Werten ist die RBW bei den untersuchten Zelllinien von der intrinsischen Strahlensensitivität unabhängig, wie auch Abbildung 5.3 dokumentiert. 

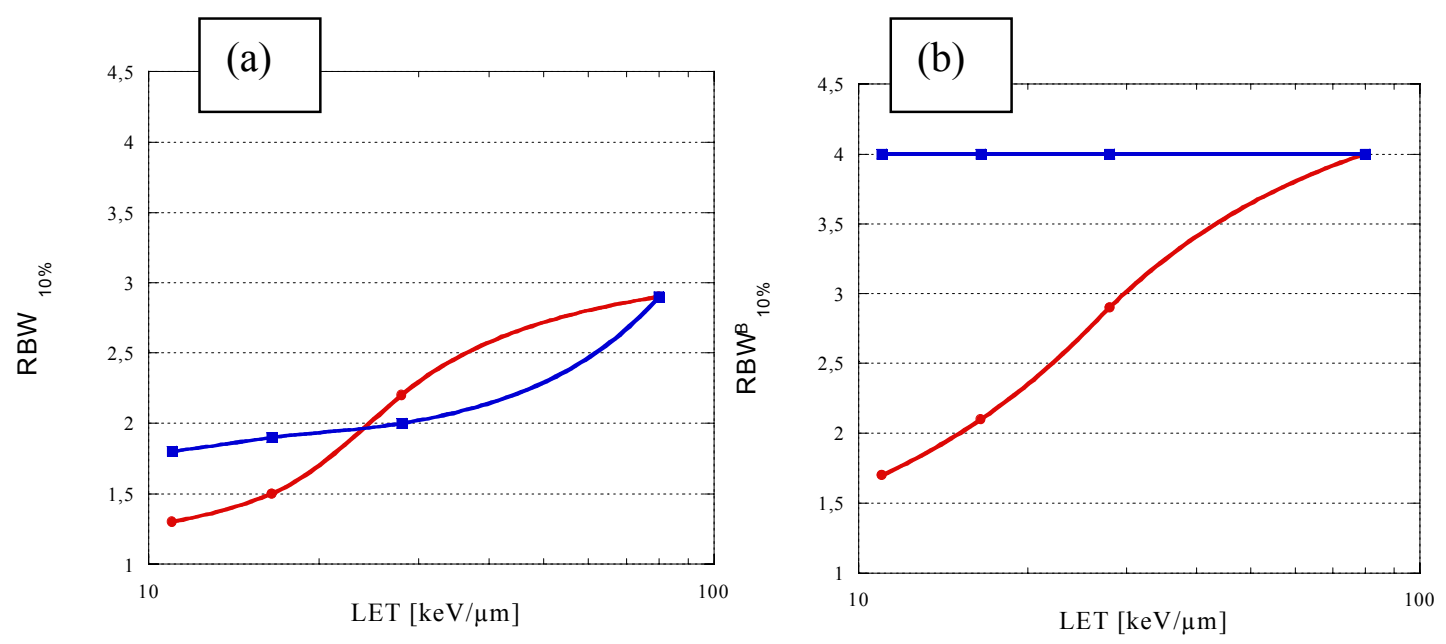

Abbildung 5.3 RBW in Abhängigkeit von LET der Kohlenstoffionen in MCF-7(blau) und in WiDr-Zellen (rot). Die RBW-Werte wurden aus den Überlebenskurven für das 10\%ige (a) und 40\%ige (b) Überlebensniveau bestimmt.

Vergleicht man diese RBW-Werte mit den entsprechenden Werten, die für normale Zellen (Fibroblasten der Lunge und der Haut) und verschiedene Tumorzellen bei einem LET von $13,1 \mathrm{keV} / \mu \mathrm{m}$ bzw. 16,5 keV/ $\mu \mathrm{m}$ ermittelt wurden, so liegen die RBW-Werte für das 10\%ige Überleben bei 1,1-1,5 für alle untersuchten Zellen, bis auf die MCF-7, bei denen höhere RBW-Werte (1,8-1,9) ermittelt wurden (siehe auch Tabelle 5.9). Bei höheren LET-Werten $(80 \mathrm{keV} / \mu \mathrm{m}$ bis $100 \mathrm{keV} / \mu \mathrm{m})$ unterscheiden sich die in den verschiedenen Zelllinien ermittelten RBW-Werte wenig voneinander. Bei diesen LETWerten sind praktisch keine RBW-Unterschiede feststellbar, und der Einfluss der intrinsischen Strahlensensitivität kann vernachlässigt werden. 
Tabelle 5.9 RBW-Werte für unterschiedliche Tumorzellen nach Bestrahlung und Kohlenstoffionen mit unterschiedlichem LET. Werte sind für das 10\%ige Überlebensniveau angegeben. Der LET im Bragg Peak wurde als Mittelwert der LET-Verteilung angegeben.

\begin{tabular}{|c|c|l|c|}
\hline LET & RBW & \multicolumn{1}{|c|}{ Zellen } & Referenz \\
\hline$[\mathrm{keV} / \mu \mathrm{m}]$ & & & \\
\hline 11 & $1,3-1,8$ & WiDr- und MCF-7-Zellen & vorliegende Arbeit \\
\hline 13 & $1,1-1,2$ & zwei Hepatoma Zelllinien & Ofuchi et al., 1999 \\
\hline 13,1 & $1,1-1,4$ & 2 normale Zelllinien und 4 Tumorzellen & Suzuki et al., 2000 \\
\hline 13,3 & $1,1-1,3$ & 16 humane Zellen verschiedener Gewebe-Arten, & Suzuki et al., 2000 \\
\hline 16,5 & $1,5-1,9$ & WiDr- und MCF-7-Zellen & vorliegende Arbeit \\
\hline 20 & $1,5-1,7$ & 4 Glioblastom- und 1 normale Fibroblasten-Zelllinier & Tsuboi et al., 1998 \\
\hline 20 & $1,5-2,2$ & 13 Tumorzellinien verschiedener Gewebe-Arten & Ka et al., 1996 \\
\hline 28 & $2,0-2,2$ & WiDr- und MCF-7-Zellen & vorliegende Arbeit \\
\hline 76 & 2,6 & zwei Hepatoma Zelllinien & Ofuchi et al., 1999 \\
\hline 77 & $2,0-3,0$ & 16 humane Zellen verschiedener Gewebe-Arten, & Suzuki et al., 2000 \\
\hline 77,5 & $2,5-2,9$ & 2 normale Zelllinien und 4 Tumorzellen & Suzuki et al., 2000 \\
\hline 80 & $2,3-3,5$ & 13 Tumorzelllinien verschiedener Gewebe-Arten & Ka et al., 1996 \\
\hline 80 & 2,9 & WiDr- und MCF-7-Zellen & vorliegende Arbeit \\
\hline 105 & $2,9-3,1$ & 4 Glioblastom- und 1 normale Fibroblasten-Zelllinier & Tsuboi et al., 1998 \\
\hline
\end{tabular}

Vergleicht man die ermittelten RBW-Werte für die Induktion dizentrischer Chromosomen für WiDr-Zellen (ca.4) und für MCF-7-Zellen (ca.1), so kann keine Übereinstimmung mit den RBW-Werten, die für das klonogene Überleben ermittelt wurden, festgestellt werden. Die RBW-Werte für das 10\%ige Überleben (LET 28 $\mathrm{keV} / \mu \mathrm{m}$ ) liegen bei 2,2 für WiDr-Zellen und 2,0 für die MCF-7-Zellen. Offensichtlich wirken sich nicht alle dizentrischen Chromosomen letal für die WiDr-Zellen aus. Für MCF-7-Zellen sind offensichtlich nicht nur dizentrische Chromosomen letal, sondern auch andere Aberrationstypen, wie z.B. Translokationen, wie in der Arbeit von Gardner und Tucker [2002] für menschliche Lymphozyten beschrieben wurde. Auch Deletionen könnten prinzipiell letale Ereignisse hervorrufen, falls sich auf dem deletierten Material z.B. wichtige housekeeping-Gene befänden.

Da dizentrische Chromosomen aus Fehlreparatur von Doppelstrangbrüchen entstehen, stellt sich die Frage, ob eine Korrelation zwischen der Induktion von Doppelstrangbrüchen und der Induktion dizentrischer Chromosomen besteht. Die genauen RBW-Werte für die Kohlenstoffionen liegen nicht vor, bis dato nahm man an, dass die RBW für die Kohlenstoffionen nicht größer oder gleich 1 sind [Heilmann et al., 1995] Entsprechend der neuesten Untersuchungen von Höglund et al., die einen genaueren 
Assay angewendet hat, liegen die RBW-Werte zwischen 1,2 und 1,5 [Höglund et al., 2000]. Die RBW für die Induktion von dizentrischen Chromosomen in WiDr-Zellen korreliert also nicht mit der Induktion von Doppelstrangbrüchen. In WiDr-Zellen sind die RBW-Werte gegenüber den RBW-Werten der Doppelstrangbruch-Induktion deutlich erhöht. Dagegen korrelieren diese RBW-Werte im Rahmen der experimentellen Genauigkeit in den MCF-7-Zellen. Dies konnte auch als ein Hinweis auf eine unterschiedliche räumliche Verteilung der DNA-Schäden in den untersuchten Tumorzellen gedeutet werden.

Die RBW-Werte für den unreparierten Schaden, also für die extra azentrischen Fragmente, wurden unter der Verwendung der PCC-Methode (premature chromosome condensation) in Melanom-Zellen für Kohlenstoffionen mit LET- Werten von 13 und $76 \mathrm{keV} / \mu \mathrm{m}$ im Vergleich zu Röntgenstrahlung gemessen [Ofuchi et al., 1999]. Die Autoren fanden RBW-Werte zwischen 1,10-1,24 für die $13 \mathrm{keV} / \mu \mathrm{m}$ bzw. 2,64-2,79 für die $76 \mathrm{keV} / \mu \mathrm{m}$. Vergleicht man die in dieser Arbeit für $28 \mathrm{keV} / \mu \mathrm{m}$ ermittelten RBWWerte (1,8 für WiDr-Zellen und 2,1 für die MCF-7-Zellen) mit Daten anderer Autoren, sind die gesamten RBW-Werte sehr ähnlich.

Zusammen betrachtet deuten die in dieser Arbeit beschriebenen ChromosomenAberrationsdaten darauf hin, dass neben der Effizienz und Genauigkeit der Reparatur von Doppelstrangbrüchen auch die räumliche und zeitliche Verteilung der primären Schäden eine signifikante Rolle spielen. Die räumliche Verteilung ihrerseits hängt von der jeweiligen Chromosomen-Domänen-Topologie ab. Die vorliegenden Ergebnisse könnten unter der Annahme erklärt werden, dass die hohe intrinsische Strahlensensitivität der MCF-7-Zellen sowohl auf eine defiziente NHEJ-Reparatur als auch auf eine, im Vergleich mit WiDr-Zellen unterschiedliche Domänen-Topologie zurückzuführen ist. 


\section{Zusammenfassung}

Die Ursachen unterschiedlicher Strahlensensitivität der Zellen gegenüber ionisierender Strahlung sind bis heute nicht vollständig geklärt. Eine in bezug auf den reproduktiven Zelltod erhöhte Strahlensensitivität korreliert häufig mit einer erhöhten chromosomalen Sensitivität. Ein Verständnis der Mechanismen, die der Entstehung strahleninduzierter Chromosomenaberrationen zu Grunde liegen, ist auch wegen ihrer grundsätzlichen Bedeutung für die Prozesse der Karzinogenese und für die Prozesse der Zelltötung sehr wichtig.

Im Rahmen dieser Arbeit wurde deshalb neben der Zellinaktivierung, auch die Induktion von strukturellen Chromosomenaberrationen untersucht, die überdies für die Strahlentherapie und für den Strahlenschutz relevant sind. Da in der $G_{1}$-Phase des Zellzyklus die Chromosomenaberrationen aus einer NHEJ-Reparatur resultieren, wurden auch die, an der DNA-PK-abhängigen NHEJ-Reparatur beteiligten Proteine, untersucht.

Als Modellsystem wurden zwei etablierte Tumorzelllinien ausgewählt, die unterschiedliche intrinsische Strahlensensitivität gegenüber der Röntgenstrahlung haben: eine resistente Kolonkarzinom-Linie, WiDr, und eine strahlenempfindliche Mamma-Karzinom-Linie, MCF-7. Die konfluenten Zellen wurden mit Kohlenstoffionen verschiedener Energien (100 MeV/u, $200 \mathrm{MeV} / \mathrm{u}, 400 \mathrm{MeV} / \mathrm{u}$ und im ausgedehntem Bragg Peak) bestrahlt. Als Referenzstrahlung wurde die 200 kVRöntgenstrahlung verwendet.

Die nach Röntgenstrahlung beobachtete unterschiedliche intrinsische Strahlensensitivität der analysierten Tumorzellen blieb auch nach Bestrahlung mit Kohlenstoffionen vorhanden. Die RBW für den strahleninduzierten klonogenen Zelltod stieg mit steigendem LET von Kohlenstoffionen sowohl bei WiDr- als auch bei MCF7-Zellen an. Die Kohlenstoffionen induzierten in den untersuchten Zellen nur selten den apoptotischen Zelltod $(<12 \%)$. Bei den untersuchten Tumorzellen wurde also der strahleninduzierte Zelltod vor allem durch den reproduktiven Zelltod verursacht.

Die Häufigkeiten instabiler Chromosomenaberrationen, also Häufigkeiten an dizentrischen Chromosomen und extra azentrischen Fragmenten nahmen mit steigendem LET zu. Die WiDr-Zellen waren im Bezug auf die reziproken 
Translokationen strahlenresistenter als die MCF-7-Zellen und in beiden Zelllinien waren die Translokationsausbeuten annähernd proportional den jeweiligen GesamtDNA-Gehalten von den untersuchten Chromosomen.

Es wurde ein hohes Vorkommen von komplexen Aberrationen nach Bestrahlung mit Kohlenstoffionen beobachtet - im Gegensatz zur Röntgenbestrahlung, die in dem untersuchten Dosisbereich nur selten komplexe Aberrationen induzierte. Eine besondere Klasse der komplexen Aberrationen stellen die Insertionen dar. Dieser Aberrationstyp tritt nach Röntgenbestrahlung praktisch nicht auf, durch Kohlenstoffionen wurde er jedoch häufiger induziert. Insertionen scheinen damit eine für dicht ionisierende Strahlung typische Aberrationsform zu sein. Die Anzahl an Insertionen nahm mit dem steigenden LET zu. Alle mit Einzelfarbe-FISH detektierbaren Aberrationen in den untersuchten Chromosomen wurden als GesamtAberrationen zusammengefasst. Nach Bestrahlung mit $\mathrm{D}=1 \mathrm{~Gy}$ waren die partiellen Häufigkeiten an Gesamt-Aberrationen pro Zelle in den untersuchten Zelllinien dem LET proportional, nach Bestrahlung mit $\mathrm{D}=4 \mathrm{~Gy}$ war in den strahlensensitiven MCF7-Zellen kein Unterschied mehr zwischen Röntgenstrahlung und Kohlenstoffionen zu beobachten. Die Verteilungsmuster der verschiedenen Aberrationstypen und die DosisEffekt-Beziehungen der analysierten Chromosomenaberrationen ließen zudem Rückschlüsse auf die Rolle der Domänen- bzw. Chromatinstruktur für die Strahlenreaktion der Zellen zu.

Darüber hinaus wurden auch an der DNA-PK-abhängigen NHEJ-Reparatur beteiligte Proteine untersucht. Bei beiden untersuchten Zelllinien sind alle drei untersuchten NHEJ-Proteine (DNA-PK $\mathrm{CS}_{\mathrm{CS}}, \mathrm{Ku} 70$ und $\mathrm{Ku}$ 86) vorhanden, und diese bilden nach Bestrahlung Cluster. Nach Bestrahlung mit Kohlenstoffionen wurden mehr Cluster als nach Röntgenbestrahlung gebildet. Die Clusterbildung in beiden Tumorzelllinien war sowohl nach Röntgenbestrahlung als auch nach Bestrahlung mit Kohlenstoffionen mit der Clusterbildung in normalen Epithelzellen (NEC) vergleichbar.

Die Ergebnisse zeigen, dass für verschiedene Tumorzelllinien und Strahlenarten sehr unterschiedlich ausgeprägte biologische Effekte auftreten können. Die intrinsische Strahlensensitivität scheint aus einem Zusammenwirken mehrerer Faktoren zu resultieren. Eine signifikante Rolle spielen neben der Reparatureffizienz auch die Verteilung und die Art des initialen Schadens sowie die Struktur und die geometrische Verteilung der Chromosomen-Domänen. 


\section{Literaturverzeichnis}

ALLALUNIS-TURNER, M. J., BARRON, G. M., DAY, R. S., DOBLER, K. D. and MIRZAYANS R. (1993): Isolation of two cell lines from a human malignant glioma specimen differing in sensitivity to radiation and chemotherapeutic drugs. Radiat. Res. 134, 349-354

ANDERSON, R., MARSDEN, S., WRIGHT, J., KADHIM, M., GOODHEAD, D. and GRIFFIN, C. (2000): Complex chromosome aberrations in peripheral blood lymphocytes as a potential biomarker of exposure to high-LET $\alpha$-particles. Int. J. Radiat. Biol. 76, 31-42

BALDEYRON, C., JACQUEMIN, E., SMITH, J., JACQUEMONT, C., DE, O. I., GAD, S., FEUNTEUN, J., STOPPA-LYONNET, D. and PAPADOPOULO, D. (2002): A single mutated BRCA1 allele leads to impaired fidelity of double strand break end-joining. Oncogene 21, 1401-1410

BARENDSEN, G., WALTER, H., FOWLER, J. and BEWLEY, D. (1963): Effects of different ionizing radiations on human cells in tissue culture: III. Experiments with cyclotron-accelerated particles and deuterons. Radiat. Res. 18, 106-119

BAUCHINGER, M. and SCHMID, E. (1998): LET dependence of yield ratios of radiation-induced intra- and interchromosomale aberrations in human lymphocytes. Int. J. Radiat. Biol. 74, 17-25

BERGER, S. (2001): Untersuchung der Wirkung von Schwerionenstrahlen auf menschliche Hautfibroblasten unter besonderer Berücksichtigung chromosomaler Veränderungen. Dissertation 2001

BJÖRK-ERIKSSON, T., WEST, C. M., KARLSSON, E., SLEVIN, N. J., DAVIDSON, S. E., JAMES, R. D. and MERCKE, C. (1998): The in vitro radiosensitivity of human head and neck cancers. Br. J. Cancer. 77, 2371-2375 
BOEI, J. J., VERMEULEN, S., MUllENDERS, L. H. and NATARAJAN, A. T. (2001): Impact of radiation quality on the spectrum of induced chromosome exchange aberrations. Int. J. Radiat. Biol. 77, 847-857

BOGUHN, O. (1999): Fluoreszenzuntersuchungen zur Reaktionskinetik strahleninduzierter DNA-Läsionen in menschlichen Zellen. Dissertation 1999, Mathematisch-Physikalische Fakultät der Universität Göttingen

BROOKS, S. C., LOCKE, E. R. and SOULE, H. D. (1973): Estrogen receptor in a human cell line (MCF-7) from breast carcinoma. J. Biol. Chem. 248, 6251- 6253

BUNCH, R. T., GEWIRTZ, D. A. and POVIRK, L. F. (1995): Ionizing radiationinduced DNA strand breakage and rejoining in specific genomic regions as determined by an alkaline unwinding/Southern blotting method. Int. J. Radiat. Biol. 68, 553-562

CHAN, D. W. and LEES-MILLER, S. P. (1996): The DNA-dependent protein kinase is inactivated by autophosphorylation of the catalytic subunit. J. Biol. Chem. 271 (15), 8936-8941

CHU, G. (1997): Double strand break repair. J. Biol. Chem. 272, 24097-24100

COLlis, S. J., SANGAR, V. K., TIGHE, A., ROBERTS, S. A., ClARKE, N. W., HENDRY, J. H. and MARGISON, G. P. (2002): Development of a novel rapid assay to assess the fidelity of DNA double- strand-break repair in human tumour cells. Nucleic Acids Res. 30, E1

CORDEIRO-STONE, M., FRANK, A., BRYANT, M., OGUEJIOFOR, I., HATCH, S. B., MCDANIEL, L. D. and KAUFMANN, W. K. (2002): DNA damage responses protect xeroderma pigmentosum variant from UVC- induced clastogenesis. Carcinogenesis 23, 959-965

DÁMOURS, D. and JACKSON, S.P. (2002): The MRE11 complex: At the crossroads of DNA repair and checkpoint signaling. Nature Reviews / Molecular Cell Biology 3, 317-327 
DEFAZIO, L. G., STANSEL, R. M., GRIFFITH, J. D. and CHU, G. (2002): Synapsis of DNA ends by DNA-dependent protein kinase. EMBO J. 21 (12), 3192-3200

DENG, W., MORRISON, D. P., GALE, K. L. and LUCAS, J. N. (2000): A comparative study on potential cytogenetic fingerprints for radiation LET in human lymphocytes. Int. J. Radiat. Biol. 76, 1589-1598

EDWARDS, A. A., LlOYD, D. C., PURROTT, R. J. (1979): Radiation-induced chromosome aberrations and the Poisson distribution. Radiat. Environm. Biophys. $16,89-100$

EVANS, H. J. and O'RIORDAN, M. L. (1975): Human peripheral blood lymphocytes for the analysis of chromosome aberrations in mutagen tests. Mutat. Res. 31, 135148

EVANS, H. J., BUCKTON, K. E., HAMILTON, G. E. and CAROTHERS, A. (1979): Radiation-induced chromosome aberrations in nuclear dockyard workers. Nature $277,531-534$

FERGUSON, D. O. and ALT, F. W. (2001): DNA double strand break repair and chromosomal translocation: lessons from animal models. Oncogene 20, 55725579

FRANKENBERG-SCHWAGER, M. (1989): Review of repair kinetics for DNA damage induced in eukaryotic cells in vitro by ionizing radiation. Radiother. Oncol. 14, 307-320

GALLOWAY, A. M. and ALLALUNIS-TURNER, J. (2000): cDNA expression array analysis of DNA repair genes in human glioma cells that lack or express DNAPK. Radiat. Res. 154, 609-615

GARDNER, S. N. and TUCKER, J. D. (2002): The cellular lethality of radiationinduced chromosome translocations in human lymphocytes. Radiat. Res. 157, $539-552$ 
GAYMES, T. J., NORTH, P. S., BRADY, N., HICKSON, I. D., MUFTI, G. J. and RASSOOL, F. V. (2002): Increased error-prone non homologous DNA endjoining--a proposed mechanism of chromosomal instability in Bloom's syndrome. Oncogene 21, 2525-2533

GEORGE, A. M. and CRAMP, W. A. (1987): The effects of ionizing radiation on structure and function of DNA. Prog. Biophys. Mol. Biol. 50, 121-169

GERTHSEN, C. and VOGEL, H. (1993): Ein Lehrbuch zum Gebrauch neben Vorlesungen. Springer Verlag, Berlin, Heidelberg, New York

GOODHEAD, D. T. (1999): Mechanisms for the biological effectiveness of high-LET radiations. J. Radiat. Res. (Tokyo) 40, Suppl., 1-13

GOODWIN, E., BLAKELY, E., IVERY, G. and TOBIAS, C. (1989): Repair and misrepair of heavy-ion-induced chromosomal damage. Adv. Space Res. 9, 83-89

GRIFFIN, C., MARSDEN, S., STEVENS, D., SIMSON, P. and SAVAGE, J. (1995): Frequencies of complex chromosome exchange aberrations induced by ${ }^{238} \mathrm{Pu} \alpha$ particles and detected by fluorescence in situ hybridization using single chromosome-specific probes. Int. J. Radiat. Biol. 67, 431-439

GRIGOROVA, M., BRAND, R., XIAO, Y. and NATARAJAN, A. T. (1998): Frequencies and types of exchange aberrations induced by X-rays and neutrons in Chinese hamster splenocytes detected by FISH using chromosome-specific DNA libraries. Int. J. Radiat. Biol. 74, 297-314

GUAN, J., DIBIASE, S. and ILIAKIS, G. (2000): The catalytic subunit DNAdependent protein kinase (DNA-PKcs) facilitates recovery from radiation-induced inhibition of DNA replication. Nucleic Acids Res. 28, 1183-1192

HABERER, T., BECHER, W., SCHARDT, D. and KRAFT, G. (1993): Magnetic scanning system for heavy ion therapy. Nucl. Instr. Methods A 330, 296-305

HEILMANN, J., RINK, H., TAUCHER-SCHOLZ, G. and KRAFT, G. (1993): DNA strand break induction and rejoining and cellular recovery in mammalian cells after heavy-ion irradiation. Radiat. Res. 135, 46-55 
HEILMANN, J., TAUCHER-SCHOLZ, G. and KRAFT, G. (1995): Induction of DNA double-strand breaks in CHO-K1 cells by carbon ions. Int. J. Radiat. Biol. 68, $153-162$

HEILMANN, J., TAUCHER-SCHOLZ, G., HABERER, T., SCHOLZ, M. and KRAFT, G. (1996): Measurement of intracellular DNA double-strand break induction and rejoining along the track of carbon and neon particle beams in water. Int. J. Radiat. Oncol. Biol. Phys. 34, 599-608

HEINRICH, W., WIEGEL, B. and KRAFT, G. (1991): $\beta, \mathrm{Z}_{\mathrm{eff} .}, \mathrm{dE} / \mathrm{dx}$, range and restricted energy loss of heavy ions in the region $1 \leq \mathrm{E} \leq 1000 \mathrm{MeV} / \mathrm{u}$. Techn. Bericht, GSI Preprint 1991

HÖGLUND, E., BLOMQUIST, E., CARLSSON J. and STENERLOW B. (2000): DNA damage induced by radiation of different linear energy transfer: initial fragmentation. Int. J. Radiat. Biol. 76, 539-547

HOPPE, B. S., JENSEN, R. B. and KIRCHGESSNER, C. U. (2000): Complementation of the radiosensitive M059J cell line. Radiat. Res. 153, 125-130

HSU, H.-L., YANNONE, S. M. and CHEN, D. J. (2002): Defining interactions between DNA-PK and ligase IV/XRCC4. DNA Repair 1, 225-235

JEGGO, P. A. (1998): DNA breakage and repair. Adv. Genet. 38, 185-218

KA, W. J., ITO, H., SHIGEMATSU, N., YAMASHITA, S. KUBO, A. and KANAI, T. (1996): Biological effect of carbon beams on cultured human cells. Nippon Igaku Hoshasen Gakkai Zasshi 56, 669-673

KANAAR, R., HOEIJMAKERS, J. H. and VAN GENT, D. C. (1998): Molecular mechanisms of DNA double strand break repair. Trends Cell. Biol. 8, 483-489

KHANNA, K. K. and JACKSON, S. P. (2001): DNA double-strand breaks: signaling, repair and the cancer connection. Nat. Genet. 27, 247-54

KOLIN-GERRESHEIM, J. and BAUCHINGER, M. (1981): Dependence of the frequency of harlequin-stained cells on BrdU concentration in human lymphocyte cultures. Mutat. Res. 91, 251-254 
KRAFT, G. (1999): RBE and ist interpretation. Strahlentherapie und Onkologie 175 Suppl. II, 44-47

KRAFT, G., KRAFT-WEYRATHER, W., TAUCHER-SCHOLZ, G. and SCHOLZ, M. (1997): What kind of radiobiology should be done at a hadrontherapy center? Advances in Hadrontherapy

KRAFT-WEYRATHER, W., HABERER, T. and KRAFT, G. (1992): First survival curves irradiated with the magnetic scanning system at SIS. GSI Scientific Report 1991, GSI-92-1, 301

LAMBIN, P., MALAISE, E. P. and JOINER, M. C. (1996): Might intrinsic radioresistance of human tumour cells be induced by radiation? Int. J. Radiat. Biol. 69, 279-290

LEA, D.E. (1946): Actions of radiations on living cells. Cambridge University Press

LEBER, R., WISE, T. W., MIZUTA, R. and MEEK, K. (1998): The XRCC4 gene product is a target for and interacts with the DNA- dependent protein kinase. J. Biol. Chem. 273, 1794-1801

LEES-MILLER, S. P., GODBOUT, R., CHAN, D. W., WEINFELD, M., DAY, R. S., BARRON, G. M. and ALLALUNIS-TURNER, J. (1995): Absence of p350 subunit of DNA-activated protein kinase from a radiosensitive human cell line. Science $267,1183-1185$

LIMOLI, C. L., PONNAIYA, B., CORCORAN, J. J., GIEDZINSKI, E. and MORGAN, W. F. (2000): Chromosomal instability induced by heavy ion irradiation. Int. J. Radiat. Biol. 76, 1599-1606

LIMOLI, C. L., PONNAIYA, B., CORCORAN, J. J., GIEDZINSKI, E., KAPLAN, M. I., HARTMANN, A. and MORGAN, W. F. (2000): Genomic instability induced by high and low LET ionizing radiation. Adv. Space Res. 25, 2107-2117

LINDAHL, T. (1987): The 1987 Walter Hubert lecture. Regulation and deficiencies in DNA repair. Br .J. Cancer 56, 91-95 
LINDAHL, T. and WOOD, R. D. (1999): Quality control by DNA repair. Science 286, 1897-1905

MA, Y., PANNICKE, U., SCHWARZ, K. and LIEBER, M.R. (2002): Hairpin opening and overhang processing by an Artemis/DNA-dependent protein kinase complex in nonhomologous end joining and V(D)J recombination. Cell 108, 781-94

MARTIN, T. (2001): Zytogenetische und molekularbiologische Untersuchungen zur Reparaturkapazität und Reparaturgenauigkeit von isolierten Tumorzellen. Diplomarbeit 2001, Biologische Fakultät der Universität Göttingen.

MCGREGOR, W. G. (1999): DNA repair, DNA replication, and UV mutagenesis. J. Investig .Dermatol. Symp. Proc. 4, 1-5

MCKAY, M. J. and KEFFORD, R. F. (1995): The spectrum of in vitro radiosensitivity in four human melanoma cell lines is not accounted for by differential induction or rejoining of DNA double strand breaks. Int. J. Radiat. Oncol. Biol. Phys. 31, $345-352$

MCKAY, M. J. and KEFFORD, R. F. (1995): The spectrum of in vitro radiosensitivity in four human melanoma cell lines is not accounted for by differential induction or rejoining of DNA double strand breaks. Int. J. Radiat. Oncol. Biol. Phys. 31, $345-352$

MORRISON, C., SONODA, E., TAKAO, N., SHINOHARA, A., YAMAMOTO, K. and TAKEDA, S. (2000): The controlling role of ATM in homologous recombinational repair of DNA damage. EMBO J. 19, 463-471

MOUSTACCHI, E. (2000): DNA damage and repair: consequences on dose-responses. Mutat. Res. 464, 35-40

MUller, C., RODRIGO, G., CALSOU, P. and SAlleS, B. (1999): [DNAdependent protein kinase: a major protein involved in the cellular response to ionizing radiation]. Bull. Cancer 86, 977-983 
NOGUCHI, P., WALlACE, R., JOHNSON, J., EARLEY, E. M., O'BRIEN, S., FERRONE, S., PELlEGRINO, M. A., MILSTIEN, J., NEEDY, C., BROWNE, W. and PETRICCIANI, J. (1979): Characterization of the WIDR: a human colon carcinoma cell line. In Vitro 15, 401-408

NUSSENZWEIG, A., SOKOL, K., BURGMAN, P., LI, L. and LI, G. C. (1997): Hypersensitivity of Ku80-deficient cell lines and mice to DNA damage: the effects of ionizing radiation on growth, survival, and development. Proc. Natl. Acad. Sci. U.S.A 94, 13588-13593

OBE G. and NATARAJAN A. (1985): Chromosomal aberrations induced by the restriction endonuclease Alu I in Chinese hamster ovary cells: influence of duration of treatment and potentiation by cytosine arabinoside. Mutat. Res. 152, 205-10

OBE, G., JOHANNES, C. and SCHULTE-FROHLINDE, D. (1992): DNA doublestrand breaks induced by sparsely ionizing radiation and endonucleases as critical lesions for cell death, chromosomal aberrations, mutations and oncogenic transformation. Mutagenesis 7, 3-12

OFUCHI, T., SUZUKI, M., KASE, Y., ANDO, K., ISONO, K. and OCHIAI, T. (1999): Chromosome breakage and cell lethality in human hepatoma cells irradiated with X rays and carbon-ion beams. J. Radiat. Res. (Tokyo) 40, 125-133

OLIVE, P. L., BANATH, J. and MACPHAIL, H. S. (1994): Lack of a correlation between radiosensitivity and DNA double-strand break induction or rejoining in six human tumor cell line. Cancer Research 54, 3939-3946

OTTOLENGHI, A., BALLARINI, F. and MERZAGORA, M. (1999): Modeling radiation-induced biological lesions: from initial energy depositions to chromosome aberrations. Radiat.Environ.Biophys. 38, 1-13

PAULL, T. T. and GELLERT, M. (1999): Nbs1 potentiates ATP-driven DNA unwinding and endonuclease cleavage by the Mre11/Rad50 complex. Genes Dev. $13,1276-88$ 
PAULL, T. T. and GELLERT, M. (2000): A mechanistic basis for Mre11-directed DNA joining at microhomologies. Proc. Natl. Acad. Sci. USA 97, 6409-14

PETERS, L. J. (1990): The ESTRO Regaud lecture. Inherent radiosensitivity of tumor and normal tissue cells as a predictor of human tumor response. Radiother. Oncol. $17,177-190$

PFEIFFER, P. (1998): The mutagenic potential of DNA double-strand break repair. Toxicol. Lett. 96-97, 119-129

PFEIFFER, P., GOEDECKE, W. and OBE, G. (2000): Mechanisms of DNA doublestrand break repair and their potential to induce chromosomal aberrations. Mutagenesis 15, 289-302

PLUTH, J. M. FRIED, L. M. and KIRCHGESSNER, C. U. (2001): Severe combined immunodeficient cells expressing mutant hRAD54 exhibit a marked DNA double-strand break repair and error-prone chromosome repair defect. Cancer Res. 61, 2649-2655

POLISCHOUK AG, CEDERVALL B, LJUNGQUIST S, FLYGARE J, HELLGREN D, GRENMAN R, LEWENSOHN R. (1999): DNA double-strand break repair, DNA-PK, and DNA ligases in two human squamous carcinoma cell lines with different radiosensitivity. Int. J. Radiat. Oncol. Biol. Phys. 43,191-198

PRISE, K. M., PINTO, M., NEWMAN, H. C. and MICHAEL, B. D. (2001): A review of studies of ionizing radiation-induced double-strand break clustering. Radiat.Res. 156, 572-576

RAVE-FRÄNK， M., VIRSIK-KÖPP， P.， PRADIER， O., NITSCHE， M., GRUNEFELD, S. and SCHMIDBERGER, H. (2001): In vitro response of human dermal fibroblasts to X-irradiation: relationship between radiation-induced clonogenic cell death, chromosome aberrations and markers of proliferative senescence or differentiation. Int. J. Radiat. Biol. 77, 1163-1174

RITTER, M. A., CLEAVER, J. E. and TOBIAS, C. A. (1977): High-LET radiations induce a large proportion of non-rejoining DNA breaks. Nature 266, 653-655 
RITTER, S., BERGER, S., GRÖßER, T., HESSEL, P., KRAFT, G., NASANOVA, E., ANDO, K. and GUDOWSKA-NOWAK, E. (2001): Quantification of high LET induced chromosome aberrations. GSI Scientific Report 2000, GSI-2001-1, 154

RITTER, S., NASONOVA, E., GUDOWSKA-NOWAK, E., SCHOLZ, M. and KRAFT, G. (2000): High-LET-induced chromosome aberrations in V79 cells analysed in first and second post-irradiation metaphases. Int. J. Radiat. Biol. 76, $149-161$

ROTHKAMM, K., KUHNE, M., JEGGO, P. A. and LOBRICH, M. (2001): Radiationinduced genomic rearrangements formed by nonhomologous end- joining of DNA double-strand breaks. Cancer Res. 61, 3886-3893

RUIZ DE ALMODOVAR, J. M., NUNEZ, M. I., MCMILlAN, T. J., OLEA, N., MORT, C., VILLALOBOS, M., PEDRAZA, V. and STEEL, G. G. (1994): Initial radiation-induced DNA damage in human tumour cell lines: a correlation with intrinsic cellular radiosensitivity. Br .J. Cancer 69, 457-462

SACHS, R. K., HLATKY, L. R. and TRASK, B. J. (2000): Radiation-produced chromosome aberrations: colourful clues. Trends Genet. 16, 143-146

SAVAGE, J. R. (1976): Classification and relationships of induced chromosomal structural changes. J. Med. Genet. 13, 103-122

SAVAGE, J. R. and PAPWORTH, D. G. (1996): Comment on the ratio of chromosome-type dicentric interchanges to centric rings for track-clustered compared with random breaks. Radiat. Res. 146, 236-240

SAX, K. (1938): Chromosome aberrations induced by x-rays. Genetics 23, 494-516

SCHOLZ, M. and KRAFT, G. (1992): A parameter-free track structure model for heavy ion action cross section. Biophysical modeling of radiation effects, Verlag Adam Hilger, Bristol, Philadelphia, New York

SCWARTZ, J. L. (1992): The radiosensitivity of the chromosomes of the cells of human squamous cell carcinoma cell lines. Radiat. Research 129, 96-101 
SEYMOUR, C. B. and MOTHERSILL, C. (1997): Delayed expression of lethal mutations and genomic instability in the progeny of human epithelial cells that survived in a bystander-killing environment. Radiat. Oncol. Investig. 5, 106-110

SIMPSON, P. J. and SAVAGE, J. R. (1996): Dose-response curves for simple and complex chromosome aberrations induced by X-rays and detected using fluorescence in situ hybridization. Int. J. Radiat. Biol. 69, 429-436

SIRZEN, F., NILSSON, A., ZHIVOTOVSKY, B., LEWENSOHN, R. (1999): DNAdependent protein kinase content and activity in lung carcinoma cell lines: correlation with intrinsic radiosensitivity. Eur. J. Cancer 35, 111-116

SKARSGARD, L., KIHLMAN, B., PARKER, L., PUJARA, C. and RICHARDSON, S. (1967): Survival, chromosome abnormalities and recovery in heavy-ion- and xirradiated mammalian cells. Radiat. Res. 7, Suppl. 208-221

SUTHERLAND, B. M., BENNETT, P. V., SAPARBAEV, M., SUTHERLAND, J. C. and LAVAL, J. (2001): Clustered DNA damages as dosimeters for ionising radiation exposure and biological responses. Radiat. Protect. Dosimetry. 97, 3338

SUTHERLAND, B. M., BENNETT, P. V., SCHENK, H.; SIDORKINA, O., LAVAL, J., TRUNK, J., MONTELEONE, D. and SUTHERLAND, J. (2001): Clustered DNA damages induced by high and low LET radiation, including heavy ions. Phys. Med. 17, Suppl. 1, 202-204

SUZUKI, M., KASE, Y., KANAI, T. and ANDO, K. (1998): Correlation between cell death and induction of non-rejoining PCC breaks by carbon-ion beams. Adv. Space Res. 22, 561-568

SUZUKI, M., KASE, Y., KANAI, T. and ANDO, K. (2000): Correlation between cell killing and residual chromatin breaks measured by PCC in six human cell lines irradiated with different radiation types. Int. J. Radiat. Biol. 76, 1189-1196 
SUZUKI, M., KASE, Y., YAMAGUCCHI, H., KANAI, T. and ANDO, K. (2000): Relative biological effectiveness for cell-killing effect on various human cell lines irradiated with heavy-ion medical accelerator in Chiba (HIMAC) carbon-ion beams. Int. J. Radiation Oncology Biol. Phys. 48, 241-250

TESTARD, I., DUTRILLAUX, B. and SABATIER, L. (1997): Chromosomal aberrations induced in human lymphocytes by high-LET irradiation. Int. J. Radiat. Biol. 72, 423-433

TRUJILLO, K.M., YUAN, S. S., LEE, S. Y. and SUNG, P. (1998): Nuclease activities in a complex of human recombination and DNA repair factors Rad50, Mre11, and p95. J. Biol. Chem. 273, 21447-50

TSAI, S., WEAR, D. J., SHIH, J. W. and LO, S. C. (1995): Mycoplasmas and oncogenesis: persistent infection and multistage malignant transformation. Proc. Natl. Acad. Sci. U.S.A 92, 10197-10201

TSOBOI, K., TSUCHIDA, Y., NOSE, T. and ANDO, K. (1998): Cytotoxic effect of an accelerated carbon beams on glioblastoma cell lines with p53 mutation: clonogenic survival and cell-cycle analysis. Int. J. Radiat. Biol. 74, 71-79

TUTEJA, N. and TUTEJA, R. (2001): Unraveling DNA repair in human: molecular mechanisms and consequences of repair defect. Crit. Rev. Biochem. Mol. Biol. $36,261-290$

VAGANAY-JUERY, S., MULLER, C., MARANGONI, E., ABDULKARIM, B., DEUTSCH, E., LAMBIN, P., CALSOU, P., ESCHWEGE, F., SALLES, B., JOINER, M. and BOURHIS, J. (2000): Decreased DNA-PK activity in human cancer cells exhibiting hypersensitivity to low-dose irradiation. Br. J. Cancer 83, $514-518$

VAN GENT, D. C., HOEIJMAKERS, J. H. and KANAAR, R. (2001): Chromosomal stability and the DNA double-stranded break connection. Nat. Rev. Genet. 2, 196206 
VIRSIK-PEUCKERT, P., RAVE-FRÄNK, M. and SCHMIDBERGER, H. (1996): Further studies on the possible relationship between radiation-induced reciprocal translocations and intrinsic radiosensitivity of human tumor cells. Radiother. Oncol. 40, 111-119

VIRSIK-PEUCKERT， P., RAVE-FRÄNK, M., LANGEBRAKE, U. and SCHMIDBERGER, H. (1997): Differences in the yields of dicentrics and reciprocal translocations observed in the chromosomes of irradiated human skin fibroblasts and blood lymphocytes from the same healthy individuals. Radiat. Res. 148, 209-215

WANG, H., ZENG, Z. C., BUI, T. A., SONODA, E., TAKATA, M., TAKEDA, S. and ILIAKIS, G. (2001): Efficient rejoining of radiation-induced DNA double-strand breaks in vertebrate cells deficient in genes of the RAD52 epistasis group. Oncogene 20, 2212-24

WEYRATHER, W., RITTER, S., SCHOLZ, M. and KRAFT, G. (1999): RBE for a carbon track-segment irradiation in cell lines of differing repair capacity. Int. J. Radiat. Biol. 75, 1357-1364

WHITAKER, S. J., UNG, Y. C. and MCMILLAN, T. J. (1995): DNA double-strand break induction and rejoining as determinants of human tumour cell radiosensitivity. A pulsed-field gel electrophoresis study. Int. J. Radiat. Biol. 67, 7-18

WOUDSTRA, E. C., BRUNSTING, J. F., ROESINK, J. M., KONINGS, A. W. and KAMPINGA, H. H. (1996): Radiation induced DNA damage and damage repair in three human tumour cell lines. Mutat. Res. 362, 51-59

WU, H., DURANTE, M. and LUCAS, J. N. (2001): Relationship between radiationinduced aberrations in individual chromosomes and their DNA contect: effects of interaction distance. Int. J. Radiat. Biol. 77, 781-786 
YAMADA, S., DURANTE, M., ANDO, K., FURUSAWA, Y., KAWATA, T., MAJIMA, H. and TSUJII, H. (2000): Complex-type chromosomal exchanges in blood lymphocytes during radiation therapy correlate with acute toxicity. Cancer Lett. $150,215-21$

YOO, S., KIMZEY, A. and DYNAN W. S. (1999): Photocross-linking of an oriented DNA repair complex. Ku bound at a single DNA end. J. Biol. Chem. 274, 2003420039 


\section{Anhang A}

\section{Abkürzungen}

AT

ATCC

bp

BrdU

BS

CS

D

DAPI

DMEM

DMSO

DNA

DNA-PK

DNA-PK ${ }_{C S}$

DSB

EDTA

FA

FISH

FITC

FKS

GSI

Gy

HEPES

HR

LET

Mbp

MEM

NBS

NHEJ
Ataxia telangiektasia

$\underline{\text { American }} \underline{T}$ ype $\underline{\text { Culture }} \underline{\text { Collection }}$

Basenpaare

5-Bromo-2-deoxyuridin

Bloom Syndrom

Cockayne Syndrom

Dosis

4,6-iamidino-2-phenylindol

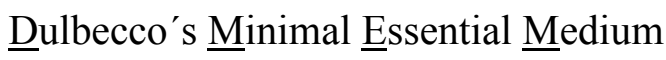

Dimethyl $\underline{\text { Sulfoxide }}$

Desoxyribonukleinsäure (desoxyribonucleic acid)

DNA-abhängige-Protein-Kinase

katalytische Untereinheit (catalytic subunit) der DNA-PK

Doppelstrangbruch

Ethylene-diamine-tetraacetic acid

Fanconi Anämie

Fluoreszenz in situ Hybridisierung

Fluorescein-Iso-Thio-Cyanat

Fötales Kälberserum

Gesellschaft für Schwerionenforschung $\mathrm{mbH}$

Gray

$\mathrm{N}$-[2-Hydroxyethyl]piperazine-N'-[2-ethanesulfonic acid]

Homologe Rekombination

linearer-Energie-Transfer $[\mathrm{keV} / \mu \mathrm{m}]$

Mega-Basenpaare

Minimal Essential Medium

Nijmegen-Breakage-Syndrom

non-h̆homologous end-joining 


$\begin{array}{ll}\text { p.a. } & \text { per analysis } \\ \text { PBD } & \text { phosphate buffered detergent } \\ \text { PBS } & \text { phosphate } \underline{b} u f f e r e d \underline{s} \text { saline } \\ \text { PE } & \text { plating efficiency } \\ \text { PS } & \text { Phosphatidylserin } \\ \text { RB } & \text { Retinoblastom } \\ \text { RBW } & \text { Relative biologische Wirksamkeit } \\ \text { SIS } & \underline{\text { Schwerionensynchrotron }} \\ \text { UV } & \text { Ultraviolette Strahlung } \\ \text { WCP } & \text { Whole Chromosome Probes } \\ \text { WS } & \text { Werner Syndrom }\end{array}$




\section{Anhang B}

\section{B.1 Medien und Zusätze für die Zellkultur}

Die verwendeten Medien wurden mit Aqua bidest. angesetzt und anschließend steril filtriert.

\section{B.1.1 Medien}

MEM-Basismedium [5 l]
MEM mit Earle's Salzen, Trockenmedium
Fa. Biochrom, Berlin, D
$10 \mathrm{~g}$ Natriumhydrogencarbonat
Fa. Merck, Darmstadt, D
$50 \mathrm{mg}$ Neomycin
Fa. Serva, Heidelberg, D
$25 \mathrm{ml}$ Penicillin/Streptomycin-Lösung
Fa. Biochrom, Berlin, D

DMEM-Basismedium [5 l]

DMEM, Trockenmedium,

Fa. Biochrom Berlin, D

$15 \mathrm{~g}$ Natriumhydrogencarbonat

Fa. Merck, Darmstadt, D

$25 \mathrm{ml}$ Penicillin/Streptomycin-Lösung

Fa. Biochrom, Berlin, D

WiDr-Medium

MEM-Basismedium

$10 \%$ FKS

Fa. PAA, Linz, A

$2 \%$ Glutamin

Fa. Merck, Darmstadt, D

\section{MCF-7-Medium}

$50 \%$ MEM-Basismedium

50 \% DMEM-Basismedium

$10 \%$ FKS

Fa. PAA, Linz, A

$2 \%$ Glutamin

Fa. Merck, Darmstadt, D 


\section{HNEpC-Medium}

Bronchial Epithelial Cell Growth Medium Fa. Promocell, Heidelberg,D

\section{B.1.2 Zusätze für die Zellkultur}

DMSO

Trypsin-EDTA-Lösung
Fa. Sigma, München, D

Fa. Biochrom Berlin, D

\section{B.2 Chemikalien}

$\begin{array}{ll}\text { Aceton } & \text { Fa. Merck, Darmstadt, D } \\ \text { Ampuwa } & \text { Fa. Fresenius, Bad Homburg, D } \\ \text { BrdU } & \text { Fa. Sigma, München, D } \\ \text { Colcemid } & \text { Fa. Biochrom Berlin, D } \\ \text { DAPI/Antifade-Lösung } & \text { Fa. Qbiogene-Appligene/Oncor, F } \\ \text { Earle's salt solution } & \text { Fa. Biochrom Berlin, D } \\ \text { Essigsäure } & \text { Fa. Merck, Darmstadt, D } \\ \text { Ethanol } & \text { Fa. Merck, Darmstadt, D } \\ \text { Formamid } & \text { Fa. Serva, Heidelberg, D } \\ \text { Giemsa } & \text { Fa. Merck, Darmstadt, D } \\ \text { Glutaraldehyd 25\% } & \text { Fa. Merck, Darmstadt, D } \\ \text { Hoechst Nr. 33258 } & \text { Fa. Merck, Darmstadt, D } \\ \text { Kaliumdihydrogenphosphat } & \text { Fa. Merck, Darmstadt, D } \\ \text { Kristallviolett } & \text { Fa. Merck, Darmstadt, D } \\ \text { Methanol } & \text { Fa. Merck, Darmstadt, D } \\ \text { Natriumchlorid } & \text { Fa. Merck, Darmstadt, D } \\ \text { Natriumcitrat } & \text { Fa. Merck, Darmstadt, D } \\ \text { Natriumhydrogencarbonat } & \text { Fa. Merck, Darmstadt, D } \\ \text { Natriumhydrogenphosphat } & \text { Fa. Merck, Darmstadt, D } \\ \text { NP-40/ Igepal } & \text { Fa. Sigma, München, D } \\ & \end{array}$


PBD

Proteinase K

RNAse

Tween 20
Fa. Qbiogene-Appligene/Oncor, F

Fa. Sigma, München, D

Fa. Sigma, München, D

Fa. Sigma, München, D

\section{B.3 Lösungen und Puffer}

$2 \times \mathrm{SSC}$

$2 \times \mathrm{SSC} / 0,05 \% \mathrm{NP}-40$

$2 \times \mathrm{SSC} / 70 \%$ Formamid

$49 \mathrm{ml}$ Formamid

$7 \mathrm{ml} 20 \times$ SSC, pH 5,3

$14 \mathrm{ml}$ Ampuwa

$\mathrm{pH} 7,0$

$20 \mathrm{x}$ SSC- Stammlösung $\quad 175,3 \mathrm{~g}$ Natriumchlorid

88,4 g Natriumcitrat

ad $1000 \mathrm{ml}$ Wasser, $\mathrm{pH}$ 5,3 und 6,3

EBSS-Pufer

$100 \mathrm{ml}$ Earle's salt solution

$885 \mathrm{ml}$ Wasser

2,2 g/1 Natriumhydrogencarbonat

Fixativ für Chromosomen 3 Teile Methanol

1 Teil Eisessig

Glutaraldehyd-Lösung 1 Teil Glutaraldehyd

4 Teile PBS 


\begin{tabular}{|c|c|}
\hline Hypotone Lösung & 0,06 M KCl-Lösung \\
\hline & $6 \%$ Natriumcitrat \\
\hline PBD-Lösung & 100 ml PBD-Lösung \\
\hline & $900 \mathrm{ml}$ Wasser \\
\hline PBS-Puffer: & $8 \mathrm{~g}$ Natriumchlorid \\
\hline & 0,2 g Kaliumchlorid \\
\hline & 1,15 g Natriumhydrogenphosphat \\
\hline & $0,2 \mathrm{~g}$ Kaliumdihydrogenphosphat \\
\hline & ad 11 Aqua bidest. \\
\hline Weise-Puffer & 5ml Weise-Puffer-Stammlösung $+100 \mathrm{ml}$ A.dest. \\
\hline Weise-Puffer Stammlösung & $228 \mathrm{~g}$ Natriumhydrogenphosphat-di-hydrat \\
\hline & 98g Kalium-di-hydrogenphosphat \\
\hline & ad 11 Aqua dest. \\
\hline
\end{tabular}

\title{
B.4 Färbelösungen und Färbekits
}

\begin{abstract}
Annexin-V-Fluos-Staining-Kit $\quad$ Fa. Boehringer-Mannheim
\end{abstract}
DAPI-Färbung

0,2 $\mathrm{ml}$ DAPI [5 $\mu \mathrm{g} / \mathrm{ml}]$
9,8 ml Methanol

Giemsa-Lösung 3-10\% Giemsa in PBS-Puffer

Höchst-Färbelösung $\quad 16 \mu \mathrm{g} / \mathrm{ml}$ Hoechst Nr. 33258

$75 \mathrm{ml}$ Weise-Puffer 


$\begin{array}{ll}\text { Kristallviolett-Lösung } & 1 \mathrm{~g} \text { Kristallviolett } \\ & 400 \mathrm{ml} \text { Alkohol } 95 \% \\ & 200 \mathrm{ml} \text { Wasser }\end{array}$

\section{B.5 Antikörper und Sonden}

Anti-humaner DNA-PK-Antikörper der Maus

Anti-humaner Ku-70-Antikörper der Maus

Anti-humaner Ku-86-Antikörper der Maus

FITC-markierter Anti-Maus-Antikörper

WCP-Sonden für Chromosom 2,4 und 5

$\mathrm{F}$
Fa. Kamiya Biomedical, USA

Fa. Kamiya Biomedical, USA

Fa. Kamiya Biomedical, USA

Fa. Kamiya Biomedical, USA

Fa. Qbiogene-Appligene / Oncor,

\section{B.6 Einwegmaterial und Geräte}

\section{B.6.1 Einwegmaterial}

Cryoröhrchen 1,8 ml

Deckgläser 24 x $24 \mathrm{~mm}$

Filter Filtropur 0,20 $\mu \mathrm{m}$

Multischalen „Nunclon ${ }^{\mathrm{TM}}$ “، 6 Well

Objektträger mit Kammer „CC Chamber Slide“

Objektträger

Objektträgerflaschen „Flaskette“

Objektträgerflaschen „Slideflask“

Parafilm

Pipettenspitzen (versch. Größen)

Pipettenspitzen mit Filter (versch. Größen)

Röhrchen 15 ml
Fa. Sarstedt, Nümbrecht, D

Lager der Universität

Fa. Sarstedt, Nümbrecht, D

Fa. Nunc, Wiesbaden, D

Fa. Nunc, Wiesbaden, D

Lager der Universität

Fa. Nunc, Wiesbaden, D

Fa. Nunc, Wiesbaden, D

Fa. Schütt, Göttingen, D

Fa. Eppendorf, Hamburg, D

Fa. Biozym, Hess. Oldendorf, D

Fa. Greiner, Frickenhausen, D 
Röhrchen $45 \mathrm{ml}$

Serologische Kunststoff-Pipetten (1 - 25 ml)

Spritzenfilter Minisart 0,20 $\mu \mathrm{m}$

Zellkulturflaschen $25 \mathrm{~cm}^{2}$

Zellkulturflaschen $80 \mathrm{~cm}^{2}$

Zellkulturschalen „Nunclon ${ }^{\mathrm{TM} \text { ، }}$

Zentrifugeröhrchen (Kunststoff)
Fa. Greiner, Frickenhausen, D

Fa. Sarstedt, Nümbrecht, D

Fa. Sartorius, Göttingen, D

Fa. Nunc, Wiesbaden, D

Fa. Greiner, Frickenhausen, D

Fa. Nunc, Wiesbaden, D

Fa. Sarstedt, Nümbrecht, D

\section{B.6.2 Geräte}

Autoklav „Bioclav“

Begasungsbrutschränke

Bi-dest-Anlage „Destamat“

Bildbearbeitungssoftware "MetaMorph"

CCD-Kamera „MicroMax“

Filtersatz für Axioplan 2 Blau-Anregung

Filtersatz für Axioplan 2 Grün-Anregung

Filtersatz für Axioplan 2 UV-Anregung

Fluoreszenz-Mikroskop „Axioplan 2“

Imersionsobjektive 10-100x

Inverses Mikroskop „Telaval 31“

Laminar FlowBoxen

Mikroskop

Röntgenröhre „Stabilipan 2“

Schüttler

Stereomikroskop „Stemi 2000C““

Sterilisator

UV-Lampe „Philips HPM 13, 1000 W“

Wärmeschrank

Wasserbad

Zentrifuge I „Megafuge 1.0R““

Zentrifuge II „Labofuge ${ }^{\mathrm{GL} ،}$
Fa. Schütt, Göttingen, D

Fa. Heraeus, Hanau, D

Fa. Heraeus, Hanau, D

Fa. Visitron, Puchheim,D

Fa. Visitron, Puchheim,D

Fa. Zeiss, Göttingen, D

Fa. Zeiss, Göttingen, D

Fa. Zeiss, Göttingen, D

Fa. Zeiss, Göttingen, D

Fa. Zeiss, Göttingen, D

Fa. Zeiss, Göttingen, D

Fa. Heraeus, Hanau, D

Fa. Zeiss, Göttingen, D

Fa. Siemens AG, Laatzen, D

Fa. Heidolph, Schwabach, D

Fa. Zeiss, Göttingen, D

Fa. Memmert, Schwabach, D

Hersteller unbekannt

Fa. Memmert, Schwabach, D

Fa. GFL, Burgwedel, D

Fa. Heraeus, Hanau, D

Fa. Heraeus, Hanau, D 


\section{Danksagung}

Ein besonderer Dank gilt Prof. Dr. P. Virsik-Köpp für die Vergabe des Themas und die hervorragende Betreuung. Sie war während der ganzen Arbeit, nicht nur im wissenschaftlichen Bereich, sondern auch privat, mein wichtigster Ansprechpartner. Durch ihre stete Diskussionsbereitschaft, Freundschaft, Lob und Ansporn hat sie den Fortgang dieser Arbeit entscheidend beeinflusst.

Herrn Prof. Dr. R. Hardeland danke ich für seine Bereitschaft das Hauptreferat zu übernehmen, sowie für sein stetes Interesse am Fortgang der Arbeit.

Herrn Prof. Dr. H.-J. Fritz danke ich für die Übernahme des Korreferats und das Aufbringen der damit verbundene Zeit.

Herrn Prof. Dr. C. F. Hess danke ich für die Möglichkeit, einen Teil der experimentellen Arbeiten in den Laborräumen der Klinik für Strahlentherapie und Radioonkologie durchzuführen. Bei allen Mitgliedern dieser Abteilung möchte ich mich ganz herzlich für die liebevolle Aufnahme und stetige Unterstützung in den großen und kleinen Dingen bedanken. Vor allem möchte ich mich bei Frau Rave-Fränk bedanken, die in vielen Diskussionen durch konstruktive Anregungen zum Fortgang dieser Arbeit beigetragen hat. Ein ganz besonderer Dank gilt Frau J. Kasten-Krapp, die mich durch ihre humorvolle Art immer wieder aufgebaut hat und damit eine ausgezeichnete Arbeitsatmosphäre geschaffen hat. Herrn Prof. Dr. D. Harder danke ich ebenfalls für die Möglichkeit, einen Teil der experimentellen Arbeiten in den Laborräumen des Instituts für Medizinische Physik und Biophysik durchzuführen.

Mein Dank gilt Prof. Dr. G. Kraft und seiner Biophysik-Arbeitsgruppe bei der GSI Darmstadt für das hervorragende Arbeitsklima und den fachlichen Gedankenaustausch. Vor allem danke ich Dr. S. Ritter für ihr offenes Ohr bei den kleinen und den großen Laborproblemen, und für ihre fortwährende Diskussionsbereitschaft. Vielen Dank auch dem Bestrahlungsteam, das immer ihr Bestes getan hat, um meine Tumorzellen so schnell wie möglich zu bestrahlen. Besonders möchte ich mich bei Dr. M. Scholz für sein unermüdliches Engagement während der langen Bestrahlungsnächte bedanken.

Ein ganz herzlicher Dank gebührt meiner Familie, vor allem meinen Eltern, die mich immer wieder unterstützt haben.

Mein letzter Dank gilt schließlich meinem Ehemann Frank, dessen Unterstützung, sein Interesse am Fortgang der Arbeit, seine Liebe und sein Vertrauen mich durch alle Phasen dieser Arbeit begleitet haben. Vielen Dank! 


\section{Lebenslauf}

\section{Persönlichen Angaben}

Name:

Adresse:

Geburtsdatum:

Geburtsort:

Familienstand:

Staatsangehörigkeit:

Eltern:
Hana Hofman-Hüther, geb. Hofman

Uhlandstr.46

37120 Bovenden

g: Hana.Hofman@gmx.de

05. April 1969

Louny, Tschechische Republik verheiratet seit 17.10.1999 mit Frank Hüther deutsch (seit 07.08.1991) MUDr (Univ. Prag) Jan Hofman und Hana Hofman

\section{Schulausbildung in der Tschechischen Republik}

$1975-1982$

$1982-1983$

Sommer 1983

$1983-1985$

Sommer 1985
Grundschule in Louny

Grundschule in Vlasim

Aufnahmeprüfung für das Staatliche Gymnasium in Vlasim Staatliches Gymnasium in Vlasim

Emigration in die Bundesrepublik Deutschland

\section{Schulausbildung in Bundesrepublik Deutschland}

$1985-1986$

$1986-1987$

$1987-1991$
Euro-Sprachschule in München

Gastschülerin im Erasmus-Grasser-Gymnasium in München Helmholtz-Gymnasium in Zweibrücken 
1991

$1991-1996$

$1996-1997$

Januar 1998

März 1998

Mai 1998 - März 2000

Seit April 2000

Seit Herbst 2000
Abitur

Universität Kaiserslautern: Studium der Biologie (Diplom)

Schwerpunkt: Humanbiologie

Externe Diplomarbeit am Bundesinstitut für gesundheitlichen Verbraucherschutz und Veterinärmedizin in Berlin

Thema: Experimentelle Untersuchungen zur Genotoxizität von Aromastoffen

Diplom-Prüfung in den Fächern Humanbiologie, Zoologie, Mikrobiologie und Biochemie

Exmatrikulation an der Universität Kaiserslautern

Tätigkeit als wissenschaftliche Angestellte in der Abteilung Strahlentherapie und Radioonkologie der Georg-AugustUniversität Göttingen, Kooperationsprojekt mit der GSI Darmstadt

Arbeit an der vorliegenden Dissertation (unter der Leitung von Prof. Dr. P. Virsik-Köpp) in der Abteilung Strahlentherapie und Radioonkologie der Georg-AugustUniversität Göttingen, Kooperationsprojekt mit der GSI Darmstadt

Immatrikuliert an der Georg-August-Universität Göttingen, Fachbereich Biologie (Promotion) 